FORMAL PROBLEMS IN

SEMITIC PHONOLOGY AND MORPHOLOGY

by

JOHN JOSEPH MCCARTHY, III

A.B., Harvard College

(1975)

\author{
SUBMITTED IN PARTIAL FULFILLMENT \\ OF THE REQUIREMENTS FOR THE \\ DEGREE OF \\ DOCTOR OF PHILOSOPHY \\ at the \\ MASSACHUSETTS INSTITUTE OF TECHNOLOGY \\ June, 1979
}

Signature of Author...U ... Department of Linguistics and $\ldots$ Philosophy, 29 May, 1979

Certified by $n$, , Thesis Supervisor

Accepted by.

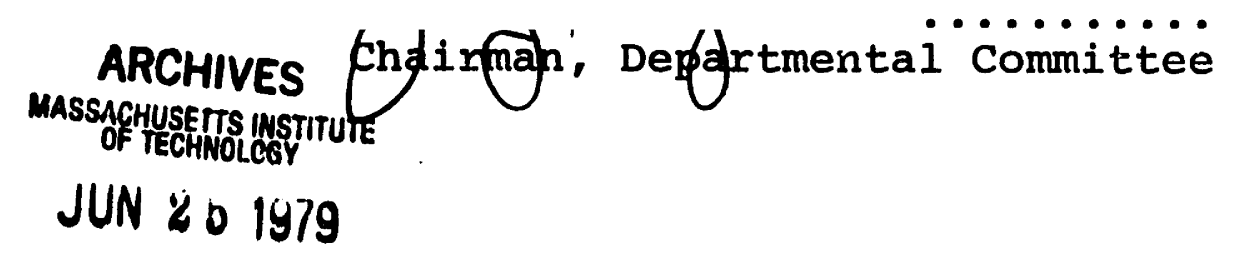




\author{
FORMAL PROBLEMS IN \\ SEMITIC PHONOLOGY AND MORPHOLOGY
}

\author{
by \\ JOHN JOSEPH MCCARTHY, III
}

Submitted to the Department of Linguistics and Philosophy on 29 May, 1979 in partial fulfillment of the requirements for the Degree of Doctor of Phjlosophy

\begin{abstract}
This study deals with the formal character of phonological representations and rules. Two basic lines of investigation are pursued. One, the metrical, holds that there is hierarchic metrical structure within syllables and accentual groups. A metrical theory of syllable structure and of stress is elaborated based on data from Tiberian Hebrew, Classical Arabic, and the modern Arabic dialects of Cairo and Damascus. The effects of syllable structure on the form and function of segmental phonological rules are adumbrated with data from Tiberian Hebrew as well. The role of metrical structure in vowel harmony also figures briefly.

The other formal line followed is prosodic. An essentially autosegmental theory of nonconcatenative morphology is developed and extensively illustrated with data from Classical Arabic and Tiberian Hebrew. A general corstraint limiting the morphology to context-sensitive rewrite rules is developed and defended on the basis of this theory. The prosodic model is also shown to solve several traditional problems in the characterization of reduplication phenomena. Finally, a theory of internally-structured lexical entries is proposed and is demonstrated to have significant empirical consequences within this morphological system.
\end{abstract}

Thesis Supervisor: Morris Halle

Title: Ferrari P. Ward Professor

of Modern Languages and Linguistics 
And this our life, exempt from public haunt, finds tongues in trees 
Acknowledgments

At one point in Der Zauberberg Hans Castorp nearly dies of exposure. In a way that is said to be typical of this mode of dying, he feels a great deal of joy and internal peace. Finishing a dissertation is like death by exposure, and I can only thank those who have hastened this pleasant demise. My committee, Morris Halle, Paul Kiparsky, and Jay Keyser, were unfailingly worthy of their high calling. Halle especially contributed both intellectually and geistlich to nearly all that appears here. I have had no more pleasant or fruitful arguments than those in his office, and I have learned a great deal from him about linguistics and the rest.

I have benefited as well from contact with others of the MIT faculty, especially Joan Bresnan, Jim Harris, and sometime faculty members Mark Liberman and Edwin Williams. All read some portion of this work at one time or another, and their comments have been quite useful to me. Others who have read and commented on some part are John Goldsmith and Nick Clements. For their help too I am grateful.

The fellow students who have aided me morally or intellectually include Hagit Borer, Wilson Gray, Nick D. M. Ostler, David Pesetsky, Ken Safir, and Tim Stowell. David Nash and former fellow students Joel Rotenberg and Mark Baltin deserve special thanks for everything. 
Two people merit special thanks. Alan Prince has often read versions of this and commented insightfully. I could think of no other place to ackowledge it, so let me say that he first suggested that I extend my prosodic treatment of Arabic vocalism to the consonants as well, which turned out to be quite useful in chapter 4. I am grateful for his assistance and his friendship. Ellen Woolford endured my moods with patience and offered help in matters both intellectual and material. She is responsible no less than I for the completion of this, and I am grateful to her as well. As always, errors remaining despite this help are mine. With love and gratitude I dedicate this study to my parents. 
Table of Contents

Acknowledgments 4

Chapter 1: Prologue $\quad 9$

Chapter 2: Syllable Structure and Segmental Phonology

1. Introduction 14

2. Syllable Structure 16

3. Syllable Structure and Phonological Rules 30

4. The Segmental Phonology of Tiberian Hebrew 35

$\begin{array}{ll}\text { Footnotes } & 76\end{array}$

Chapter 3: Syllable Structure and Accentuation

$\begin{array}{ll}\text { 1. Introduction } & 78\end{array}$

Excursus: Foot Structure in English 92

2. Stress Assignment in Arabic 101

2.1 Cairene Colloquial 101

2.2 Damascene Colloquial 118

2.3 Classical Arabic 127

2.4 Diachronic Considerations 131

3. The Accentual System of Tiberian Hebrew 135

3.1 Introduction $\quad 135$

3.2 Main Stress 139

3.3 The Rhythm Rule nasstig ?ahớr 145

3.4 Imperfect Consecutive Stress Retraction 165

3.5 Perfect Consecutive Stress Shift 170

$\begin{array}{ll}3.6 \text { Secondary Stress } & 180\end{array}$

$\begin{array}{ll}3.7 \text { Summary } & 191\end{array}$ 
4. Nonprosodic Metrical Structure

$\begin{array}{ll}4.1 \text { Tigre } & 198\end{array}$

4.2 Maltese 203

$\begin{array}{ll}\text { Footnotes } & 206\end{array}$

Chapter 4: Prosodic Structure, Morpholocy, and the Lexicon

1. Introduction 209

2. Basic Formalism 218

2.1 The Representation of Morphemes 218

2.2 Autosegmental Theory 230

3. The Classical Arabic Verbal System 239

3.1 Consonantism 245

3.2 Vocalism 281

3.3 The First Binyan 290

3.4 Subject Agreement 295

4. The Classical Arabic Nominal System 304

4.1 Nouns with m-preformative 305

4.2 Masdars 321

4.3 Diminutives and Broken Plurals 330

4.3.1 Quadriliteral Nouns 332

4.3.2 Nouns CVVCV(V)C 337

4.3.3 Nouns CVCVVC 340

4.3.4 Nouns CVC(V)C 343

4.3.5 Other Plural Patterns 348

5. Theoretical Consequences

5.1 Formal Properties of Morphological Rules 356 
5.2 Morphology and the Lexicon

5.2.1 The Structured Lexical Entry

393

5.2.2 Lexical Idiosyncracy 408

Footnotes

417

Bibliography 
Chapter 1; Prologue

This study is based to a great extent on the basic assumptions of generative phonology, and for that reason. assumes a certain familiarity with representative works like Chomsky and Halle (1968) and subsequent literature. This is not to say that it is a purely descriptive work within that theoretical framework; rather, it deviates in fairly fundamental ways from Chomsky and Halle's modes of representation and rule formulation. In fact, the underlying thesis here supports a variety of far-reaching changes in the received generative theory with a number of empirical consequences.

Two basic issues figure in this study. The first, dealt with in chapters 2 and 3 , concerns the representation of syllabj.c and accentual structure, and the effects of those structures on the formulation of phonological rules. An essentially hierarchic model is developed, along the lines first introduced in Liberman (1974). This model is shown to have very broad consequences for the segmental phonology and accentual system of Tiberian, and equally important results in the accentual systems of Classical Arabic and two Arabic dialects.

In chapter 4 , a solution to the traditional problem of the root and pattern morphological system of Semitic is proposed and illustrated by an extensive treatment of Classical Arabic. The solution basically runs along the lines of theoretical proposals developed most clearly in Goldsmith 
(1976). Although the Semitic problem is itself of great inherent interest, the morphological model as conceived here is shown to lead to a variety of other consequences, in particular a strong constraint on the form of morphological rules and a deeper understanding of nonconcatenative morphology in general.

Although these two aspects of this study are to some extent independent, and in fact any of the three following chapters can be read separately with little loss of comprehension, there is one unifying idea behind all. The thesis is that several formal enrichments, along basically prosodic lines, of the theory of Chomsky and Halle (1968) are both descriptively necessary and theoretically desirable. The descriptive necessity emerges throughout the discussion, while the theoretical desirability of these enrichments lies in the possibility, explicitly followed at several junctures, of either constraining or eliminating the eaxlier apparatus. One important point about the mode of presentation is in order here. The discussion throughout this work almost invariably eschews polemic in favor of more direct arguments in support of the proposals made. Thus I have avoided the construction of straw men and like rhetorical devices on the grounds that they properly belong to the process of scientific discovery and not to the exposition of finished results. Another aspect of this arises in the development of the model 
of metrical structure here. I have benefited a great deal from reading Halle and Vergnaud (1979) as well as other recent, often unpublished works on this subject, and this debt is ackowledged throughout the text. In many cases these other treatments conflict with mine on matters of varying significance. I have not felt it necessary to give direct recognition to all of these disagreements for two reasons. First, for most of them the data now known and understood with any degree of clarity do not determine whether the issue is substantive or merely notational. Second, in view of the very rapid changes in such a novel theory, I have thought it best to present a single, relatively consistent model which is fairly simple formally and which is supported by several thorough analyses.

This brings us to another point, the descriptive basis of this work. It goes without saying that any analysis that tends to disprove any proposals made here will have to be based on an empirical foundation equal to or greater in depth than the analyses here. I do not claim to offer an exhaustive treatment of the phonology or morphology of any language, but a fair degree of coverage, particularly in Hebrew phonology and Arabic morphology, is achieved. This aspect of the study has been aided by the existence of two previous generative treatments, Brame (1970) on Arabic phonology and Prince (1975) on Hebrew phonology. Prince's work especially contributed much to the analysis of Hebrew in chapter 2 and some preliminary metrical 
insights in chapter 3 . Where some phenomenon is known to me solely through a published description (as in the case of Tigre and Maltese in chapter 3), I have noted this explicitly. A few practical matters. Because of the very large number of forms and rules cited in displays, I have adopted a policy of numbering displays anew beginning at each major subdivision of a chapter. Thus unique reference to any display will require three integers, like "chapter 3 , section 4, (43)". To abbreviate the footnotes I have left out glosses and have sometimes used orientalists' technical terms where the alternative is a very long explanation. I urge those with sufficient interest to consult a reference grammar of the appropriate language for a definition of the term and often an extensive discussion of the relevant phenomenon. With this exception, however, the notes are mostly quite accessible.

Finally, the mode of transcription. In both Hebrew and Arabic, $\underline{9}$ and $\underline{\underline{h}}$ are the voiced and voiceless pharyngeal

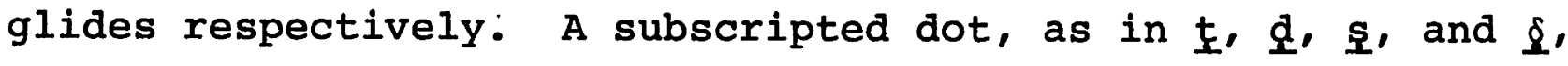
indicates emphatic (pharyngealized) articulation. $g$ is a voiceless unaspirated uvular stop, and ? indicates glottal stop. All other consonants have their familiar values. Because of the difficulties in devising a suitable transcription, I have not marked spirantized allophones of Hebrew stops except when relevant (in chapter 2), when they are indicated 
by an extra subscript line in $\underline{b}, \underline{\underline{t}}, \underline{\underline{d}}, \underline{\underline{k}}$ and by a superscript line in $\overline{\underline{g}}$ and $\bar{g}$. Hebrew $\underline{\underline{s}}$ is a consonant of unknown value, possibly palatalized $\underline{s}$.

Long vowels in Arabic are indicated simply by gemination. Gemination in Hebrew long vowels is also the formal representation adopted here and followed in discussions of syllable structure and accentuation, but actual cited examples use a somewhat more elaborated mode of transcription. Long vowels written without a mater lectionis have a macror

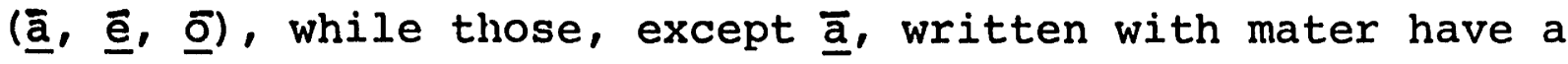

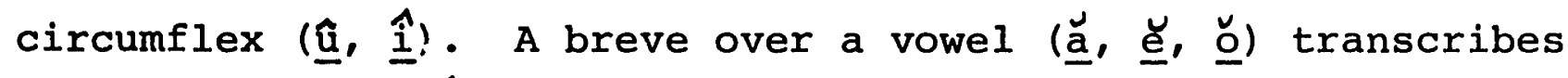
one of the hătêfím, an extra-short or reduced version of that vowel. I should point out here that my assumption that the basic distinction in Hebrew vowels is quantitative is supported by the Qimhi school as well as a vast number of internal phonological considerations. I do not exclude the possibility of an earlier pronunciation like the modern Ashkenazic, but I would point out that this pronunciation involves a simple mapping from vowel quantity onto [tense], with an adjustment for the rounding of $\underline{\bar{a}}$. Thus the quantitative distinction is basic, though some traditions superimpose a qualitative one onto it.

Portions of chapter 3 on Arabic stress appear in my article "On Stress and Syllabification," Linguistic Inquiry 10,3. A very early version of the treatment of Arabic vocalism in chapter 4 was presented in 1976 at the North American Conference on Afro-Asiatic Linguistics. 
Chapter 2: Syllable Structure and Segmental Phonology

1. Introduction

A theory of syllable structure is presented here in which segments are hierarchically arranged into higherorder constituents of a binary-branching tree. In general, one and only one such tree is associated with each syllable, rooted on the syllable node $\sigma$ with individual segments as the terminal nodes. This first section of this chapter develops the very broad outlines of a theory of these syllable trees, illustrating the points with examples from Arabic and Hebrew.

The second section deals with the application of phonological rules to these enriched segmental representations. Phonological rules are allowed to operate on the trees directly, as well as on the segments, and some general principles governing their interaction are proposed. In this chapter our attention is mostly confined to segmental phonological rules, in the familiar sense, while chapter 3 deals in detail with a variety of accentual issues.

The final section of this chapter offers an extensive illustration of these principles of rule application and of the hierarchic syllable structures from the segmental phonology of Tiberian Hebrew. An even more thorough analysis of the accentual phenomena of this language can be found in 
section 3 of chapter 3 .

The basic notion that syllables have internal hierarchic structure -- that they can be parsed into units smaller than a syllable but larger than a segment -- is scarcely new. The earliest explicit reference to this idea that I have located is Pike and Pike (1947), though undoubtedly one could find earlier treatments, perhaps even in antiquity. In fact, the so-called syllabic orthography of Akkadian in the second millenium $B C$ is not strictly syllabic, but depends on a hierarchic treatment of this sort. Thus, the writing i-na-ad-di-in for inaddin 'he gives' implicitly reflects a division of closed syllables (CVC) into two partiallyoverlapping subunits each larger than an individual segment. The notational foundation of this theory of syllable structure comes from two separate sources. First, there is the idea of an essentially autosegmental characterization of syllable membership developed in Goldsmith (1976) and most extensively in Kahn (1976). Rather than say that syllables are delimited by boundary symbols in the segmental string, this claims that for every syllable there is a node $\sigma$ on an autosegmental tier which is associated with just the segments in that syllable. Second, an extension of this notation by allowing $\sigma$ to dominate a full binary-branching tree permits us to give an internal constituency to the syllable. This first appeared in Prince (1975), where it was intended to 
describe some processes of compensatory lengthening in Hebrew. A further extension of this by Paul Kiparsky (in class lectures and in Kiparsky (to appear)) involves labeling the nodes of this tree for a relationship of relative strength, along the lines of the theory of stress prominence in Liberman (1974) and Liberman and Prince (1977).

\section{Syllable Structure}

The justification of constituent structure in classical transformational syntactic theory has scarcely been uncontroversial in particular cases, but the methodology is generally agreed upon. First, application of rules of movement, deletion, agreement, and concord to syntactic strings is usually taken as prima facie evidence that they form constituents. Second, the statement of distributional regularities -- like specifications of lexical subcategorization -is usually supposed to be confined to constituents. Third, the consistent appearance of similar strings in a variety of different rules of the first and second sorts leads to a theory of syntactic types.

Evidence of this sort exists in phonology as well, though there is a fundamental difference. While syntactic constituency can be shown to be an essential part of any observationally adequate theory, this is not the case in phonology. The statement of the most fundamental syntactic regularities requires 
reference to constituents because syntactic strings can be of potentially infinite length. Thus, verb agreement in English must recognize a constituent NP, since there is no upper bound on the length on the subject noun phrase. Because we can ordinarily set a limit on the length of the phonological phrase, to take the largest relevant phonological constituent, there is no possibility of demonstrating the necessity for a theory of constituents in phonology.

This is, however, not an insurmountable handicap. The finiteness of the phonological phrase also means that it is possible to simply list all the phonological phrases in any language and still achieve observational adequacy. It is, however, axiomatic that the large number of regularities within this list of phonological phrases must be expressed in the grammar. If these regularities generally take the form that the theory of phonological constituents predicts, then clearly this is evidence for that theory.

The phonological theory of Chomsky and Halle (1968) implicitly eschews reference to phonological constituents, though it does recognize morphological constituents delimited by square brackets and boundary symbols. Because the phonological phrase is finite, it is always possible to characterize phonological constituents of any sort simply by listing their members with the familiar abbreviatory devices, including abbreviations for potentially infinite strings like $C_{0}$. 
There has, however, been no dearth of arguments that Chomsky and Halle's theory is inadequate because it fails to take cognizance of perhaps the best established phonological constituent, the syllable. This is much of the thrust of the claims in Kahn (1976) for English and in the literature cited there and in the brief survey by Bell and Hooper (1978). In fact, I will assume that a syllable constituent does exist, holding in abeyance the consideration of its basic characteristics, and I will proceed to the question of whether it itself contains subconstituents larger than the segment.

There is such a basic internal constituency to the syllable with a certain amount of traditional support. This is the division between syllable onset and syllable rhyme. We can define the rhyme informally as the string including the syllable nucleus and any segments following within the syllable, while the onset is the complement of this. Note that this definition is not strict, since it will emerge that the onset and rhyme are formal categories within an overall syllable structure. Thus, we would like to allow for the possibility, for example, of including some types of onglides in the rhyme constituent.

The rhyme is perhaps the best supported subconstituent of the syllable. We will see in this chapter that it functions in a variety of segmental processes -- like those that refer to "doubly open syllables" -- and, in chapter 3, 
throughout the accentual systems of Hebrew and Arabic. Distributional regularities often can be stated most transparently on this constituent; for example, many languages limit the rhyme to just vowels or to just sonorant segments. Any evidence for the rhyme is clearly evidence for the existence of the onset as well, though direct evidence for the onset is perhaps not so common. One instance is the limitation of $\underline{h}$ in English to onsets which contain no other segments. Another is the English pig latin rule, which severs and postposes the syllable onset. Notice here that the onset must also include a prenuclear glide if we are to account for pig latin [yû́wtkey] from cute.

This is not to say that the constituent structure within syllables is exhausted merely by the division into onsets and rhymes. For example, I argue (McCarthy 1977) that an internal hierarchic structure for obstruent clusters must be recognized to state regularities of the distribution of [+cor] in these clusters in English and Greek. More extensive work along these theoretical lines can be found in Selkirk (forthcoming) and Kiparsky (to appear). I will, however, confine my attention here almost exclusively to the basic hierarchic division onset/rhyme. This is partly because these constituents can be most extensively justified by the operation of rules as well as distributional constraints, and partly because the relatively simple syllable structure of the languages analyzed here does not require recognition of 
any smaller constituents.

It now remains to develop a means of referring to the internal constituency of syllables and to give it a universal characterization. The basis of this proposal comes from the work by Prince and Kiparsky mentioned in the introduction. Suppose that each segment is the terminal node of a binary-branching tree labeled $s$ and $w$, where the root is the syllable node $\sigma$. In conformity with the usual observations about syllable structure, relative prominence in this tree is mapped onto relative sonority in the segmental string. Thus, the designated terminal element, the node of the tree dominated only by s's and the root, is the syllabic nucleus. In consonant clusters, relatively more sonorous segments will be labeled s, corresponding to a $\mathrm{w}$ label over adjacent less sonorous consonants. A specification of the possible syllabic trees, along with some language-particular conditions on the way in which they are associated with strings of segments, constitutes the rules of syllabification for a given language.

Without yet considering the general constraints on this notation, we can see that a binary tree yields the desired result. All syllables except those consisting of a single segment will be immediately divisible into two daughter nodes immediately dominated by the syllable node $\sigma$. I will say, as universal definitions, that the onset is the left branch of 
$\sigma$ and the rhyme is the right branch of $\sigma$. Further subconstituents of the rhyme and onset, if necessary, can be defined in a similar purely structural way.

The issue now is to correctly characterize the possible structures that actually occur as syllable trees, and to describe the possible relationships between these structures and the segmental string. I will confine my attention to just three basic trees:

(I) a.

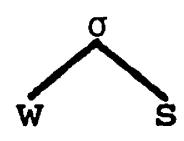

b.

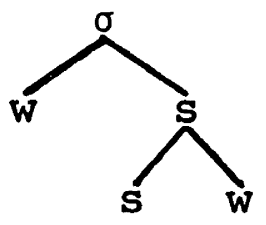

c.

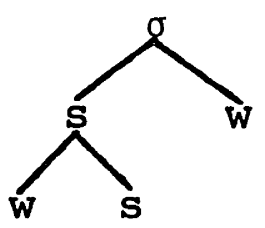

Even if we limit the possibilities to trees with three or fewer terminal nodes, as in (1), then it is clear that this list hardly exhausts the trees that this notation can in principle generate. Since my purpose is to develop only the basic characteristics of syllable-internal structure, whether these other types actually occur is not at issue here.

As was already stipulated, the nucleus of the syllable will be the designated terminal element, the node dominated only by s's and the root, in the syllable trees in (1). Other positions in the syllable must be occupied by segments whose sonority is less than or equal to that of the nucleus. This follows inherently from the relationship of relative strength 
defined by the $s$ and $w$ labels of the tree. The rhyme node -by definition the right branch of $\sigma--$ is the single node at the rightmost extremity in (1a) and (1c), while it is the entire branching node on the right in (lb).

Let us suppose that there is a very simple theory of possible mappings between syllable trees like those in (1) and the segmental string. Any node in a syllable tree can be specified as bearing values for any members of the set of distinctive features, subject of course to the overriding conditions on relative sonority induced by the labeling. Therefore constraints on segment distribution within syllables will be stated structurally on nodes of the tree (including terminal nodes), and a ranking of relative complexity of syllable types emerges from counting features in the overall tree. In some ways this is too strong, since not all features function in syllable structure constraints, and also too weak, since some cooccurrence restrictions may be linear rather than structural, but the general outlines of the proposal emerge. We could, for instance, limit constraints on nodes like the rhyme and syllable nucleus to major class features. It is an empirical question whether this is correct.

One other question remains: at what point in the derivation is syllabification defined? Anticipating slightly the discussion in the following section, I will claim that syllable structure is assigned on the underlying representation, so any proposed conditions must hold at that level. We can 
now turn to the consideration of some actual data.

The basic syllable inventory of Classical Arabic is $\mathrm{CV}, \mathrm{CVC}$, and CVV, where the notation $\mathrm{C}$ includes the high and low glides. So far as I know no cooccurrence restrictions hold within the syllable in Arabic (though some hold on morphemes like the root, as we will see in chapter 4). This full repertoire of syllables is somewhat reduced in surface representations by the operation of phonological rules, though even these are subject to numerous lexical exceptions. I propose, then, that the syllable structure rubrics of Arabic are those of (la) and (1b), repeated here as (2):

(2) a.

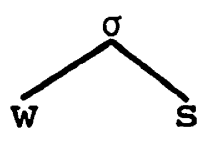

b.

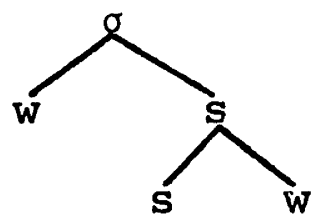

A single condition holds on the application of these trees to segmental strings: the onset, the left branch of $\sigma$, must be [-syll]. Therefore only glides and true consonants, but not vowels, can appear in onset position. We will see later that one other syllable type, the superheavy syllable, is also recognized by Arabic under particular conditions. Extensive support for syllable trees of the form in (2) arises in the treatment of Arabic accentuation in chapter 3. It turns out there that CV syllables, with the tree (2a), and CVV and CVC syllables, with the tree in (2b), have quite different accentual properties of the sort usually referred to syllable weight. The accentual theory in chapter 
3 describes syllable weight in terms of the branching character of syllable rhymes. Notice for now that the rhymes of $\mathrm{CV}$ syllables will be nonbranching nodes (the right branch of $\sigma$ in (2a)), while the rhymes of CVV and CVC syllables will be branching nodes (the right branch of $\sigma$ in (2b)).

The modern Arabic dialects spoken in Damascus and Cairo have essentially the syllable structures of Classical Arabic with one major exception. They allow consonant clusters word-initially. I should point out that this property is not unprecedented. For example, there is a certain amount of evidence from vowel reduction in English that the cluster sm, while freely permissible in word-initial position, does not begin syllables word-internally. Words with internal $\underline{\text { sm }}$ are rare, and when they occur they seem to resist reduction of the preceding syllable, as in Asmodeus [æsmówdijjas] or Rasmussen [ræsmyứwsp]. However, since my purpose in the treatment of the various Arabic dialects is not to exhaustively describe the syllable structures, but rather to show how syllabification relates to accentuation, I will have nothing more to say about these facts here.

Tiberian Hebrew offers an interesting contrast with Arabic, since it demonstrably has a quite different type of syllable structure. I claim that syllabification in Hebrew observes the rubrics in (3): 
(3) a.

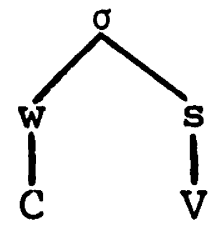

b.

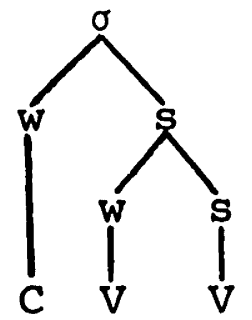

c.

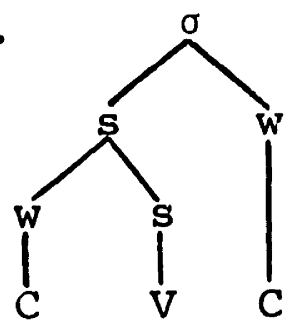

That is, although Hebrew has the same three canonical syllable patterns -- CV, CVV, and CVC -- as Arabic, Hebrew makes a fundamental distinction in the structures assigned to them. Hebrew has all three of the syllable trees in (1), subject to the condition that a strong rhyme node is [+syll] and a weak rhyme node is [-syll]. This yields, as in (3), a basically right-branching structure for CVV syllables and a basically left-branching structure for CVC syllables.

This important structural difference is supported extensively by considerations of Hebrew segmental phonology in section 4 of this chapter and by Hebrew accentuation in chapter 3. For the segmental phonology, the trees in (3) correctly predict a distinction between two rules that strengthen a CV syllable; one by making it $\mathrm{CVV}$, and the other by making it CVC. For the accentuation, the definition of a rhyme as the right branch of $\sigma$ yields a system in which the rhymes of (3a) and (3c) cluster together as opposed to the rhyme of $(3 \mathrm{~b})$, since the former are nonbranching and the latter are branching.

This is, in fact, the basic insight behind the analysis of Hebrew in this chapter and in chapter 3. In many respects 
CV and CVC syllables constitute a natural class as opposed to CVV syllables, whereas CVC and CVV syllables constitute the class in Arabic. Given the purely structural definition of rhyme followed here, this distinction must be notated by structures of the sort in (3). I should point out, however, that this basic idea is relatively independent of the exact nature of the notation chosen. For example, one could claim, along the lines of the proposals for English syllabification in Selkirk (forthcoming), that category labels appear within the syilable trees. We might then sippose that Hebrew has just the syllable repertoire of (2), but with a different label attached to $\mathrm{VV}$ rhymes as opposed to $\mathrm{V}$ and VC rhymes. ${ }^{1}$ The basic character of this analysis of Hebrew will remain, but will be notated in terms of these category labels rather than the structural distinction followed here. It remains for further research to determine whether any empirical differences exist between the essentially categorial and essentially structuxal theoriè of syllabification.

I recognize one other type of syllable in both Arabic and Hebrew, with a somewhat different structure from those already discussed. There is, in Classical Arabic, a particular syllable type that is limited almost exclusively to the position at the end of a phonological phrase, the superheavy syllable CVVC and CVCC. This syllable results from the loss of final short vowels before a major pause, discussed 
further in chapter 3. The superheavy syllables of Arabic, although more complex than the other types, are, however, clearly single syllables by any measure of surface syllabification. Thus, they scan as simple heavy syllables, not as two syllables, in the meter mutadaarik, where they occur most often.

In addition to the basic templates in (2), Classical Arabic has the following rule of syllabification:

(4)

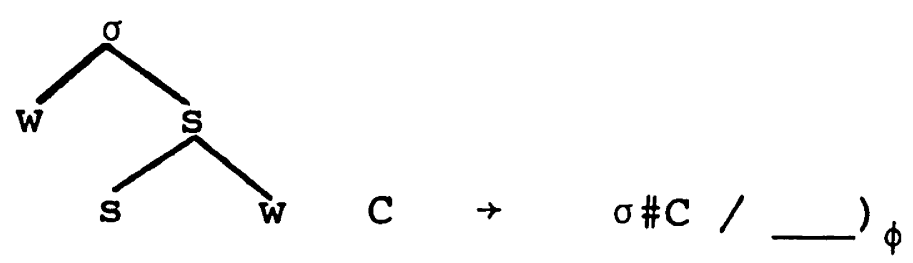

$$
\phi=\text { phonological phrase }
$$

The context, the right boundary of a phonological phrase, follows notational proposals in Rotenberg (1978) and Selkirk (forthcoming). What this rule says is that a phrase-final consonant is Chomsky-adjoined to a preceding syllable with the indicated structure. I assume that the output of this rule is labeled $s-w$, so the following structure results:

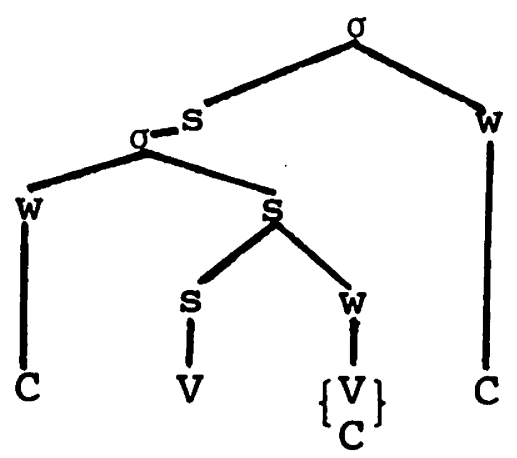


A superheavy syllable, then, has a Janus-like character: it presents itself to surface representation and phenomena like meter as a single syllable, the superordinate $\sigma$ in (5). But it also properly contains a syllable, the subordinate $\sigma$ in (5), and this property turns out to have no little significance in the operation of accentual processes in chapter 3. Specifically, the two $\sigma$-nodes in (5) yield two rhymes, if defined as the right branch of $\sigma$, with the first rhyme branching and the second nonbranching.

The modern Arabic dialects of Cairo and Damascus also have superheavy syllables with identical structure. In underlying representations these are limited not to phrasefinal but to word-final position. This property is accounted for by altering the environment of (4) slightly to wordjuncture rather than phrase-juncture.

Tiberian Hebrew offers a somewhat different set of facts in this vein. Superheavy CVVC syllables occur freely in word-final position in underlying representation. Here also there is evidence, from an arguably syllable-counting meter, that these CVVC strings are single syllables phonetically. But final CVCC syllables in Hebrew are more problematic. It seems fairly clear that the actually occurring strings CVCC in underlying representation are not properly syllabified at that stage, but appear as CVC syllables with a following extrametrical consonant. They are then subject to epenthesis 
of a vowel, as in the derivation /qebr/ + géber 'grave'. Therefore the improperly syllabified string CVCC is brought into conformity with the syllable structure rubrics by application of an epenthesis rule. What few cVCC syllables actually appear on the surface are restricted to word-final position in a highly restricted set of forms derived by either of two morphological truncation rules discussed in Prince (1975)..$^{2}$ I conclude, then, that CVCC syllables do not occur in underlying representations in Hebrew. A little more on this subject can be found in sections 3.2 and 3.3 of chapter 3.

Therefore the rules of syllabification in Hebrew will include provision only for the creation of CVVC syllables and not CVCC syllables. In fact, exactly such a property already holds of rule (4), extended to word-final contexts, as in the modern Arabic dialects. Since only CVV and not CVC syllables in Hebrew have the right-branching structure demanded by (4), only CVVC superheavy syllables will be created by it.

This structure for the Hebrew superheavy syllables, as well as for the Arabic, is justified extensively by accentual considerations in chapter 3. There is in Hebrew one other small argument in support of this constituent. CVVC syllables whose vowel is nonlow and whose final consonant is a laryngeal or pharyngeal glide (known as a guttural) are subject to 
insertion of the a off-glide called furtive pathach: $\underline{r \bar{u}^{a} h}$ 'breath', $\underline{r \bar{r}^{a} g}$ 'companion'. 'The result of this rule is still a single syllable by anyone's reckoning. I suggest, then, that the domain of insertion of the furtive pathach is specifically a superheavy syllable, subject of course to conditions on the quality of the vowel and the final consonant. I will return to the consideration of somewhat more complex properties of Hebrew phonology in section 4 of this chapter.

3. Syllable Structure and Phonological Rules

We must now decide how the syllable structure trees of the previous section will function in the application of phonological rules. There are two aspects to this question. First, how is syllable structure referred to in structural descriptions, and second, how does it govern possible structural changes?

The answer to the first of these questions is relatively clear. Given a theory in which syllables and internal constituents of syllables are recognized as structural units, phonological rules will be able to refer to those units as contexts or perform operations on them. Therefore phonological rules will be able to specifically mention constituents like syllable or rhyme as the domain of some process or as a participant in it. For the rhyme in particular, I will depend on the notion of projection (Vergnaud 1976). A projection is a representation, simultaneous with the ordinary phonological 
representation, on which only those elements are present that share some well-defined phonetic or structural characteristic. The projection of greatest significance here is the rhyme projection, a projection of all and only those units that share the property of being the right branch of some $\sigma$. Phonological rules have available to them the possibility of stipulating that they apply directly on some projection like the rhyme projection. The results of operations on any projection are carried over to the regular phonological representation. Although the projection mechanism functions in some segmental rules developed in section 4 , it is most ge?rmane to the treatment of accentuation. Therefore a more thorough discussion of projection can be found in section 1 of chapter 3, and extensive exemplification from Tiberian Hebrew can be found in section 3 of the same chapter. I suggest a reading of this now for those unfamiliar with these notions.

The other question is essentially how syllable trees affect the function, in the technical sense, of phonological rules. My proposal is that all phonological rules are syllable structure preserving unless deviations are explicitly mentioned. That is, a phonological rule may apply if and only if its output conforms to the canonical syllable structures of the language. As a corollary, syllable structure is reassigned for the affected segments after the application of each phonological rule as well as with the addition of any new 
morphological material. Thus, the basic mechanism is syllabification on underlying representations, and then repeatedly throughout the course of the derivation. I should note that this behavior, although atypical in ordinary phonological rules, may be the ordinary case with the assignment of some types of metrical structure. An essentially identical model of Hebrew metrical foot assignment is developed in section 3 of chapter 3 .

There are several consequences of this claim of syllable structure preservation throughout the derivation. First, it incorporates much of the effect of the conspiracy notion into the syllabification apparatus. Although it is not universally true, conspiracies generally seem to involve an attempt at conformity to one set of syllable patterns by a variety of phonological rules. (More on this question can be found in McCarthy (1976)).

A second point is that many kinds of insertion or lengthening rules can be vastly simplified by removing characteristics that are predictable from considerations of syllable structure. I will assume that nodes of syllable structure that are inserted with unspecified feature values will receive those values from adjacent segments, subject to the overall permissible syllable structure of the language. These nodes are introduced by an operation of sister adjunction, notated by "+", to any syllable or constituent of a syllable. Like all phonological rules, the output of these adjunctions is subject to the usual 
syllable structure preservation.

Thus, in Tiberian Hebrew, as we will see, adjunction of an unspecified node to the rhyme yields a branching rhyme in which the inserted node conventionally receives the features of the vowel to which it is adjoined. But adjunction of a node to the syllable will yield, for the structure in (4c), a final consonant that receives the feature values of the adjacent consonant in the following syllable.

This is not to say, however, that the canonical syllable patterns must remain invariant throughout the derivation. This is easily falsified, again on the vasis of the following analysis of Hebrew. Although superheavy CVVC syllables in Hebrew are limited to word-final position in underlying representation, they occur somewhat more freely elsewhere in the derivation. Three separate rules -- Schwa Deletion, Tonic Lengthening, and Pausal Lengthening -- which are ordered at widely different points in the phonological derivation all create superheavy syllables that are not necessarily word-final.

I suggest, then, that stipulated deviations can be made from the underlying syllabification, and that these deviations must hold throughout the derivation. In Hebrew, this deviation is very simple to express. The Hebrew counterpart of the superheavy syllable rule (4) has the context before wordjuncture. This context holds only for underlying representations, and it is suppressed for all intermediate and surface representations. The fact that such a simple stipulation 
correctly describes the observed deviation from underlying syllabification supports the general structure-preserving character of syllabification as well as the specific formulation of rule (4). Damascene, although not Classical, Arabic also has a deviation almost identical to that in Hebrew.

The last point before we turn to the analysis concerns the representation of segmental quantity. I reject the feature [long], which has often had at best a diacritic function in previous studies, and so I represent all quantitative distinctions by gemination. In vowel systems, the usual evidence for this feature has been the fact that alleged [+long] vowels behave as a unit under phonological rules. We can now offer a structural interpretation of this observation: an entire [+syll] rhyme, containing two vowels, is subject to the particular rule. Thus all long vowels are represented as geminates, but individual rules may specify whether they apply to the structure or the segments. Parallel considerations hold for tautosyllabic geminate consonants. As for heterosyllabic geminate consonants, the only case I know of where the feature [+long] has been suggested involves the Hebrew spirantization rule (Sampson 1973). This has, however, been convincingly dismissed by Barkai (1974), and, moreover, a different analysis of the same facts is presented here in section 4. 
4. The Segmental Phonology of Tiberian Hebrew

The phonology of Hebrew is easily identifiable typologically; it involves a wide range of reduction and lengthening phenomena that refer chiefly to syllable structure and stress placement. Therefore it provides a good testing ground for the theory of syllable structure developed in the preceding sections and for the stress theory presented in Chapter 3.

Certain aspects of the data presented here are rather controversial. As with any language that is no longer living, Biblical Hebrew is subject to conflicting interpretations of the orthographic record. On another level, the fact that no aspect of the orthography other than the consonants demonstrably dates earlier than the sixth century $A D$ has led some scholars to conclude that certain aspects of the traditional pronunciation were borrowed from the native language of post-Biblical speakers of Hebrew. On the other hand, we know that a long oral tradition of study and memorization preceded the fixing of the nonconsonantal orthography. The parallel to the reputed accuracy of transmission of Vedic Sanskrit is not inappropriate here. The, to my mind, correct view of this matter is embodied in the statement of Orlinsky (1966) that the Masoretes, the medieval scholars, "from first to last were essentially preservers and recorders of the pronunciation of Hebrew as they heard it". For further discussion of these issues, see section 3.1 of Chapter 3 and the footnotes. 
The treatment here is heavily dependent on the analysis presented by Prince (1975), including some early work on the nature of metrical structure. Certain new observations, particularly in the rule of consonant gemiration, tend to confirm Prince's basic insights and to support an interestingly abstract analysis of the Hebrew facts. I should say also that no attempt is made here to give an exhaustive description of the phonology of Tiberian Hebrew. My attention is confined to those rules that are most germane to the issues of syllabic and accentual structure developed in this chapter and in Chapter 3. I refer the reader to Prince's work for treatment of other phenomena and more extensive justification of the underlying representations and the processes presented here.

Since most of the segmental phonology of Hebrew is crucially dependent on the position of main stress, let me first informally sketch the effect of the Main Stress Rule as it is developed in Chapter 3. Essentially this rule assigns penult stress in vowel-final words and final stress otherwise. It accomplishes this formally by creating a binary branch, labeled $s-w$, over the rhymes of the last two syllables of vowel-final words. We can assume as well that a right branching structure picks up the remaining syliables in the word, so a rough metrical structure for representative penult and ultima stressed forms will be: 
(1) a.

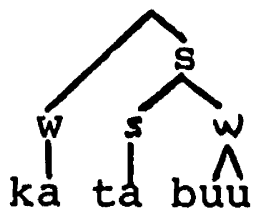

b.

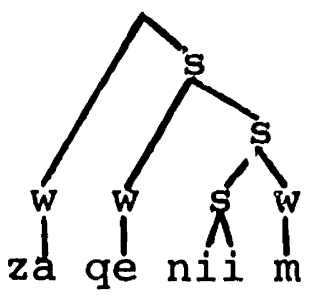

These forms are from a very early stage of the derivation, and are subject to heavy modification by subsequent rules. Since the application of these rules depends on the position of main stress, we will need a notation to allow us to refer to it. Moreover, since some syllables will bear secondary stress throughout the derivation, we must be prepared to distinguish miin stress frum secondary stresses. For this I suggest the notation [DTE], which refers to the designated terminal element of the metrical tree (Liberman and Prince 1977). The designated terminal element is the terminal node that is dominated only by s's all the way up to the root. It is the rhyme of the penult syllable in (1a) and of the ultima in (Ib).

I will assume that [DTE] is a binary feature whose value is derivative of the characteristics of the metrical tree. Any segment in a syllable riose rhyme is the designated terminal element of the metrical stress trae will be marked [rDTE]: all other segments will be [-DTE]. Note that this is not to be confused with the earlier feature [stress], which was a memb $\leadsto$ r of the set of primitive universal distinctive features. [DTE] is assigned solely on 
the basis of prosodic structure. It is tlierefore purely a notational device to allow easy reference to a particular property of that structure in phonological rules.

The first major phonological rule, a rule of no little theoretical interest, lengthens vowels in open syllables that immediately precede the syllable bearing the main stress (here and subsequently, actual surface forms are in parentheses) :

(2) a. katábuu $\rightarrow$ kaatábuu (kātbQ́) 'they wrote' yišlahéka - yišlaahéka (yišlăhăká) 'he sends you 900lamíim + 900laamíim (981āmî́m) 'eternities' (mg.)' b. lebáb - leebáb (1êbấb) 'hear' zaqeníim $\rightarrow$ zaqeením (zaqēnî́m) 'old (m. pi.)' c. ?ooyebím (?סुbî́m) 'enemies' yagaddeléka (y ggaddelká) 'he magnifies you (m. sg.)' d. katabtém (katabtém) 'you (m. pl.) wrote' maptéh (maptế ${ }^{a}{ }_{\text {) }}$ ) 'key'

The forms in (2a) show that a lengthens in an open pretonic syllable regardless of what precedes. In (2b) we see that e lengthens in the same context if $i:$ is in the first syllable of the word or if the preceding syllable is open with a short vowel. But in (2c) e resists pretonic lengthening (and is subject to later deletion) because the preceding syllable either contains a long vowel or is closed. 
Finally, the forms in (2d) demonstrate that no vowel can lengthen when in a closed syllable or a syllable that is not immediately before the stress.

Therefore the basic generalizations are as follows. The nonround vowels $\underline{a}$ and $\underline{e}$ lengthen in an open syllable immediately preceding the stress, except that e alone fails to lengthen if the preceding syllable is CVV or CVC.

Let's consider in detail how these observations can be expressed in a metrical theory of syllable structure. First, the structural change of vowel lengthening in an open syllable is expressed simply by adjunction of a node $\mathrm{n}$ to a rhyme that already contains a vowel. By convention, this inserted node is labeled in accordance with the basic syllable structure of Hebrew and adopts the feature values of its sister node. Formally, in a syllable of type (3a), a node $\mathrm{n}$ is adjoined to the rhyme, yielding ( $3 b)$, and conventially labeling and distinctive feature values are distributed as in (3c):

(3) a.

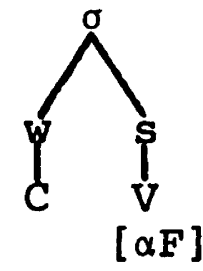

b.

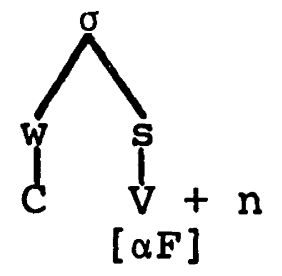

c.

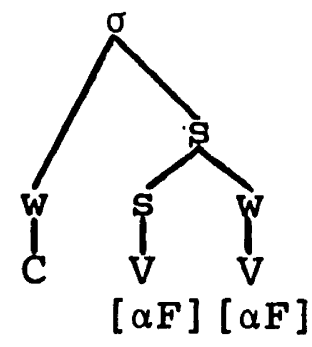

By $[\alpha F]$ I mean the phonological features borne by the nucleus segment. In (3), the only stipulation is the 
adjunction of $\mathrm{n}$ to the rhyme; all additional properties of (3c) follow from the principles developed in section 3. The context of this rule can be similarly abbreviated by structural considerations. We must say that the syllable whose rhyme is lengthened is immediately followed by the syllable bearing main stress. Moreover, $\underline{e}$ is lengthened only if the preceding syllable is $\mathrm{CV}$ and not $\mathrm{CVV}$ or CVC. Both of these conditions require us to ignore material in the onset of the syllable. We look for the main stressed vowel but skip the onset of the syllable containing it. We look for a preceding $C V$ syllable but skip the onset of the syllable whose vowel is lengthened. I suggest, then, that here is a clear case where reference to a projection of rhymes, in the sense developed earlier and in,chapter 3, will allow the rule to refer only to essential contextual properties. Schematically, on a rhyme projection a vowel lengthens if immediately followed

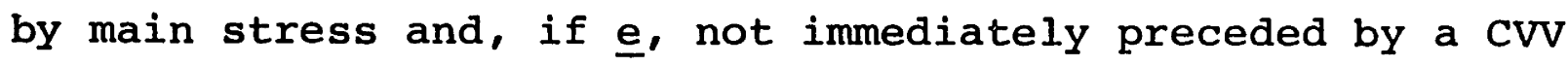
or CVC syllable. We can refer to main stress formally with the feature [+DTE]. A preceding CVV or CVC syllable is characterized as a syllable whose rhyme has a terminal weak node, since CV syllables like (3a) have terminal strong nodes as rhymes. A terminal node will be notated by $\tau$. We can incorporate these observations into the following rule: 
(4) Pretonic Lengthening (on Rhyme Projection)

$$
\left[\begin{array}{c}
V \\
\text {-round } \\
\langle- \text { low } \\
a
\end{array}\right]+v+n /\left\langle\prod_{\tau}^{w}\right\rangle_{b-}[+D T E]
$$

Condition: $a \supset \sim b$

The feature [-round] ensures that only $\underline{\text { a }}$ and $\underline{e}$ are subject to this rule; we will shortly see the fate of the round vowel 으. The structural change takes a rhyme containing a vowel and turns it into a branching rhyme. Since the only branching rhymes in Hebrew are long vowels, this operation suffices to induce lengthening of the pretonic vowel. The specification of a vowel rhyme will also vitiate the possibility of a pretonic lengthening in a closed syllable, where the rhyme is a consonant.

It is appropriate to note here that some scholars have expressed discomfort with pretonic lengthening in Hebrew on the grounds that this sort of rule is unprecedented in the world's languages. Therefore they have suggested that it may be a sort of Masoretic fiction, adopted long after the Biblical period. If true, this would be a serious problem not only for the analysis of Hebrew presented here but also for the theory, since the metrical notation values pretonic lengthening only slightly less highly than the well-known process of tonic lengthening. In fact, one other case of pretonic lengthening has come to my attention. Chafe (1970) demonstrates that 
Onondaga clearly has a rule lengthening vowels in pretonic open syllables. He also observes several other complications, one of which is slightly revealing here. Apparently the onondaga rule must count parity as well, since only a pretonic vowel which is in an even syllable counting from the beginning of the word can be lengthened. It is tempting to speculate that a formally similar property may have held at one time for Hebrew, since the requirement that $\underline{e}$ not be preceded by a CVC or CVV syllable usually has the effect of making e an odd-numbered mora, counting from the beginning of the word as well. For a metrical explication of a structurally similar process, see the treatment of Cairene Arabic in Chapter 3.3

Anyway, let's now turn to the treatment of the kack round vowel 으 in pretonic open syllables. It is never subject to Pretonic Lengthening, as the feature [-round] in the structural description ensures. The sole exception to this is the special archaic imperfective paradigm yiktoobún, tiktoobíin, and so on. As Prince (1975) points out, these are almost certainly the result of hypercorrection in response to the archaic morphology and their frequent use in pausal (phrase-final) positions, where a long and stressed 으 is regularly expected. Therefore I will ignore them in the rest of this discussion.

What we find instead for 0 is split behavior. In verbs with clitics, 으 remains unchanged and is subsequently 
subject to vowel reduction, as we will see shortly. In nouns and adjectives, 으 in a pretonic open syllable causes lengthening of the following consonant (whence o is regularly realized as $\underline{u})$ :

(5) a. kotónt $\rightarrow$ kottónt (kuttónet) 'garment' b. 9agolóot + 9agollóot (9ăgullốt) 'round (f.pl.)' c. 9eeromíim + 9eerommíim (9êrummîm) 'naked (m. pl.)' d. 9amoqóot + 9amoqqóot (9ămuqqốt) 'deep things'? 9amoqá + 9amoqqá (9ămuqqáa) 'deep (f. Job 12,22 Ez 23,32

Forms like Stoloomíim 'peace (p1.)' and m.agoomóot 'places' show that underlying long $\underline{\sigma}$ in a pretonic syllable cannot engender the doubling.

Significantly, quite a number of nouns and adjectives with a display doubling instead of the expected pretonic lengthening:

(6) a. ?agamíim + ?agammíim (?ăgammî́m) 'marshes' Ex 8,1 b. qațaníim - qațanníim (qațanním) 'small (m. pl.)' qațanóot $\rightarrow$ qațannóot (qaţannốt) 'id. (f. pl.) ', CEz 16,61 c. ?adamdamóot + ?adamdaminóot (?ădamdammốt) 'reddish (f. pl.)' Lev 14,37 a. ?asíir + ?assíir (?assî́r) 'captive' Is 10,4

Though long $\underline{\underline{a}}$ is very rare in underlying representations in Hebrew, except for a few loan words, it is still true that 
long $\underline{\bar{a}}$, like long $\underline{\underline{ }}$, never induces this gemination. Therefore we can say, as a first generalization, that the nouns in (6) are lexical exceptions to Pretonic Lengthening, so they are subject to a following rule that geminates a consonant after short a. Since o is excluded in the formulation of Pretonic Lengthening, all o's, at least in nouns and adjectives, are subject to this putative pretonic gemination rule. On the other hand, virtually no $e^{\prime} s$ ever have pretonic gemination. They either have Pretonic Lengthening, or, when that is excluded by a preceding CVC or CVV syllable, they remain unchanged and subsequently are reduced. Consonant gemination relies on the same formal conventions as Pretonic Lengthening -- both structuring the derived syllable in conformity with the basic patterns and borrowing feature values from adjacent segments -- but it applies them to a somewhat different structure. I have claimed that CVC syilables in Hebrew are associated with a left-branching metrical tree. Therefore consonant gemination will sisteradjoin the inserted node $n$ not to the rhyme but to the syllable node itself. This will yield (7b) from (7a):

(7) a.

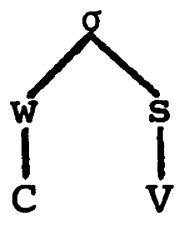

b.

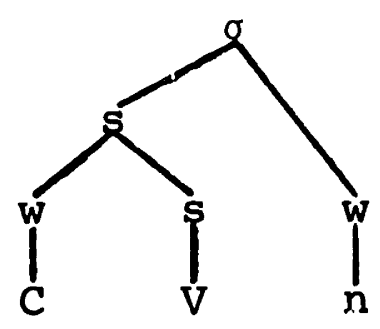


The node $\mathrm{n}$ must be a consonant in this case since only a consonant can appear as the weak right branch of $\sigma$. So the fundamental difference between vowel lengthening and consonant lengthening under the Hebrew syllable rubrics is a purely structural one. The first type of lengthening adjoins a node to the rhyme; the second type adjoins a node to the syllable.

Adjunction to the syllable node can be expressed by the following rule:

(8) Pretonic Gemination

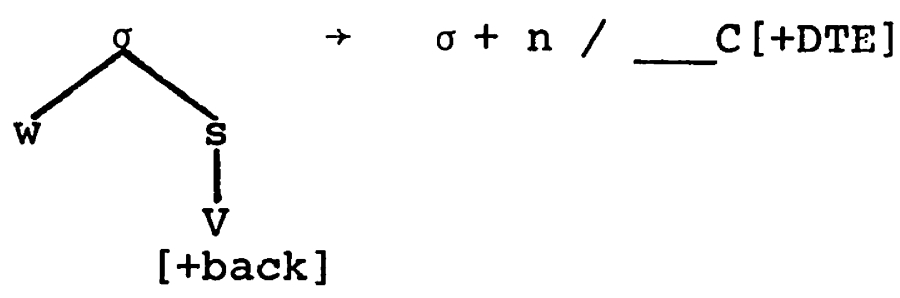

The feature [+back] ensures that only a and 으 can precipitate Pretonic Gemination. As in Pretonic Lengthening, [+DTE] indicates main stress on the following syllable. We will also have to exclude Pretonic Gemination in some verb forms, but I will deal with this shortly.

There is one apparently serious problem with this scenario, however. The difficulty is that many of the nouns in (5) and (6) retain the gemination even when the following syllable is stressless in suffixed forms or socalled construct phrases: 
(9) a. kottontíi (kuttontîi) 'my garment' Job 30,18

b. ma9rommeehém (ma9ărummêhém) 'their nakednesses' $2 \mathrm{Ch} 28,15$

c. paqoddat (paquddat) 'numbering of' $1 \mathrm{Ch} 23,11$ paqoddaatám (pəquddătấm) 'their stores' Is 15,7

d. ?abbiiríim (?abbîrî́n) 'valiant (m. pl.) Ps 50,13

Actually, though, the real story is a little more encouraging than this. A significant minority of nouns with gemination before the stress do give it up when the following syllable is stressless:

(10) a. kotónt (kətónet) 'garment of' Gen 37,33 kotonóot (kotnốt) 'garments' Neh 7,69\&71

b. ?abiir (?ăbîr) 'valiant of' Gen 49,24

c. ?agamee (?agmê) 'marshes of' Is $14,2.3$

?agameehém (?agmêhém) 'their marshes' $\operatorname{Ex~7,19~}$

d. nikbadeehém (nikbədểém) 'their wealth' Ps 149,8

e. 9aweríim (9iwr $\hat{i}$ ' $)^{4}$ 'blind (m. pl.)' Is 29,18

These forms in (10) compared to those in (5) and (6) and others are consistent with the claim that phonological gemination is limited to pretonic syllables. The problem is to explain why the forms in (9) have extended pretonic gemination to nonpretonic syllables.

Much of this is idiosyncratic variation or historical paradigm leveling, but nevertheless the jrammar ought to 
offer some account of it. The basic problem is the extension of gemination to nonpretonic environments. What is significant is that some forms also display a similar overapplication of Pretonic Lengthening. In certain subclasses, particularly feminine nouns in $\underline{e}$, this overapplication seems to be the rule:
(11) a. śamehee $\rightarrow$ Sameehee (కวmēhê) 'joyful of' Ps 35,26 b. me9eehém $\rightarrow$ mee9eehém (mê9êhém) 'their bowels' c. 9aremat $\rightarrow$ 9areemat (9ărēmat) 'heaps of ' Hag 2,16 d. sariisiim $\rightarrow$ saariisiim (sārîstím) 'officers' a. sariisiim $\rightarrow$ saariisilm (sărisim) 'officers' 20,18 e. pariisiim $\rightarrow$ paariisiim (pārîsîm) 'violent (m.pl.)' d. Šabuu9oot $\rightarrow$ šaabuu9oot (šābû9ốt) 'weeks' Ex 34,22

The importance of these two kinds of overapplication is not in the lexical variation, but rather in that this lexical variation is tightly constrained phonologically. Pretonic Lengthening overapplies with $\underline{e}$ and $\underline{a}$, and Pretonic Gemination overapplies with $\underline{\text { a }}$ and 으, but the other two possibilities do not usually occur. This variation follows the structural descriptions of Pretonic Lengthening and Pretonic Gemination in this respect, since the former applies only to nonround vowels and the latter only to back vowels. In sum, my interpretation of this variation is as follows. In lexically and morphologically governed contexts, it is possible to suppress the pretonic environment 
(the feature [+DTE]) of the rules of Pretonic Lengthening and Pretonic Gemination. When it is suppressed, we find lengthening of $\underline{a}$ and $\underline{e}$ (as in (11)) or gemination of the consonant following a and $\underline{\text { o }}$ (as in (8)). This mechanism of suppression of a particular contextual feature under morphological government is not new; for instance, it is needed to account for the different modes of stress retraction under the one English stress rule (Liberman and Prince (1977) and Chapter 3). Moreover, it makes the apparently correct claim that no morphological idiosyncracy will allow e to induce gemination or o to lengthen, pretonically or otherwise. These possibilities are expressly excluded in the frrmulation of the two rules.

There is another possible objection that is more serious than these empirical difficulties. Both rules, Pretonic Lengthening and Pretonic Gemination, seem to duplicate the effect of strengthening the syllable immediately before the main stress. Thus, both refer to the context [+DTE]. But the possibility of collapsing these two rules is precluded by the metrical analysis of Hebrew syllabification proposed here. CVV and CVC syllables have fundamentally different structures, the first right-branching and the second left-branching. Therefore only the most baroque notational devices would allow us to conflate two rules that each create one of these syllable types. 
We will see shortly, though, that Pretonic Gemination demonstrably applies in the context between words, while Pretonic Lengthening is limited to worr internal contexts. Therefore the split between the two rules, required on formal grounts by the analysis of Hebrew syllable structure presented here, is independently justified on strictly empirical grounds as wel1. But first we must consider the rule of vowel reduction.

In a number of circumstances short vowe?s in open syllables will survive the ministrations of Pretonic Lengthening and Pretonic Gemination. In particular, most nonpretonic vowels and some nonlow pretonic vowels will still be short and their syllables open. These vowels are, then, generally subject to a rule of vowel reduction that yields the vowel schewa. A subsequent rule deletes this schewa in some contexts.

Prince (1975) argues that this process of vowel reduction has ari alternating character, applying to every other one of a series of shc:t vowels in open syllables:
a. malakíim + malaakíim - məlaakím
b. malakeehém $\rightarrow$ mal akeehém 


\section{(13) a. ?agamíim $\rightarrow$ ?agammíim $\rightarrow$ ?agammíim b. ?agameehém $\rightarrow$ ?ag ameehém}

The form in (12a) is initially subject to Pretonic Lengthening, making the second a long. The first $\underline{a}$ is then reduced because it is short in an open syllable. But in (12b) neither $\underline{a}$ is lengthened and so both are potentially reducible. In fact, reduction alternates, so only the rightmost a reduces. In (13a), Pretonic Gemination creates a closed syllable that protects the second a from reduction, so the first one reduces. (13b) works just like (12b).

Given that the mode of vowel reduction is a simple alternating pattern, the metrical theory allows just one possibie formulation of the rule. It must assign a binarybranching structure -- let us assume w-s assigned from right to left -- whose weak position is a short vowel in an open syllable. The vowel in the weak position of this structure is then interpreted phonetically as schwa.

But I argue in Chapter 3 , section 3.3 on grounds of tie surface quality of schwa and the accentual behavior of syllables containing reduced vowels that all reduced vowels in Hebrew should be represented as weak nodes in a binary branching structure. That is, Hebrew does not make the apparent three way quantity distinction aa- $\underline{a}-\underline{\partial}$, but rather the opposition between $\underline{a}$ and $\underline{\partial}$ is purely a prosodic one, 
since $\partial$ is in the weak position of a particular binary branching structure, which I designate as $\rho$.

It follows, then, that the rule of vowel reduction just assigns this binary branching structure $\rho$ from right to left under appropriate conditions. Conventionally, any vowel in the weak position of a $p$-structure is interpreted as reduced. I formalize these properties in (14):

(14) Vowel Reduction (on Rhyme Projection)

Assign a structure $\overbrace{s}$ from right to

left, where the left node is nonbranching and is a vowel.

In detail, this rule creates a binary-oranching structure called $\rho$. The left branch of this structure cannot be a long vowel (it does not branch), but it must be a vowel. Further discussion of the formal properties of $\rho$ and similar structures can be found in Chapter 3.

We can illustrate the application of Vowel Reduction on the forms in (12) with the following sample derivations:

(15) a.

Rhyme Projection $\mathrm{m}$ a

Vowel

Reduction

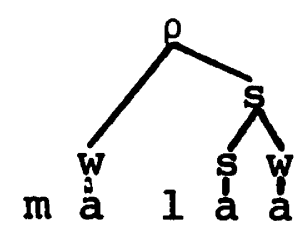

b.
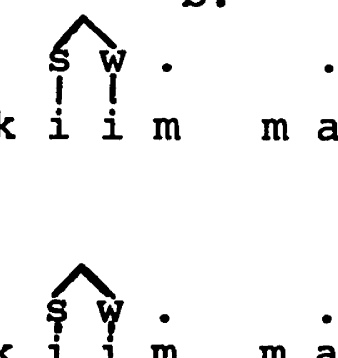

.

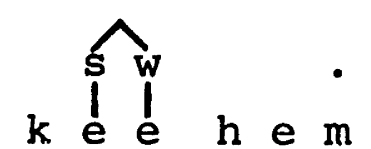

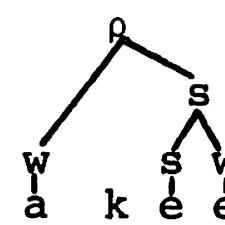


The weak position in the $\rho$-structure, the first a in (1.5a) and the second $\underline{a}$ in $(15 b)$, is interpreted phonetically as a reduced vowel, which may be subject to ] ater deletion, as we shall see.

One of the most interesting properties of the Vowel Reduction rule is its application to short streused vowels in open syllables. This engenders a rightward movement of stress, as in the following examples:
(16) a: katábuu
b. giddíluu

Pretonic

Lengthen:ing kaatábuu "

Vowel

Reduction

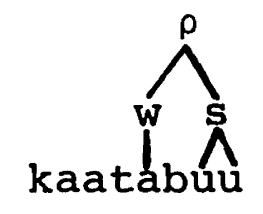

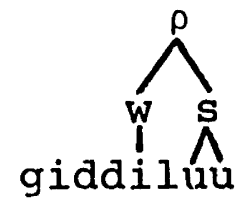

The topmost forms in (16) are the outputs of the Main Stress Rule, with the regular penult stress of vowel-final words (compare yaagúumuu, pausal kaatáabuu).

In view of the treatment of this rule developed in

Chapter 3 and sketched above, we can say that the metrical output of the Main Stress Rule for some of the examples we have discussed is as in (17):

(17) a.

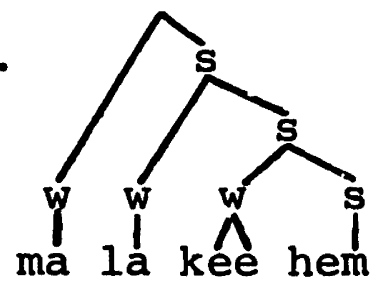

b.

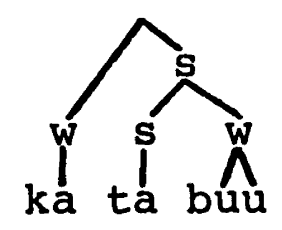


The designated terminal element of this main stress tree is the DTE referred to by the rules of Pretonj.c Lengthening and Pretonic Gemination. But we will stipulate that Vowel Reduction freely creates its own $\rho$-structure, appropriately labeled, uncler any node of the main stress tree. This will yield the foilowing structures from (17):

(18) a.

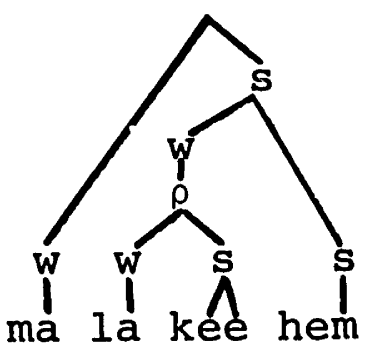

b.

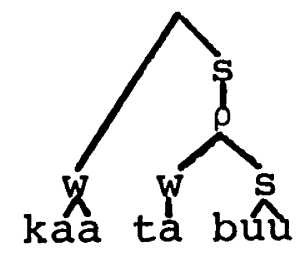

In (18b) in particular, the rightward shift of stress off of the reduced vowel is an automatic consequence of the formulation of Vowel Reduction and the prosodic representation of reduced vowels. No additional stipulation is required.

With this much in hand, we can now turn to the very interesting properties of the phenomenon of junctural consonant gemination, which has never been suitably integrated into any treatment of Hebrew phonology known to me. The traditional orientalist's designation for this is dages forte conjunctivum -- dages forte the symbol for gemination, conjunctivum because of its junctural nature. The relevant juncture for this rule is the position between two phonological words that are sole sisters in the syntactic 
phrase-marker. This context, which functions also in the Rhythm Rule of Chapter 3 and the spirantization rule discussed later, is treated fully in Rotenberg and McCarthy (forthcoming).

Apart from the syntactic condition on junctural gemination, a variety of other phonological conditions have been observed. Stated baldly on the surface level, they make quite a mass: ${ }^{5}$

(19) a. The first word must: end in â (though very rare examples in $\underline{\hat{u}}$ and $\underline{\hat{i}}$ are attested): i. šàbî́tāá šsébî̀ you-led-captive captivity

'you have led captivity captive' Ps 68,19 ii. 1ō-higgádtā $11 \hat{i}$ not-you-showed to-me 'you did not show me' Gen 12,18 versus iii. $\begin{array}{ll}\text { 9āsî́t î̀ } & \text { kḗn } \\ \text { I-did } & \text { thus }\end{array}$ 'thus I acted' Neh 5,15 iv. šînu Iánûu sing torus 'sing (m. pl.) to us' Ps $: 37,3$ 
(19) continued

b. The first word can have penult stress, as above. If it has ultima stress (before the Rhythm Rule), then its penult must be a superheavy syllable:

i. mấş?āa bóyit (<mãș?á)
she-found house

'(the swallow) found a nest' Ps 84,4

ii. yốrdā mmáyim (<yōraá) going-down water

'going down (f. sg.) to the water' Lam 1,16

versus

iii. méēà késep $\quad(<m e ̄ e \bar{a})$
hundred siiver

'a hundred pieces of silver' Dt 22,.29

c. The second word must have main stress on the first syllable, as in the examples above. Thus there is no gemination in the following cases:

i. bāráktā bārếk you-knelt kneeling

'you knelt dow'n' Num 23,11

ii. hếmmā y'î̀ršû-?ắreş they will-inherit-earth

'they will inherit the earth' Ps $3 \%, 9$

iii. mabārăkếkā bārû́k

your-blessers blessed

' (make) your (m. sg.) blessers blessed' Num 24,9 
Let's begin with the first of these conditions. The only vowel that may precede the juncturally-doubled consonant is $\underline{\bar{a}}$. There is little doubt that $\underline{\bar{a}}$ is at best a marginal phoneme of Hebrew in underlying representations, though the surface $\underline{a}^{\prime} s$ can result from a variety of rules. One of these is a process of great generality, creating ā from underlying a word-finally:

(20) Final Lengthening

$$
\mathrm{v} \rightarrow \mathrm{v}+\mathrm{n} \quad /)_{\omega} \quad \omega=\text { word }
$$

The notation for word-juncture adopted here is that developed by Rotenberg (1978). This rule says, simply, that any vowel is lengthened in absolute word-final position. As in the other lengthening rules proposed, the basic operation is insertion of a node $n$, which is adjoined to the vowel, creating a branching rhyme. The phonological features of $\mathrm{V}$ are then conventionally distributed throughout the entire rhyme.

At the stage of the derivation before Final Lengthening applies, all word-final $\underline{\bar{a}}^{\prime} s$ will be short. Moreover, the skewing of the lexicon by redundancy rules is such that /a/ is the only underlying word-final short vowel. Since we have already observed that only a triggers junctural gemination of tre foilowing consonant, we can simply say that any 
word-final short vowel induces gemination provided the proper syntactic conditions are met. We can incorporate this into a preliminary formulation of Junctural Gemination:

(21) Junctural Gemination \#1

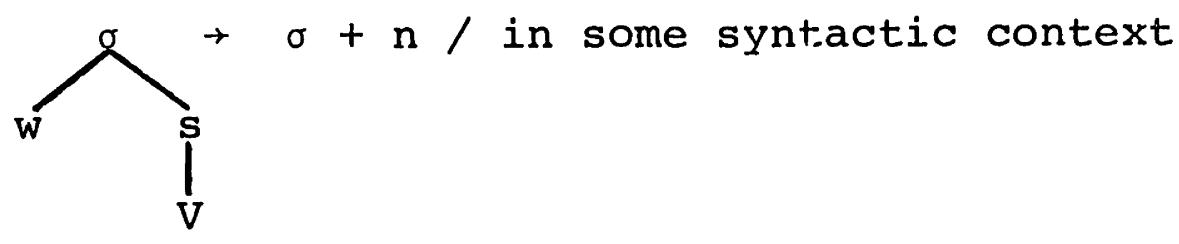

Like the Pretonic Gemination Rule already presented, this rule simply adjoins a node $\mathrm{n}$ to a syllable, provided that syllable is CV and not CVC or CVV. By the story just above, Junctural Geminction must precede Final Lengthening if it is to exploit the existence of underlying short $/ a /$.

The second informal condition on jur..ctural doubling (19b) says that the first word of the pair must have stress on the penult, or it may be ultima stressed only if the penult is a superheavy syllable. Both conditions refer to the situation obtaining before stress retraction by the Rhythm Rule developed in Chapter 3. Now if we go back a bit to the treatment of Vowel Reduction, the explanation for this rather curious restriction to forms with superheavy penults becomes evident. With only two exceptions, all Hebrew words with superheavy penults, like kaåbúu, are derived from penult-stressed kaatábuu by the application of Vowel Reduction and subsequent deletion of the reduced vowel, 
a phenomenon discussed below. Therefore if Junctural

Gemination is ordered before Vowel Beduction, the two conditions on the stressing of the first word fall into one: it must be stressed on the penult.

This analysis is confirmed by the behavior of forms where the reduced vowel of the penult does not delete for reasons discussed below. Here junctural doubling applies

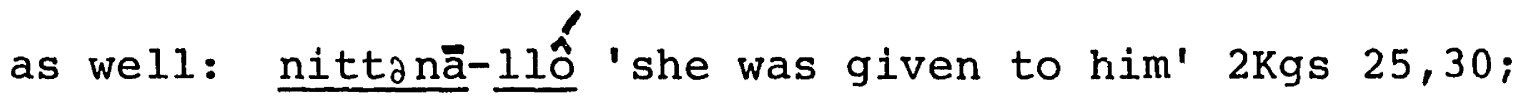
gašă-nná 'approach (f. pl.), please!' Gen 27,26. These forms are as well derived from nitténa and gésa by the rule of Vowel Reduction. The hyphen in these citations reflects a kind of destressing process, complementary to the Rhythm Rule, that is treated briefly in Chapter 3.

At this early stage of the derivation, then, it suffices to say that the final syllable of the word preceding the geminated consonant is unstressed. I incorporate this into a new version of the rule:

Junctinal Gemination \#2

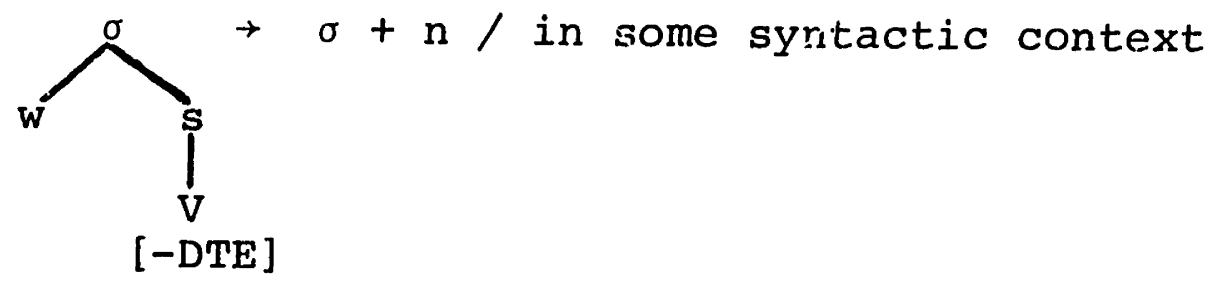

The feature [-DTE] refers to a segment which is not the designated terminal element of the metrical stress tree. 
Therefore the vowel must not bear the main stress. In all other respects this rule is identical to the first formulation of Junctural Gemination. Minimally, this rule precedes Vowel Reduction as well as Final Lengthening.

The third informal condition on junctural doubling (19c) says that the second word -- the word whose initial consonant is geminated -- must have main stress on the first syllable. Baer (1880) claims also that methegh, the symbol of secondary stress anaiyzed in Chapter 3, will also suffice to induce gemination. But here I will follow the textus receptus, which only rarely indicates gemination before a syllable containing methegh. Partly holding this question in abeyance for further philological research, I will formulate Junctural Gemination so as to require main stress on the syllable following the doubled consonant:

(23) Junctural Gemination \#3

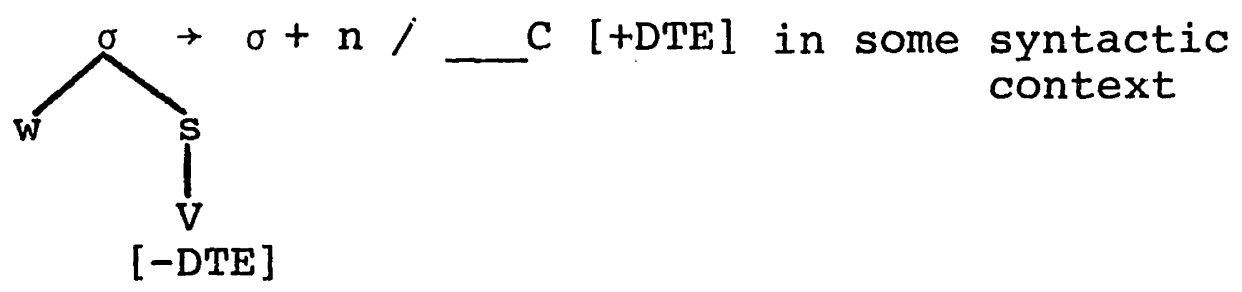

Now this final formulation of junctural gemination is clearly reminiscent of the Pretonic Gemination rule motivated earlier. Both rules geminate a consonant after a short vowel in an open syllable before the stress. Junctura.l 
Gemination requires that the preceding syllable be unstressed as well, but this is obviously true of the cases of Pretonic Gemination as well, since only one main stress is possible within a single word. Moreover, the fact that Pretonic Gemination applies only after a back vowel is mirrored in the contexts for Junctural Gemination, since we have seen that only a is subject to this rule generally and final short 으 does not occur. Finally, real confirmation is the fact that the two rules are ordered at the same very early stage of the derivation, demonstrably before the application of Vowel Reduction.

So we can collapse both rules into a single gemination process, applying to any consonant that follows a short unstressed back vowel and precedes a stressed vowel:

(24) Gemination (Final Version)

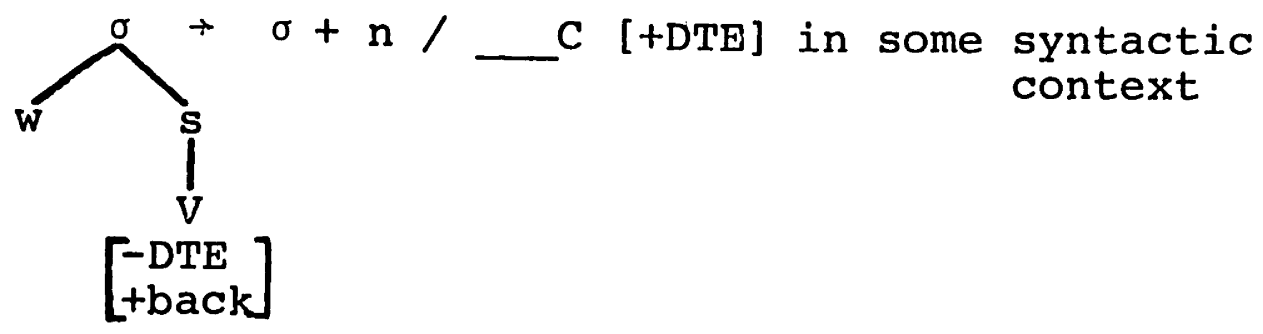

The syntactic context of this rule, as well as the other rules that apply in sandhi discussed in this section, is treated fully in McCarthy and Rotenberg (forthcoming). For our purposes here it is enough to say that the context $(\omega \omega)$ -- that is, two phonological words that are syntactic sole sisters -- constitutes ar upper bound to the application 
of Gemination. It applies freely on strings that are wholly contained within one word or within the (ww) context. The one systematic exception to this is the verbtpronominal clitic group, like/yiktobúunii/, where the pretonic consonant does not geminate so 으 reduces. This deviation will be included in the syntactic context of the rule. 6

This result has several interesting theoretical consequences. First, it is inconsistent with various interpretive theories of phonology that necessarily distinguish systematically between sandhi and word-internal rules. Clearly such a theory would miss essential generalizations here. Second, in a larger sense it supports a quite abstract model of Hebrew phonology, since the listing of sandhi alternations ought to be excluded ex hypothesi. Third, the most germane point to the proposals made here is that (24) supports the distinction between Pretonic Lengthening and Pretonic Gemination that was made on the formal basis of the structural difference between CVV and CVC syllables in Hebrew. In no case do we find Pretonic Lengthening applying in sandhi; its upper bound is just the phonological word. This is not an empty prediction. Although Final Lengthening will obscure the direct output of putative Pretonic Lengthening in sandhi, Pretonic Lengthening would still bleed Gemination, since Gemination does not apply after long vowels. That this is not the case is shown by the cited examples of Gemination and many others, so this prediction is clearly borne out by the data. 
An apparent inadequancy of rule (24) is the existence of cases of junctural gemination after the nonback vowel $\underline{e}$. Except in a few nouns like śådé 'field' and pronouns like ?élle 'these', forms with final e are imperfectives or participles of verbs whose final root consonant was historically $\underline{y}$ or $\underline{w}$, the so-called final-weak verbs. Some representative examples are:

$$
\begin{aligned}
& \text { (25) a. nibne- l1ấnûu (<nibné) } \\
& \text { was-built for-us } \\
& \text { 'it was built for us' Gen } 11,4 \\
& \text { b. yəzakke- nnágar (<yəzakké) } \\
& \text { will-cleanse boy } \\
& \text { 'a boy will cleanse' Ps } 119,9 \\
& \text { c. 9ốse llấk (<9ōśé) } \\
& \text { making for-you } \\
& \text { 'making for you (m. sg.)' Gen 31,12 } \\
& \text { d. yinnấqe rráá (<yinnāqé) } \\
& \text { be-innocent evil } \\
& \text { 'an evil man will (not) be innocent' Prov 11,21 }
\end{aligned}
$$

It is apparent from these examples that, at the early stage of the derivation where Gemination applies, the verbs and participles with final e have final stress, and therefore should not be subject to gemination. Therefore these facts are doubly anomalous, since they have not only gemination after a nonback vowel but also after a vowel that is stressed. 
There is as well a little evidence for word-internal gemination after $\underline{e}$. The sole circumstance where this might be expected in the verbal system is the feminine plural of final-weak roots. Usually there is no gemination, but two forms are attested with it, and both geminate the consonant after the stress: ta9ănénnā Jd 5,29; tir?énnā Mi 7,10. It also appears systematically regardless of accentual conditions after the particles še, ze, and me (usually ma). Finally, the frequently attested phrase mōšé llēmốr 'Moses (quote)' shows junctural gemination in violation of the pretonic position requirement observed by the forms in (25). Because of this significant variation I am reluctant to offer a rigorous treatment of gemination after $\underline{e}$ at this time. The outlines of the analysis might be as follows. The forms in (25) and others show that gemination after $\underline{e}$ is independent of the stress position in the first word. If this is the case, then there is no reason for a very early ordering of gemination after $\underline{e}$, or in fact for attempting to collapse it with Gemination. Rather, we should look to the segmental makeup of these forms in final e. I mentioned that they historically had final high glides; there is some synchronic evidence for this as well. Therefore we might suppose that the real effect here is assimilation of the final glide to the following consonant. Although this fails to explain the usual limitation of this 
gemination to pretonic syl ables, it at least suggests an account of both (25) and the facts outlined above.

Up to this point, the rules motivated and their order of application are:

\section{(26) Pretonic Lengthening \\ Gemination \\ Vowel Reduction}

The next major rule with a syllabic environment is schwa deletion. But first, for completeness, let's consider the phenomenon of spirantization, which can be shown to follow Gemination (since geminate stops do not spirantize) and precede schwa: deletion (since spirants appear after deletion sites of schewa).

After a vowel, the stops $\underline{b}, \underline{p}, \underline{d}, \underline{t}, \underline{g}$, and $\underline{k}$ are realized as spirants:

(27) a. mélek, malkí 'king, my king'

b. kātáb, yiktốb 'he wrote, he writes'

c. gâdál, yigdốl 'he was great, he is great'

Not all stops spirantize, however, the two systematic classes of exceptions are:

i. Uvular $\underline{q}$ and emphatic $\underline{t}$.

ii. Any stop when it is a member of a geminate cluster: 


$$
\begin{aligned}
& \text { giddếl 'he magnified' } \\
& \text { dibbér 'he said' } \\
& \text { haddérek 'the road' }
\end{aligned}
$$

Here I will follow the suggestion of Prince (1975) in offering a unified account of these exceptions. The emphatics $q$ and ț were apparently unaspirated, judging from a variety of evidence. First, this situation obtained in Classical Arabic, as Blanc (1967) demonstrates from the attestations of ancient grammarians. Second, it is confirmed by transcriptions of Hebrew into Greek letters (Brфnno 1943). Plausibly, the first (postvocalic) member of a geminate stop lacks consonantal release, akin to the lack of aspiration in the emphatics. I will identify this common property somewhat arbitrarily with the feature [-tense], and will require stops that undergo spirantization to be [ttense] : 7

(28) Spirantization

$\left[\begin{array}{l}\text { tobst } \\ + \text { tense }\end{array}\right] \rightarrow[+$ cont $] /[$ [ syll]

This rule, like several other rules discussed here, is also able to apply across word juncture, as the attestations in (29) show: 


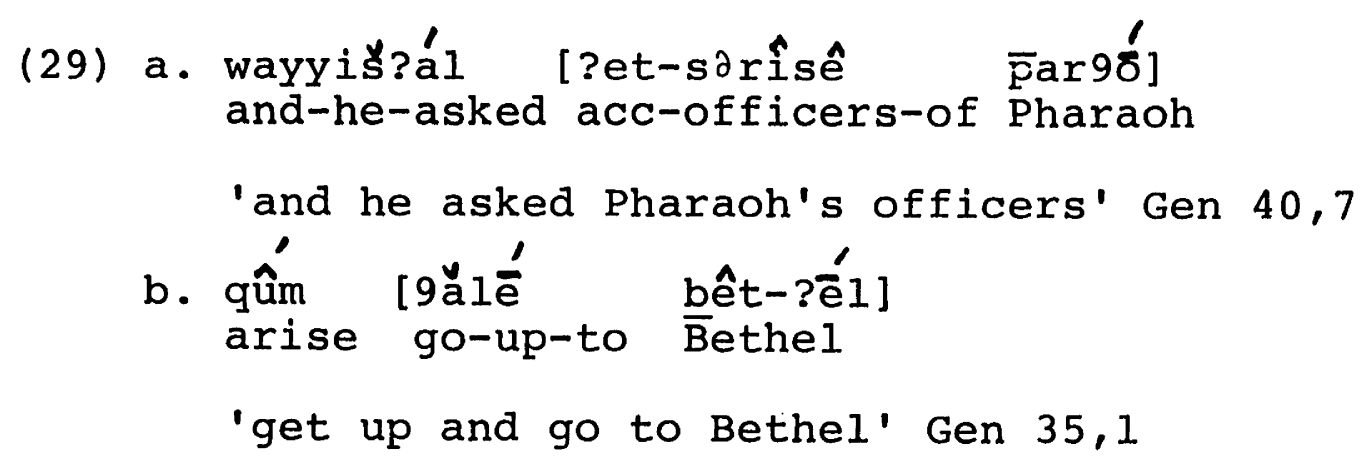

Simple reference to single or double word boundary in the spirantization rule will not suffice, though, since many other citations fail to show spirantization even though the phonological conditions are apparently met:

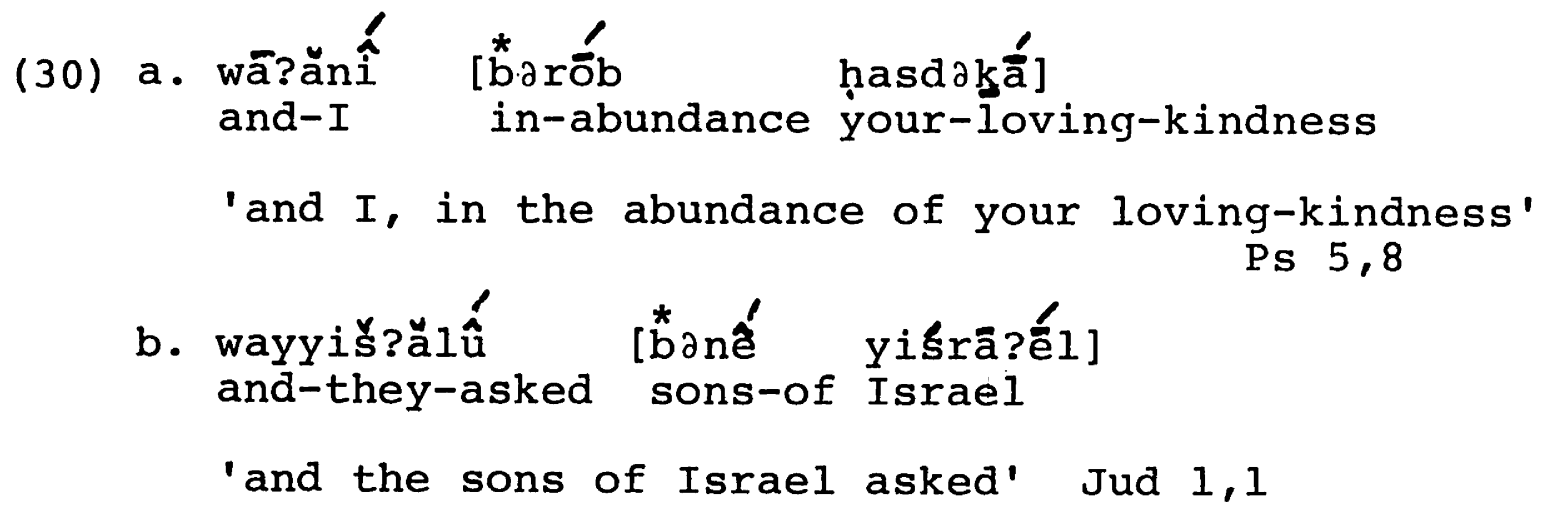

Here, the starred stops follow a vowel in the preceding word but are not spirantized.

The generalization that distinguishes these two classes of examples is apparent from the indicated syntactic bracketing -- Spirantization applies in sandhi only when the first word is sole sister to the second. This is the same syntactic context assumed by Gemination and the Rhythm Rule. 
The application of Spirantization in sandhi confirms a fairly abstract analysis of Hebrew phonology, since its context is often rendered opaque by the subsequent application of Schewa Deletion.

The fate of the reduced vowels -- the vowels in the weak positions of the $\rho$-structure assigned by Vowel Reduction -- is complicated somewhat by other factors. The consonants called gutturals, the laryngeal and pharyngeal glides, cause an assimilation of a following schwa to a, a very short low vowel: šăhithû́ $\rightarrow$ šăhătúu. As I have nothing to contribute to Prince's (1975) treatment of this process, I will not formulate it here. Schwas which are not lowered in accordance with this rule are deleted in the well-known doubly open syllable context:

$$
\begin{aligned}
& \text { (31) a. malakee } \rightarrow \text { malkee 'kings of' } \\
& \text { b. kaatabúu } \rightarrow \text { kaatbúu 'they wrote' } 8 \\
& \text { c. dabaaríim, yiktabúu 'things, they write' }
\end{aligned}
$$

In (31a) and (31b) schwa deletes because it is in an open syllable and is also preceded by an open syllable. In (31c), though, schwa is not preceded by an open syllable.

The context doubly open syllable has always been somewhat problematic, since it seems to depend rather artificially on the nature of the syllable preceding the focus. It also requires a notoriously awkward expression in terms of 
the $\mathrm{C}$ and $\mathrm{V}$ abbreviatory devices. A somewhat more elegant characterization of doubly open syllables is possible under the theory proposed in section 3 of this chapter. The sole effect of the doubly open syllable context in Hebrew schwa deletion is to avoid the creation of a word-initial CC cluster or a word-internal CCC cluster. Thus the failure of deletion in (3lc). I have already claimed that syllable structure governs the application of phonological rules: in a very precise way: a rule may apply if and only if its output can be syllabified by the syllable canons of the language. In this way we can speak coherently of syllable-structure preservation. Hebrew, as we saw, does not permit tautosyllabic consonant clusters (except in the special word-final cases mentioned). Therefore word-initial CC and word-internal CCC will have no proper syllabification, and consequently will resist the application of schwa deletion. In view of these considerations, we can formulate the following quite simple rule:

(32) Schwa Deletion (on Rhyme Projection)

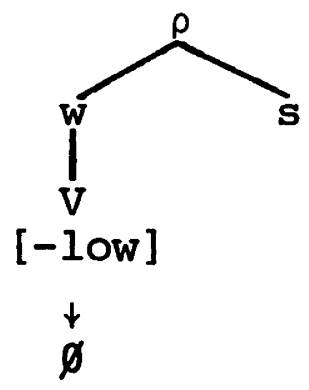

That is, any vowel that is the left branch of a $\rho$-structure will delete. The specification [-low] is necessary to prevent 
deletion of schwa that has assimilated to a preceding guttural, as in šăhătúu.

There is some additional fallout from the exact formulation of Schwa Deletion in (34). It deletes a vowel that is specifically the left branch of a $\rho$-structure, though it does not specify the source of that $\rho$-structure. In fact, there is one other major process yielding structures of this type, the insertion of a reduced vowel after an unstressed syllable-final laryngeal or pharyngeal glide, a class traditionally known as gutturals. This rule is responsible for the partial derivations in (33):

$$
\begin{aligned}
& \text { a. ya9mód } \rightarrow \text { yagămód 'he stands' } \\
& \text { b. yehzáq } \rightarrow \text { yehĕzáq 'he is strong' } \\
& \text { c. ho9mad } \rightarrow \text { ho9ŏmád 'he was caused to stand' } \\
& \text { d. billa9núuhuu } \rightarrow \text { billagănúuhuu 'we annihilated him' } \\
& \text { e. Saamá9tii, laaqáhtii, 'I heard, I took' }
\end{aligned}
$$

The final pair of forms shows that a stressed syllable resists this insertion, as Prince (1975) points out.

Notice that, in every case, the inserted reduced vowel has exactly the quality of the vowel in the preceding syllable. I suggest that in these forms the $\rho$-structure includes the rhymes of the first two syllables in the derived forms, so the reduced vowel is dominated by the right branch of the p-structure. Notice as well that this allows us to say that the vowel that is part of the conditioning environment for the insertion rule participates in the resulting structure. 
I therefore formulate the vowel insertion rule as in (34):

(34) Postguttural Epenthesis

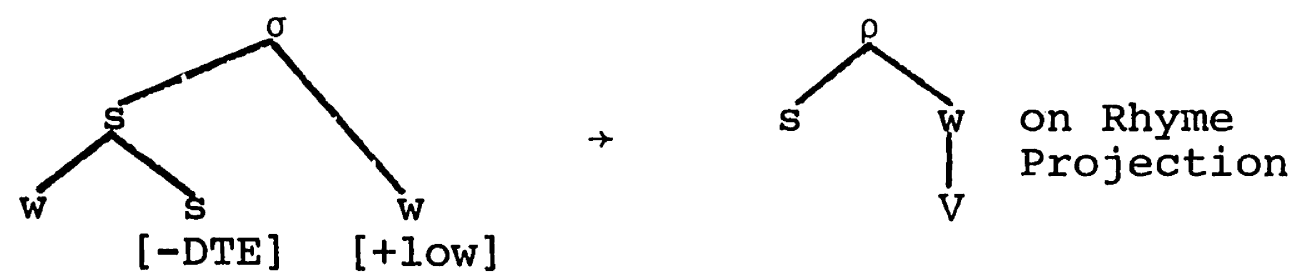

That is, a p-structure is created that includes as its left branch any unstressed vowel which is followed in the same syllable by a guttural consonant. I assume that the gutturals are correctly characterized as [+low] (they are specified as consonants by the overall left-branching structure of the syllable in (34)). Sample outputs of this rule appear in (35):

(35) a.

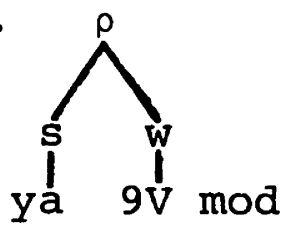

b.

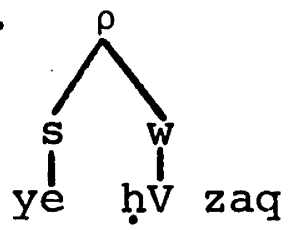

c.

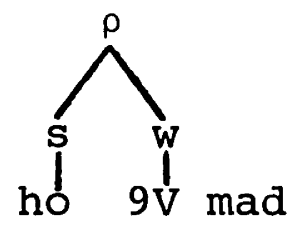

The relationship of vowel quality between the two daughters of these $\rho$-nodes is described by a mechanism of assimilation within $\rho$ developed in section 4 of chapter 3 .

The relevance of these facts to the formulation of Schwa Deletion in (32) lies in the following considerations. The vowel inserted by Postguitural Epenthesis is not necessarily [+low]; in fact, its surface quality as a result of assimilation to the preceding vowel is nonlow in (35b) and (35c), yet this vowel fails to delete by Schwa Deletion. The reason for this failure is that Postguttural Epenthesis creates a $\rho$-structure with schwa on the right branch, while Schwa Deletion is 
specifically restricted to schwas on the left branch of $\rho$. Therefore the metrical formalism naturally incorporates this essential characteristic of the rules governing reduced vowels.

Notice as well that the same result is not available by ordering Postguttural Epenthesis after Schwa Deletion, thus letting the insertion counterfeed the deletion. In fact, the opposite rule order is demonstrably the correct one. Epenthesis must precede Spirantization, accounting for the spirantized $\underline{b}$ in yagăbód 'he will work' from /ya9bod/. But Deletion must follow Spirantization in order to get spirantized $\underline{\mathrm{k}}$ in malkê from /malakee/. So by transitivity of ordering Postguttural Epenthesis precedes Schwa Deletion, and consequently the structural treatment of Schwa Deletion does solve a genuine problem.

There is another point to note about both Schwa Deletion and Postguttural Epenthesis that is relevant to the issues treated here. These rules, among others, alter the overall number of syllables in the word. The inherent structure-preserving character of syllabification will cause these new syllables to be formed by the same rubrics as the underlying syllabification. The one exception to this, noted already in section 3 , is the superheavy syllable type CVVC. These syllables are limited to word-final position in underlying representation, but this limitation is explicitly suppressed throughout the rest of the derivation. Thus, the 
superheavy initial syllable of kaatbúu $(=31 b)$, sreated by Schwa Deletion from the intermediate representation /kaatabúu/, will be correctly syllabified in accordance with the structure in (5) of section 3. Because this structure is restricted to word-final position only in underlying representation, CVVC is a canonically permitted syllable type in the outputs of phonological rules, and therefore Schwa Deletion is not blocked in this case by syllable-structure preservation. The structure assigned to the superheavy syllables, both final and nonfinal, turns out to have some significance in the treatment of Hebrew accentuation in chapter 3 .

Schwa Deletion is not the only rule that creates superheavy CVVC syllables. They also result from a fairly general process that lengthens stressed vowels in pause; that is, before the end of a phonological phrase. This accounts for the partial derivations of sample pausal forms in $(36)$ :

(36) a. kaatáb - kaatáab 'he wrote'

b. kaatábtii - kaatáabtii 'you (f. sg.) wrote" c. kaatábuu + kaatáabuu 'they wrote'

I will refer to this process as Pausal Lengthening, one of a complex of rules that apply in pause. P.lthough structurally it involves a very simple adjunction of a node $n$ to the vowel of the stressed syllable, I will eschew formulation of it here because of some unsolved difficulties in the mode of 
reference to the external context "end of phonological phrase". In (36a) and (36b) Pausal Lengthening creates wordfinal and word-internal superheavy syllables with equal equanimity. The form in (36c) and many others show that Pausal Lengthening must precede Vowel Reduction. Since Vowel Reduction applies only to short vowels (whence the left node must be nonbranching in (14)), the prior application of Pausal Lengthening will bleed the rule of Vowel Reduction and its concomitant rightward accent shift. These properties of pausal forms, along with others, are demonstrated in detail by Prince (1975). Their significance for the treatment here emerges in sections 3.4 and 3.5 of chapter 3 , where Pausal Lengthening can be seen to suppress the subsequent application of two accent movement rules.

The last group of facts that have some importance here concern the formulation of a rule of Tonic Lengthening, which applies to any vowel that bears main stress under certain phonological and morphological conditions. In nouns, adjectives, and particles, we find the following partial derivations: ${ }^{9}$

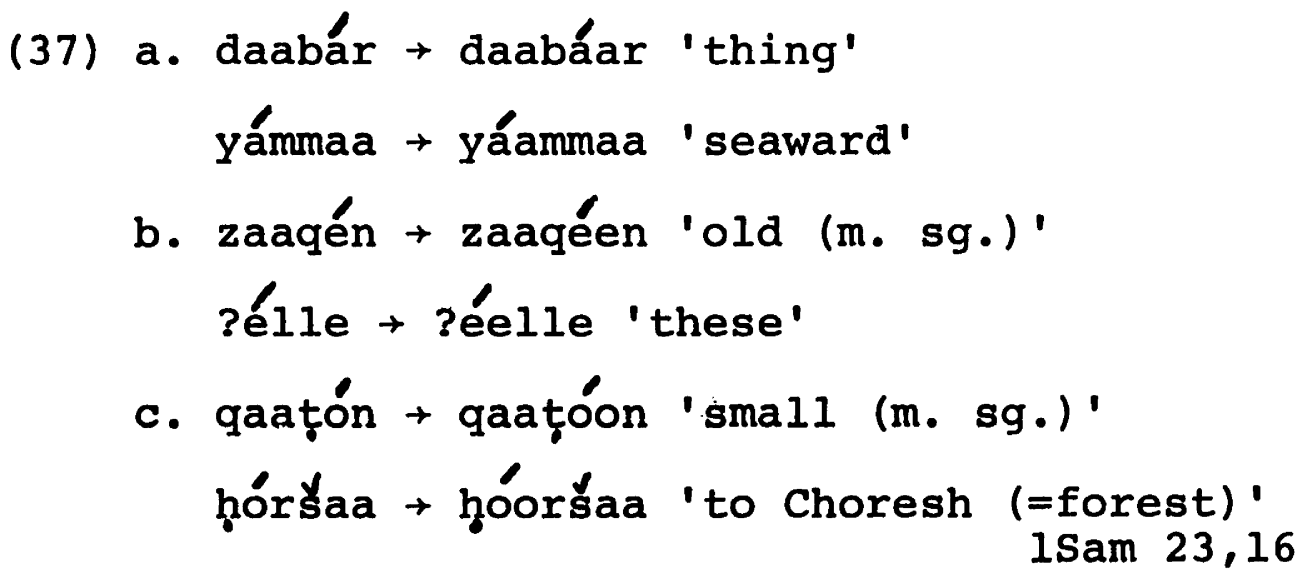


In the first example of each pair the Tonic Lengthening rule applies to create a final superheavy syllable, while in the second example it creates a penult superheavy syllable. These latter forms are a little unusual morphologically -- two are directive adverbials, and the other is a pronoun -- but this is only because of the difficulty of finding clear cases of penult stress in the noun system. In view of these facts, I will formulate Tonic Lengthening as in (38):

(38) Tonic Lengthening (Nonverbs)

$$
\underset{[+\mathrm{DTE}]}{\mathrm{V}} \rightarrow \mathrm{V}+\mathrm{n}
$$

Therefore any vowel which bears the main stress will have an unspecified node adjoined to it, with a resulting long vowel according to the principles developed and exemplified earlier in this chapter.

The issue brought up by Tonic Lengthening that will be relevant later concerns the parallel phenomenon in verbs. As it stands now, based on the data in (37), Tonic Lengthening ought to be restricted to forms [-verb]. But a similar, though more limited, rule apparently applies in the verb system:

(39) a. giddél $\rightarrow$ giddéel 'he magnified'

$$
\text { tagaddélnaa } \rightarrow \text { tagaddéelnaa } \underset{\text { magnified' }}{\text { they/you }}(\mathrm{f} \text {. pl.) }
$$

b. yiktób - yiktóob 'he writes'

$$
\text { qómnaa + qóomnaa 'arise (f. pl.)' }
$$


The surprising limitation on this process concerns lengthening of a; it never occurs in (cliticless) verb forms. Thus, short a is retained in forms like kaatáb 'he wrote' or gámtii 'I arose'.

If Tonic Lengthening in nouns were to be conflated with this lengthening rule in verbs, the result would be a rather baroque set of disjunctions referring to the quality of the vowel and the lexical category of the form. There is, however, another interpretation of the verb facts based on a more subtle understanding of the orthographic record. It has been traditionally held that the vowels $\underline{\underline{e}}$ ana $\underline{\underline{o}}$ in the verb system, although written as long, were to be pronounced as short. This belief is supported very strongly by the writing of Hebrew in Greek letters in the Hexapla, where Tiberian $\underline{\underline{e}}$ and $\underline{\underline{o}}$ in verbs are written as $\varepsilon$ and $\circ$ with remarkable consistency, while $\eta$ and $\omega$ appear in nouns (Brфnno 1943). Moreover, it emerges in chapter 3 , section 3.3 that there is evidence within the Tiberian system from the application of the Rhythm Rule that supports this distinction as well. I conclude, then, that Tonic Lengthening in (38) is limited to forms that are [-verb]. If there is an actual rule of lengthening in verbs, then it functions as a kind of late adjustment, evidently restricted solely to the Tiberian vocalization system.

I will not attempt a summary of the segmental phonological rules of Hebrew here. Rather I will wait until chapter 3, where an ordered list of all segmental and accentual rules appears. 
Chapter 2: Footnotes

${ }^{1}$ A preliminary study along these lines can be found in a recent unpublished paper by Hagit Borer at MIT.

${ }^{2}$ Word-final consonant clusters are limited to just two morphological classes: second feminine singular verbs (e.g. kâtábt) and jussive III-w, $y$ verbs under certain inconsisţently observed conditions of relative sonority (yêbk, yest). Both of these classes arguably involve relatively late morphological truncation rules.

${ }^{3}$ Further evidence in support of the reality of pretonic lengthening, cited by Brockelmann (1961), is the existence of Syriac and Arabic writings of Hebrew words with pretonic lengthening, like Arabic ?ibraahíim = Hebrew ?abraaháam.

${ }^{4}$ This sort of alternation is consistently observed by adjectives of defect. I assume that the underlying a of the first syllable is realized on the surface as $i$ by a reasonably general process applying in closed initial syllables. For further discussion of this rule see Prince (1975).

${ }^{5}$ Two small cautions are in order here. First, the data and taxonomy presented here as well as in most handbooks come chiefly from a compilation by Baer (1880). Baer worked not just from the textus receptus but also from a text reconstructed in accordance with variant readings under the general guidance of rules laid down by medieval Hebrew grammarians. Second, some scholars, notably Bergstrüsser (1962) and Dothan (1971), have disputed the interpretation of dages forte conjunctivum as a mark of gemination, suggesting that it is a case of using the symbol dages to indicate stress or word boundary. However, Lambdin (1971) describes the arguments in support of this view as "totally unconvincing". In the light of the similarity between junctural and the undisputed internal gemination, and the existence of a formally similar process in some dialects of Italian, I hold with gemination here.

${ }^{6}$ There are as well sporadic exceptions to gemination after 0 in the noun system, like /mahloqoot/ $\rightarrow$ mahlizqóot 'divisions?.

${ }^{7} \mathrm{~A}$ variety of attempts have been made to show that Hebrew spirantization is a late addition to the reading of the text after the language was dead. This view usually holds that Spirantization was borrowed from Aramaic. But derivations where Spirantization is rendered opaque by later Schwa Deletion show a degree of abstractness in this rule that is quite unlikely in a late borrowed process. 
${ }^{8}$ It is sometimes thought that schwa is pronounced after a syllable containing a long vowel, like kātabû. For convincing demonstrations that this mode of pronunciation is a late addition, see W. Chomsky (1972) and Baer (1867, 1868).

${ }^{9}$ Here I have avoided reference to segholate nouns (those with the pattern [CVCC]) because they present a number of poorly understood problems to the rule of Tonic Iengthening. These involve chiefly the class distinction seper/géber and the application of Tonic Lengthening to a only in some geminate types with the definite article (haagáam) and without (yáam). I have no solution to these difficulties here.

I should point out that Tonic Lengthening of a is not consistently carried out word-internally in nonverbs. With lengthening we have forms like yáammaa, sáammaa, láammaa, and without ?árşaa, láylaa, báytaa. Again I have no solution to offer. 
Chapter 3: Syllable Structure and Accentuation

\section{Introduction}

Certain fundamental results emerge from the theory of accentuation developed in Liberman (1974) and Liberman and Prince (1977). Stress is seen chiefly in relational terms, as expressing a property of relative strength for stressed elements. Alternation and disjunction of stress assignment are shown to follow from certain very general conditions that are expressed formally by labeled binary branching structure.

There is, however, a residue of interesting traditional observations about stress assignment not accounted for directly in this theory. In particular, stress rules refer to certain typical characteristics of the forms to which they apply. The best known of these, and perhaps the most universal one, is syllable weight, the distinction between heavy and light syllables. The richness of this problem is apparent in its many ramifications. First, in some languages the notion heavy syllable invokes a disjunction of syllables containing a long vowel or diphthong and syllables with a short vowel but closed by a consonant. Second, though heavy syllables are usually supposed to attract the stress, there exist coherent stress rules where heavy syllables attract or reject the stress subject to, say, distance from a word boundary. Third, the weight of 
some syllables may itself vary across languages, though nevertheless some clear generalizations can be ascertained. Very little has been said about these issues in earlier work in generative phonology. The notation of Chomsky and Halle (1968) - abbreviatory devices like V, C, and subscripts and superscripts - allows free stipulation of any arbitrary string in a rule of stress assignment. This notation actually values a rule assigning stress to light syllables more highly than a rule assigning stress to heavy syllables since the former can be referred to with fewer symbols. This difficulty did not pass unnoticed; Chomsky and Halle concede (1968:241, note) that the appearance of the rather ungainly weak cluster context in at least four different rules indicates a defect in their theory. A more traditional account would say that, subject to the lexical and morphological government typical of some of these processes, the proper context of weak cluster phenomena is a light (CV) syllable.

Perhaps the most productive approach to these problems is the notion of mora in Prague school structuralism (Trubetzkoy 1969, Jakobson $1971 a, c)$. The mora is a relatively abstract property of syllables. Syllables themselves are not exhaustively parsed into moras - rather, the mora measures the weight of a syllable. A light syllable is associated with or contains one mora, a heavy syllable two moras, and analyses have been suggested where syllables of 
greater weight (CVVC and CVCC) have three moras (Lecerf 1974). Consider the rhyme of the syllable, the string including the nucleus and any segments following within the syllable. Then, subject to some language-particular variation, the number of moras associated with a syllable equals the number of segments in its rhyme.

What does this sort of theory do? It explains the common metrical equivalence of two light syllables and one heavy syllable and the converse. That is, two moras in separate adjacent syllables equal two moras in one syllable. In demarcative stress languages, of which Classical Latin (and Damascene Arabic) is the usual exponent, it explains disjunctions of the sort "stress a heavy penult, otherwise stress the antepenult". In this case, stress is said to lodge on the syllable containing the second mora preceding the final syllable, whose moraic count is irrelevant. Certain types of alternating stress with partly demarcative character, for which Southern Paiute (Sapir 1930) is usually adduced, stress every other mora from the beginning of the word. In general, then, a moraic stress rule assigns stress to every mora that is some number $n$ of moras distant from a boundary or from another stress. As long as $\mathrm{n}$ is small -- perhaps one or two moras -- then bimoraic, therefore heavy, syllables will be seen to attract the stress. The basis of the metrical treatment of these phenomena is to characterize the moras in syllable structures like 
those presented in Chapter 2. The claim here is that moras can be identified structurally as units of the rhyme constituent, where rhyme is defined formally as the right branch of $\sigma$, the syllable root. The mechanism of this identification is the notion of projection, developed in Vergnaud (1976).1 A projection is a representation that is derivative of the ordinary phonological representation by selection of only those elements with some defining characteristics. For instance, a projection of all [+syll] segments in a word yields a string of vowels. I should say that there is no true sense of derivation here; the two representations are simultaneous and they share many properties. In particular, the results of operations performed on units of the projection are carried over automatically to the basic phonological representation, and conversely. So the units projected must have a well-defined characteristic. In view of the Praguian observations, it is clear that the proper projection on which syllable-weight dependent accentual rules operate is a projection strictly of rhymes, which are well-defined structural units of the syllable. This is not to say that all stress rules apply on rhyme projections; only those with some dependence on syllable weight demonstrably do. Stress rules of the type typical in some Australian languages (Nash 1979) display iteration by syllables with no reference to weight. The rhyme projection has no role in these cases. 
Now that the projection mechanism allows us to isolate the syllable rhyme, we have two options. A direct translation of the Prague school theory would say that accentual rules count segments on this rhyme projection; that is, they count moras. This theory, however, makes the extremely weak claim that the potential number of syllable weight distinctions in any language is bounded only by the cardinality of the integers. Languages with extremely complex rhymes could potentially distinguish four-mora rhymes from three-mora rhymes. My proposal is far more restrictive than this. The accentual rules can refer only to the geometry of the rhyme, and to a very limited kind of geometry at that. The rules are reduced to a binary distinction, reference to branching or nonbranching rhymes. I will show that apparent cases of trimoraic syllables, like the superheavy syllables of Cairene Arabic discussed below, follow from a more general characteristic by which these syllables have two rhymes, and not one trimoraic one.

This geometric treatment of syllable weight also claims that structural differences within syllables will be the sole factor determining whether particular syllables are heavy or not. The other major theoretical defect of the Prague mora is its essentially diacritic nature -nonuniversal rules map syllables onto particular moraic configurations. Jakobson (1971b) comments critically on 
several treatments of the Greek recessive accent that arbitrarily assign 0,1 , or 2 moras to syllables depending on their rhyme and their position in the word. Under the theory proposed here, languages can vary in syllable weight if and only if they vary in the internal structure of syllables. This claim is extensively justified for Tiberian Hebrew, where CV and CVC syllables are classified as light and CVV as heavy. The structural difference is supported by the treatment of the segmental phonology in Chapter 2 , while the corresponding difference in syllable weight appears in the anlysis of Hebrew accent in this chapter. Certain higher level structures, in addition to the rhyme, are recognized. The basic unit of stress assignment -- and the unit that refers to rhyme distinctions -- is the foot, though a slightly different foot from the structure developed in Liberman and Prince (1977). Recall that in their model a foot is built rightward from each iterative application of the feature [+stress]. Here I will follow a very natural proposal first made by Prince (1976) that stress is assigne solely by the iterative application of foot structure. That is, stress rules themselves are instructions for building metrical structure, and the position of stress is located by examining the labeling of the tree at different levels. Furthermore, with Selkirk (1979) and Kiparsky (1979) I will assume that the category foot has a kind of independent existence, so reference to it is possible 
in other phonological rules. The significance of this will emerge chiefly in the discussion of accent retraction in Tiberian Hebrew.

Since the basic stress operation is foot-assignment, reference to syllable weight will be made by describing the distribution of branching and nonbranching rhymes within the foot. Certain evident generalizations emerge from the cases discussed in this chapter. Suppose we have a string of terminal nodes $n_{1}, \ldots, n_{i}$ of a left-branching foot of unspecified size:

(1)

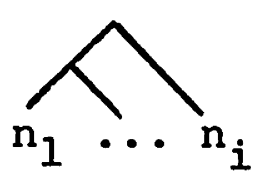

If we now consider the attested possibilities of conditions on the geometry of these nodes, without regard to foot size, the following generalizations emerge:

(2) a. In a given language, either $\mathrm{n}_{1}$ explicitly branches in all feet or it explicitly fails to branch.

b. In a given language, either $n_{i}$ explicitly fails to branch in all feet or it branches at will.

c. In all languages the intervening nodes $n_{2}, \ldots, n_{i-1}$ (if any) never branch. 
The categories in (2a) and (2b) are the parameters of interlinguistic variation in foot-construction. Some languages, like Hebrew, consistently require $\mathrm{n}_{1}$ to be a branching rhyme. Therefore every foot must begin with a heavy syllable. Others require that $\mathrm{n}_{1}$ never branch, like the Arabic dialects of section 2. In this case a foot may obviously begin with a light syllable, and it may begin with a heavy syllable only by including the entire rhyme in the constituent $\left[n_{1} n_{2}\right]$. (For clarification of this, see the analyses ad loc.)

Similarly, some languages allow $n_{i}$ branch, so the foot may terminate with a heavy syllable. Hebrew and some Arabic dialects agree in this respect, though Cairene Arabic and the nonprosodic rules of section 4 do not. They allow only light syllables to terminate the foot.

Finally, it is invariably the case that internal syllables, if there are any, must be light. This is the thrust of condition (2c). Each of these observations hold complementarily for right-branching syllables.

Another major parameter of foot-formation is the size of the foot. Again restricting our attention to leftbranching feet, we find only three sizes:

(3)

$$
\text { a. Binary }
$$

b. Ternary

c. n-ary
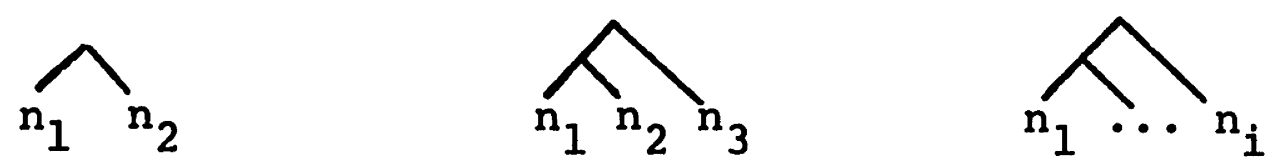
(3c), the n-ary branching foot, has the additional property of being maximal; it is as large as possible consistent with any conditions on its terminal nodes with respect to the form to which it applies. Examples of binary and ternary branching feet are Cairene and Damascene Arabic, respectively. All other rules presented in this chapter involve n-ary branching feet.

From a formal, although pretheoretical, standpoint, this is a rather peculiar distribution of foot sizes. It is easy to see why there might be binary and n-ary feet exclusively, but it is difficult to understand why ternary feet should be allowed but not 4-iary or 5-ary. Obviously this presents no difficulties to our taxonomic survey, but it does militate against the construction of a relatively elegant theory of foot structure.

A final parameter of variation is the choice of leftbranching versus right-branching feet, which I will refer to by the term chirality.

We can achieve some understanding of this overall taxonomy if we first attempt a formalization of these observations with respect to n-ary metrical feet. Suppose first of all that the archetypal, unmarked left- and rightbranching feet contain only terminal nodes that never branch. These unmarked feet are subject to certain stipulated modifications in particular languages. The most deeply embedded node -- $n_{1}$ of the left-branching tree in 
(1) -- may be explicitly required to branch. I will call this explicitly branching node a head. The least deeply embedded node -- $n_{i}$ of (1) -- may be allowed to branch or not branch at will. I will call this freely branching node a tail.

Therefore the observations in (2) translate into two unmarked feet -- one left-branching and one right-branching -- in which no terminal nodes branch, plus the additional possibilities of stipulating that the foot has a head or a tail or both. Suppose we refer to the foot in general as F, and suppose further that there exist two binaryvalued features, [head] and [tail], whose unmarked values are minus. Thus the unmarked foot has neither head nor tail, and so none of its terminal nodes may branch. I will define the positive values of these features as in (4):

(4) a. [thead]: A right-branching (left-branching) foot is [thead] if and only if its rightmost (leftmost) terminal node must branch into two nonbranching nodes, i.e., $\left[\mathrm{n}_{1} \mathrm{n}_{2}\right]$, where neither $\mathrm{n}_{1}$ nor $\mathrm{n}_{2}$ branches. b. [ttail]: A right-branching (left-branching) foot is [+tail] if and only if its leftmost (rightmost) terminal node may branch freely. The parenthesized references to left-branching feet make the obvious point that heads and tails are in complementary 
positions in the two foot chiralities. Note that the definition of [thead] includes an addicional stipulation; the head node must not only branch, but it must branch into nonbranching nodes. That is, the head node must branch only once. This property will turn out shortly to have some significance.

It is fairly easy to see how this set of features will behave with respect to $F$, where $F$ is an $n$-ary foot which is specified as either right-branching or left-branching. The full set of possibilities is $F$ $\left[\begin{array}{c}\text { F } \\ \text { thead } \\ \text { tail }\end{array}\right]$

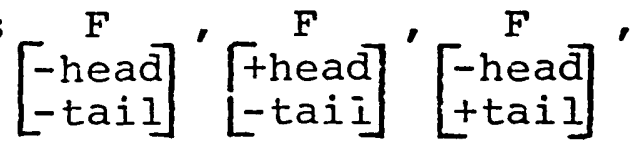

I have suggested that the first of these is least marked, and the second and third less marked than the fourth; but nothing in the theory hinges on this conjecture. Of the n-ary feet proposed in this chapter, we have, without regard to chirality, examples of the first in Maltese, of the second in Tigre, of the third in Classical Arabic, and of the fourth in Hebrew. If the rather tentative analyses of Maltese and Tigre in Section 4 should prove incorrect, this certainly does not invalidate the theory, though clearly new examples of these n-ary foot types would have to be found.

So a reasonably confident conclusion at this point is that all four types of n-ary feet defined by two crossclassifying features actually occur. The question now is 
whether binary and ternary feet are also attested in the same four types. The Cairene Arabic stress foot contains two nodes, neither of which may branch. Clearly, then, it must be a binary foot that is [-head, -tail]. It is also of undefined (or vacuously defined) chirality.

Somewhat more revealing is the binary foot assigned by the Hebrew Vowel Reduction rule developed in Chapter 2 . This foot -- called a $\rho$-structure -- determines quantitative distinctions in vowels rather than stress, so it reflects a Hebrew foot type that is distinct from the accentual foot motivated in this chapter. The p-structure is of the form $\left[n_{1} n_{2}\right]$, where $n_{1}$ does not branch and $n_{2}$ may branch. $\mathrm{n}_{2}$, then, has the hallmarks of a tail, though the value of the feature [ttail] appears to be undefined for a foot of unspecified chirality. The solution to this technical problem is to stipulate that the Hebrew $\rho$-structure is left-branching, from which it follows that the tail must be the rightmost terminal node, $\mathrm{n}_{2}$. In general the parameter of chirality must extend to binary feet. In support of this claim, I note also that if the relationship between chirality and direction of assignment conjectured in section 2.4 holds, we can correctly predict that a stipulated left-branching binary foot lise the Hebrew $p$-structure is assigned from right to left.

I have motivated the feature value [+tail] for binary feet, and in the process I have included assignment of 
chirality to these feet. The remaining issue is whether [thead] occurs with binary feet as well. In fact, the only interpretation of a headed binary foot is as a ternary foot. In other words, there are no primitive ternary feet, just binary feet which are [thead].

To see how this works, consider the Damascene Arabic stress rule which, like Classical Latin, involves a ternary foot. This foot has the form $\left.\left[\begin{array}{ll}n_{1} & n_{2}\end{array}\right] n_{3}\right]$, where neither $\mathrm{n}_{1}$ nor $\mathrm{n}_{2}$ branch, but $\mathrm{n}_{3}$ branches at will. This ternary foot is based on a left-branching binary foot which is [thead, +tail]. The tail is the rightmost node, $\mathrm{n}_{3}$. The head is the node which dominates $n_{1}$ and $n_{2}$. Because of the definition of [thead] in (4a), neither of the daughter nodes of the head -- therefore neither $\mathrm{n}_{1}$ nor $\mathrm{n}_{2}$-- can branch. It follows that a ternary foot can be described simply as a headed binary foot.

In sum, the full apparatus we reed is a pair of features on feet. [head] and [tail], right-branching and left-branching chirality, and binary and n-ary size. These generate all and only the desired types of feet. We can eliminate the stipulation of ternary feet in our list of primitive sizes, since ternary feet are derivative. Moreover, this makes the additional, apparently correct, claim that there cannot be headed ternary feet. That is, there is no foot of the form $\left.\left[\begin{array}{ll}n_{1} & n_{2}\end{array}\right] n_{3}\right]$, where $n_{1}$ must branch. 
Although motivation of this representation of foot structure is one of the main points of the analyses presented here, there are certain residual matters in the theory that deserve attention.

In addition to the structure of the foot, we must also stipulate its direction of assignment. Here I will have little to say about the question of whether direction can be predicted on some independent basis, though some conjectures in this vein may be found in section 2.4. For now it will suffice to indicate in each case whether feet are assigned from right to left or from left to right.

With Liberman and Prince (1977), I assume a level of structure that gathers up all feet and stray syllables in the word, referred to naturally as word-level structure. This may be left-branching or right-branching, subject to interlinguistic variation. I assume as well that there exists some set of possible labeling rules for metrical trees. Here, however, I will depend almost exclusively on their Lexical Category Prominence Rule (LCPR), which says that of a pair of a sister nodes, the right one is labeled strong (s) if and only if it branches.

Finally, I propose a notion of opacity of particular levels of branching structure. It is clear from the operation of English compound stress in Liberman and Prince (1977) that only some kinds of branching count for the assignment of labeling. In particular, syntactic branching -- 
that is, branching structure of the compound -- is treated as branching but word-internal branching -- either as a compound like overdrive or as a polysyllabic word with a complex word-stress tree -- does not induce such treatment. Therefore the word is an opaque domain with respect to the LCPR. This means that application of LCPR outside the word cannot "see" branching structure inside the word. A similar opacity constraint is developed in the treatment of Arabic stress.

Excursus: Foot Structure in English

This theory of the formal structure of feet provides a very elegant account of the different types of stressretraction in English. Liberman and Prince (1977) classify these different sorts of retraction, selected under various lexical and morphological circumstances, according to three modes. Weak retraction skips over one syllable that is, roughly, a weak cluster in the sense of Chomsliy and Halle (1968): molýbdenite, stalágmite. Strong retraction skips over one syllable of any type: oríginàte, désignàte. Finally, long retraction skips over two syllables, of which the left one is a weak cluster and the right one is unconstrained: Monòngahéla, Tàtamagóuchi, héterodòx.

Obviously there are great complications in the morphological conditioning and lexical idiosyncracy of English stress. Here I intend to suggest only the roughest outlines 
of an analysis. First, in light of the arguments in Kahn (1976) and Nanni (1977), I will assume that weak clusters in English are properly identified as light syllables. Thus syllables of this type will have nonbranching rhymes, while heavy (CVC and CVV) syllah.les will have branching rhymes. There are evident difficulties with this claim, particularly in the case of final syllables. Nevertheless this seems to be a valid observation, and we will see later that some peculiarities of the final syllables in English are explicable by reference to the rhymes of superheavy syllables.

Second, I will follow Selkirk (1979) in supposing that each foot contains just one stressed vowel, and I will further assume that no stressed vowels appear outside feet. Therefore a full specification of English foot structure will locate all and only the stressed vowels. In a foot containing more than one syllable, the stressed one is selected by the labeling rule LCPR.

Given these assumptions, the stress retraction modes are equivalent to three metrical trees with somewhat different conditions on their geometry: 

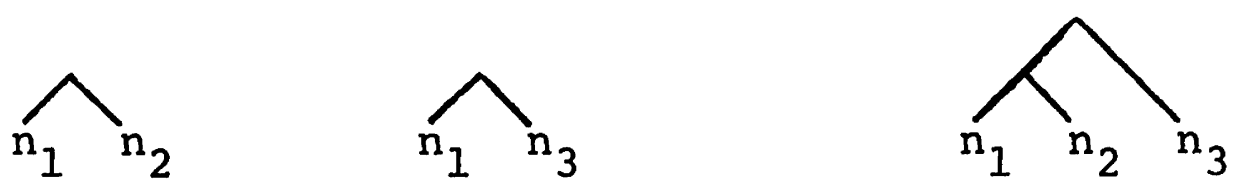

Conditions: Neither $\mathrm{n}_{1}$ nor $\mathrm{n}_{2}$ branches. $\mathrm{n}_{3}$ branches freely.

These three structures can be characterized formally in the following way. English contains a left-branching binary foot for stress assignment. In forms designated as weak retractors, this foot is [-head, -tail]. Strong mode is [-head, ttail], and long mode is [thead, +tail]. That is, English has a single foot structure whose head and tail parameters are varied under morphological and lexical government. I have no ready explanation for the absence of the fourth set of values -- [thead, -tail], which yields a foot $\left.\left[\begin{array}{ll}n_{1} & n_{2}\end{array}\right] n_{3}\right]$, where no node may branch -- but I note that actually attested examples of long retractors with branching $\mathrm{n}_{3}$ are quite infrequent. It may be that the data are not rich enough to distinguish between the two possible types of headed feet.

The mode of application of these foot types to some representative examples is instructive. The foot structures are applied to representations on the rhyme projection, in which light syllables are represented by nonbranching nodes and heavy syllables by branching nodes. I will call the mapping of a foot structure onto this rhyme 
projection, subject to conditions on branching of the nodes of the foot, a proper analysis by the foot structure. More explicit treatments of the rhyme projection mechanism and of proper analyses can be found in the following sections. Consider first the behavior of weak retractors, like words in -ite:

(6) $a$.

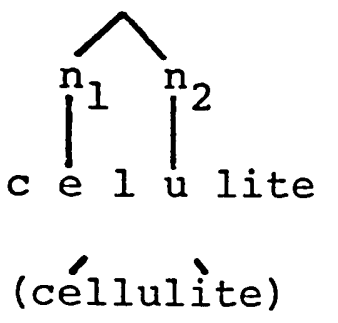

b.

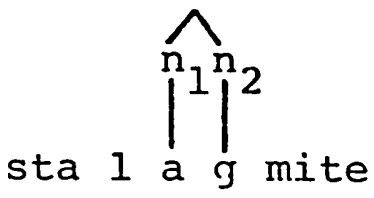

(stalágmìte) c.

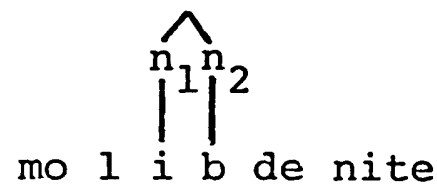

(molýbdenìte)

I have indicated the proper analyses by actually showing the nodes $n_{1}$ and $n_{2}$ of (5a), the weak retraction foot. This is an informal expository device, and in the actual foot representation they are not present. In (6a) the rhymes of both syllables preceding the suffix -ite are nonbranching, so both are brought together into a foot. subsequent labeling by the LCPR selects the first of these as stressed. In (6b) the only proper analysis takes the branching rhyme of the syllable lag as a foot, since this is the only way of fulfilling the condition that neither $\mathrm{n}_{1}$ nor $\mathrm{n}_{2}$ branches. Thus the rhyme of lag constitutes a foot ail by itself, and it bears the stress. In $(6 \mathrm{c})$, on the other hand, the syllables lib and de have branching and nonbranching rhymes, respectively. In this case the proper 
analysis must take the rhyme of $l i b$ as a foot. The syllable de is, at least at this stage, not assigned to any foot, so it may not kear the stress.

Similar proper analyses hold for the long mode retractors, as in the contrast between Tàtamagóuchi and Monòngahéla:

(7)

a.

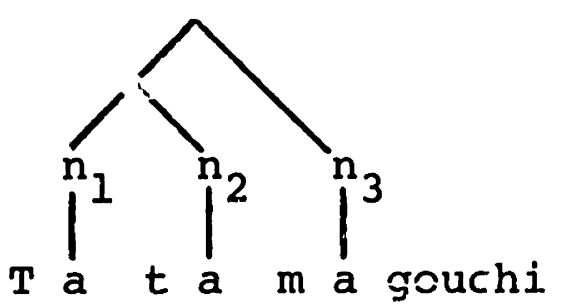

b.

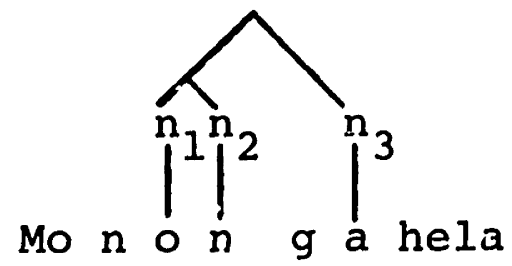

Note in particular that the requirement that $\mathrm{n}_{2}$ not branch prevents retraction of the stress onto the initial syllable in (7b). It is generally, though not exclusively, the case that the long mode tree also assigns the rightmost stress of the word, and not just the retracted stress. Thus the assignment of main stress in words like América and agénda is exactly parallel to the retraction of stress in the structures in (7). Moreover, in the case of pélican or agéndum, as in retraction in héteródóx (with the first o long), the option to let the tail branch is exercised. Let me point out one aspect of this proposal that should not escape notice. In long retractors like hè̀licográph, as well as in unretracted stress in molybdenum, 
the foot encompasses only the heavy stressed syllable and the immediately following one, as in (8):

(8)

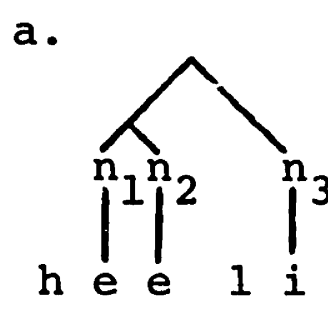

b.

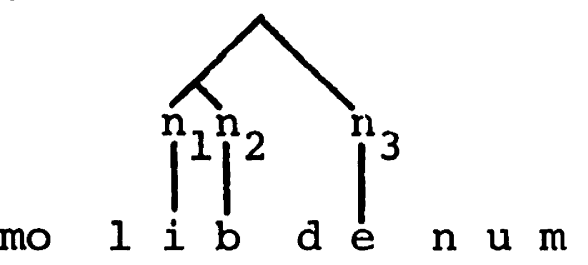

The syllables co and num are unstressed because their rhymes do not belong to any feet. The nature of these proper analyses follows chiefly from the condition that $n_{1}$ may not branch in (5c), which itself is a consequence of the definition of [thead] in (4a).

This characteristic of the feet is a little unexpected, since a direct translation of Liberman and Prince's (1977) segmental description of long retraction would say that $n_{1}$ may branch freely. This would yield trisyllabic feet

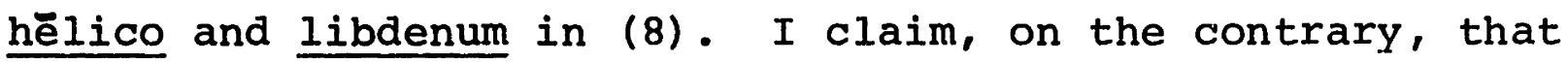
freely branching behavior is limited to the tail position. Although this makes no empirical difference for English long retractors, it does matter in the cyclic application of the formally Identical Damascene Arabic stress rule discussed below. Furthermore, the behavior of strong retractors in English gives support to the schema in (5), specifically ruling out a branching $n_{1}$. 
I will confine my attention to the most consistent morphological class of strong retractors, verbs in -ate. Consider the two syllables in the domain over which retract.ion proceeds. If both syllables are light, or if only one of them is light, then strong mode retraction applies normally: humíliàte, offíciàte, syllábicàte; désignàte, exácerbàte; incórporàte, elúcidàte, repátriàte. In the first group of examples, both syllables are light, in the second group only the first is light, and in the third group only the second syllable is light.

But when both syllables are heavy, we find a surprising number of examples where strong mode retraction fails to apply, so both syllables are stressed on the surface: imprégnàte, infíltràte, dèmárcàte, ìncárnàte, dèfálcàte, incúlcàte, è̀rúctàte, ìnsúfflàte, incúlpàte, èxcúlpàte, and so on.

My observation, then, is that the true nature of strong retraction is not captured by saying that stress skips over any syllable, light or heavy. In plain language, strong retraction skips over a light or heavy syllable to lodge stress on a light syllable (oríginàte, exácerbàte), and it skips over a light syllable to lodge stress on a heavy syllable (elficidàte), but it will not skip over a heavy syllable to lodge stress on a heavy syllable (ìmprégnàte). There is some speaker variation on this last point in forms like ínfiltrate, and consistent retraction in cómpensàte. 
These variants and sporadic consistent forms are designated as exceptional long retractors, like péregrinàte. Forms with medial [F] like alltercàte and éxpurgàte may have the underlying syllabic $\underline{\underline{r}}$ suggested by Kahn (1976), so they predictably retract stress over a light syllable.

These observations about strong retraction are readily explained by the theory of English foot assignment presented here. In the first two types of forms, where the first syllable is light and the second is either light or heavy, (5b) joins the rhymes of these two syllables together into a branching node, as in (9):

(9)

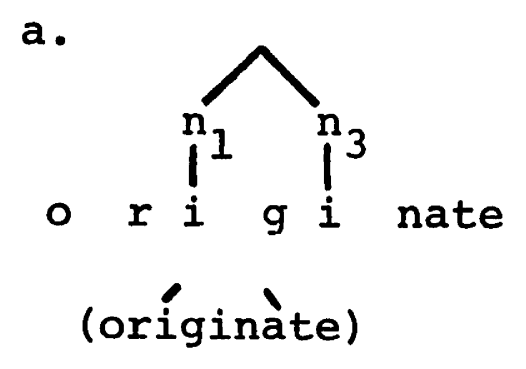

b.

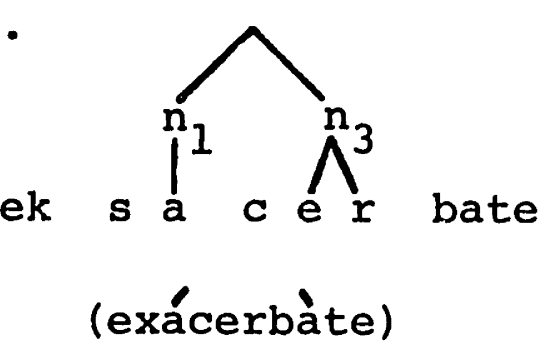

In the third type, where the first syllable is heavy and the second is light, the only possible analysis under (5b) is one where the foot includes only the rhyme of the first syllable:

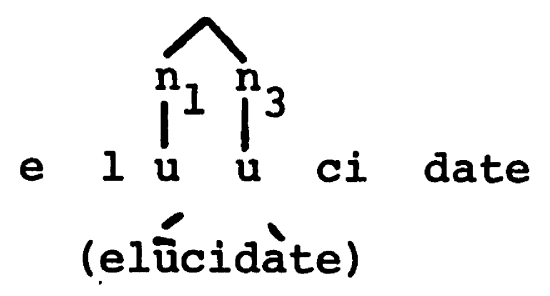


Finally, when both syllables are heavy the rhymes of both syllables will have feet according to (5b), so both syllables will be stressed:

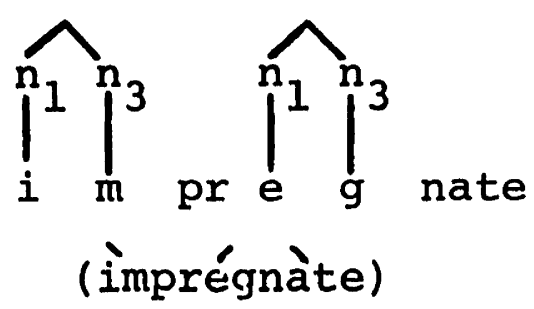

No other proper analyses of the words with these rhyme structures are possible under the strong retraction foot (5b). It therefore follows as an automatic consequence that the constellation of strong retraction facts includes the fairly consistent behavior of words like imprégnàte. Under the theory of English foot structure that just translates the segmental stress rules, $n_{1}$ of (5b) would be allowed to branch freely. Thus the strong mode would typically retract stress over a heavy syllable onto a heavy syllable. This, however, fails for what appear to be the typical examples cited above. Occasional forms like cómpensàte, where the segmental formulation holds, can be adequately treated as sporadic long mode retractors.

In sum, the theory proposed here allows a unified account of English stress retraction. All types of retraction share the stipulation of a binary, left-branching foot labeled by the LCPR. Different modes of retraction differ only in assignment of plus and minus values to the two 
features [head] and [tail]. The basic character of stress retraction and the parameters of morphological and iexical variation follow from clear formal properties of the theory.

2. Stress Assignment in Arabic

The stress rules of Classical Arabic and of two eastern dialects of modern colloquial Arabic clearly illustrate the major priniples of metrical structure developed in the introduction. In particular, they display foot structures with tails (Damascene, Classical) and with heads (Damascene), both binary (Cairene, Damascene) and n-ary (Classical). They share the general syllable structures of Chapter 2 and assignment of feet to the projected rhymes of these syllables. Certain differences in these stress rules are shown in section 2.4 to follow from a diachronic analysis involving formal changes in foot schemata.

\subsection{Cairene Colloquial}

Perhaps the most interesting accentual phenomena of Arabic are found ir a dialect spoken in Egypt from Cairo northward. Harrell (1957) gives three principal stress rules for this dialect, along with a few morphological exceptions :

(1) a. Stress the ultima if it is a superheavy syllable (CVCC or CVVC): katábt 'I wrote', sakakíin 'knives'. 
b. Otherwise stress the antepenultimate syllable if the antepenult and penult are light syllables (CV;, unless the preantepenult is also light: búxala 'misers', muxtálifa 'different (f. sg.)'.

c. Otherwise stress the penultimate syllable: martába 'mattress', 9amálti 'you (f. sg.) did', béetak 'your (m. sg.) house', katabítu 'she wrote it (m.)'.

This rule offers several notable peculiarities to an investigation of the relationship between heavy syllables and stress.

First, there is some evidence of a ternary syllable weight distinction. Word-internally, the stress rule contrasts light syllables (CV) with heavy syllables (CVC or CVV) - Word-finally, stress lodges on a superheavy syllable (CVVC or CVCC), but a word-final CVC syllable fails to attract the stress: mudárris 'teacher', ?ábadan 'never'. Although word-final CVV syllables are always stressed -nisíi 'he forgot him', šafúu 'they saw him' - I argue later that this is due to other properties of the derivation of these forms. In sum, there are two binary syllable weight distinctions, light versus heavy word-internally, and light and heavy versus superheavy word-finally. 
Second, there is a Janus-like aspect to (Ib). It stresses the antepenult, but it must also take note of the weight of both the preceding and the following syllables. ordinarily, stress rules are sensitive only to conditions exclusively to the right or the left. of the focus.

Third, perhaps the most notable characteristic of this dialect is the rejection of stress by heavy antepenults: martába 'mattress', yiktíbu 'they write', mudarrísit 'teacher (f. construct)'. Since stress can go as far back as the antepenult, and since heavy syllables are stressed in penult position, this treatment of heavy antepenults is genuinely anomalous. It goes exactly counter to the universal tendency of stress assignment described in the introduction.

If that were all, then we might simply be compelled to accept occasional deviations from the attraction of stress to heavy syllables. Fortunately, though, additional data suggest a subtle realignment of the relationship of stress to syllabification. The examples in (1) exhaust the possible arrangements of heavy and light syllables in words of the Cairene dialect. But Classical Arabic words have a much richer set of canonical patterns, allowing very long strings of light syllables. Since there is no pandialectal tradition for stressing Classical Arabic, in many regions the colloquial stress rule is applied to Classical Arabic forms. 
Mitchell (1975) reports the pronunciation of a large number of Classical Arabic words by two Egyptians educated in Cairo. Their treatment of words with the same canonical pattern as those in (2) shows that the Cairene rule holds as well for their pronunciation of Classical Arabic:

(2) a. dạábt 'I/you (sg.) beat', hajjáat 'pilgrimages'

b. kátaba 'he wrote', ?inkásara 'it got broken'

c. qattála 'he killed', katábta 'you (m. sg.) wrote', haadáani 'these (m. du.)', fa9alátun 'deed (nom.)'

So the accentuation of Classical Arabic words is another source of information about the form of the Cairene stress rule.

By Harrell's formulation in (1), we expect (IC) to give penult stress whenever the penult, antepenult, and preantepenult are light, like katabítu. Classical Arabic words with longer strings of light syllables than katabitu sometimes observe (1) and sometimes do not: 
(3) a. Observe (1):

$$
\begin{aligned}
& \text { śajarátun 'tree (nom.)' } \\
& \text { śajaratuhúmaa 'their (du.) tree (nom.)' } \\
& \text { ?adwiyatúnu 'his drugs (nom.)' } \\
& \text { b. Violate (1): } \\
& \text { baqarátuhu 'his cow (nom.)' } \\
& \text { šajarátuhu 'his tree (nom.)' } \\
& \text { ?adwiyatúhumaa 'their (du.) drugs (nom.)' }
\end{aligned}
$$

Clearly, Harrell's rule does not extend to forms like those in $(3 b)$.

Mitchell never formulates a uniform rule to stress these words, though he does give a thorough list of canonical patterns. On the basis of these, we can extract some coherent generalizations (Langendoen 1968):

(4) a. Stress a superheavy ultima.

b. Otherwise stress a heavy penult.

c. Otherwise stress the penult or antepenult, whichever is separated by an even number of syllables from the rightmost nonfinal heavy syllable or, if there is no nonfinal heavy syllable, from the left boundary of the word. 
This rule covers all of Harrell's cases and Mitchell's as well. (4b) stresses the penult in, say, 9amálti. Under rule (4c), búxala contains no heavy syllable, so we begin counting parity at the left boundary of the word. The antepenult then receives the stress because zero syllables -- an even number -- separate it from the left boundary. The preantepenult is the rightmost heavy syllable of ?inkásara, and zero syllables separate it from the antepenult, which then receives the accent.

A rough treatment of Cairene stress in the metrical structure formalism is as follows:

(5) a. Binary feet are assigned from left to right to pairs of light syllables:

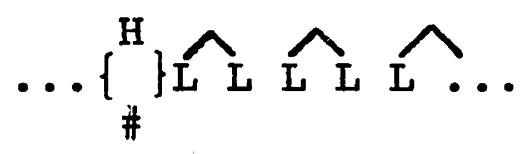

b. A right-branching superstructure gathers up all feet and stray syllables in the word.

c. The entire tree is labeled according to the principle that a right node is strong (s) if and only if it branches.

If the tree is assembled in this way, then the designated terminal element, the terminal node of the tree that is dominated only by s's, will mark the stress-bearing syllable. 
On some typical examples, the informal stages of tree construction are:

(6) a.

by (5a)

by $(5 b)$

by $(5 c)$
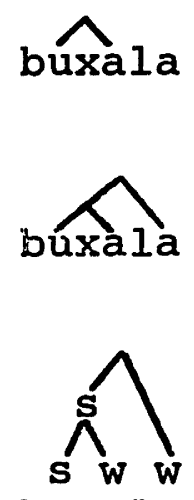

b.
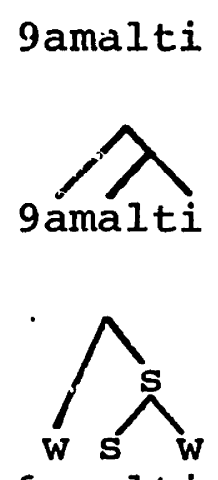

c.
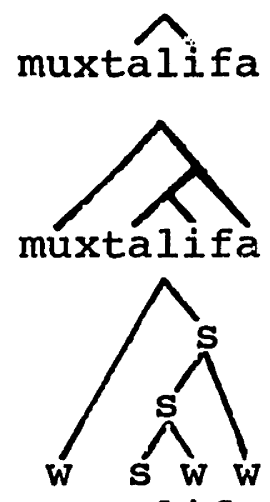

muxt.alifa d.
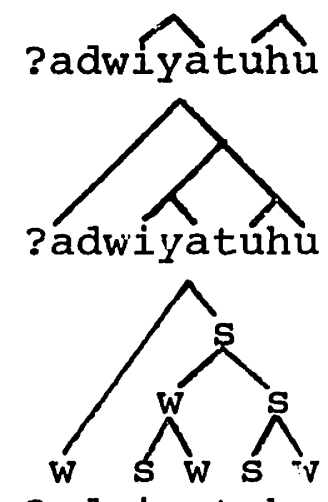

?adwiyatuhu

Some of the advantages of the solution outlined in (5) are already apparent, although it still awaits formalization. First, the parity-counting is stipulated once and for all by a single rule of foot assignment. Second, it is unnecessary to refer to a disjunction of rightmost heavy syllable and left word boundary. Instead, the left-to-right assignment of feet applies whenever (5) finds adjacent light syliables. Third, the stressing of heavy penults is brought under the same rubric as the other syllable patterns.

From the formulation above we have a rough idea uf what the foot looks like in Cairene Arabic: it is a pair of light syllables. Now we can integrate this into the theory of syllable structure presented in Chapter 2. Recall the basic syllable structures of Arabic: 
(7) a.

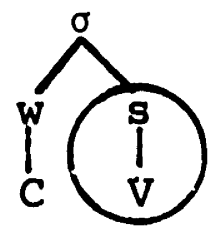

b.

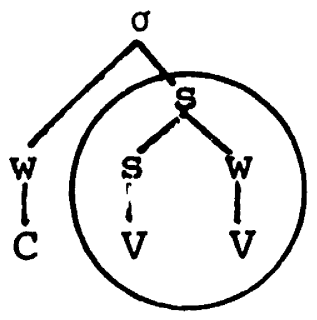

c.

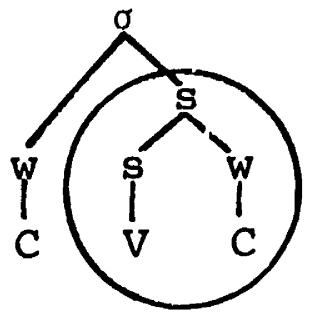

The rhyme node -- defined formally as the right branch of $0--$ is circled in the trees above. The mechanism of rhyme projection allows us to examine unly the circled subtrees. Evidently the Cairene foot is made up of pairs of rhymes that do not branch.

We can now formalize some of the properties of the informal algorithm (5) for creating the metrical structure of stress in cai::ene. The first operation is to project all the rhymes of the word, yielding (8) from (6), for example:

(8)

a. b $\dot{\mathrm{u}} \mathbf{x} \quad \dot{\mathrm{a}} \mathbf{1} \dot{\mathrm{a}}$

c.

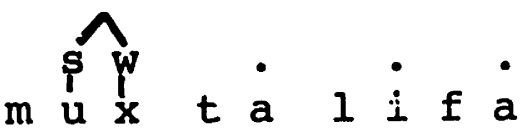

b.

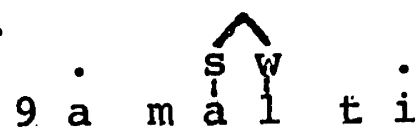

d.

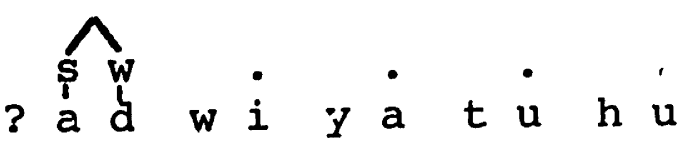

For expository convenience I have displayed the entire word in (8), although strictly speaking only the segments in the rhyme appear on a rhyme projection. The geometry of the rhymes is indicated as branchiny or nonbranching (a superscript dot). 
Feet are formed over pairs of rhymes, where neither member of the pair is the rhyme associated with a heavy syllable. Geometrically, the foot must take the shape of (9a), with the stated conditions. The formal rule of foot assignment appears in (9b):

(9) a.

$\mathrm{n}_{1}$ Condition: Neither $\mathrm{n}_{1}$ nor $\mathrm{n}_{2}$ branches.

b. Foot Assignment (on Rhyme Projection)

Assign a binary foot [-head, -tail] from left to right.

I.t follows from the theory that a headless and tailless binary foot has all the characteristics of the structure in (9a). I note in passing that there is no way of determining the chirality of this foot, whether it is left- or right-branching.

Application of Foot Assignment (9b) to the rhyme projections in (8) yields the results in (10):

(10) a.

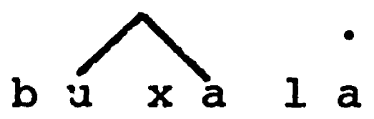

b.

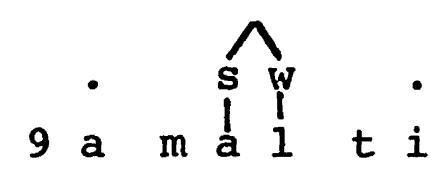


c.

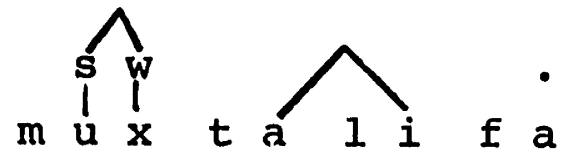

d.

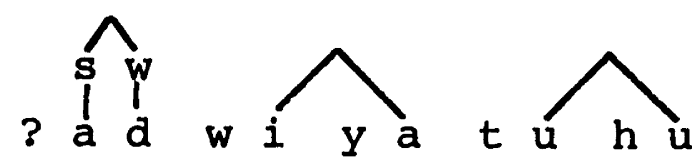

Finally, these structures are gathered up into a rightbranching word-level structure, and labeled in accordance with the principle that the right node is strong (s) if and only if it branches:

(11) a.

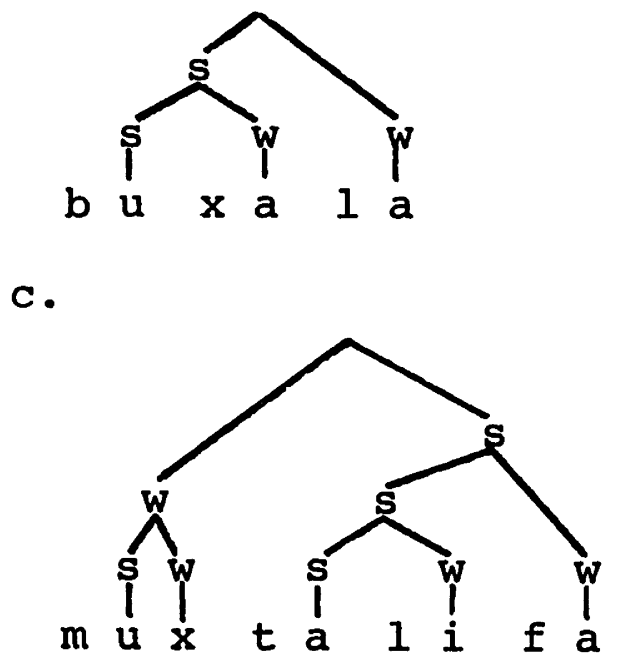

b.

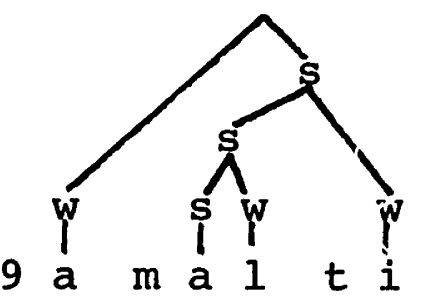

d.

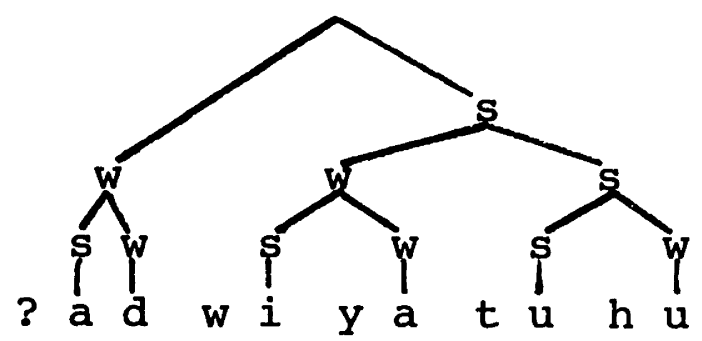

In the trees in (11) the designated terminal element, the node dominated only by s's and the root, correctly labels the rhyme of the syllable that bears the main stress.

There are several interesting points to note about this formalization. Consider words like gamálti or riaa dáani, 
with heavy syllables in the penult. Since the rhymes of heavy syllables are branching nodes, Foot Assignment applies vacuously to these forms. They receive penult stress, however, from the application of right-branching superstructure, as in (1lb). Since the right-branching superstructure is independently necessary to get main stress near the right boundary of the word, the stress in forms like these is additional confirmation for the metrical theory.

A second result concerns the stressing of words with superheavy (CVVC or CVCC) final syllables. The treatment in Chapter 2 of Arabic syllable structure argues that syllables of this sort are formed by Chomsky-adjoining the final extrametrical consonant to the precediny syllable. The result of this adjunction is repeated here for reference:

(13) a.

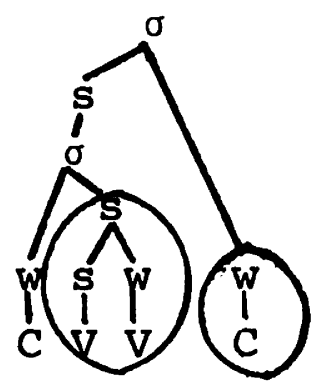

b.

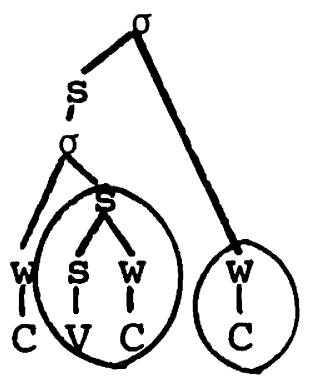

The formal definition of rhyme as the right branch of $\sigma$ produces the circled constituents in (13). It follows then that superheavy syllables have two rhymes, the first branching and the second nonbranching. This makss them formally equivalent to words with heavy penults and light ultimas 
(to which they are related historically). Therefore the full metrical structure of representative examples like katabt and sakakiin is:

(14) a.

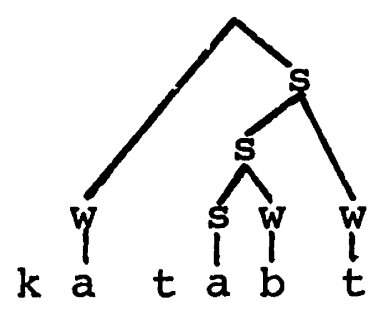

b.

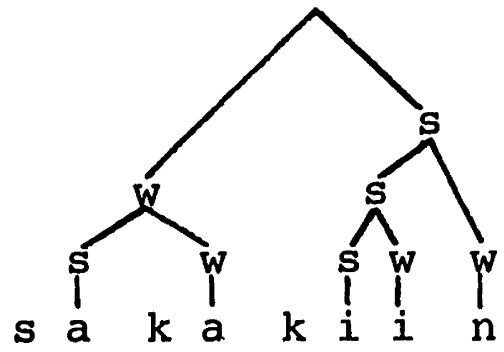

As predicted, stress falls on the nucleus of the final superheavy syllable.

This general mode of accentuation of superheavy syllables holds as well for Damascene Arabic, Classical Arabic, and Tiberian Hebrew, all discussed below. The fundamental idea behind it is that superheavy syllables have two o-nodes, and consequently they project as if they were two syllables -- one heavy and one light -- rather than a single syllable, which they are by all other measures. This same notion turns out to have some significance in English accentuátion as well.

Halle and Keyser (1971:78) offer some fairly well known observations about the stressing of English verbs. If we limit our attention to those which do not have Latinate prefixes, then the basic generalization seems to be that vowel-final words have penult stress (fóllow, árgue), as do words ending in a consonant preceded by a short vowel (gállop, frólic, devélop). But words ending either in a 
consonant cluster or a consonant preceded by a tense vowel have final stress: molést, cavórt, bombárd; negáte, eróde, devóte. There are a few exceptions to the final cluster generalization, like Dóllix or scávenge, but these are scarcely alarming.

These facts are clearly parallel to the Arabic ones. Verbs ending in CVCC and CVVC syllables behave accentually like words with heavy penults and light ultimas. On the rhyme projection, in fact, the two classes are geometrically indistinguishable. of course, these properties are not immune to the widespread morphological and lexical idiosyncracy of English. Not only do we have the verb exceptions like bollix, but much of the noun system fails to stress final CVCC syllables. The observations by Ross (1972) are obviously relevant here, but I am not prepared to offer a reanalysis of them. I would suggest, however, that consonant cluster types that fairly consistently allows stress to skip over them have final CVCC syllables with only a single $\sigma$-node. These would then project only single rhymes and consequently would not have the geometric properties of superheavy syllables. This type may be represented by the surface CVCC syllables of Hebrew discussed in Chapter 2.

In Cairene Arabic, there is another issued raised by the accentuation of final syllables. Words like colloquial madáaris or classical śajaratuhúmaa, with heavy -- though 
not superheavy -- final syllables present an interesting technical problem. The full metrical structure assigned to these words except for the accentual labeling is:

(15) a.

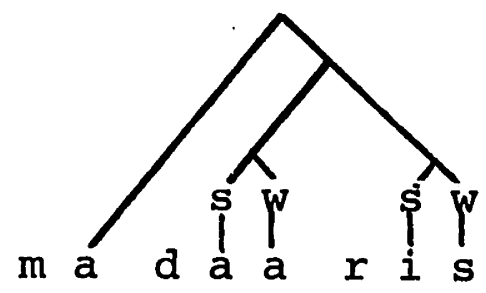

b.

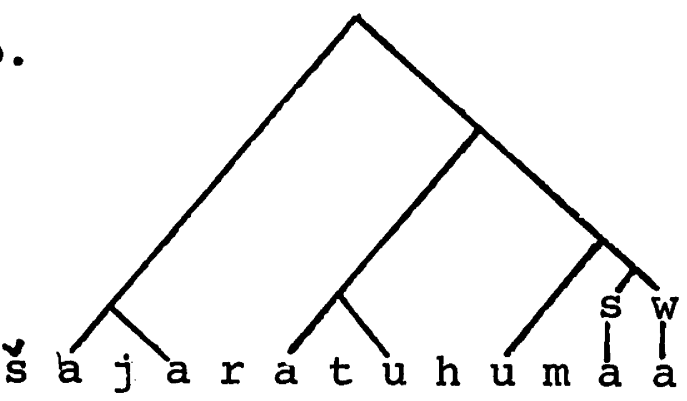

If these structures are labeled in accordance with the rule that the right node is strong if and only if it branches, then clearly the designated terminal element will be the nucleus of the final syllable, rather than the observed penult stress in both forms.

What we see here is really a result of the operation of the principle of opacity developed in the introduction to this chapter. It is stipulated in, so far as I know, all the Arabic dialects that the syllable rhyme is an opaque domain with respect to the labeling rule for word-level metrical structure. Consequeritly the branching structure of rhymes like those of the final syllables in (15) is not availabie to the labeling. Therefore these final heavy syllable rhymes are labeled $w$, and the correct penult stress is derived. I caution here that it is not necessarily the case that the rhyme is an opaque domain for labeling; as we 
will see, this is clearly not true in Tiberian Hebrew accentuation. ${ }^{2}$

The accentuation of final heavy syllables raises a small empirical issue as well. Open heavy (CVV) final syllables are always stressed in colloquial words of the Cairene dialect but they are unstressed in Classical Arabic words that are otherwise stressed in accordance with the colloquial pattern. The solution to this evident inconsistency comes from an examination of the source of stressed CVV ultimas in the colloquial.

With only rare exceptions, stressed word-final CVV syllables are the surface reflex of a third person masculine singular objective or genitive suffix on a verb, prepo-sition, or noun: ramáa 'he threw him', ?axúu 'his brother'. Actually, these forms have superheavy final syllables at a more remote stage of the derivation, and so are stressed regularly. Besides the motive of maintaining the parallel between CVV and CVC syllables, two arguments support this position.

First, all these forms with a stressed final long vowel are in stylistically-conditioned variation with forms with final $\underline{h}$ : ramáah, ?axúuh. The forms with $\underline{h}$ are apparently characteristic of slow or emphatic spec:ch (Tomiche (1964); Harrell (1957)). Since $\underline{h}$ is invariant when part of the stem (e.g., minábbih 'alarm clock'), I follow Brame's (1971) suggestion for a similar phenomenon in a Levantine dialect and restrict deletion to suffixal $\underline{h}$ : 


$$
\mathrm{h} \rightarrow \varnothing /[\overline{+\operatorname{suffix}}])_{\omega} \quad \omega=\text { word }
$$

Brame presents an argument from this dialect that also carries over to Cairene. If a dative suffix follows the third person masculine singular object suffix, the $\underline{h}$ shows up overtly: rama+hu+lha 'he threw it (m.) to her'. He argues that this morpheme is subject to a metathesis rule, and I will assume that the same is true of Cairene. Since the full analysis wouid take us too far afield, I refer to Broselow (1976:130) for a varsion of this rule.

Pace deletion of final $\underline{h}$, then, these forms with final clitics are unremarkable, since they are stressed like any forms with final CVVC syllables. ${ }^{3}$

A final result of the metrical analysis of Cairene stress concerns a set of forms that are exceptional under morphological government. If a third person feminine singular verb is followed by a pronominal object clitic, the accent falls on the feminine suffix it: kallimítak 'she spoke to you (m. sg.)', ramítu 'she threw it (m.) '.4 The expected stressing of these forms by the rules already developed is *kallímitak and *xámitu. If no pronominal clitic is present, then stress is regular: kallímit, rámit.

The metrical stress theory permits an explanatory but very restrictive account of this sort of exceptionality. A morphologically-governed rule creates a special foot over the 
node of the rhyme projection associated with the verbal sufrix -it and any following node: 17

(17) Feminine Adjunction (on Rhyme Projection)

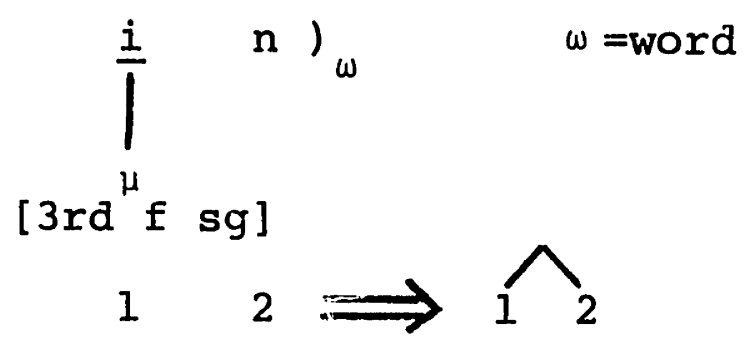

The $\mu$-notation of this rule is developed in Chapter 4. For now it suffices to note that (17) applies only to the feminine suffix in verbs.

If the node $\mathrm{n}$ of (17) is null, then no branch can be created since the notation expresses relations between nonnull elements. In that case normal stress rules apply, as in kallimit. But if $\mathrm{n}$ is nonnull, then a branching node is created and subsequently other metrical structure is built. The branching node created by (17) is, like the rest of the tree, labeled in accordance with (5c). A couple of examples will illustrate the final result:

(18) a.

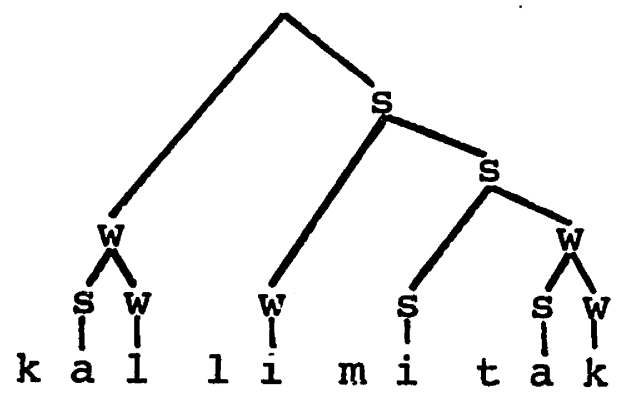

b.

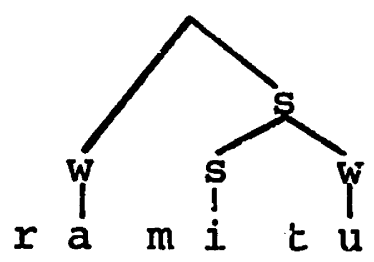


One last point: the right word-juncture in (17) ensures that $\mathrm{n}$ is the last rhyme node in the word, preventing application of (17) in forms like mastalamitúuš 'she didn't receive it $(\mathrm{m})$ '.

This natural treatment of exceptionality within the metrical theory explains why it is stressed only when it is followed by other material. It also restricts or evaluates the possible exceptions. For instance, if it always induced final stress in *kallimiták, *ramitú, then rule (17) would need to create labeling a.s well as structure. The labeling of these exceptional forms comes from more general rules of the phonology.

\subsection{Damascene Colloquial}

The stress rule of the dialect of Damascus is quite different from the Cairene one. Except for the Cairenelike stressing of superheavy ultimas, it is identical to the Classical Latin stress rule: accent a heavy penult or the first syllable of a disyllabic word, otherwise accent the antepenult:

a. darrást 'I/you (m. sg.) taught' bət?úul 'you (m. sg.) will say' b. fáthet 'she opened', madáares 'schools', sírib 'he drank' 


\section{c. dárasu 'they studied', mádrase 'school', muttánide 'united (f. sg.)'}

The final example is a loanword from Classical Arabic with a properly noncolloquial surface canonicil pattern. It confirms the impossibility of retracting stress beyond the antepenult under any conditions.

Damascene is clearly subject to the same syllabification and labeling rules as cairene. The real difference between Damascene and Cairene is foot construction. The Damascene stress rule, like that of classical Latin, requires an equivalence between a heavy penult and an antepenult plus light penult. To see this formally, consider the rhyme projections of the crucial canonical patterns (abstracting away from the weight of the final syllable):

(20) a. heavy penult

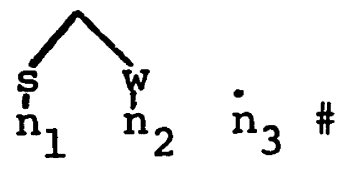

b. light penult and light antepenult $\quad \dot{n}_{1} \quad \dot{\mathrm{r}}_{2} \quad \dot{\mathrm{n}}_{3} \#$

c. light penult and heavy antepenult

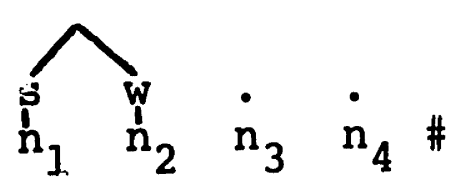

In each of these cases, the desired result is that $n_{1}$ be the leftmost rode in the foot. Suppose, then, that we 
create a foot with the structure $\left[\left[\begin{array}{ll}n_{1} & n_{2}\end{array}\right] n_{3}\right]$, where neither $\mathrm{n}_{1}$ nor $\mathrm{n}_{2}$ may branch. $\mathrm{n}_{3}$, on the other hand, can branch at will. The proper analyses of the schematic rhyme projections in (20) by this foot will yield the following structures :

(21)

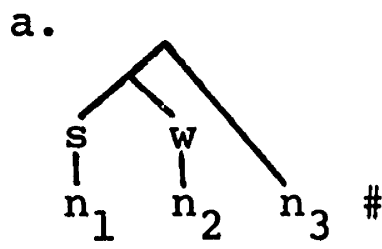

c.

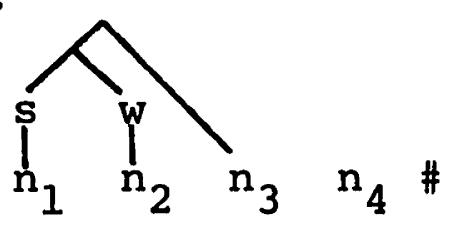

b.

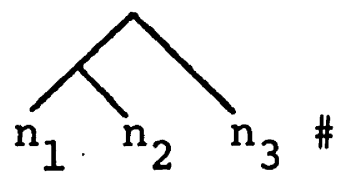

The foot contains the rhymes of the last two syllables in (2la) and of the last three syllables in (2lb). In (2lc) -and this is something to note -- it contains only the rhymes of the penult and antepenult, not of the final syllable. Although $\mathrm{n}_{3}$ is allowed to branch, there is no possibility of skipping over a branching node in the $n_{3}$ position of (21c), since foot assignment must apply from right to left in any case.

Given these observations about the foot in Damascene Arabic, we are prepared to formulate a rule to assign it:

(22) Foot Assignment (on Rhyme Projection)

Assign a binary, left-branching foot [thead, +tail] from right to left. 
The feature [thead] generates the two nonbranching nodes $\mathrm{n}_{1}$ and $\mathrm{n}_{2} ;$ the tail is $\mathrm{n}_{3}$. Some representative examples illustrate the application of this schema to the three types in (21):

(23) a.

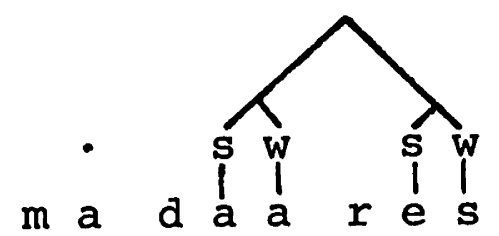

b.

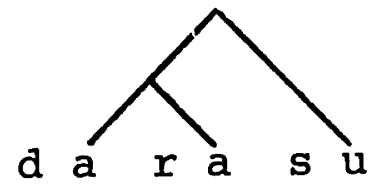

C.

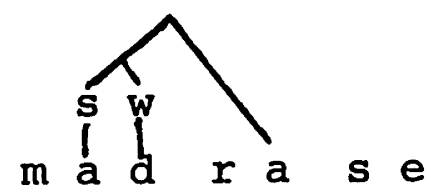

In all other major respects stress assignment is identical to what happens in Cairene. Right-branching word-level structure is applied, and the entire tree is labeled according to the LCPR. Since syllable structure is identical in all relevant respects in the two dialects, final superheavy syllables receive stress by the same mechanism. ${ }^{5}$

Several interesting sorts of irregularity occur in Damascene stress under various morphological circumstances. The first of these is particularly instructive because it confirms the exact nature of the foot assignment rule.

As in Cairene, this irregularity centers around the third person feminine singular verbal inflection when followed by an object clitic: 
Without clitic

a. fáthet 'she opened' sáafet 'she saw' ḩtámlet 'she bore'

b. gállamet 'she taught' káatabet 'she corresponded'

?ákramet 'she honored
With Clitic (3rd m. sg.)

fátho

šáafto

ḩtámlto

9allamáto

kaatab d́to

?akram áto

A useful summary of these facts for several dialects can be found in Diem (1970).

To understand fully what is going on in (24), we first have to consider some of the segmental phonology of Damascene. First, short unstressed nonlow vowels are deleted in open nonfinal syllables: m9állem 'teacher', m9allmíin 'teachers'; tóle9 'he came out', tól9u 'they came out'. This accounts for the loss of the vowel $e$ in the forms on the right in (24a), while in (24b) e is retaired in an open syllable because it is stressed. On the other hand, the nonlow short vowels when stressed are neutralized to $\underline{\partial}$ : 9ámel 'he did', 9mjilt 'I/you did'. This reduction is responsible for the quality of the stressed vowel in the forms on the right in (24b) •

Given these two rules, we can deduce the more remote representations for the forms on the right in (24) to which stress is applied: /fatheto/, /śaafeto/, etc.; /9allameto/, /kaatabeto/, etc. It should now be evident what the correct 
generalization is: stress falls on the feminine suffix -et when it is followed by a clitic and preceded by a heavy syllable followed by a light syllable. That is, stressed -et occurs in words of the pattern $\mathrm{H}$ L-et + clitic. This is a rather baroque and quite discontinuous dependency for an otherwise reasonable stress rule like that of Damascene. In particular, the difficulty is that this special dependency holds to the left of the stress whereas the foot includes the stress and the syllables to its right.

We can, however, account for this property elegantly by the mechanism of cyclic metrical structure assignment first suggested by Kiparsky (to appear). I will, with Brame (1973) and others, assume the natural cyclic bracketing for these forms as [[9allamet]o] and so on, where the clitic appears on the superordinate cycle. I will make somewhat different assumptions from Kiparsky about the restructuring on later cycles. I suggest that foot assignment is cyclic but assignment of word-level structure awaits the end of the word-level cycle. My principle of restructuring says that the foot structure inherited from previous cycles is subject to one modification: any foot with a branching tail is erased. This principle applies once at the beginning of each cycle to any preexisting foot structure, after resyllabification on the new cycle. Given this apparatus, it is not difficult to derive the correct surface stress for a couple of verb forms with enclitics: 
(25) a. [ [yedrob]o]

First Cycle

Foot

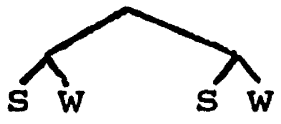

$y$ e d $r \circ b$

Second Cycle Resyllabification and

Restructuring

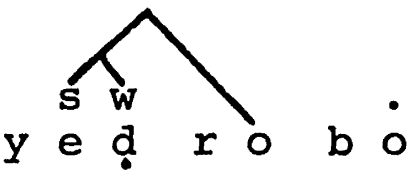

Foot

Word-level

Structure

other rules b. [ [yedrob]ni]

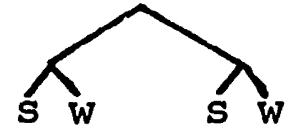

$y \in d r o b$
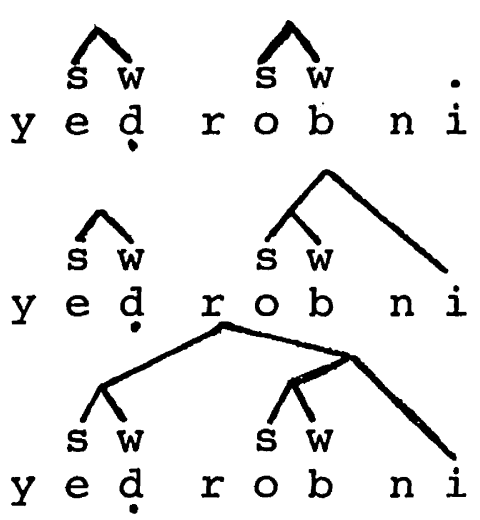

yad̆rábni 'let him beat me'

Note that application of the restructuring principle on the second cycle erases only the foot on the right, which has a branching tail. It does not apply on the left.

This same apparatus also directly yields the somewhat anomalous stress contrast of the forms in (24):

(26) a. [ [fathet]o]

First Cycle

Foot

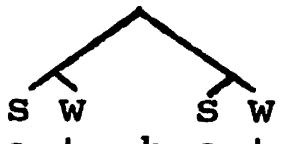

$$
\text { f a } t \text { h e } t
$$

Second Cycle Resyllabification and Restructuring

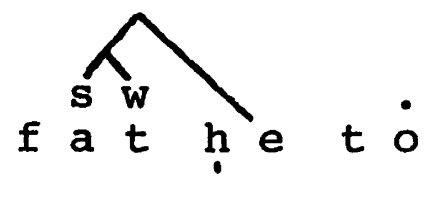

Foot

Word-level Structure

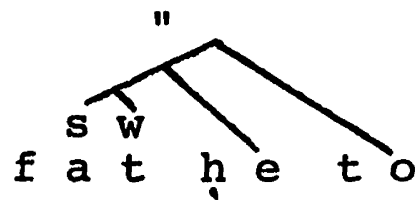

other rules fáthto b. [[9allamet]o]
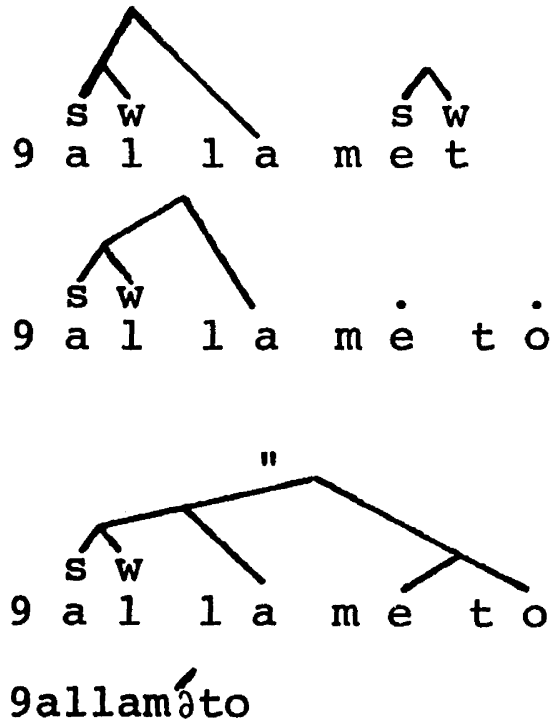
The explanation for this stress contrast is not too difficult to see. On the first cycle a foot is assigned that includes only the first two syllables of 9allamet. This follows from familiar conditions on the geometry of the foot; in particular, $\mathrm{n}_{1}$ may not branch. This foot does not have a branching tail on the second cycle, so it is not subject to restructuring. Foot Assignment cannot reapply, since it has no proper analysis in this form. The assignment of right-branching word-level structure, along with labeling by LCPR, yields the observed penult stress of 9allamáto. The crucial different between (26a) and (26b) lies in the application of Foot Assignment on the first cycle. In fathet it encompasses the whole word, but not in 9allamet. ${ }^{6}$

The restructuring principle adduced here operates as well in some other cases that involve morphologicallygoverned stress. The Damascene reflexes of the Classical Arabic seventh and eighth binyanim (see Chapter 4) have exceptional penult stress in the participle and the imperfective: byanbáset 'he is satisfied', byaštáğel 'he works'. This is apparently a result of a minor rule of structure formation, like the treatment of the feminine suffix in Cairene Arabic. I will formulate this rule as follows: 
(27) Seventh, Eighth Binyan Stress (on Rhyme

Projection)

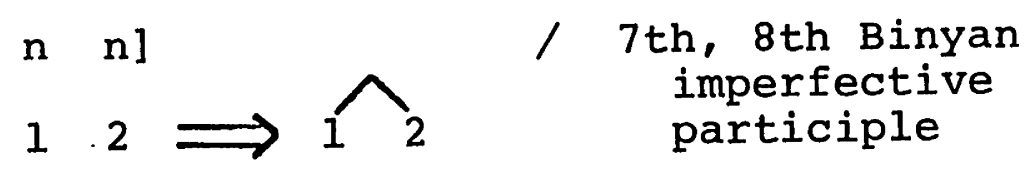

This structure is labeled in the usual way, yielding the correct penult stress.

If, however, these forms appear with a consonant initial pronominal suffix, the stress moves to the final

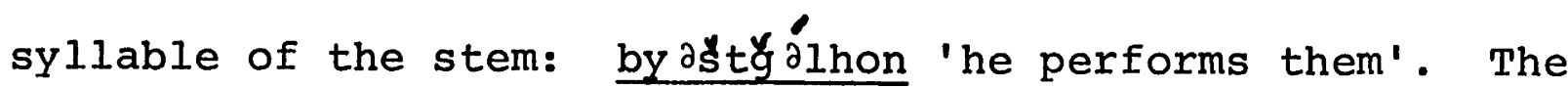
derivation of this form proceeds as:

[ [yešteğel]hon]

First Cycle

by (27)

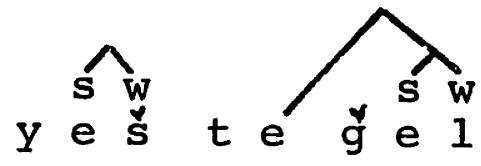

Foot

"

Second Cycle

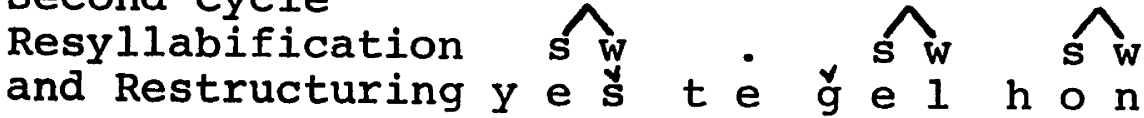

Foot

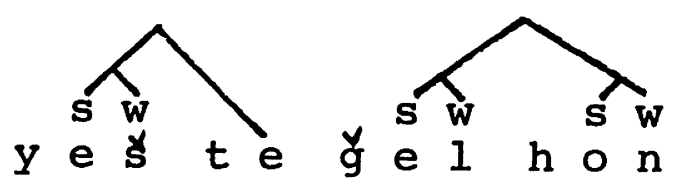

Word-level

Structure

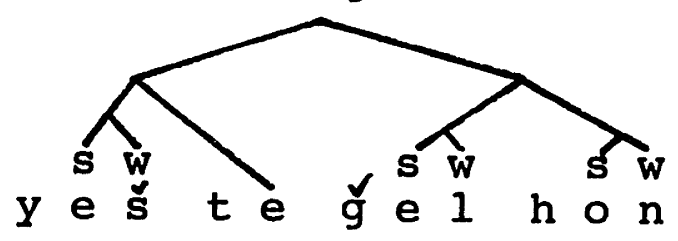

Other rules

byวśtğ́n Ihon

Here the erasure of the morphologically-governed structure derived from the previous cycle is crucial to the operation of Foot Assignment on the superordinate cycle. 
2.3 Classical Arabic

The stress phenomena of Classical Arabic have a somewhat difficult provenience. The native orthoepists said nothing about stress in their usually detailed descriptions. Consequently, in most areas the colloquial stress rule is applied to Classical Arabic, as in Cairo. Chiefly for this reason, it is widely believed that Classical Arabic had no regular word-stress (Birkeland (1954); Rabin (1978); Ferguson (1956)). But there is a stress patteri: -- the same one described in handbooks like Wright (1971) -- that is traditionally observed in some areas despite the dialectal pronunciation. For instance, Abul-Fadl (1961) reports the following accentuation of Classical Arabic in an area where the Cairene and Damascene stress rules generally apply to the colloquial:

(29) kitáabun 'book (nom. sg.)', manaadíilu 'kerchiefs (nom.)', yusáariku 'he participates', mámlakatun 'kingdom (nom. sg.)', kátaba 'he wrote', bálaḥatun 'date (nom. sg.)'

The rule usually formulated to account for these facts is:

(30) a. Stress a superheavy ultima.

b. Otherwise stress the rightmost nonfinal heavy syllable. 
c. Otherwise stress the first syllable.

In addition to the observance of (30) in some modern traditions, there are two other arguments for this rule in Classical Arabic. First, it has been retained in a few modern colloquials like the Egyptian Sa9iidi (Khalafallah (1969)) and Yemen Plateau (Diem (1973)) dialects. Second, there is some basis for inferring stress patterns from the system of rhyming in verse or rhymed prose (saj9). For instance, the difference between masculine and feminine rhymes in English is just the difference between endstressed and penult- or antepenult-stressed words. The Arab orthoepists recognized an elaborate typology of Classical Arabic rhyming. The type known as mutaraadif rhymes superheavy final syllables, the rnutawaatir rhymes the sequence of heavy penult and heavy ultima (verse-final syllables are always heavy), and so on. The longest rhyme for which they had a name is mutakaawis, which is the string HLLLH, as in the line (Wright 1971:356):

qad jabara ddiina 1?ilaahu fajabar

Here the rhyme extends over two words, indicative of poetic encliticization as in English. The mutakaawis type is rare, and presumably the scarcity of longer strings of light syllables in the lexicon, as well as their impossibility in the metre, obviated the need for terms for longer rhymes. 
One other point on the stress data for Classical Arabic. As I describe the situation in Chapter 2, the occurrence of superheavy syllables is limited to immediately before a pause, as at the end of a verse. The pausal forms are created by truncation of final short vowels such as case and mood desinences. One might suppose that this truncation follows the assignment of stress, so that stressing of superheavy ultimas actually is a reflex of stressing heavy penults and subsequent truncation of the final syllable. This move would eliminate the first clause of the informal characterization of Arabic stress distribution in (30). What makes this impossible are the facts of words like wuzaráa?u. In this form, the heavy penult receives stress regularly. The glottal stop is, however, inserted at the hiatus between the long and short vowels. This insertion rule follows the truncation of final short vowels in pause, so the pausal form is wúzaraa, with initial stress. This initial stress is only possible if stress assignment follows the pausal truncation. This means that the stress rule must be able to handle the superheavy final syllables created by pausal truncation.

In general, then, Classical shares with Damascene Arabic the stressing of superheavy ultimas and the failure of stress to skip over the rightmost nonfinal heavy syllable. But Classical Arabic allows retraction of stress a potentially infinite distance from the right boundary, 
rather than the maximum of three syllables permitted in Damascene. This means that the Classical Arabic foot must also be of potentially infinite size. In all other resperts it is basically familiar. This rule is schematized in (3la) and stated formally in (3lb):

(31) a.

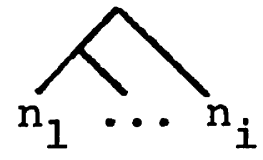

b. Foot Assignment (on Rhyme Projection) Assign $\geq$ n-ary, left-branching foot [-head, ttail] from right to left.

The universal characteristic of n-ary feet is maximality: they must expand to fill the form to which they are applied subject only to conditions on the branching of their terminal nodes. As in the modern colloquials, feet are assigned from the right, word-level structure is rightbranching, and labeling goes by the LCPR. A few sample derivations are: 
Rhyme Projection ma na a di $j$. lu

Foot Assignment ma na a di $i$ lu

Word-level structure
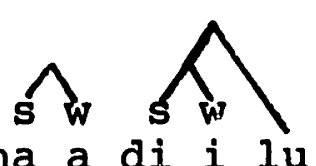
ma na a di $i$ lu

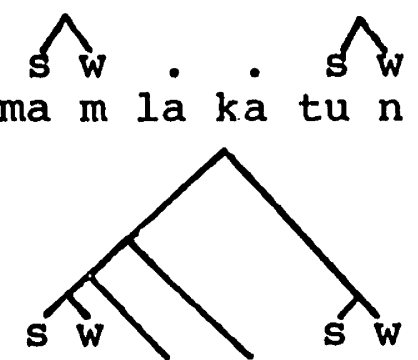

ma m la ka tu n

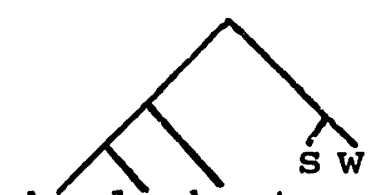

bá la há tu n

$\widehat{s}$ ba la hà tu n

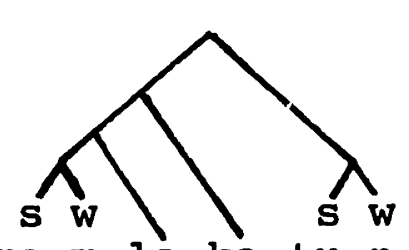
ma m la ka tu n
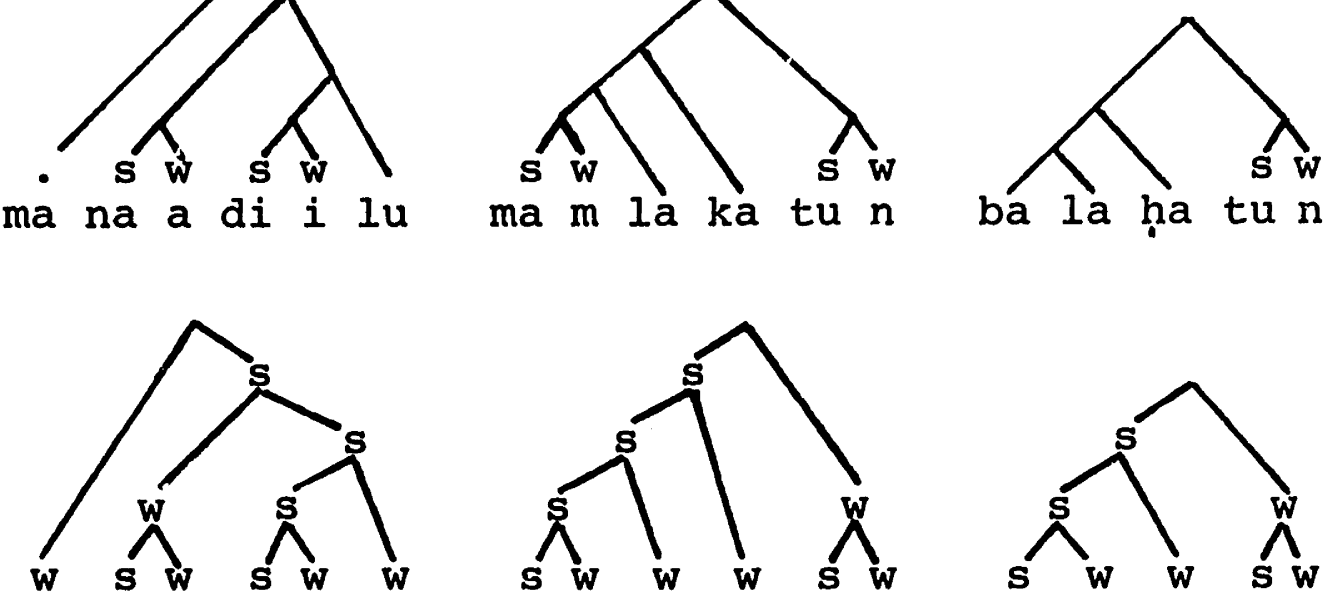

I.abeling ma na a di $i$ lu

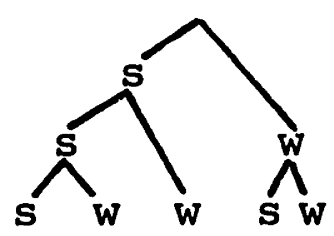

ba la ha tu $n$

\subsection{Diachronic Considerations}

These evident similarities between the stress rules of Damascene and Classical Arabic certainly suggest an historical connection. In previous work, the issue has been clouded somewhat by the view that Classical Arabic was without word-stress. So Cowan (2960), for instance, holds that the ancient ancestor of the modern dialects was without regular stress, and that the modern eastern stress patterns arose independently. My view is closer to the more traditional one of Brockelmün (1961, originally published in 1907); more recently Janssens (1972) that the phenomena 
in all the modern dialects should be related historically to a rule like (29). Apart from (29) I attribute no properties to a protocolloquial Arabic (Ferguson (1978)) that is distinct from Classical Arabic.

In the metrical analysis of Arabic stress that has been proposed here, the major difference between Classical Arabic and the two colloquials is that the former has potentially infinite feet while the latter have feet with only one or two terminal nodes. Formally this involves a shift from n-ary to binary size. This shift was nearly , universal, so that, except for a few scattered dialects, no modern colloquial has n-ary feet.

Now notice that this aistinction seems to correlate with the existence of extensive vowel reduction (deletion of unstressed vowels in open syllables, sometimes restricted to nonlow vowels) in the same colloquials. If vowel reduction is -- at least in its initial phonetic development -a reflex of stress timing, then we can see that the colloquials must be stress timed, while classical Arabic was not. Stress timing in a metrical theory can be understood as just timing of the duration of feet. If the feet are limited to two or three syllables, as in the colloquials, they can be easily, though not necessarily, stress timed. This is clearly not the case with the classical feet. Potentially infinite feet are presumably unmanageable for a stress timing rule. 
The two modern feet -- Cairene and Damascene -- involve somewhat different changes from the Classical prototype apart from the common shift from n-ary to binary. The Classical foot is [-head, ttail], and just one of these features takes a different value in each dialect. Cairene is [-tail] while remaining [-head], whereas Damascene is [-head] and still [+tail]. If there is a direct historical relationship here, then it involves simple revaluations of binary features from a common source.

Unfortunately, Cairene presents one other historical problem that remains intractable. Feet must be assigned from left to right in Cairene but from right to left in the other colloquial and in Classical Arabic. This change in direction is entirely unexplained under the account offered here. The ideal explanation would be to posit a relationship between the form of the foot and the direction of its application, so the change in direction in Cairene would be automatic. Although no complete solution is forthcoming, some new evidence bearing on this question suggests that the form of the feet does partially or fully determine the direction of their assignment.

It is generally agreed (Sturtevant (1940)) that preclassical Latin was prototone: stress the initial syllable. The Classical Latin .stress rule was like the Damascene rule we have already seen. In the paragraphs that follow are some conjectures toward explaining this historical change. 
The only evidence of any intermediate historical stage comes from early Latin verse, where the correlation of metrical ictus and accent is supposed to show the position of stress (Fraenkel (1928)). In this material, quadrisyllabic words with the first three syllables light were often accented as in earlier Latin fácilius, sometimes as in classical facílius, and rarely, though interestingly, facilíus (particularly before major constituent breaks). Trisyllabic words with heavy first and light second syllable are usually stressed like córpore in this verse, as in prehistoric and Classical Latin. But again, some examples occur before syntactic breaks with the accentual type corpóre. ${ }^{7}$

The evidence of ictus is apparently not sufficient to determine whether the acute marks primary or secondary stress in facilíus and corpore. What is significant is that these two types are identical in effect to the Cairene stress rule. So in addition to initial stress, preclassical Latin apparently had a left-to-right foot assignment just like Cairene.

For reasons that $I$ do not understand, the Latin foot was expanded historically from the Cairene to the Damascene type. To the point at issue, this change in feet seems to have automatically induced "a change in the direction of foot assignment. It seems likely that left-branching feet, as in Damascene or Classical Latin, require right-to-left 
application in some way that this formalism fails to capture. It is equally likely that cairene may at least allow, and perhaps require, the opposite direction of assignment. Historically, the change in the Latin foot from headless to headed and left-branching required a shift to right-to-left assignment. In short, these two languages appear to have had opposite diachronic accentual developments.

3. The Accentual System of Tiberian Hebrew

3.1 Introduction

The sources of the present Hebrew Biblical. text are quite complicated. The consonantism is of great antiquity, but other indications of the pronunciation date from much later periods. Apparently as a result of a deterioration in the received pronunciation some time in the sixth century $A D$, it was felt necessary to record other details besides the consonantism, presumably relying on the most authoritative of those who had memorized the text for recitation. A system of diacritics of great subtlety was developed, and was added to the written consonants. This system marks a variety of phonemic and subphonemic vowel distinctions, as well as primary and secondary stresses. By a complex system of conjunctive and disjunctive accents, which are now interpreted chiefly as a musical notation, the text also indicates the full hierarchic structure of the surface phrase marker for every verse. This partly 
syntactic notation and its relationship to the phonological sandhi phenomena treated here and in Chapter 2 are discussed fully in McCarthy and Rotenberg (forthcoming).

There is, of course, some variation in the received pronunciation of the text. At one level we have the traditional pronunciation of Hebrew in Jewish communities throughout the world. This often fails to make distinctions that we know to be fairly ancient, like the loss of the spirantized value of $\mathrm{g}$ in all groups except the Yemenite. At another, we have three distinct systems of diacritic marking, Tiberian, Babylonian, and Palestinian. The best attested and best studied, as well as the most elaborated in accentual matters, is the Tiberian, and it will serve as the basis of all statements here. But the other systems do show interesting differences from the Tiberian in some aspects of segmental phonology, and although some defects in the transmission are inevitable, the different traditions may stand to one another as different dialects of Biblical Hebrew. A fourth type of pronunciation is represented in the Greek alphabet transcriptions of Origen's Hexapla. Finally, there is some variation within the Tiberian system itself, chiefly between the punctators Ben Asher and Ben Naphtali. The former is responsible for the textus receptus, and all observations here will refer to his readings. Ben Naphtali's work is known only through lists of sporadic variants. 
Besides the authors of this complex diacritic system, several early grammarians also plied their hand at developing rules for the pronunciation of the Biblical text. These scholars were chiefly taxonomists, but they nevertheless left a number of reliable generalizations and a useful metalanguage, both of which I will depend on heavily here. For further study of their contributions, the most useful works in English are William Chomsky's (1933) commentary and translation of David Qimhi's Mikhlol and Dothan's survey •

This section is divided into five subparts treating different accentual phenomena of Hebrew. The first deals with the distribution of main stress, while the second shows how that stress is shifted systematically under certain rhythmic conditions. The following two subparts offer analyses of two other accent movement rules that apply under particular morphological circumstances in the verb system. These are followed by an analysis of the distribution of secondary stress as represented by the diacritic symbol methegh. A final summary shows the full effects of rule ordering and of the interaction of these accentual processes with the segmental phonology. In total, this section virtually exhausts the accentual facts of Hebrew that hold with any great generality.

Several major theoretical points are illustrated in depth by this analysis. First, it appears that the basic 
structural characteristics of Hebrew syllables proposed in Chapter 2 have direct correlates in a wide variety of accentual phenomena. In particular, the claim is extensively supported that Hebrew syllable structure is as in (1), repeated from Chapter 2:

(1) a.

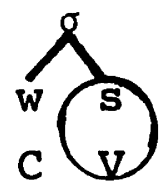

b.

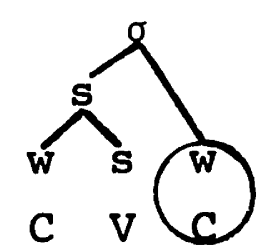

C.

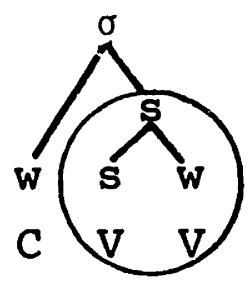

d.

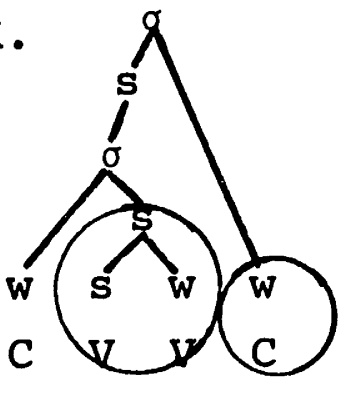

The geometry of the rhyme nodes -- circled in (1) -- is such that $\mathrm{CV}$ and $\mathrm{CVC}$ syllables constitute a natural class with nonbranching rhymes as distinct from CVV syllables with branching rhymes. Moreover, CVVC syllables are structurally equivalent in their rhymes to the rhymes of a CVV and a CVC syllable in that order.

Second, a foot structure with particular formal properties not found in Arabic is shown to be necessary for the proper formulation of several rules. These rules, which all involve movement of accent under different phonological or morphological conditions, demonstrably refer to this same structural unit, and therefore provide clear evidence for its existence and characteristics. 
3.2 Main Stress

The treatment of Hebrew segmental phonology in Chapter 2 assumes certain characteristics of the distribution of main stress, referred to formally as [DTE] or designated terminal element of the metrical tree. This is the terminal node which is dominated only by s's and the root, and is therefore relatively more prominent than any other terminal node of the tree. In that chapter a relatively informal presentation of the main stress phenomena was sufficient. Here I will show how a more rigorous analysis of these facts works.

The forms in (2) exhaust the possibilities for main stress assignment by type of the final and penult syllables. The representations given are near-underlying -- the surface forms in parentheses reflect subsequent application of segmental rules motivated in Chapter 2 as well as a few others adumbrated by Prince (1975) .

Final Stress

a. katáb (kätáb)

b. yaqúum (yãqúm)
Penult Stress

c. katábta (kātábtā)

d. katábtii (kātábtî)

e. katába (kãtbá)

f. katábuu (kātbáa)

The fundamental generalization that can be extracted from this paradigm is a fairly simple one: stress the ultima 
if it ends in a consonant, otherwise stress the penult. Projection of the syllable rhymes -- the circled constituents in (1) -- yields the following results for some of the crucial examples in (2):

\section{(3)}

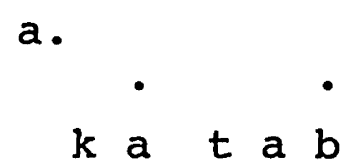

c.

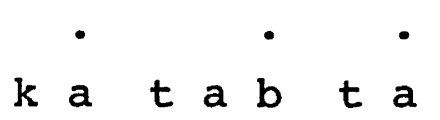

b.

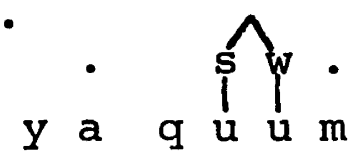

d.

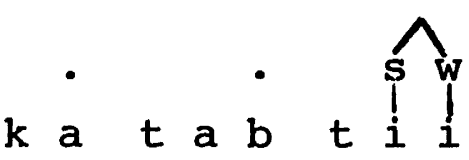

Main stress, then, is assigned to these structures on the basis of whether the last rhyme in the word is a consonant or not. If the final syllable has a consonantal rhyme, then stress is on the final syllable, and if the word ends in a vowel rhyme, then stress is on the penultimate syllable. The basic characteristic of the main stress rule is formation of a single binary branch, labeled $s-w$, over the rhymes of the last two syllables if the second of them is vocalic. Some independent motivation for the existence of this particular constituent appears later in the treatment of stress shift in perfect consecutive verb forms.

If main stress does not fall on the penult, then it is on the ultima. The most direct method of accomplishing this is to suppose that the right branch of the binary s-w structure is optional, so that consonant-final words receive just 
the label $s$ of the left branch, marking them as bearing the stress. These observations are formalized by the following rule:

(4) Main Stress Rule (on Rhyme Projection) Assign

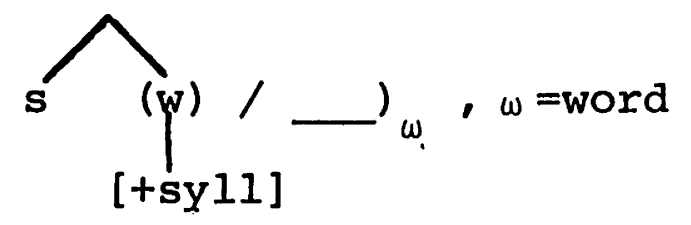

The context -- using the notation of Rotenberg (1978) -ensures that rule (4) applies only at the right boundary of the word. It consequently does not iterate leftward. I will assume as well that word-level structure, incorporating all lower-level structure including feet and rhymes, is assigned at this stage with the following characteristics:

(5) Word-level Structure (on Rhyme Projection) a. Assign a right-branching tree

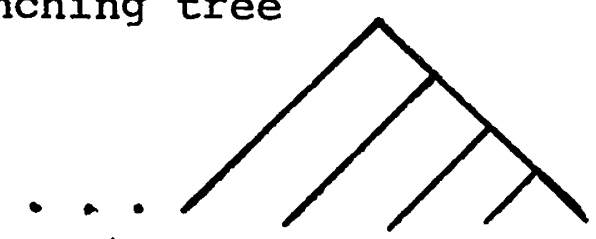

b. Label it by the rule that the right node is strong (s) if and only if it branches.

For the representative forms in (3), the rules (4) and (5), applied in this order, will yield the following sample derivations: 
(6) a.

by (4)

by (5)

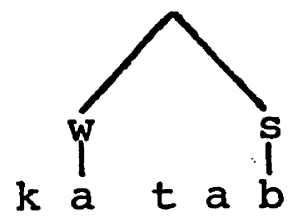

c.

by (4)

by (5) $k$ a $\quad t a \stackrel{s}{b}$

b.
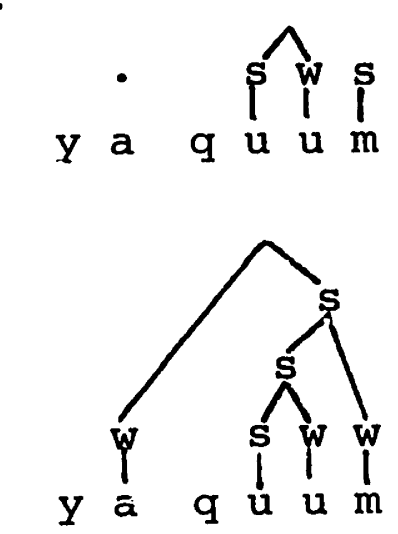

d.
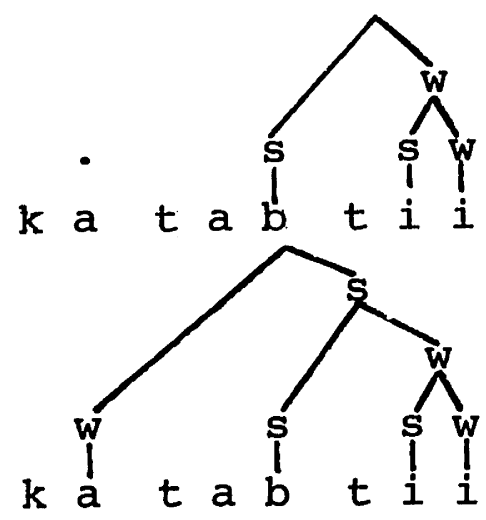

Note in (6a) and (6b) that the label s assigned by the application of the Main stress Rule takes precedence over labeling assigned by (5b), since application of Main Stress precedes assignment of word-level structure.

I should point out one peculiarity of the structures in (6): in consonant-final words, the label $s$ is assigned to a rhyme that just contains a consonant. Since there is little doubt that the preceding vowel carries the phonetic stress, we must assume that there is an adjustment here, shifting the stress to the nucleus of the syllable. In the case of superheavy final syllables like (6b), I will assume that this adjustment actually affects the labeling of the rhymes as well, so that the rhymes of the syllable quum 
constitute an s-w unit in the word-level structure. I have indicated the result of this ad hoc adjustment in the derived representation in $(6 \mathrm{~b})$.

There is one other notable case of main stress assignment -- forms with final consonant clusters. By the analysis given in Chapter 2, these forms are usually not properly syllabified at the early stage of the derivation when the Main Stress Rule applies. Rather, the final consonant is extrametrical, not a member of any syllable, as in the representation of /qebr/ 'grave':

(7)

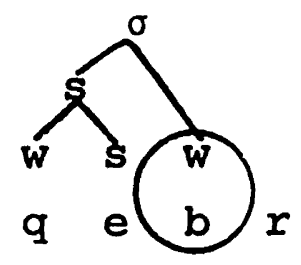

Consequently the rhyme projection of this word will yield only the single circled node in (7) since the final consonant is not a member of any syllable and consequently does not appear on the rhyme projection. In this case the Main Stress Rule applies vacuously, assigning an $\mathbf{s}$ label that is never joined into a tree. But with subsequent insertion of a vowel into this final cluster, the form becomes eligible for word-level structure and labeling by (5). The result is the structure in (8): 
(8)

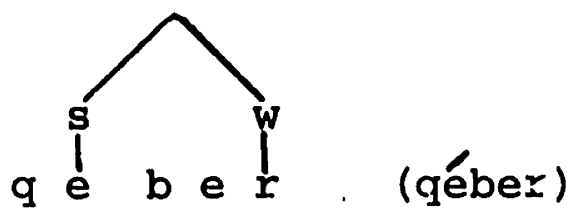

So penult stress of this type requires no additional rules. In many ways the Hebrew Main Stress Rule deviates from the characteristics of stress assignment we have already seen in Arabic. Since this rule makes reference to a segmental property -- the final $\mathrm{V}$-- and a morphological one -the word-final context -- and since it assigns labeling directly, it is much less highly valued than any of these rules already discussed. One could imagine various ad hoc manipulations of the rhyme geometry that would give the illusion of a more highly valued rule, such as erasure or insertion of branching nodes. This approach, however, is not highly recommended even apart from its ad hocness. For one thing, there is a circumscribed set of clear cases where particular aspects of rule (4) as formulated are suspended under idiosyncratic morphological government. The right branch is suppressed regularly in ?änōkî́ ' I' or ?att⿳⺈ 'you (m. sg.)' and in verbs like bāná 'he built', as well as sporadically in verbs like šăbû́ discussed further in section 3.2. The requirement that the right branch dominate a vowel is regularly violated by certain suffixed perfect verbs like ?ăhēbâtek 'she loves you (f. sg.)' 
Ru 4,15 and s2rappattam 'she burns them (m.)' Is 47,14. Both types of deviation are entirely predictable within the formulation of rule (4), since they involve systematic suppression of particular well-defined elements of the rule. This analysis is similar to the treatment of morphological irregularity in English stress by Liberman and Prince (1977).

More significantly, Hebrew does have a foot constituent with exactly the geometric properties predicted in the introduction to this chapter. Further, this constituent is demonstrably labeled according to the same principle as the word-level structure in $(5 b)$. We see, then, that the Hebrew Main Stress rule, involving allowable although fairly complex formal apparatus, is not the central generalization predicted by the theory, but a sort of adjunct to a very broad process of foot assignment. The remaining sections of the chapter go toward mapping out the characteristics of this foot assignment rule.

3.3 The Rhythm Rule năsốḡ ?āhốr

A well-known phenomenon of English is the resolution of clashing word-stresses by retraction of the first stress:

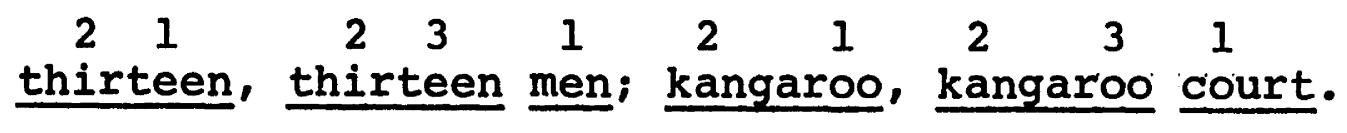


This retraction displays a variety of other interesting properties, like the failure of stress to retract onto unstressed syllables and some lexical (or discoursegoverned) exceptionality. The basic generalization in metrical terms is captured by a transformation on the metrical structure, which we can state informally as (9) (Kiparsky 1979, Liberman and Prince 1977):

(9)

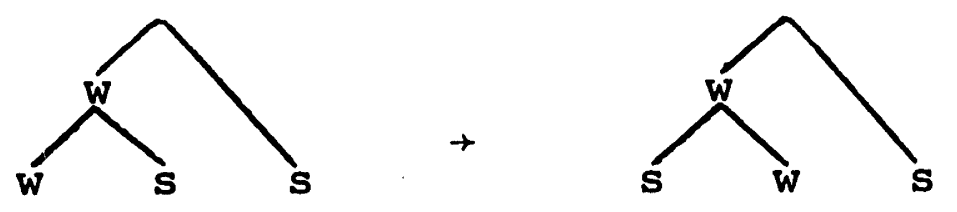

In particular, this easily expresses the fact that the stress can retract over a potentially unbounded number of syllables subject to the expansion of the subtree dominated by the node on the left.

Hebrew displays a similar process for resolving clashing word stresses, although it differs in a number of interesting ways from the English Rhythm Rule. The traditional designation of this process is nāsốg ?ăhốr 'receding', which shifts the stress of the first word if it is adjacent to the stress of the second word. This sandhi process is further governed by the syntactic condition that the two words involved be sole sisters $(A, B)$ in the phrase structure tree, subject to some readjustments. This important 
syntactic condition for Hebrew sandhi rules -- including the Gemination and Spirantization rules of Chapter 2 -- is discussed fully in McCarthy and Rotenberg (forthcoming). This syntactic conditioning will not figure further in the discussion here.

In the following examples, the destressed vowel, the expected position of word-stress, is marked with a superscript asterisk. The words which are sole syntactic sisters are bracketed:
(10) a. wa 1ăốšek
[qấra
1 lầ 1 ã]
and-to-the-dark he-called night
'and the darkness he called night' Gen 1,5
$\begin{array}{ll}\text { b. wayydhî́ [bóné } & \text { gír ] } \\ \text { and-he-was building city }\end{array}$
'and he was building a city' Gen 4,17
c. [?al-yếșé
not-wili-go man mimmaqômố
man-place-his
'a man shall not go forth from his place'
Ex 17,29

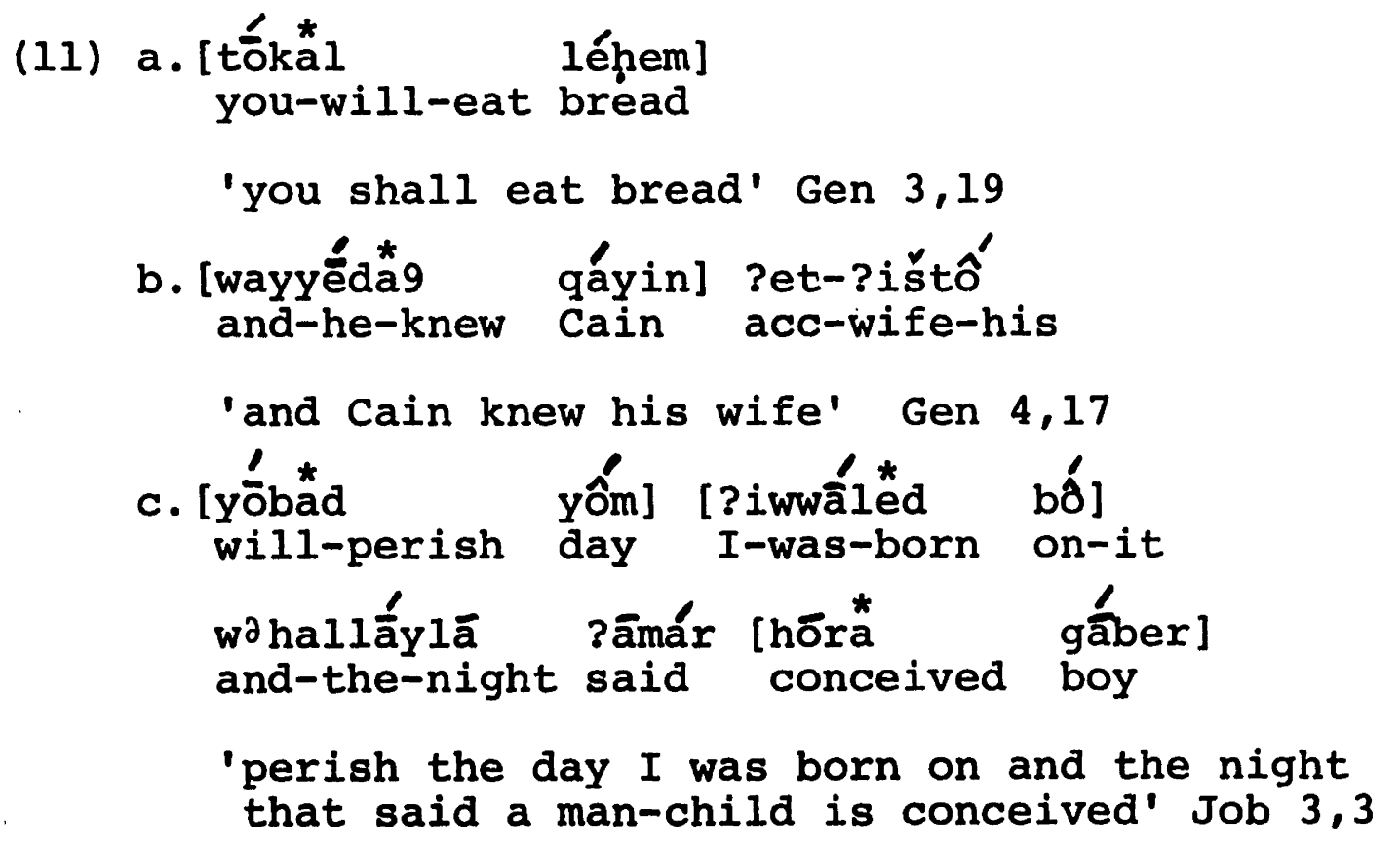


In this last, most striking example, the Rhythm Rule applies in three different instances in a single verse.

Let's consider the various conditions that will have to be placed on the application of the Rhythm Rule. First, the syllable that loses the stress can be either a final open syllable with a long or short vowel as in (10) or a final closed syllable with a short vowel as in (11). The remaining possibility -- a final closed syllable with a long vowel -- does not permit stress shift:

$$
\begin{aligned}
& \begin{array}{l}
\text { (12) a. [1āșúd } \\
\text { to-hunt gáyid] } \\
\text { game }
\end{array} \\
& \text { 'to hunt game' Gen 27,5 } \\
& \text { b. [?āšî́ lo lấk] } \\
& \text { I-render to-you } \\
& \text { ' (double) I will render to you' Zach 9,12 } \\
& \text { c. [dābấr rấ9] } \\
& \text { word evil 'an evil word' Ps } 64,6
\end{aligned}
$$

Long mid vowels occasionally deviate from this pattern (Prätorius 1897). Whether or not surface $\overline{\mathrm{e}}$ or $\underline{\underline{0}}$ can be destressed in a final closed syllable by the Rhythm Rule depends on the lexical categnry of the word containing them. Although there is some variation, generally finite verb forms permit destressing of $\underline{\underline{e}}$ in a final closed syllable. Idiosyncratically (or according to undiscovered conditions) this destressed vowel is realized as $\underline{\overline{\underline{e}}}$ or $\underline{e}$ : 


$$
\begin{aligned}
& \text { (13) a. [?ēlèk } 1 \hat{i} \text { ] } \\
& \text { I-go } \\
& \text { 'Let me go (dat. comm.)' Cant 4,6 } \\
& \text { b. [wayinnâtền lák ] } \\
& \text { and- is-given to-you } \\
& \text { 'and it will be given to you (m. sg.)' Est 9,12 }
\end{aligned}
$$

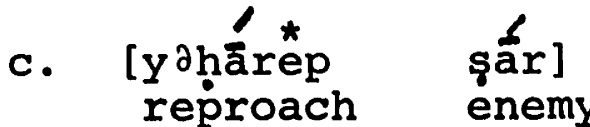

$$
\begin{aligned}
& \text { 'an enemy will reproash' Ps } 74,10
\end{aligned}
$$

Generally, nouns (including participles), as well as the

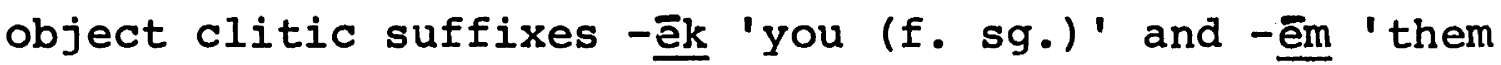
(m.)', eschew the stress retraction:

$$
\begin{aligned}
& \text { (14) a. } \begin{array}{l}
\text { [yōsép } \\
\text { Joseph háy] } \\
\text { 'Joseph is (still) alive' Gen } 45,26
\end{array} \\
& \text { b. [yōšếb } \\
& \text { dwelling there }
\end{aligned}
$$$$
\text { ' (he who is) dwelling (active part.) there' }
$$$$
1 \text { Kgs } 17,19
$$

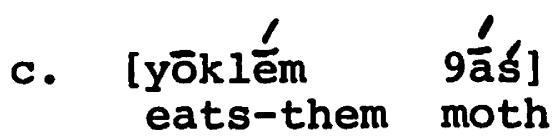$$
\text { 'a moth will eat them' Is } 51,8
$$

A similar paradigm of facts holds for 흐, though the attestation is not as extensive. 
The difference between these two types of surface long mid vowels -- destressable and nondestressable -- becomes evident when we look at some non-Tiberian evidence for the vocalization of final stressed syllables. The Mercati fragments of the second column of Origen's Hexapla (Brønno 1943) represent a reasonably consistent effort to write Hebrew in the Greek alphabet. There are certain important differences between this early (c. 4th C. AD) source and the Tiberian tradition. In particular, origen writes $\underline{\bar{e}}$ of the first, destressable type usually with $\varepsilon$, while $\underline{\underline{e}}$ of the nondestressable type is written with $n$. Similar facts hold for $\underline{0}$. This supports the idea that only short vowels can destress in closed syllables if we assume that the Tiberian tradition invokes a late lengthening rule in verb forms, ordered after the Rhythm Rule. ${ }^{8}$ For more on this issue, see the discussion in Chapter 2 of the rule of Tonic Lengthening.

There is an obvious similarity here to the facts of Arabic stress already discussed. Final syllables CVVC receive the word-stress regularly in Arabic, and resist destressing in Hebrew. We will see shortly that the formal account of these facts is identical in the two languages. But first we might wonder whether Hebrew has CVCC syllables with similar accentual properties. In fact, the occurrence of these syllables is highly restricted for morphological reasons. But the second person feminine singular of the 
perfective verb does provide a case where the Rhythm Rule might be expected to destress a CVCC syllable. I have found two examples where all relevant conditions are met, and in neither does the Rhythm Rule apply:

$$
\begin{aligned}
& \begin{array}{ll}
\text { (15) a. [yāládt } & \text { lî́] } \\
\text { you-bore to-me }
\end{array} \\
& \text { 'you (f. sg.) have borne to me' Ez 16,20 } \\
& \text { b. [Šeggâmált lănû] } \\
& \text { which-you-paid to-us } \\
& \text { 'which you (f. sg.) repaid us' Ps 137,8 }
\end{aligned}
$$

But since there are, as in English, other reasons like emphasis for suppressing the Rhythm Rule, these two examples cannot be taken as conclusive.

In general, subject to this last qualification, superheavy final syllables do not permit stress to be retracted off of them. Now we can turn to the other side of the question: where does the retracted stress land? In examples like (10), (11), and (13), the stress is retracted onto an open penult with a long vowel. But if a closed penult also contains a long vowel -- therefore a superheavy penult -- then stress can be retracted to there as well: 


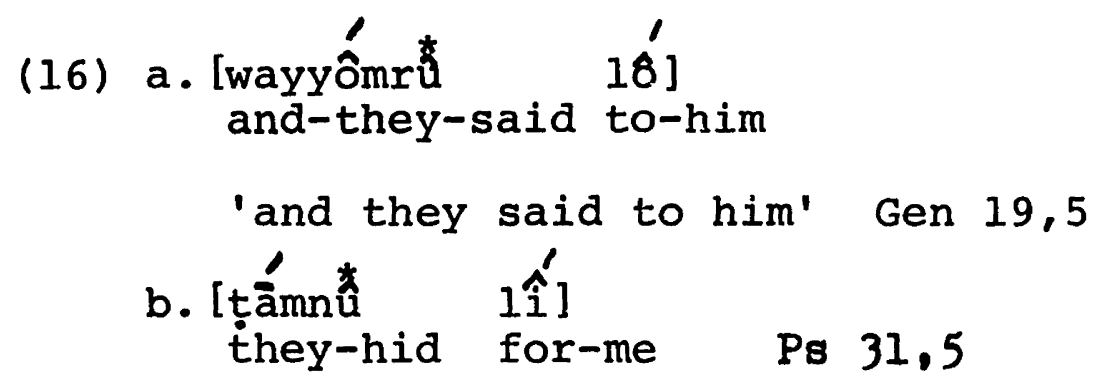

With very rare exceptions, however, the stress cannot retract onto a short vowel in either an open or closed penult. Even though all other known conditions might be met, the Rhythm Rule will not apply to forms like yišmág, malkí, or yasahếg. 9 Instead, words of this type are dealt with in one of two ways. Either the stress clash is ignored completely (17) or it is removed by a kind of cliticization process that treats the two grammatical words as a single accentual word (18). This latter process is indicated by a symbol similar to the hyphen:

(17) a. [?ebtáh bấk]

I-trust in-you

'I trust in you (m. sg.)' Ps 55,24

b. [?arzế ?él]
cedars-of God

'the cedars of God' Ps 80,11

(18) a. wayyiktob-sắm and-he-wrote-there

'and he wrote there' Jos 8,32 


$$
\begin{aligned}
& \text { b. hithallek-nốa } \\
& \text { walked-Noah } \\
& \text { 'Noah walked continually' Gen } 6,9 \\
& \text { c. İşaheq-bố } \\
& \text { to-play-in-it } \\
& \text { 'to play in it' Ps } 104,26
\end{aligned}
$$

This hyphenation process is also available in lieu of the Rhythm Rule even when the Rhythm Rule could nevertheless apply and in collocations involving monosyllabic, weakly stressed words like prepositions or complementizers.

One final point: consider the following instance of stress retraction by the Rhythm Rule:

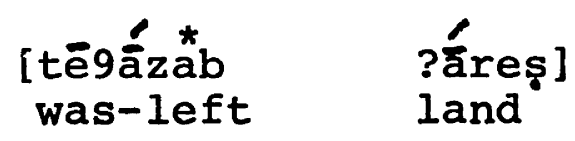

'a land was left' Job 18,4

Here there are two long vowels in the first word that the stress could retract onto. The point to notice is that it retracts onto the rightmost one, the long vowel nearest the syllable where the stress originally was located. Consequently retracted stress cannot skip over long vowels.

At this point let us informally characterize the syllables that specify the domain over which stress may retract. The syllable losing the stress must be either $\mathrm{CVV}$ or $\mathrm{CVC}$; 
superheavy syllables resist stress retraction. The syllable gaining the stress must contain a long vowel, though it may be either closed or open. It must also be the syllable with this property that is nearest the syllable losing the stress. Anticipating some of the following discussion, I will call this string of syllables that is the domain of Rhythm Rule retraction the foot, and I will now turn to its formal properties.

Rhyme projections for some representative examples where the Rhythm Rule is applicable ((20a), (20b)) and is not applicable $((20 \mathrm{c}),(20 \mathrm{~d}))$ show the basic possibilities for foot assignment:

(20) a

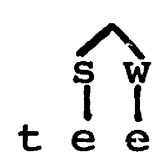

c.

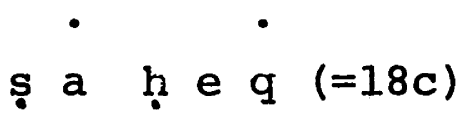

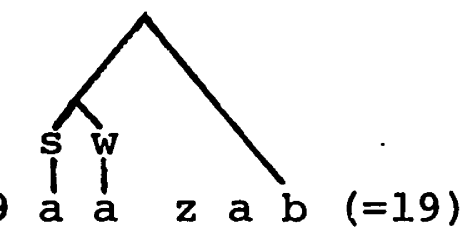

b.

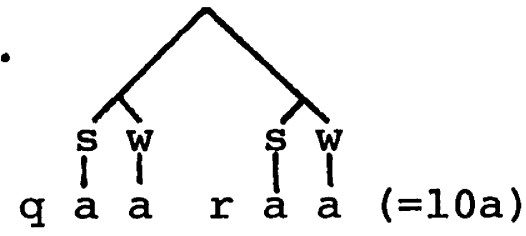

d.

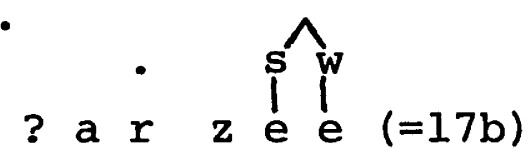

The foot -- the domain of the Rhythm Rule -- includes the penult and ultima of (20a) and (20b) but not of the other two examples, where stress cannot retract. In terms of rhyme geometry, the foot must begin with a branching node. It also cannot contain internal branching nodes; only the last two syillables of têgāzáb constitute a foot. The foot can erid in either a branching or nonbranching node. 
Therefore the foot insofar as it is the domain of application of rhythmic stress retxaction must make a distinction between CVC and CVV syllables. This is, of course, exactly the structural difference in Hebrew syllables hypothesized in Chapter 2. Moreover, the theory of syllabification offered there does further duty. Consider now the rhyme projections for forms with superheavy ultimas (2la) and penults $(21 \mathrm{~b})$ :

(2.1) a.<smiles>C1CC[SiH2]C1</smiles>

b.

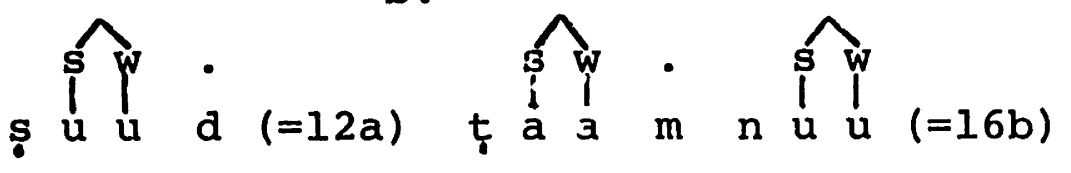

Since a foot can contain no internal branching nodes, the final superheavy syliable of (2la), with its two rhyme nodes, is a foot and therefore the domain of the Rhythm Rule. So the Rhythm Rule applies vacuously in this case, retaining the stress or a final superheavy syllable. But the entire word in (2lb) fulfills the foot definition -- it begins with a branching node and, althcurg it contains the internal rhyme node $\underline{m}$, tirat node does not branch. Therefore the domain of the Rhythm Rule is the entire word, and stress coxrectly shifts from the ultima to the superheavy penult. In both forms the assigiment of feet fundamentaily exploits the fact that, on a rhyme projection, a CVVC syllable is structurally equivalent to a CVV syllable followed by a 
light syllable. The treatment of these forms is absolutely uniform and requires no additional stipulations on the foot assignment rule.

Let me reiterate the basic structure of the Hebrew foot: it is a constituent made up of rhymes, where the first rhyme must branch, no internal rhymes branch, and the final rhyme branches or not at will. In terms of the properties developed in the introduction to this chapter, it is a foot of the unbounded type with both a head -- a node that must branch -- and a tail -- a node that may or may not branch freely. The head is on the left and the tail on the right, so the foot overall must be left-branching. (22a) describes the foot schematically, and (22b) is the formal rule of foot assignment.

(22) a.

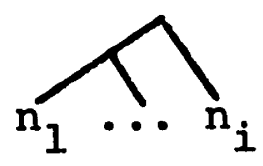

Conditions: $n_{1}$ branches.

$$
\mathrm{n}_{2}, \ldots, \mathrm{n}_{\mathrm{i}-1} \text { do } \text { not }_{\text {branch. }}
$$

$i$ is maximal.

b. Foot Assignment (on Rhyme Projection)

Assign a left-branching n-ary foot [thead, ttail] from right to left.

Insofar as we now know, rule (22) is ordered very close to the end of the derivation. It demonstrably follows several rules developed in Chapter 2 like Pretonic Lengthening 
and Tonic Lengthening in nouns, whence the facts of (14). About the only rule that follows (22) at this point is the possibly spurious Tonic lengthening in verbs, which accounts for the forms in (13). In all other respects, Foot Assignment, and consequently the Rhythm Rule, seem to be strictly sensitive to surface structure relationships.

The labeling of the structure generated by (22) is fairly unremarkable for the cases considered up until now, since in most examples a label s resides on the final syllable either as a result of Main Stress or of the Vowel Reduction rule of Chapter 2. The sole type where labeling is partly undefined is that of tâmnú,, with a superheavy ." penult. From prior application of Main Stress and subsequent Vowel Reduction, the label s appears on the rightmost node of the foot structure, as in (23):

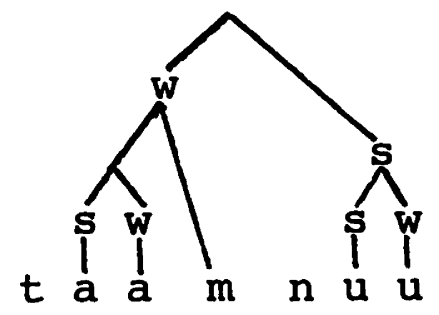

The only unspecified prominence relationship is the one that holds between the first two rhymes of the word. I will assume that in this case (5b) simply applies, making the first rhyme more prominent. This assumption about foot labeling will have significant consequences later in the 
treatment of secondary stress. In sum, a foot is labeled by (5b) only if no other labeling from the Main stress rule takes precedence.

Given this foot apparatus, which encodes various properties of the distribution of syllable types, we can offer a very simple formulation of the Rhythm Rule nasoóg ?āhốr. Stress is shifted leftward within the domain of a foot when the following syllable bears the stress. Leftward movement of the stress within a constituent involves not an actual transformational movement, but just a relabeling of the constituent from $w-s$ to $s-w$. The context of this movement is an immediately following main word stress, which is itself the main stress of the phrase that is the context for a sandhi rule. We can refer to this context with the abbreviation [DTE]:

(24) Rhythm Rule (on Rhyme Projection)

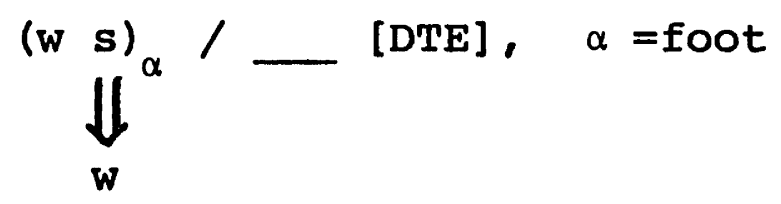

I ignore here the syntactic context, which is dealt with in McCarthy and Rotenberg (forthcoming). It will emerge below that (24) is not restricted to applying across word-juncture, so it must apply word-internally as well. The labeled parentheses specify the domain in which stress must retract, the foot. Like the indications of word-juncture 
in Chapter 2, this notation comes from Rotenberg (1978). In the following sections we will see that the foot domain or its complement functions in two other accent movement rules as well. The structural change affecting only a single label is sufficient because of the nature of the metrical notation -- paired nodes must have complementary labels, so the change of the right node to $\mathrm{w}$ implies the change of the left node to $s$.

Sample outputs of Foot Assignment and the Rhythm Rule for some examples we have seen appear in (25):

(25) a.

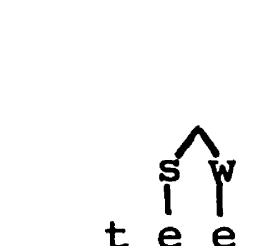

$t e r$

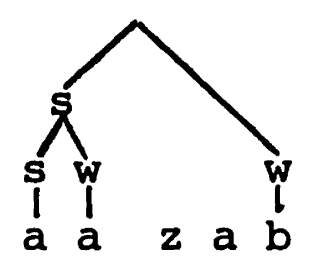

b.

c.

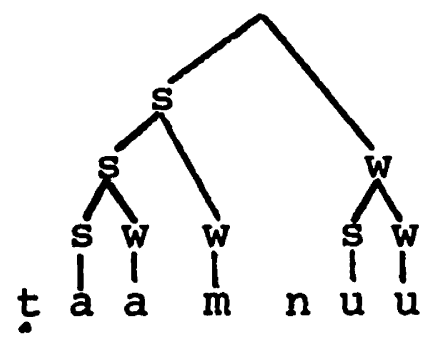

In each case the indicated constituent is a foot, and the s-w labeling of its immediate daughters is a result of the application of the Rhythm Rule in the indicated context.

The forms below in (26) seem to involve a somewhat richer notion of a foot than the one assumed by (22). To understand the significance of these examples, we must first 
digress briefly into the question of quantity in the Hebrew surface vowel system.

In addition to the usual two-way length distinction short-long, which I represent formally as gemination, Hebrew recognizes a third degree of quantity in vowels, the extra short vowels known as ḥățēpím (sg. ḥāțép'). There are four of them: $\underline{\partial}, \underline{a}, \underline{\underline{e}}$, and $\underline{\underline{o}} .{ }^{10}$ Like the reduced vowels in English, they turn out to be quite relevant to the accentual system.

If the penult contains a hatep-vowel, then the Rhythm Rule can retract stress over the penult and lodge it on a short vowel in the antepenult:

$$
\begin{aligned}
& \begin{array}{c}
\text { (26) a. [wว?áhărễ } \\
\text { and-âfter }
\end{array} \\
& \text { 'and afterwards' Gen 45,15 } \\
& \text { b. [bal-ná9ăsê ?éreş] } \\
& \text { ' (salvation) we have not brought about for } \\
& \text { the land' Is } 26,18
\end{aligned}
$$

Therefore, in na9ăsé the hatep-vowel a must be the middle vowel of a trisyllabic foot, since it is skipped over in stress retraction. But this form, because it has a short vowel in the first syllable, is obriously inconsistent with Foot Assignment as it was formulated in (22). 
But recall my earlier allusion to the fact that the three degrees of vowel length are not freely distributed in Hebrew. Consideration of their privileges of occurrence leads to a more abstract representation for Hebrew vowels to which the foot formation rule can apply successfully.

Perhaps the most interesting distributional regularity of the hatep-vowels $\underline{\partial}, \underline{a}, \underline{e}$, and $\underline{o}$ is that they cannot occur in a syllable that is adjacent to a syllable containing another hatep-vowel. In other words, you never find two syllables in a row in the same phonological word that both contain hatep-vowels. This means that there is an inherently alternating character to the surface distribution of reduced vowels in Hebrew, a situation that contrasts sharply with the possibility of successive reduced syllables in English. This immediately suggests that rules for the hatep-vowels ought to hold on some prosodic level where an alternation between reduced and unreduced syllables obtains. In terms of the metrical theory, this simple alternation is accomplished by a binary branch over the reduced syllable and some adjacent unreduced syllable. The relation between the two nodes of this binary branch is either w-s or $s-w$, where the weaker syllable is obviously the one that contains the hatep-vowel.

Not surprisingly, a treatment of this sort was anticipated in traditional grammars of Hebrew. Gesenius (1910) writes: "'́ $\underline{\text { } \partial w a ̀ ~ s t a n d s ~ u n d e r ~ a ~ c o n s o n a n t ~ w h i c h ~ i s ~ c l o s e l y ~}$ 
united, as a kind of grace-note, with the following syllable." The musical metaphor Gesenius invokes is entirely appropriate and consistent with the idea that the beat of a full syllable is split between it and a preceding reduced syllable, here by means of labeled binary structure.

One immediate consequence of this treatment is that it is no longer necessary to recognize a three-way vowel length distinction in Hebrew. There is atwo-way distinction between geminate and nongeminate vowels, and the third value is a result of a prosodic relationship between a short vowel and an adjacent syllable.

Suppose we refer to the structure in which the hatepvowel prosodic relationship is defined as $\rho$. Then the general schemata for representing these vowels prosodically are the structures in (27):

(27) Hatep-vowel Representation (on Rhyme Projection)

a.

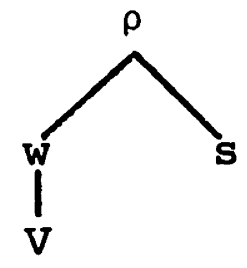

b.

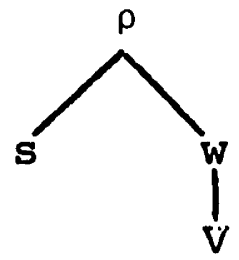

In each case the $v$, the weak node, is interpreted phonetically as a vowel of extra-short quantity.

One case of assignment of the $\rho$-structure, specifically (27a), is the rule of Vowel Reduction discussed in Chapter 2. Two other circumstances also invoke assignment of the 
$\rho$-structure under somewhat different phonological circumstances. In these cases there is explicit evidence for the phonetic character of the hatep-vowel showing that, in general, it shares the quality of its sister vowel in the $\rho$-structure. These facts therefore provide independent support for (27).

Hatep-vowels in initial syllables are either a result of Vowel Reduction or, in some cases discussed by Prince (1975), a general process of epenthesis in initial clusters. Some forms with schewa in this position are attested in Greek transcription in the Septuagint and Origen's Hexapla. Although there is no total consistency on this, with some degree of regularity the pronunciation of schewa is assimilated to the pronunciation of the vowel in the following syllable. So, for Hebrew šalōmó and sabā?ốt we have septuagintal writings $\Sigma 0 \lambda \circ \mu \omega \nu$ and $\Sigma \alpha \beta \alpha \omega \theta$ (Gesenius 1910).11 Since the $\rho$-structure must include the rhymes of the first two syllables of these forms, vowel quality within the p-structure harmonizes with the quality of the strong member. A formal mechanism for this harmony is the notion of percolation (Vergnaud 1976) within $\rho$, discussed briefly in section 4 of this chapter.

There are other cases where it seems appropriate to look to the left of the reduced syllable for its prosodic sister, as in the structure of (27b). Hebrew generally eschews syllable-final laryngeal or pharyngeal glides, known 
as gutturals, except under limited circumstances. This problem is avoided by inserting a hatep-vowel after the offending guttural, creating a new syllable. The inserted hatep-vowel mimics (both in the traditional pronunciation and in the orthography) the quality of the vowel in the preceding syllable:

(28) a. ya9ămốd 'he will stand'

b. hegĕmî́d 'he caused to stand'

c. hogormád 'he was caused to stand'

A rule responsible for this is formulated in chapter 2. If we suppose that the vowel quality is a reflex of the prosodic structure, then we must conclude that words of this type have a branching node, labeled $s-w$, over the rhymes of the first two syllables.

It follows, then, that the rule that inserts the hatep-vowel into nagăsé creates a binary branching node, labeled $s-w$, over the rhymes of the first two syllables. This structure is then part of the projection of rhymes, so the rhyme projection for this word will look like (29):

(29)

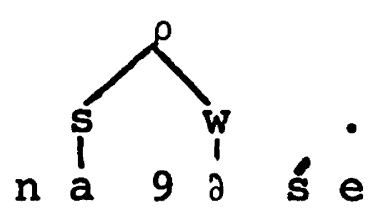

It is apparent that this structure fulfills the conditions for assignment of a foot $\left(n_{1}\right.$ branches). Therefore words of 
this type do contain feet that are available as the domain of the Rhythm Rule. The independently-motivated $\rho$-structure explains why the Rhythm Rule is applicable in the examples in $(26) .12$

3.4 Imperfect Consecutive Stress Retraction

Related to the imperfective verb form is the morphological category imperfect waw-consecutive, which involves prefixation of the conjunction wa plus initial gemination to the jussive form of the verb. The result is a form used in narrative consecution with perfective aspect: jussive yagdél 'let him magnify', consecutive wayyagdél 'and he magnified'. In a variety of formal types, the imperfect consecutive also displays retraction of the stress onto the penult:

Jussive

yāqốm 'let him arise' yơ̌éb 'let him settie' yāsốb 'let him surround' yabārếk 'let'him bless' yillâhệ́m ' let him fight'
Consecutive

wayyấqom

wayyóšeb wayyásiob waybấrek Gen 1,22 wayyil1ăhem $\mathrm{Nu} \mathrm{21,1}$

In each case the vowel of the final syllable is underlyingly short. It is lengthened in the jussive by the regular process of Tonic Lengthening in verbs discussed above and in 
Chapter 2. Since stress shift precedes Tonic Lengthening, the consecutive forms retain the underlying short: vowels in the final syllables.

It is clear from the forms in (30) that stress will retract onto a long vowel in the penult. Many examples show, however, that stress in the imperfect consecutive will not retract onto a short vowel in either a closed or open penult: wayyabdél 'and he divided' Gen 1,4\&7; wayyizrág 'and he sowed' Gen 26,12; wattakahéš 'and she denied' Gen 18,15. This is obviously reminiscent of what goes on with the Rhythm Rule, so we might want to look for other shared characteristics. In fact, some properties of superheavy syllables carry over to the consecutive also.

In three cases there is reasonably clear evidence that a superheavy final syllable is resisting stress retraction in the imperfect consecutive. First, the relatively archaic inflection in final $\underline{n}$ retains stress on an underlying superheavy final syllable even when the penult contains a

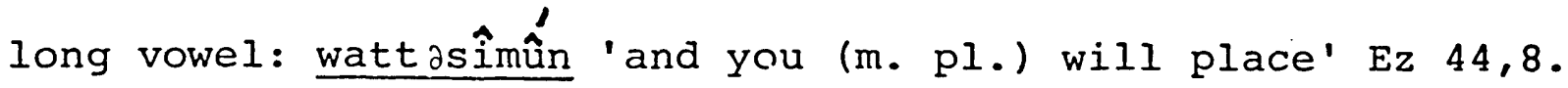
Second, in some verb types the imperfect consecutive first person singular has an underlying long vowel in the first syllable, and this is sufficient to prevent accent retraction: wāeāŝî́ 'and I returned' Neh 2,20; wā?ăqû́m 'and I arose' Ez $3,23.13$ In both these cases the failure of stress retraction in the imperfect consecutive correlates with the fact that the stressed final syllable is underlyingly superheavy. 
Finally, recall the rule of Pausal Lengthening developed in Chapter 2. In genera], this rule lengthens the vowel under main stress in pause -- that is, before a major intonational break. Apparently this rule rrecedes stress shift in the imperfect consecutive, since we find pausal forms with stressed long vowels in the final syllable: wayyăş⿰纟́m 'and he fasted' 1kgs 21,27; wattāmốg 'and she flowed down' Am 9,5. The vowel of the final syllable has already been lengthened in pause at the time when we attempt stress retraction. Retraction is then prevented by the superheavy final syllable. Certain pausal forms that idiosyncratically have a short vorel in the final syllable predictably do allow stress retraction in the imperfect consecutive: wayyốkal 'and he ate' 1Sam 30,11; poetic wayyốmar 'and he said' Job 3,2; 4,1. 'There is, however, much unexplained variation on this last point.

In sum, we have three kinds of evidence that the imperfect consecutive cannot shift stress off of final superheavy syllables. We have already seen that it must shift stress onto a long vowel. These are precisely the conditions ubserved with the Rhythm Rule that are consequences of its taking the foot as its domain. I -onclude that the foot is the domain of imperfect consecutive stress retraction as well. Let's formalize thess observations: 
(31) Imperfect Consecutive Stress Retraction ${ }^{14}$

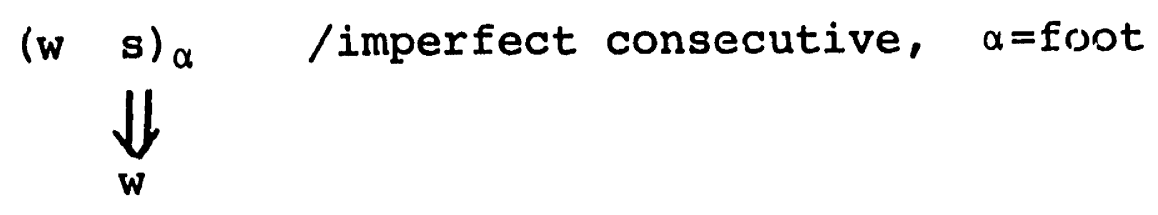

The domain of this rule -- the foot constituent -- and its structural change -- relabeling the foot as s-w -- are identical to those of the Rhythm kule. The domain foot here captures the fact that Imperfect Consecutive Stress Retraction shares a variety of quite arbitrary formal prcperties with the Rhythm Rule. Any account that did not recognize the foot would necessarily fail to capture these generalizations.

of course, the alternative of collapsing the two stress retraction rules presents itself. A clear theoretical defect in this proposal is the fact that Imperfect Consecutive Stress Retraction is patently morphological whereas the Rhythm Rule is phonological and partly syntactic. Empirically, it is not difficult to show that the morphological stress retraction rule is unsurprisingly ordered earlier thar, the sandhi stress retraction.

There exist clear minimal pairs where Consecutive Stress Retraction cannot apply and tre Rhythm Rule can in. the same form: 
(32) a. wayyōmra' 'and they said' Gen 11,3

b. [wayyớmrâ 10́]

and-they-said to-him

'and they said to him' Gen 19,5 ; Num 22,16

(33) a. wayyîtab 'and he was good' Gen 41,37

b. [yîtâb $\frac{\text { lák }]}{\text { he-is-good to-you }}$

'he is good to you (m. sg.)' Gen 40,14

In both cases the explanation for the distribution of accent shift lies in the relative ordering of the rules.

The verb in (32) is derived from a near underlying form /wayyooméruu/ by the rule of Vowel Reduction developed in Chapter 2. The result is an end-stressed form with a superheavy penult. Obviously Vowel Reduction must precede the Rhythm Rule, since it is not until the form has final stress that a stress clash exists, as in (32b). Now suppose that Consecutive Stress Retraction precedes Vowel Reduction. Penult stressed /way̌rooméruu/ has a branching node over the last two syllables, but it does not contain a foot. Therefore Consecutive Stress Retraction will be inapplicable, yielding (32).

Similar logic holds for the forms in (33). The long vowel of the penult is derived by a regular process taking iy to ii. If we suppose that this rule of vocalization applies after Consecutive Stress Retraction but before the Rhythm Rule, then at the time that the first rule applies 
the penult will still be a closed syllable. That means that no foot is present, so Consecutive Stress Retraction is inapplicable. With the subsequent application of the vocalization rule, a foot is formed, so the Rhythm Rule applies successfully in (33b).

There is, of course, a minor paradox inherent in these considerations. If we can talk about feet that are formed after the application of Consecutive Stress Retraction, how is it that that rule refers to the constituent foot at all? Clearly the answer is that Foot Assignment as formulated in (22) is not strictly speaking a rule, something that applies once in a linearly orcured derivation. Rather it is a well-formedness condition on representations on a Rhyme Projection. On that projection it defines a unit called foot. We can think of it as reapplying continually. In particular, it applies both before and after Consecutive Stress Retraction.

\subsection{Perfect Consecutive Stress Shift}

Hebrew has one other accent movement rule with somewhat different properties from those already discussed. Complementing the imperfect waw-consecutive of the preceding section is the category perfect waw-consecutive. This prefixes the conjunction wa to a perfective verb form giving it imperfective meaning. Under some conditions this category is also marked by a rightward movement of the accent. 
Some representative examples are in (34), where an asterisk marks the formerly stressed syllable:
a. walåqậhtá 'and you (m. sg.) will take' Ex 29,5
b. wohālakktî́ ' and I will go' Tu I,3
c. whâaddú 'and they will be fierce' Hab 1,8
d. waräbbấ 'and she will multiply' Is 6,12

This rightward accent movement is specific to this morphological category, so ordinary conjoined perfective verbs without imperfective meaning retain the usual accent: wa?ākáltîi 'and I ate' Lev 10,19. As is apparent from the examples in (34), this rule applies throughout the inflected verb forms, though vacuously in the case of forms that already have final stress. The sole systematic exception to this, for which there is no known phonological explanation, is the first person plural, which always retains penult stress: wayāsábnû 'and we will dwell' Gen 34,16. The basic generalization, then, is that the category perfect consecutive moves stress onto the final syllable as part of its morphology. This movement is regularly suppressed in one inflection, the first person plural. Even then, though, there remains a large set of forms which fail to have the expected rightward accent movement. The forms in (35) are characteristic of these types, and they are heuristically grouped according to binyan (see Chapter 4) or root type: 
(35) a. Hiphil

wahišmídā 'and she will destroy'

wahiqdî́šû 'and they will sanctify' Is 29,13

b. III-?

waqārấtî̀ 'and I will read' Ez 58,21

wogārátä 'and you (m. sg.) will read' Jer 7,27

wasannêtî 'and I shall hate' Ecc 2,17\&18

wàyāétā 'and you (m. sg.) will fear'

Lev $19,14 \& 32$

c. III-Y

wə şiwwî́t $\hat{i}$ 'anà I will commana' Lev 25,21

wo 9āśítā 'and you (m. sg.) will do' Ex 26,4

d. II-w, $y$

wวšábā 'and she will return' Is 6,13

wo śăbû 'and they will return' Ex 13,17

The difference between (34) and (35) is obvious from the surface forms, although we will see that the situation is slightly more complicated in underlying representation. In (34) the syllable that loses the stress -- marked with an asterisk -- is a closed syllable containing a short vowel, while in (35) the penult syllable which unexpectedly retains the stress is an open syllable containing a long vowel. In brief, long vowels are not susceptible to having stress moved off of them in the perfect waw-consecutive. 
An obvious quection at this point is how short vowels in open syllables behave with respect to this stress movement; do they pattern with CVC or CVV syllables? Unfortunately this question cannot be answered for reasons that are independent of the formulation of perfect consecutive stress shift. From the analysis in Chapter 2 we know that an intermediate representation of a perfective verb like /kaatábuu/, with stress on a CV penult, is subject to reduction of the short vowel in an open syllable with concomitant movement of the stress to the ultima. If the perfect consecutive rule follows this reduction, then we will already have a final-stressed foim when the perfect consecutive rule applies. If the perfect consecutive rule precedes this reducicion, then reduction will simply apply to the intermediate representation/kaatábuu/. In either case the same surface form results: wakảtbú 'and they will write'. In this particular case, the data underdetermine the analysis.

So we return to the same generalization: the perfect consecutive shifts stress to the right off of a CVC syllable but not off of a CVV syllable. It therefore shares an obvious property with all the other Hebrew strass phenomena we've seen -- CVC and CVV syllables have different accentual properties. So the perfect consecutive provides prima facie support for the stractural difference 
I've claimed exists between these two types of syllables in Hebrew. What remains is to formalize this accent movement rule.

We already know that assignment of penult main stress creates a branching node over the rhymes of the last two syllables of the word. This branching node is ordinarily labeled $s-w$, as in the two examples in (36):

(36) a.

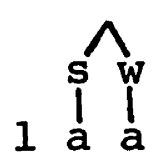

(1āqáhạtā) b.

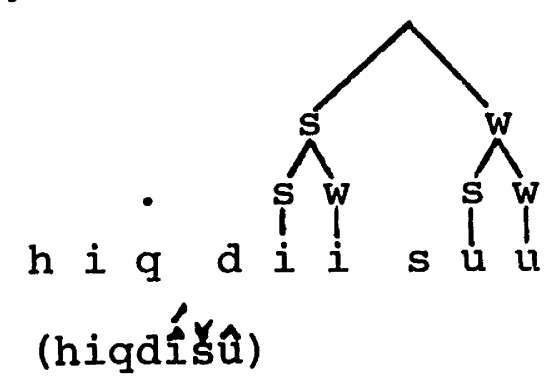

But in the perfect consecutive the superordinate branching node of the first of these is labeled w-s, as in (34a), while it remains unchanged in the second one, as in (35b). The fact that this relabeling is possible only when the penult is not a CVV syllable has its structural correlate in the nonbranching rhyme of the penult in (36a).

If we turn now to the structure of the Hebrew foot already developed, we can see that this behavior has a reflex there. In the form $(36 \mathrm{~b})$, the branching node over the final two syllables constitutes a foot, since it meets the 
requirements in (22) of a tree that begins with a branching node but contains no internal branching nodes. This is not the case with the final two syllables of (36a). Therefore the most abstract expression of the condition on perfect consecutive accent shift is as follows: the accent cannot move to the right off of a foot initial syllable. Equivalently, the accent can shift only if the domain over which it moves is explicitly not a foot, as in the following rule:

(37) Perfect Consecutive Shift

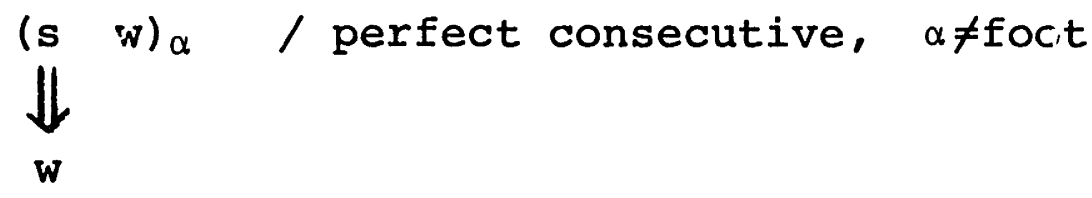

As in the case of the other accent movement rules, it suffices to relabel just one node of the relevant constituent, since the requirement that complementary labels be paired will automatically relabel the other node. Rule (37) is obviously subject to some morphological conditions -- in particular, it is restricted to perfect consecutives that are not first person plural -- but the formulation above encodes all the relevant prosodic information.

So the accent movement in perfect consecutives provides still another case where reference to the foot in an accentual rule of Hebs ew avoids the repeated stipulation of various syllabic or segmental contexts that are closely paralleled in other accentual rules. It is instructive 
that (37) differs from either the Rhythm Rule or Imperfect Consecutive Retraction in that it takes the foot not as its domain but its antidomain. That is, it applies only in the complement of the environment of the other two rules.

There are several interesting complications that can be elucidated only by placing Perfect Consecutive Shift within the context of the segmental phonological rules developed in Chapter 2. First, it is well known that (37) must follow the rule of Pretonic Lengthening. Thus, in /laqahta/ the vowel of the pretonic syllable must be geminated before the accent is shifted onto the final syllable. On the other hand, Perfect Consecutive Shift must precede Tonic Lengthening in verbs, which is a relatively late rule in any case. This accounts for the contrast between yăkốltîi 'I was able' Ju 8,3 and wayăkoltáa 'and you will be able' Ex 18,23. In the second form the stress is shifted onto the ultima before lengthening of the stressed vowel in the penult. No forms are attested (in the so-called Qal passive) that would test the ordering of this rule relative to Pretonic Gemination. And $_{\text {we }}$ have already seen that it is not possible to determine the ordering of Perfect Consecutive Shift with respect to Vowel Reduction in forms

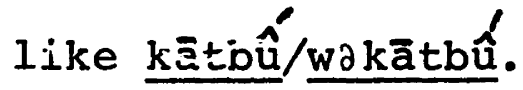

There are, huwever, several fairly' early rules that interact interestingly with rule (37). Since many of these rules involve a number of still unexplained vowe]. 
alternations under partly morphological conditions, I cannot offer a full account of them here. But I will endeavour to show that the attested possibilities are consistent with the analysis of the perfect consecutive presented here.

First, the verbs whose third root consonant is? or $\mathbb{Y}$ in (35b) and (35c) show some interesting variation in vocalism. When the vowel of the penult is $\underline{\underline{a}}$ or $\bar{i}$, as in $(35 \mathrm{~b})$ and $(35 \mathrm{c})$, then the accent does not shift. But when the penult vowel is surface $\underline{\bar{e}}$, then we usually find accent shift in the perfect consecutive:

$$
\begin{aligned}
& \text { a. III-? } \\
& \text { ûmillềt } \hat{i} \text { ' and I will fill' IKgs } 1,14 \\
& \text { wahôşêté̂ 'and you (m. sg.) will bring } \\
& \text { forth' Num 20,8 } \\
& \text { b. III-Y } \\
& \text { wagillettî́ 'and I shall roll along' Jer } 33,6 \\
& \text { woha9ălềtá 'and you (m. sg.) will send } \\
& \text { up' Ex } 40,4
\end{aligned}
$$

We have to ask now what the difference is between these forms in (38) which allow stress shift and the corresponding furms in (35b) and (35c) which dc not. It is generally accepted -- see Prince (1975) for further discussion -- that the III-? verbs of (35b) derive their long penult vowel by 
a process of compensatory lengthening from underlying /a?/ and /e?/ when the $?$ is deleted in syllable-final position. By the analysis adopted here, this compensatory lengthening must precede the application of Perfect Consecutive Shift, since the change of a closed syllable to a long vowel will bleed accent shift.

Whereas the III-? forms in (35b) are members of the underived or Qal binyan, those in (38a) and others belong to the derived binyanim. Therefore the two sets of forms are morphologically distinct. Furthermore those in (38b) cannot result directly from deletion of $\underline{?}$ with compensatory lengthening, since their expected underlying /a?/ should result in $\overline{\underline{a}}$ rather than $\underline{\underline{e}}$. The usual historical interpretation of these forms is that they result from analogy with III-y roots. In generative terms, we can say that III-? is replaced by III- $Y$ in the derived binyanim by an early readjustment rule.

So now the problem reduces to dealing with the behavior of verbs from III-y roots. Generally in the Qal and to some extent in other binyanim these roots have $\bar{i}$ penults in the crucial inflected forms, as in (35c). To my knowledge there is no direct phonolngical source for this vowel, so it behaves as an underlying long vowel in resisting stress shift. In some cases in the derived binyanim, of which the forms in (38b) are examples, underlyinq /ay/ changes by a coalescence process into $\underline{\underline{E}}$. This phenomenon is also discussed by Prince (1975). If we suppose that this coalescence follows 
the application of Perfect Consecutive Shift, then these forms will still have closed penults at the time that that rule applies. Therefore the examples in $(38 \mathrm{~b})$, and by extension those in (38a), will be correctly subject to accent shift.

In view of the transparently morphological and somewhat irregular character of these segmental alternations, it is not surprising that significant variation in the attested forms exists. Generally this variation is paralleled by the predicted variation in the accent, though some deviations appear as well. The claim here is not to an exhaustive analysis of all attested possibilities, but, as always, to the best account of what seem to be the most regular patterns.

Second, the verbs whose medial root consonant was $\underline{w}$ or $y$ show a typical alternation between a long and a short vowel in the penult in the inflected forms: gấmā 'she arose'/ gámtā 'you (m. sg.) arose'. This alternation must also precede the application of Perfect Consecutive Shift. Thus the difference between the unshifted forms of (35d) and the

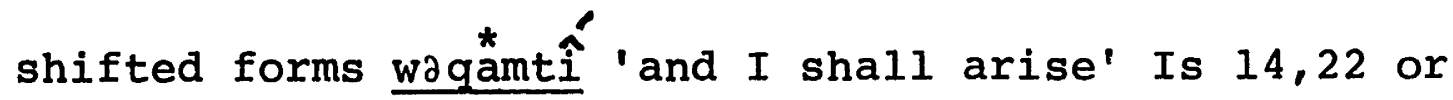
wagämtâa 'and you shall arise' Dt 17,8. The existence of some endstressed forms like wanăsû́ 'and they will flee' Lev 26,36 does not indicate unpredicted stress shift off of a long vowel, but rather a sporadic variation in the stressing of third plural forms, whether consecutive or not. This 
is clear from the many cases like nāmû́ 'they slept' Nah 3,18 ; Ps 76,6 and ná9û́ ' they wandered' Lam 4,14; Is 29,9 . Finally, the rule of Pausal Lengthening, discussed above in connection with the imperfect consecutive, must precede Perfect Consecutive Shift. This explains the failure of accent shift in pausal forms like wahāákt $\hat{i}$ ' and I shall go' Ju 4,8 and wa ?âmấrtā 'and you will say' Is 14,4 . Pausal Lengthening creates a superheavy penult in these forms, which yields a partial metrical structure like that in (39):

(39)

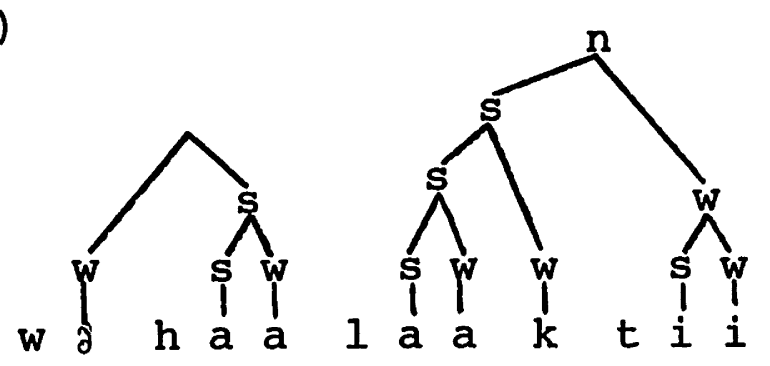

Since the node $\mathrm{n}$ fulfills the definition of a foot given in (22), this form is not subject to Perfect Consecutive Shift. So the interaction of these two rules correctly predicts the suppression of Perfect Consecutive Shift in pausal forms even when it is applicable in the context forms. 15

\subsection{Secondary Stress}

The analyses in the three preceding sections showed that different stress movement rules in Hebrew must make reference to a unit foot, defined as in (22). Furthermore, 
this unit was shown to be assigned repeatedly in the course of the derivation, so that (22) functions as a sort of wellformedness condition on structures in the Rhyme Projection, defining which of them constitutes a foot. This last section deals with the distribution of the symbol methegh, a notation for secondary stress.

The symbol methegh is generally supposed to indicate a secondary stress. In some other cases, methegh is thought by the traditional grammarians to have a different character, marking a vowel of doubtful length or some peculiarity in the vocalization. This has led to quite elaborate taxonomies of this one orthographic device according to its distribution. Here I will examine in detail the facts of light methegh as described by Baer $(1867,1868)$. Light methegh offers formal support for the secondary stress interpretation; it is often replaced by a conjunctive accent symbol, the mark of main word stress within a close juncture context (McCarthy and Rotenberg, forthcoming). Other evidence for this interpretation is its alternating character, described below, and its failure to appear on reduced vowels. On the other hand, heavy methegh appears on reduced vowels and elsewhere, and is almost never replaced by a conjunctive accent symbol. According to the medieval luminary Jekuthiel ha-Nakdan, heavy methegh is so called because "the hearts of many sages are heavy for not having understood it" 
(Dothan 1971). Light methegh, then, is the easy one, and it will be the object of the treatment here.

Light methegh has three general privileges of occurrence. First, it can fall on any long vowel separated by no less than one syllable and no more than one long vowel from the main stress or another light methegh:

(40) a. hà̀?ādấm 'the man' Gen 1,27
b. hà̀?iššá 'the woman' Gen 3,3

c. mè̀?abrăhăm 'from Abraham' Gen 18,17

d. mèhaššițî́m 'from (the valley of) the acacias'

e. mè̀nattahtônốt 'from the lower' Ez 42,5 3,1

iterative assignment of light methegh f. hà̀?aśrî̀?ēlí 'the Asrielite' Num 26,31 g. ûmè̀hattî̀ônốt 'and from the middle' Ez 42,5

Roughly, we can say there is a right-to-left iterative assignment of methegh to long vowels starting at the main stress. Usually a single syllable is skipped, but more must be skipped if the search for a long vowel requires it. ${ }^{16}$ If you'll recall from the treatment of the Rhythm Rule, the hyphenation process in Hebrew -- a kind of procliticization -- makes two or more words into an accentual unity. In these collocations we find methegh distributed just as in single words in (40): 
(41) a. ?àmar-lî́ 'he said to me' Gen 20,5

b. mē?à-šănấ 'a hundred years' Gen 17,17

c. mē?î̀m-pargố 'from with Pharaoh' Ex 11,8

d. barî̀t-?abrấm 'the covenant of Abram' Gen 14,13

e. 9ắsar-yốm 'ten days' Num 9,3

In view of the similarity between methegh's search for a long vowel and the nature of stress retraction described above, we might expect to find other parallels. First, methegh falls on any superheavy syllable, even when the immediately following syllable is stressed. Examples of this are (4lc) and (4ld), as well as (42):

(42) a. ?à̀klấ 'she ate' Num 21,29

b. bàtttế 'houses-of'

c. yì̌nû́ 'they will sleep' Prov 4,16

d. Sàt-lî́ 'he put to me' Gen 4,25

e. gà̀r-šấm 'he sojourned there' Gen 36,27

f. Sî̀m-ná 'put, please' Gen 47,29

Second, methegh also falls on a short open syllable which is immediately followed by a syllable containing a hatephvowel: 
(43) a. nà9ăśé 'we will do' Gen 1,26

b. nè?ĕház 'we will sieze' Gen 22,13

c. ?òhǒló 'his tent' Gen 9,21

To summarize these observations, in all three cases methegh falls on a long vowel or, in (43), the structurally equivalent $p$-representation for hateph-vowels. That is, methegh appears on a branching node in the rhyme projection. This is obviously reminiscent of the definition of a Hebrew foot in (22) -- a structure beginning with a branching node on the rhyme projection. To see how exactly this relationship is formalized, let us consider the treatment of some of the attested examples of methegh in (40).

Take first the word mè̀hašsitțîn. Its rhyme projection appears in (44):

$(44)$

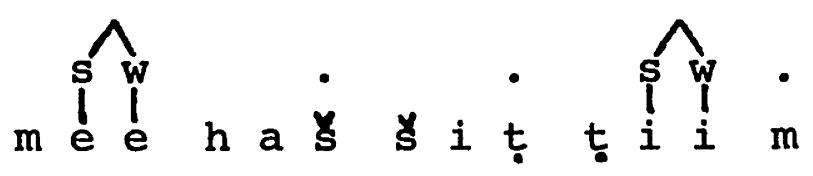

Since Foot Assignment applies from right to left, the superm heavy syllable fiim is first assigned to a foot, and then the remainder of the word -- beginning with a branching node and containing no internal branching nodes -- is assigned to another foot. The labeling of the foot tiim is given by the Main Stress Rule as described at the beginning of this section. Suppose now that the other foot, not subject to 
the Main Stress Rule because it is not word-final, is labeled according to $(5 \mathrm{~b})$ : right is strong if and only if it branches. The result is (45):

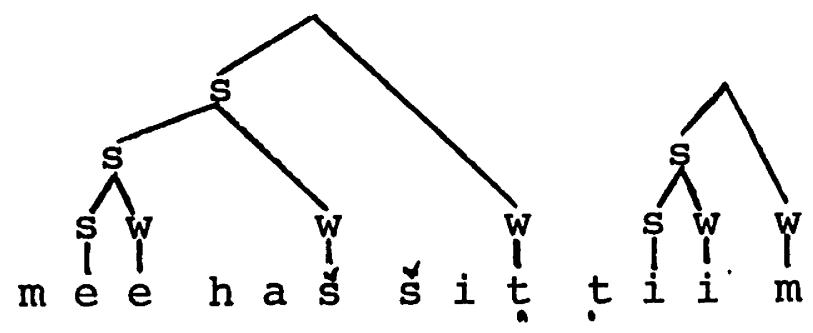

Therefore methegh on the syllable mee simply falls on the most prominent syllable in the foot. The addition of wordlevel structure, also labeled by (5b), completes the picture, making the stress on tiim relatively greater than the stress on mee.

It follows, then, that the distribution of secondary stress generally follows the lines of Foot Assignment, when feet are labeled according to the Main Stress Rule, or, failing that, rule (5b). This same mechanism holds for quite different éxamples as well.

Consider for instance bârî̀ônă ' in the first. time' Gen 13,4. Foot Assignment and appropriate labeling yield the following structure:

(46)

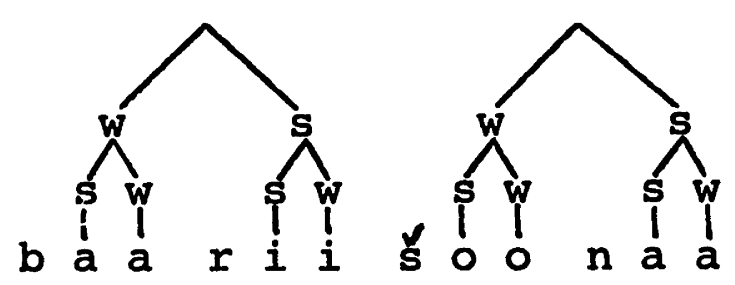


Note that, in the first foot, the second syllable is relatively more prominent and consequently bears secondary stress. Since the right branch of this foot is a branching rhyme, rule (5b) assigns it the label s. In this particular respect Hebrew aiffers from the Arabic dialects described earlier in this chapter. It is stipulated in the grammar of Arabic that rhymes constitute an opaque domain to the labeling rule. Therefore labeling is insensitive to whether particular rhymes branch. Hebrew lacks this extra stipulation, so the labeling rule, as in (46), correctly observes the branching character of the rhyme.

In somewhat more complicated cases there are two relatively more prominent syllables in a single foot -- that is, two syllables that bear more stress than other syllables in the same foot. This is the case, for example, with the first foot of hà??asrî́? êlî́ $(=40 \mathrm{f})$, as represented in (47):

(47)

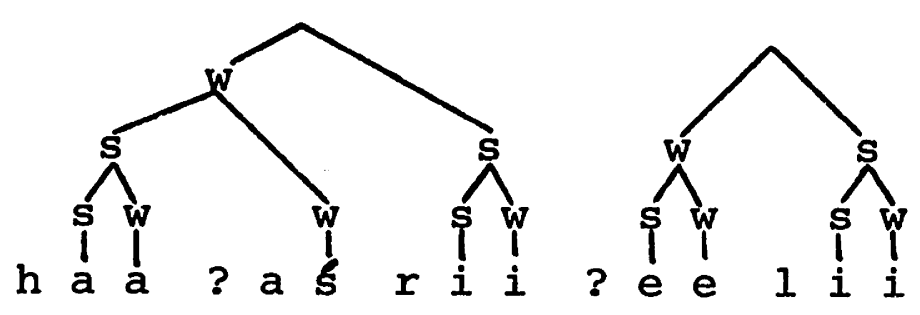

The first foot contains two secondary stresses, on haa and rii, since each of these is relatively more prominent than the medial syllable ?aś. Incidentally, although I know of no explicit evidence for this, the structure in (47) also

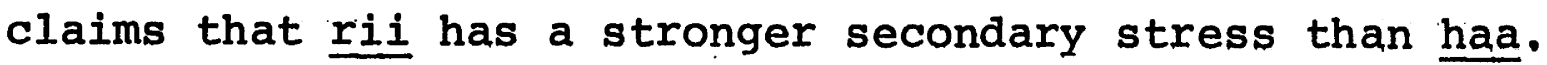


Exactly parallel considerations account for the placement of methegh on the initial syllables of the forms in (42) and (43), whose feet appear as:

(48) a. b.

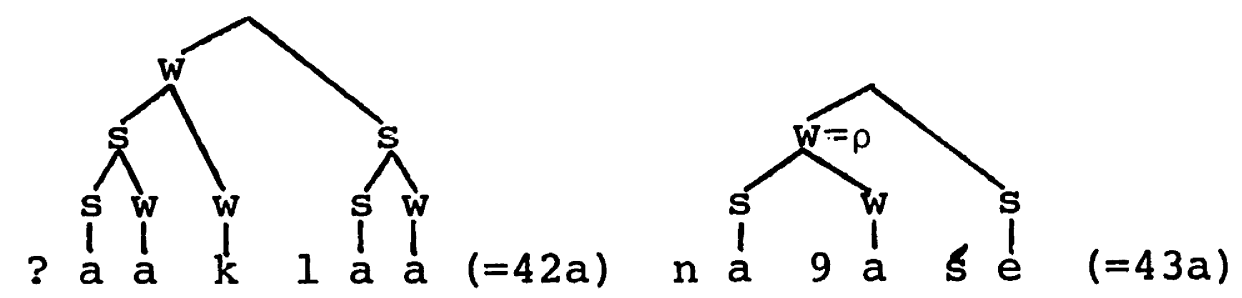

In the first case we have a superheavy penult; in the second, a hateph-vowel representation with the -structure of (27b). In both feet the first rhyme unit is relatively more prominent than the second one, though less prominent than the main stress on the second syllable. It therefore kears secondary stress, notated by methegh. It is noteworthy that when the Rhythm Rule applies in these cases, relabeling the top two nodes as $s-w$, methegh disappears on the first syllable and is replaced by a conjunctive accent symbol, since this syllable now bears the main word stress. The last major point to consider in the distribution of secondary stress involves the word-internal application of the Rhythm Rule. As this rule is formulated in (24), it does not specifically say that the trigger [DTE] and the target foot must be in different words within some syntactic sandhi context. Rather, it can apply anywhere within that 
context or anywhere within a single word. For a number of examples, this property of the Rhythm Rule is of some significance. Consider the trees for the remaining examples of (40), where full metrical structure, including foot and word-level structure is indicated:

(49) a.

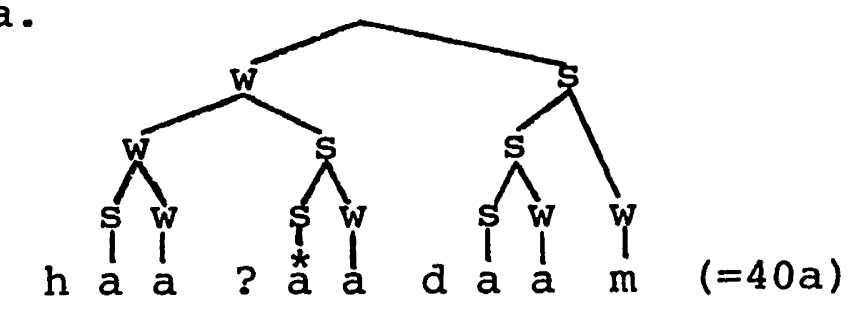

b.
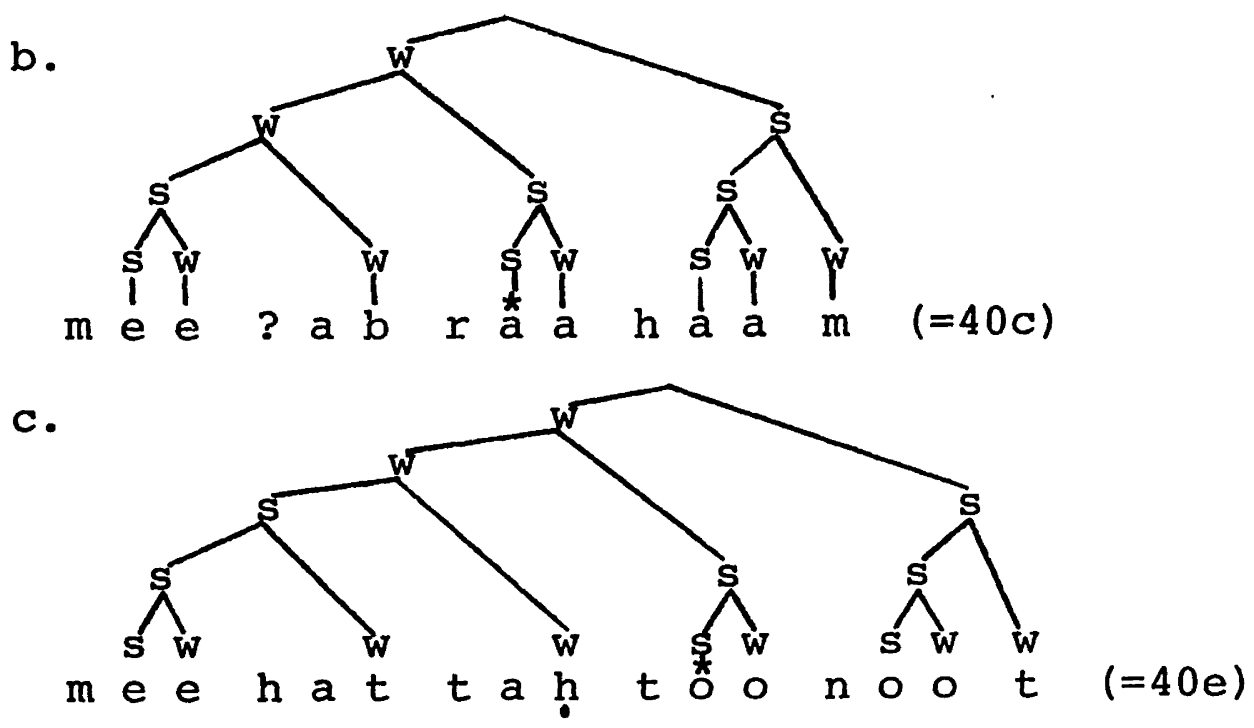

The indicated labelings, except for main stress in the final foot, are derived directly by application of the principle that the right node is strong if and only if it branches (5b). These labelings correctly show a secondary stress on the initial syllables of $(49 b)$ and $(49 c)$, but they fail to show initial secondary stress in (49a). They also incorrectly give secondary stress on the final syllable of the initial foot (indicated by *) in each form. 
The solution to this problem lies in the observation that each of these forms has a stress clash between the starred syllable and the following superheavy final syllable. Since the Rhythm Rule is applicable to word-internal contexts as well as sandhi contexts, the initial foot is subject to rhythmic relabeling of the top two nodes yielding s-w. The starred syllable no longer bears secondary stress, and moreover the initial syllable in (49a) gains the secondary stress. Therefore surface stress assignment in these forms requires no further stipulations; it follows directly from independently motivated aspects of Hebrew prosody.

In sum, then, methegh has the following distribution. It appears on any syllable whose rhyme is relatively more prominent in a foot. Notice the word relatively; as we saw, some feet can contain two stresses, both on syllables that are relatively more prominent than others in the same foot. Strings of syllables that contain no feet -- in particular, strings of syllables with short vowels -- will not bear methegh. The foot structures and prominence relationships that determine the assignment of methegh are those holding in, so far as I know, absolute surface representation, after the application of the Rhythm Rule.

One: problem in secondary stress assignment remains. Contrary to the strict interpretation of methegh as marking a relatively more prominent syllable in a foot, the initial 
syllable of words like tè̀gāzáb 'you are left' and pồtîpár 'Potiphar' has methegh. Words of this type induce the following foot structure:

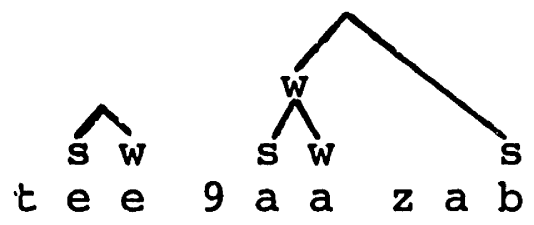

By the right-to-left application of Foot Assignment, a foot is created over the rhymes of the ?ast two syllables. This is consistent with the fact that the Rhythm Rule or the Imperfect Consecutive Rule retract stress onto the penult in forms like these. The initial syllable bears methegh even though it is not relatively more prominent within a foot; in fact, it is not obviously contained in a foot at all. We might suppose that in this case we have a degenerate foot, a foot containing nothing except the branching node required by Foot Assignment.

The conditions under which a degenerate foot bears methegh are somewhat problematic. If the main stress of a form like (50) is retracted by either the Rhythm Rule or Imperfect Consecutive Retraction, then the initial degenerate foot no longer has methegh: têgấzab. Apparently a degenerate foot receives methegh if and only if the immediately following syllable is stressless on the surface. By the same token the initial syllable of sādấm 'man', also a degenerate foot, will 
never have methegh. I am uncertain whether this is a matter of orthographic practice or demands a deeper understanding of the application of the Rhythm Rule to word-internal contexts. These facts leave us at the limit to which the analysis presented here can bring us.

\subsection{Summary}

I have offered a fairly thorough treatment of the facts of Hebrew accent in the context of a larger metrical theory of syllabification. The most significant points of the analysis are the basic structural distinction between CVC and CVV syllables, the double rhyme of CVVC syllables, and the function of the foot constituent in three accent movement rules and the distribution of the secondary stress symbol methegh.

What follows is a list of all rules of Hebrew phonology discussed explicitly in this chapter and in chapter 2. Relative ordering of the rules is indicated by position on the list, with the earliest rules first. Where parallel branches exist, these imply not simultaneous application but cases where no ordering argument has been presented, usually through lack of data. After the name of each rule a number 2 or 3 indicates the chapter it appears in, followed by the number of the display if it was actually formulated. Unformulated rules are given rough designations, along with a citation of where they are discussed in the text. Somewhat more detailed orderings of the segmental rules can be constructed -- see Prince (1975). 
Main Stress Rule (3-4)

Pausal Lengthening $(2,54)$ Pretonic Lengthening (2-4)

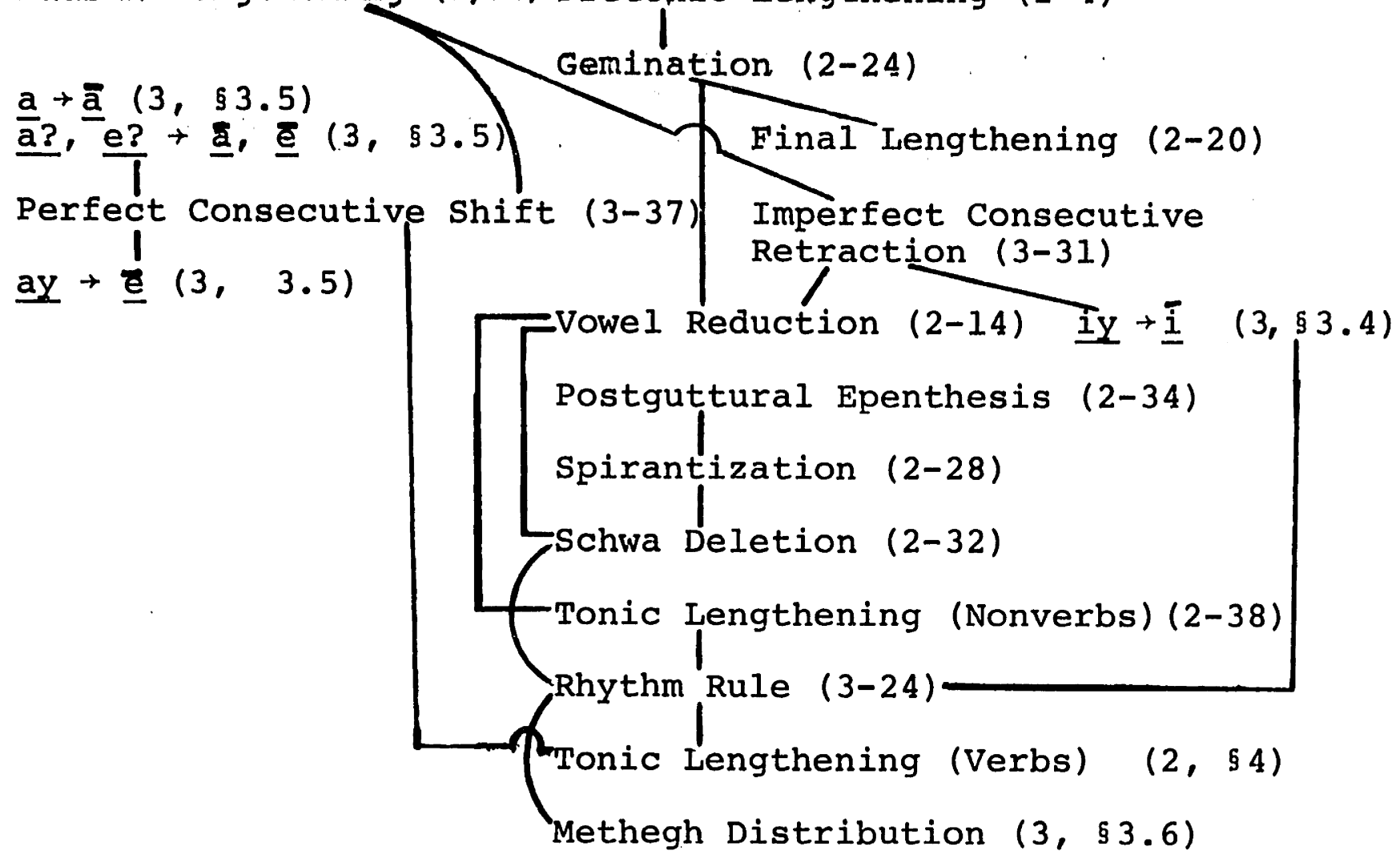

Applying throughout the derivation: Syllabification $(2, \S 3)$

Foot Assignment (3-22) 
4. Nonprosodic Metrical Structure

Although it is not a logically necessary consequence of the theory presented here, it is nevertheless likely that some nonaccentual rules should make reference to formally similar structures. In the two cases discussed here, it appears that the domain of vowel harmony processes can be characterized as a foot with familiar conditions on the branching of its terminal nodes. Moreover, given an equally familiar rule for labeling the foot, the trigger of the harmony process is just the designated terminal element, while the harmonizing vowels are all the other, metrically weaker nodes of the foot. Note that I do not say that all vowel harmony rules have these formal properties, but that there is a class of rules referring to footlike structures.

To achieve this end, we need to extend two mechanisms that have already been suggested earlier in this chapter. First it is clear that Vergnaud's (1976) notion of a projection functions in the operation of vowel harmony as it does in accentuation. The difference is that, whereas accentual structure is formed on the projection of rhymes, vowel harmony applies on a projection of vowels. We will, however, still retain some of the basic structural information of rhymes. Long vowels will project as branching nodes, and short vowels as nonbranching nodes, whether they are in open syllables or closed syllables. 
The second basic mechanism we need is the device of percolation, also developed by Vergnaud (1976). I mentioned this earlier in this chapter (section 3.3) in connection with variation in the quality of Hebrew reduced vowels or hatepim, so let's return to that question now. The hatep-vowels can be characterized formally as segments in the metrically weak position of a foot on the rhyme projection that I refer to as a $\rho$-structure. The two posited p-structures are:

(1)

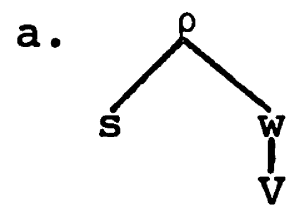

b.

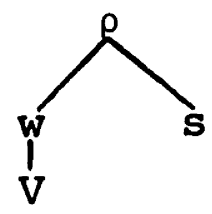

The indicated vowel $\mathrm{V}$ is interpreted phonetically as a reduced or hatep-vowel. The choice between these two structures depends on the source of the hatep-vowel; those resulting from the Vowel Reduction rule of Chapter 2 or epenthesis into word-initial clusters are represented by (1b), and the others by (la). In both trees the node in the strong position is formally a tail, so it can branch or not branch freely.

Now recall the facts about the quality of hatep-vowels. For those in the p-structure of (1b), we have evidence from Greek transcriptions that the reduced vowel written as schewa was generally pronounced like the following vowel. 
This Greek practice is reflected even in the English glosses of ša 1ōmó "Solomon' or sabąốt 'Sabaoth'. But hatep-vowels in the (la) structure mimic the quality of the preceding vowel in the writing as well as in the traditional pronunciation: yagămốd, he9ĕmî́d, ho9ŏmád. The hatep-vowels a , e, and 으 are all shorter, reduced versions of the vowels in the syllables preceding them. There is much variation in the first case, and only the second is reported by Qimhi (w. Chomsky 1933), but nevertheless there is significant regularity here.

Now if we consider the $\rho$-structures of the relevant forms, some regularity in the assimilation process emerges:

(2)

a.

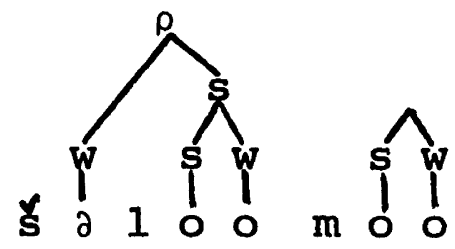

b.

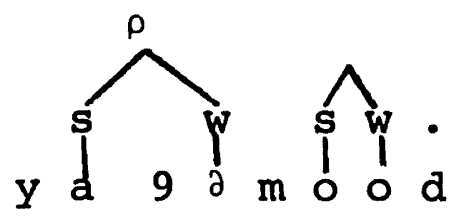

In both types, the vowel in the weak position of the $\rho$-structure is assimilated in quality to the vowel in the strong position. We can say, then, that the $\rho$-structure is the domain of a vowel harmony process, with the weak vowel harmonizing to the strong one. If the harmonizing features are [low, back, round], then these features must carry over from the weak to the strong vowel. Equivalently, the values for these features of the strong vowel are percolated up to 
the node $\rho$, and from there they spread down to the weak daughter of $\rho$, where they supplant any other values for these features. Thus the immediate result of percolation for the forms in (2) should look like:

(3)

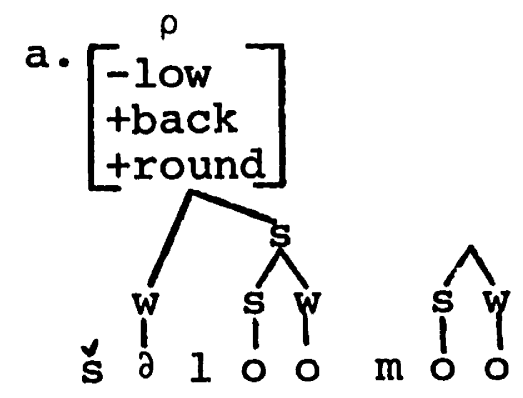

b.

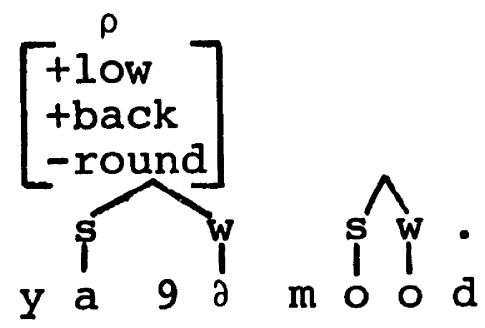

Therefore all vowels in the $\rho$-structure -- in particular, the weak vowel -- must receive these percolated feature values.

A simple formalization of this percolation rule is:

(4) Hatep Assimilation

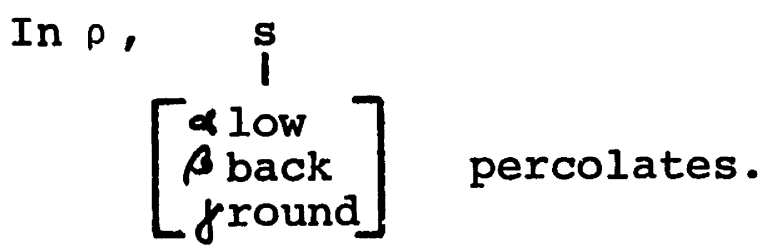

By this rule, all vowels in a $\rho$-structure must agree in lowness, backness, and roundness with the strongest vowel of the structure. The assimilation proceeds leftward and rightward with equal impunity, so long as it remains within the appropriate structure. 
Moreover, it appears that (4) is slightly overspecified. Below it emerges that in every case the percolating features take the values held by the designated terminal element, the node of the structure dominated only by s's. If we suppose that this is a universal property of harmony rules of this type, then we can eliminate s from rule (4), since it serves only to indicate the designated terminal element.

What is particularly interesting about this case of assimilation in Hebrew is that the domain of harmony is a structure that can be independently justified on accentual and quantitative grounds. It functions in the characterization of stress feet and it also obviates the need for direct expression of a three-way quantity distinction in vowels. The two cases discussed below do not involve structures that can be directly motivated on grounds other than vowel harmony. On the other hand, they do express unbounded assimilation processes, unlike Hebrew, so the domain must be a foot of $n$-ary rather than binary size. These analyses are necessarily tentative since they are not embedded in more thorough descriptions of the phonology of these languages. They are, therefore, only suggestive, but sufficiently interesting and convincing in themselves to merit special attention. 
4.1 Tigre

The vowel harmony processes of Tigre, a southeast Semitic language, have been analyzed extensively in Firthian terms in two works by Palmer $(1956,1962)$. Tigre has a system of five long vowels, $\underline{i}, \underline{e}, \underline{\text { o, }} \underline{\mathrm{u}}$, and a low front vowel a. But only a two way height distinction and no backness contrast are recognized in the short vowels, which Palmer writes as $\underline{\partial}$ and $\underline{a}$. I will assign both these short vowels the feature values [+back, -round], with $\underline{\partial}$ [+high] and with $\underline{a}$ [-high, -low], though nothing hinges on the choice of features for this bivalent height distinction. The first obvious question is why this should be characterized as a quantity distinction at all, since the short vowels obviously differ in quality as well from the long vowels. Palmer's argument is based on the greater quantity of long vowels and on their distribution: the long vowels almost never occur in closed syllables. The sole exception to this is word-final closed syllables, which I interpret as another instance of superheavy syllables limited to word-final position. Short vowels are excluded in final open syllables, a property that is paralleled, for nonlow vowels at least, in English.

Therefore considerations of syllable type argue strongly for a vowel length distinction here. Consequently I will represent the long vowels as geminates and I will assume that nongeminate vowels are reduced down to the two-way distinction. 
Tigre has a rule of vowel harmony that operates at a very low level phonetically. The short vowels are relatively fronted when followed by long front vowels, and relatively backed when followed by long back vowels. I will indicate fronting and backing with left and right superscript arrows respectively:

$$
\begin{aligned}
& \text { a. fłlitt 'half-grown calf' } \\
& \text { năbiit 'wine' } \\
& \text { b. dầbeelaa 'he-goat' } \\
& \text { c. n’ेguus 'king' } \\
& \text { sä̈mbuukaa 'her boat' } \\
& \text { d. täkkoobät 'mat' }
\end{aligned}
$$

This leftward backness harmony is unbounded; in mänă̈kkiit 'spoons' both a's are fronted by the final ii. Similarly

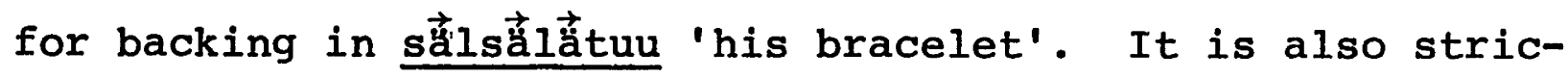
tly leftward, so only the first a is backed in (5d). Only short vowels are affected by harmony; in mänkaahuu 'his spoon' the long front vowel aa is not backed under the influence of the following uu.

The essential features of this vowel harmony rule are that it is initiated by a long vowel and that it proceeds leftward, applying to any short vowel but not to any other long vowels. Further, each long vowel in the word is potentially capable of initiating harmony, so long as at 
least one short vowel precedes it. The geometric characterization of this process is fairly simple. Since on a vowel projection all short vowels are represented by nonbranching nodes and all long vowels by branching nodes, the harmony foot should have essentially the structure in (6a), while the formalization of the foot is in (6b):

(6) a.

$$
\begin{aligned}
& \text { b. Foot Assignment (on Vowel Projection) } \\
& \text { is is maximal. } \\
& \text { Assign a right-branching, n-ary foot } \\
& \text { [thead, -tail]. }
\end{aligned}
$$

The feature [thead] means that the rightmost node must branch, so it is a long vowel. [-tail] ensures that no long vowels appear in the $\mathrm{n}_{i}$ position, so long vowels themselves are unaffected by harmony. I know of no evidence that will determine which direction this foot is assigned in.

Application of this foot to some representative examples yields the following results: 
(7) a. sälsälätuu

Vowel

Projection

Foot

Assignment säl sä lä tự b. täkoobät
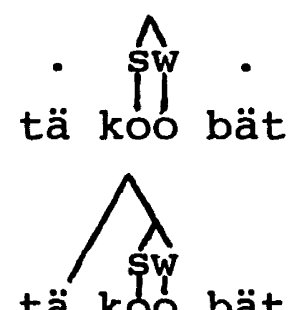

tä kờ bät c. faliit

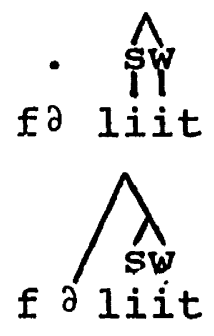

Because the foot is [thead], $n_{1}$ must branch. Therefore no harmony foot is assigned to words like madäd 'grindstone', which lack a long vowel.

Now if we label these feet according to the LCPR, the designated terminal element of the foot will be the node $\mathrm{n}_{1}$, which is also source of the backing harmony. So the harmony is effected by percolating the backness value of the designated terminal element up to the root of the foot, from which it supplants the backness values of the rest of the vowels in the foot. This operation can be formalized as :

\section{(8) Backing Harmony}

In $\phi=$ foot, $[$ aback $]$ percolates.

Since I stipulated earlier that only a feature of the designated terminal element can percolate, the application of (8) is completely unambiguous. The low-level character of this rule is evident here, since the backness value that percolates cannot be binary valued. The central vowels, although 
categorically [+back], are relatively backed before the backer round vowels, and relatively fronted before front vowels.

An interesting, related type of harmony is triggered by the low front long vowel aa. Before this vowel, central nonhigh $\underline{\text { a }}$ becomes fully low and front:

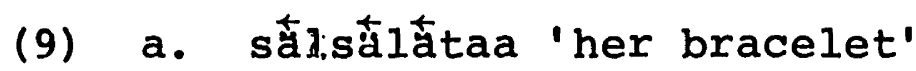

b. mä̀nkaahuu 'his spoon'

c. tä̈koobä̀taa 'her mat'

According to Palmer's description, $\underline{\partial}$ is not subject to this harmonization process, and remains central and high before aa.

It is apparent from the examples in (9) that harinony of $\underline{a}$ and aa is unbounded (9a), triggered by the nearest long vowel (9b), and does not skip over long vowels (9c). Clearly this rule refers to the same structural unit, the foot, that is assigned by rule (6). Since $\partial$ is not subject to this harmony rule, I will require that all segments in the font be [-high], and the rule will percolate both backness and lowness:

(10) aa-harmony In $\underset{[- \text { high }]}{\phi},\left[\begin{array}{l}\text {-back } \\ \text { tlow }\end{array}\right]$ percolates. 
The feature [-high] on $\phi$ ensures that this particular aspect of the harmony processes applies only to feet which do not contain $\stackrel{\partial}{-}$. We can collapse the two harmony rules by the use of angled brackets:

(11) Harmony

In

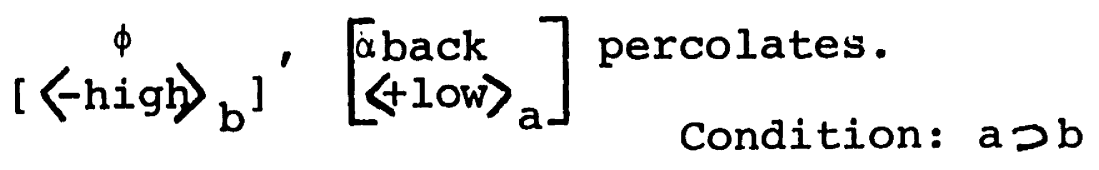

\subsection{Maltese}

An analysis of vowel harmony in standard Maltese appears in an article by Brame (1972). Treatments of vowel harmony in several other Maltese and Gozitan dialects appear in Puech (1978). One of these involves facts that fairly clearly suggest a foot-based treatment of vowel harmony. For expository reasons I deviate from Puech's transcription by writing long vowels as bimoraic and by abstracting away from the effects of subsequent rules of breaking and lowering under certain conditions.

In the dialect of Qormi (Malta), any round vowel, long or short, triggers backing and rounding harmony of a following short $\underline{i}$ :

(12) a. šurbitik $\rightarrow$ surbutuk

b. kitbuulik $\rightarrow$ kitbuuluk 'he wrote it to you' c. śurbitilim $\rightarrow$ śurbutiilim 'she drank it (f.) 
Examples (12a) and (12b) show that harmony can be initiated by a short or long round vowel, and that it is strictly rightward. Example (12c) shows that harmony cannot propagate over a long vowel, nor can it affect a long vowel.

Since the accentual foot of Maltese is virtually identical with that of Damascene Arabic, it is clear that the foot assigned for vowel harmony is different from that assigned by the stress rule. Moreover, the vowel harmony foot is assigned on the vowel projection rather than the rhyme projection. The foot must have the characteristics outlined in (13a) and formalized in (13b):

(13) a.

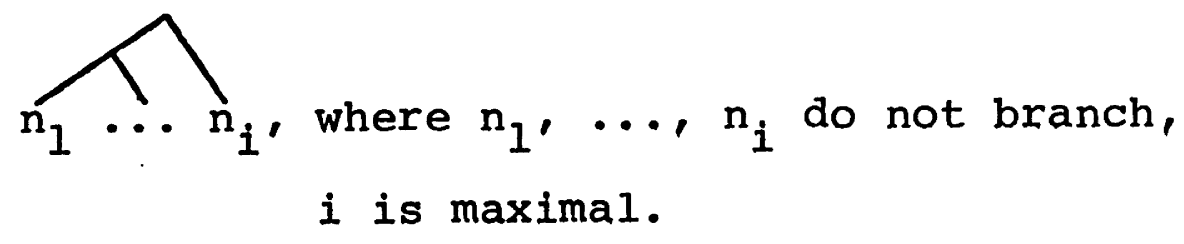

b. Foot Assignment (on Vowel Projection) Assign a left-branching, n-ary foot [-head, -tail].

If we label this foot by the LCPR, then $n_{1}$ will be the designated terminal element, and, moreover, the vowel triggering the harmony. So the harmony rule can be formalized as: 
(14) Harmony

In $\left[-1 \delta_{w}^{\phi}\right]^{\prime}\left[\begin{array}{l}\text { tback } \\ \text { tround }\end{array}\right]$ percolates.

On some fairly complex examples, this is how the rules work:

(15) a. Surbitiilim

Vowel

Projection sur bi tii lim

Foot

Assignment sur bi tii lim (and Labeling)

Vowel

Harmony

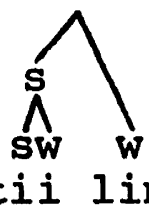

$$
\left[\begin{array}{l}
\text { tround } \\
\text { tback }
\end{array}\right]
$$

sur bu tii lim b. šurbituulik
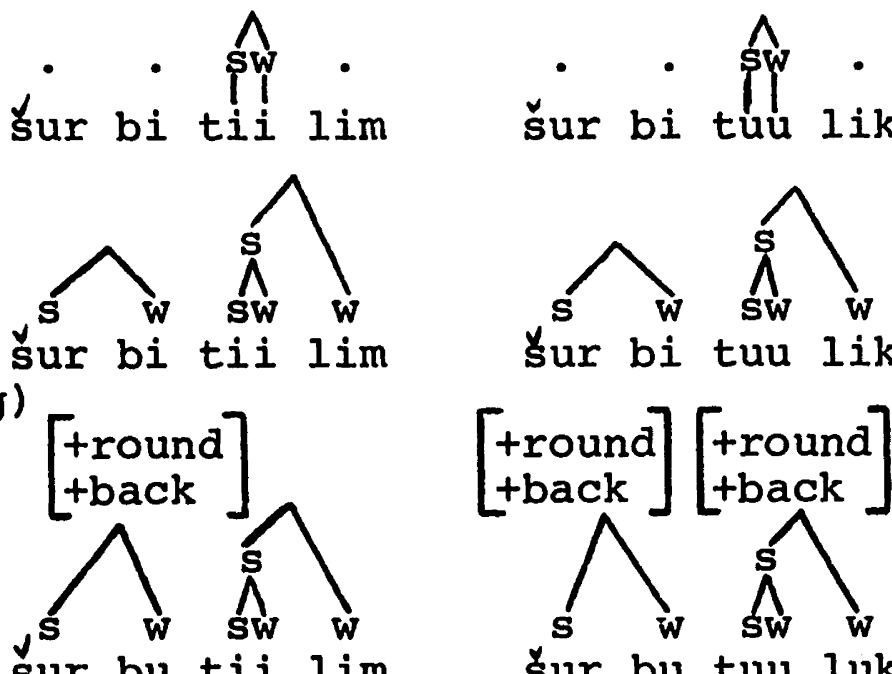
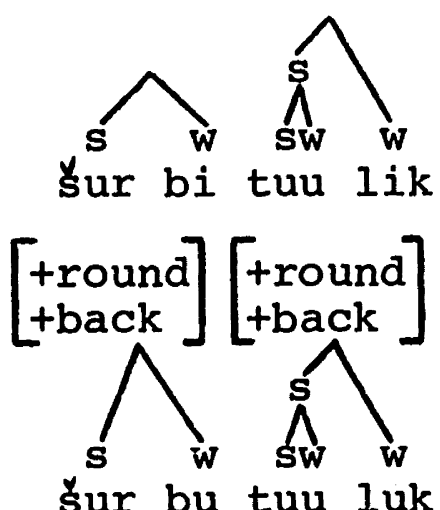

šur bu tuu luk c. kitbuulik
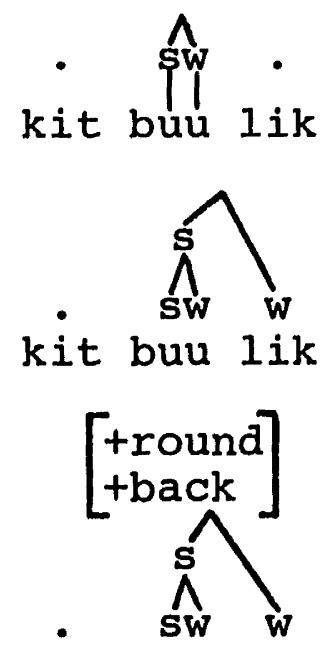

kit buu luk 
Chapter 3: Footnotes

${ }^{1}$ I am indebted to Morris Halle for first pointing out to me the utility of the profection notion in syllable weight.

${ }^{2}$ Actually final heavy syllables in Cairene Arabic will be vacuously assigned to feet, but the fact that they are still rhymes permits opacity to apply here. I am indebted to Alan Prince for pointing out the connection between English compound stress and the Arabic facts.

${ }^{3}$ Very few nouns have final stressed long vowels without a pronominal clitic: gatóo, hayáa. These extremely rare forms are costly positive exceptions to the stress rule.

${ }^{4}$ Two types of collective nouns also are subject to a rule similar to the feminine forms: dubúa, sibita.

${ }^{5}$ Damascene and other Levantine dialects differ in whether they provide evidence for final $h$ in surface CVV\# words of the sort that Cairene has. Therefore the cliticized forms may require morphologically-governed stress assignment in some or all of these dialects.

${ }^{6}$ Feminine nouns with like cyclic structure are, at first glance, counterexamples to this treatment. The suffixed form of tazkaret is tazkarto, obviously not paralleling the structurally identical verb 9allamato. There is, however, some evidence that the deletion of $e$ in the nouns is morphological, rather than a consequence of the syncope process operating in verbs. Thus e deletes despite a following cluster in băxret $\rightarrow$ baxártha. Apparentlymost feminine nouns are subject to this deletion in suffixed construct forms.

I should point out as well that the most remote representation of fáthet is fatahet, with a restricted syncope before the feminine suffix. This has, however, no bearing on the argument.

${ }^{7}$ An interesting discussion of these developments in Latin can be found in Allen (1973).

${ }^{8}$ There are some inconsistencies in the destressing of eC\# in infinitives, but these are paralleled by similar difficulties in the Greek transcriptions. This problem is of interest for the proper formulation of Tonic Lengthening in chapter 2 .

${ }^{9}$ Sievers (1901) rejects thi.s characterization of the Rhythm Rule since he finds no phonetic basis for it, and so maintains that stress is retracted onto closed syllables, notated there by magqeph, "This belies the similarities with the rules 
discussed in sections 3.4 and 3.5. It is also unsupported by arguments either from the text or from a substantive phonetic theory, and the different notation is not explained.

In rare cases stress retracts onto an open syllable with a short vowel and so-called virtual doubling of a following guttural: 1 Isáheg bâna Gen 39,14. Bergsträsser describes this phenomenon as "vereinzelt". Either two traditions with and without virtual doubling have been conflated here, or perhaps some virtual doubling types involve a late vowel shortening rile, sporadically applied.

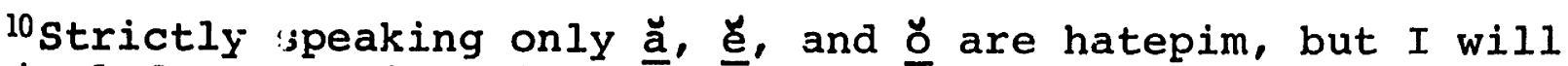
include schwa in this class for ease of reference.

11 The transcription of schwa in initial syllables in the Hexapla is more inconsistent than this description lets on, but there are clear cases of internal schwas, derived by vowel reduction, that conform to the vowel quality generalization:

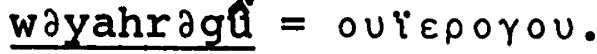

12 Three times attested is stress retraction over a closed syllable onto a short vowel: ná9amda yyăhad Is 50,8 . In every case the vowel of the second syllable was a hatep at an earlier stage of the derivation, so I assume that the p-structure is retained although the weak vowel, now in a closed syllable, is no longer interpreted phonetically as a hatep.

13 The frequent defective writings of the long vowels in these forms suggest that perhaps in some cases the vowel of the final syllable is short, so the failure of stress retraction may be partly morphologized for first singulars.

14 It may be necessary as well to incorporate the fact that verbs with retracted stress must lack object pronoun clitics into the morphological context of this rule.

15 There is an interesting tendency for following words beginning with a guttural to attract stress onto the final syllable of perfect consecutives despite the formulation of the rule. I have no explanation for this, though it merits further investigation. Perfect Consecutive Shift is also sporadically suppressed when the following word has stress on the initial syllable, though this is demonstrably not a reflex of the Rhythm Rule both because it is sporadic and because it lodges stress on a short vowel.

${ }^{16}$ As with nâsరీ́g 3ăhór, sievers (1901) cienies the evidence of the written text and assigns secondary sicess on some unexplained basis, yielding such strange accentuations as 
umibbàhūrékém Am 2,11, where stress skips over two long vowels to lodge on the third syllable back from the main stress. Sievers was apparently motivated by considerations of a stress counting meter that has been convincingly rejected in more recent work.

One aspect of the distribution of light methegh is not included in the description and subsequent discussion in the text: light methegh appears on short vowels before virtually doubled gutturals if separated by one, or more syllables from a following stress. Thus, hêhärî̀, hà?êlếk, hahillam Gen 11,6. Light methegh also falls on a short vowel before a syllable-final guttural in the certain forms of the verbs hăyā and hayan: yihyé, yihyé.

There is no certain solution to either of these problems, although several possibilities present themselves. Bauer and Leander (1962) suggest in effect that the latter may be the result of the punctators perceiving stress on the vowel because of the relatively greater articulatory force of the syllable-final guttural. It may also be the vowel before the guttural was long, although written defectively, so these are cases of superheavy penults. As for the former, there is a clear connection here with the rare cases of Rhythm Rule retraction onto short vowels before virtually doubled gutturals mentioned in note 9 , as well as the overapplication of Perfect Consecutive Shift before gutturals mentioned in note 15. This suggests a general tendency for gutturals to yield an apparent stress on the preceding vowel. Still another possibility is that the initial syllable in words like hehārim, although it does not begin a foot, is nevertheless relatively more prominent in the word-level structure, and methegh is assigned one the bassis of overall prominence rather than simply prominence within some foot.

17 There is an alternative treatment of these facts: the feminine suffix it bears a branching rhyme diacritically before all suffixes, and is thus accented as a heavy penult. This purely diacritic use of syllable istructure is prohibited under the analysis here, and with good reason. In some dialects discussed by Diem (1970), the feminine suffix really does have a branching rhyme, and this leads to surface vowel lengthening or consonant gemination, along the lines of the Hebrew analysis in chapter 2. Thus the accentual peculiarity of it lies in the foot in Cairene, but in the syllable rhyme in these other dialects. 
Chapter 4: Prosodic Structure, Morphology, and the Lexicon, 1. Introduction

One of the classic linguistic problems is the morphological system prevailing in most members of the Semitic language family. Unlike the more familiar basically concatenative morphology of the Indo-European languages, Semitic displays a wide variety of purely morphological alternations internal to the stem, chiefly of nouns and verbs. In Arabic, for instance, there is a clear sense in which the forms in (1) are morphologically related to one another although they do not share isolable strings of segments in concatenated morphemes:

(1) a. kataba 'he wrote'

b. kattaba 'he caused to write'

c. kaataba 'he corresponded'

d. takaatabuu 'they kept up a correspondence'

e. ?iktataba 'he wrote, copied'

f. kitaabun 'book (nom.)'

g. kuttaabun 'Koran school (nom.)'

h. kitaabatun 'act of writing (nom.)'

i. maktabun 'office (nom.)'

Even the fairly elaborate paradigm in (1) is far from exhaustive; for instance, it does not include inflectional alternations like kutiba 'it was written' and makaatibu 'offices (nom.)'. 
Certain observations about this morphological system, crucial to an understanding of it, date from a very early period. It has long been known that at the basis there are roots of three or four consonants which cluster around a single semantic field, like ktb 'write'. Certain changes in these roots, like gemination of the middle radical in (lb), yield reasonably consistent types like causative or agentive. Moreover, some vowel patterns seem to bear consistent meaning, like the difference in vocalism between active kataba and passive kutiba.

In the very earliest work -- the treatments by medieval Arabic and Hebrew grammarians, generally adopted in the work of Western Orientalists -- a fairly elaborate morphophonemic theory is complemented by only the most rudimentary analysis of paradigms like (1). Their approach is usually a fairly superficial taxonomy, mediated by a notation that simply shows the citation root 191 (Hebrew p91) 'do' with appropriate stem modifications. So their basic insight was to abstract away from the particular root, but not to any richer understanding of the morphological system than this. So far as I know there was no general treatment of relations between vowel patterns except as instantiated on a root. The first modern insights into these problems appear in Zellig Harris's (1941) analysis of Biblical Hebrew. He proposes a list of morphemes divided into three types on formal and semantic grounds. The consonantal roots like 
ktb have the sort of general meaning alluded to above. Patterns are composed of vowels plus symbols from the set "_",":", and affixal consonants. The dash marks "the presence of some phoneme, usually a consonant, in close juncture". The colon is the familiar notation for consonant length. The meaning of a pattern is essentially a modification of the meaning of the root. So, for instance, the pattern of (lb) will be notated _a_: a with the meaning 'intensive, causative'. The third class of morphemes is relatively uninteresting, consisting of those function words and loans not susceptible to root and pattern analysis.

The relationship between morphemes of the root class and those of the pattern class is expressed by a single statement of morpheme order; members of the root class are intercalated in patterns. This statement suffices since any pattern will contain three dashes, one for each of the consonants of the root, so the mapping of consonants to slots is unambiguous. Thus Harris has a very simple expression of the fundamental morphological process of Hebrew. The cost of this simplicity is a significant loss of generality in the characterization of patterns. It is, therefore, an accident under this theory that nearly all verb patterns contain a portion of the form _ $v_{-} v_{-}$, or that all patterns with two vowels have them placed in that way with respect 
to the dashes for the root consonants. The actually attested possibilities of intercalating roots and patterns are much more limited than this apparatus allows.

Chomsky's (1951) analysis of Modern Hebrew eliminates this defect, though at greater cost in the intercalaction process. He offers general schemata for roots and patterns of the form:

$$
\begin{aligned}
& \text { a. } \left.R \rightarrow C_{1}^{R} C_{2}^{R} C_{3}^{R} \text { (: , sometimes, if } C_{2}=Y_{2}\right) \\
& \text { b. Vowel Pattern: } \alpha_{1}--\beta_{2} \text { where }{ }^{\alpha}{ }_{1},{ }^{\beta}{ }_{2}=v \text { or } \varnothing
\end{aligned}
$$

The notation $C^{R}$ in the definition of a root refers to a set of morphophonemes that can occur in roots. The parenthesized material refers to a special case where the medial root consonant is a high glide (hollow root). The definition of a vowel pattern is quite general; the hyphens serve only to separate the two vowels, and not to indicate the position taken by a zonsonant. In practice, although not in this formal definition, he also allows patterns with the symbol ":" immediately preceding $\beta_{2}$, indicating gemination of a consonant.

Since Chomsky's analysis is one of the earliest and most extensive demonstrations of rule ordering within a modified structuralist framework, we can coherently speak of a morphophonemic derivation. At the earliest stage of this derivation there is a linear concatenation of morphemes 
from the different classes. So, for instance, the form in (1b) will have the remote representation ktb+a--a a (the wordfinal a is an inflectional affix of Arabic absent in Hebrew). Several morphophonemic rules apply to representations of this form. These rules must, by his argument, crucially precede a morphophonemic rule of intercalation, formulated as in (3):

$$
\begin{aligned}
& \text { (3) } \mathrm{C}_{1} \mathrm{C}_{2} \mathrm{C}_{3}[:]+Q_{1}-(:) Q_{2}[:]+ \\
& C_{1} Q_{1} c_{2}(:) Q_{2} c_{3}\left[\begin{array}{l}
: \\
-
\end{array}\left[\begin{array}{c}
: \\
-
\end{array}\right] \text {, and : : } \rightarrow\right. \text { : } \\
& \text { where } Q_{\underline{i}}=V_{\underline{i}} \text { or } \varnothing[\underline{i}=1,2]
\end{aligned}
$$

Since the mode of application of this rule may not be entirely perspicuous, I will attempt to paraphrase it.

The consonants of a root and the vowels of a pattern are indexed by subscript integers from left to right. In concatenation the first vowel $\left(Q_{1}\right)$ is placed after the first consonant $\left(c_{1}\right)$. If the second vowel is preceded by the colon, then this is placed after $\mathrm{C}_{2}$, indicating gemination of the second root consonant, which is itself followed by the second vowel $\left(Q_{2}\right)$ and then by the third root consonant $\left(C_{3}\right)$. Curly brackets and square brackets are identical in effect to the curly brackets of Chomsky and Halle (1968), except that the former are expanded before the latter. The 
result of these notations in (3), along with the reduction of "::", is that length of either $c_{3}$ or $Q_{2}$ or both in the input is realized by length of $\mathrm{c}_{3}$ in the output.

In essence, then, the operation of intercalation in Chomsky's analysis is a transformational rule that refers to indices on vowels and consonants according to their positions in the stems and roots. While Harris stipulates for each pattern where consonants will fall within it by the dash notation, Chomsky abstracts away to a generalized vowel pattern and writes a rule to indicute the relative ordering of members of roots and vowel patterns.

Chomsky's analysis, although a model of thoroughness and compact statement, is descriptively inadequate on a few relevant points. One of these is the treatment of quadriliteral roots. Most of the Semitic languages contain a number of roots with four consonants instead of the usual three. In Arabic, for instance, the basic verbal instantiation of such a root conforms to the pattern in (1b), with two different consonan's replacing the medial geminate: tarjama 'he translated' from the root trjm. Although he disavows an explicit treatment of them, Chomsky rather tentatively suggests that these roots are accommodated by replacing ":" with a root consonant in vowel patterns of the form $v_{1}--: v_{2}$. That is, a root consonant is substituted formally for medial gemination. Thus, replacement by $g$ in i--:e would yield tirgem 'he translated'. Apart from the 
obvious fact that this requires a new, ad hoc rule to deal with quadriliteral roots, it also apparently makes the incorrect claim that these roots are derivative of triconsonantal roots by augmentation. It is not possible to substitute any consonant for ":"; only $g$ will do if the rest of the root is trøm. I conclude, then, that the mode of intercalation in (3) is inadequate for roots of four consonants.

Far more serious than this sort of empirical difficulty are the theoretical issues raised by a rule like (3). This rule is, obviously, a transformation, implying an apparctus with corresponding descriptive power. It also refers to indexing of segments by integers, which potentially allows the inclusion of number theory in the theory of morphology. The significance of these observations should not be underestimated. Chomsky (1951) contains all the notational apparatus later adopted by Chomsky and Halle (1968) except for distinctive feature theory, so it could reasonably be claimed that this is a very early work in classical generative phonology. Therefore it is not untoward to say that a transformational morphological analysis, similar to rule (3), is essentially the analysis predicted by this tradition. The analysis of Classical Arabic morphology in this chapter offers a comprehensive alternative to the transformational morphological rules of the classical theory. 
This analysis is based on a version of autosegmental phonology, characterized below in section 2.2. Since the analytic sections do not contain polemics or straw man arguments, the reader may want to reflect from time to time on how exactly the same facts can be expressed by transformational morphological rules, and just how powerful an apparatus is needed. This theoretical issue is, however, taken up in detail in section 5.1, where the relative merits of the transformational theory and the proposals made here are considered.

A problem closely related to the formal character of morphological rules is the formal character of morphemes, the units that those rules manipulate. Again the classical theory makes a fairly explicit proposal: a morpheme is a string of segments delimited by the symbol "+" which contains no internal "+". A somewhat richer notion of morpheme is proposed and justified in section 2.1. This notion, based on Zellig Harris's (1951) long components, is also essentially autosegmental in character.

The third necessary characteristic of a morphological theory is a theory of the structure of the lexicon and of lexical entries. Here there is no need to examine the classical theory closely. The basic view adopted by Chomsky and Halle (1968) that the lexicon is a list of single morphemes only, and that these units are subject to lexical insertion, has been convincingly dismissed by Halle (1973), 
Jackendoff (1975), and Aronoff (1976) based on the original proposals in Chomsky (1970). I see no reason to repeat these arguments here.

But in spite of these earlier insights broad empirical questions about the form of lexical entries remain. One problem is which forms merit listing in the lexicon. Although I opt later for Halle's (1973) fully-instantiated lexicon, nothing here depends on this and so this is not an important theme of the analysis. But another problem, the structure of the lexical entries, does elicit fairly extensive proposals here. Earlier work has suggested lexical entries in the form of paradigms (Halle 1973), paradigms with a head (Aronoff 1978), and simplex entries containing single words (Jackendoff 1975). Evidence is offered in section 5.2 based on the analysis of Arabic that suggests that the lexical entry is structured into trees, where the relationship of domination in the tree relates forms to their derivational sources. Let me also note at this point that the term "derived from" is used in a technical sense in the following analysis. It refers to a particular morphological relationship that may exist between two words $A$ and $B$ whether or not A or B or both appear in the lexicon. An indication of the characteristics of this relationship appears in section 5.2 also.

To sum up this introduction I will map out the overall geography of the chapter. Sections 2.1 and 2.2 present some 
basic formal apparatus that is essential to the analysis of the later sections. Sections 3 and 4 offer extensive treatments of Arabic verbal and nominal morphology, respectively, with occasional deviations into Hebrew. section 5 deals with the major theoretical issues raised above: section 5.1 on the form of morphological rules, with some particular observations on reduplication, and section 5.2 on the lexicon. This latter section divides further into separate consideration of capturing morphological relation." ships by means of a structured lexical entry and describing eemantic and morphological irregularity in such a lexicon.

You can see, then, that the bulk of the theoretical interpretation follows the description and analysis. I have adopted this somewhat skewed presentation because both the facts and analysis of Arabic are unfamiliar to many and resist a brief synopsis. Because of this, I suggest the following plan of reading for those concerned mostly with the theoretical results: sections 2.1 and 2.2 , and section 3 through 3.2 , at which point the major characteristics of the verbal system should be apparent. From there it is possible to turn to the theoretical claims in section 5 with only a limited loss of the particulars.

\section{Basic Formalism}

\subsection{The Representation of Morphemes}

It is well known that a number of idiosyncratic morphological and phonological properties cluster around words 
like permit, subsume, and submit, with Latinate prefixes and stems. In the verb form, stress invariably falls on the final syllable in spite of the possibility of further retraction. Certain special assimilation and deletion rules apply at the boundary between the prefix and stem; compare admit, assume, attempt, appear, accept. Finally, as Aronoff (1976) notes, the types of nominalizations of these forms are determined entirely by the stem morpheme: submission, permission with mit versus assumption, consumption with sume. This clustering of properties means that the grammer must be able to recognize words of this type as a class composed of Latinate prefix and stem morphemes. But the exact delineation of this clasis in the representation of these words is an empirical question for which there are several alternative solutions.

One theory might say that one or both of the morphemes in words of this sort are delimited by brackets. That is, these words have internal hierar shical structure, with the possibilities in (1):

(1) a. [[per]mit] b. [per[mit]] c. [[per][mit]]

What the bracketing in (1) claims is that words like permit have a derivational history of suffixation, prefixation, or compounding, respectively. That is, one or both of the constituent morphemes serves as the base for syntactic or 
lexical process of word-formation. Serious difficulties with both the syntactic (Lees 1957, Chomsky and Halle 1968) and the lexical (Aronoff 1976) derivations of words of this type have long been noted. In either case, an analysis along the lines of (1) seems to violate the fairly fundamental notion that a morpheme must bear meaning and be listed in the lexicon to serve as a base for word-formation. Aronoff (1976) convincingly demonstrates the impossibility of assigning any sort of invariant meaning to morphemes like per and mit. The structures in (1) are equally suspect in that there is no principled basis for choosing between them -- words like permit give no evidence of any derivational history at all. Without some very different conception of the morphology, then, we must reject the analysis of these forms by derivation and consequently by bracketing.

A second possibility, essentially the one followed by Chomsky and Halle (1968), is to analyze permit as a sequence of two morphemes separated by a boundary but without internal hierarchical structure: per+mit. It is irrelevant here whether this class has a special boundary like "=" or not. The boundary allows us to recognize permit words as a class -- they contain an internal boundary but have no other structure.

Rotenberg (1978) and, Selkirk (forthcoming), in some interesting proposals for the treatment of various junctural phenomena, present convincing arguments against the use of 
boundary symbols in phonological representations. They claim instead that junctural rules actually refer not to boundaries but to hierarchical structure itself, structure in the morphological, accentual, syllabic, or syntactic realms. Notice that here we have an obvious problem for this theory: there is no likely hierarchical structure in permit class words, but nevertheless several rules must have access to some sort of morphological analysis of them. There is, however, a third formal possibility. This alternative is implicit in work by Zellig Harris (1951), and essentially involves an extension of his notion of the long component. While the boundary solution basically says that morphemes are delimited by symbols in the segmental string, the long component idea says that the string of segments is uninterrupted, but the morphological analysis is given by another, simultaneous level of representation. Harris's long components were designed to handle discontinuous phenomena -- in particular, the semitic roots that figure prominently in this chapter. But it requires very little to extend a long component analysis to include segmentally-continuous morphemes like per or mit.

The formal basis of this interpretation is essentially the notation of autosegmental phonology (Goldsmith 1976). A particular version of this theory is summarized in section 2.2. Formally, I will define a morpheme as an ordered string of $1 \mathrm{Xn}$ feature matrices associated autosegmentally with a root node $\mu$. This is schematized in (2): 
(2)

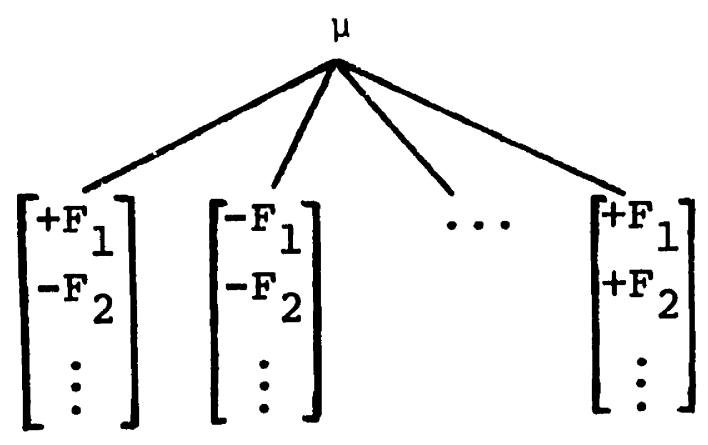

The root node $\mu$ identifies this string as a particular morpheme. Moreover, $\mu$ bears all nonphonological information associated with the morpheme, such as rule diacritics and in fact its identity as a morpheme. Note that this is not intended as a substitute for hierarchic structure where that structure is motivated. It does, however, replace all delimitation of morphemes by boundary symbols like "+".

Run of the mill English morphology has a very simple translation into this notation, as does any basically. concatenative segmental morphological system. In this case $\mathrm{n}$ equals the cardinality of the set of phonological features and all daughters of any $\mu$ form a continious segmental string. For example, permit will be represented as:

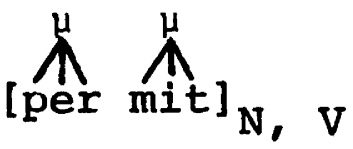


This sort of representation achieves the desired end. The grammar can refer to per and mit as separate morphemes with special phonological and morphological properties without reference to either unmotivated bracketing or boundary symbols. Because separate nodes $\mu$ dominate per and $\underline{\mathrm{mit}}$, they are necessarily interpreted as distinct morphemes. A number of arguments can be developed in support of this position. The first group consists essentially of plausibility arguments, based on fairly well accepted properties of phonological rules without explicit justification. The second group deals with actual cases where the $\mu$-notation is richer than the boundary notation in ways that are essential to the expression of linguistic generalizations.

First, this notation allows us to construct a plausible evaluation measure for reference to nonphonological information in phonological rules. The boundary theory, if it has any empirical content at all, says that phonological rules can refer to boundaries at no greater cost than to segments. In fact, since the set of boundaries contains no more than one feature (to distinguish "\#" from "+"), it takes only this feature and the feature [-seg] to refer to any boundary. other nonphonological information is, by the usual conventions, encoded in each segment, so it can be referred to equally cheaply. 
But under the $\mu$-notation it is possible to refer to a particular segment in a particular morpheme only by a representation like $\mu$. This obviously involves more symbols, segment

and is therefore more costly, than a purely segmental context. Other morphological information -- diacritic features, minor rule features -- is also associated with $\mu$ only, not with the individual segment, so reference to it will require an even more complex representation. This is apparent from the formalization of several rules in the following sections. This is surely the correct result; phonological condit_oning of phonological rules is, in general, more highly valued than morphological conditioning.

Second, certain hypothetical cases which have not previously been considered display a potential ambiguity in tne boundary solution. Suppose we have some morpheme $s_{1} s_{2} s_{3}$ which is deleted in the context $x$. Under the boundary treatment this deletion rule would look something like (4):

$$
\text { (4) }+s_{1} s_{2} s_{3}+\emptyset / x
$$

But suppose there are two other morphemes $s_{1} s_{2}$ and $s_{3}$. Then the sequence of morphemes $+s_{1} s_{2}+s_{3}+$ will, by clear SPE conventions, be subject to this deletion rule as well. A.1though it is an empirical question, I suspect strongly that 
that this is the wrong result. The proposal offered here eliminates this problem; the single morpheme is represented formally as (5a), while the sequence of morphemes is (5b):

(5)

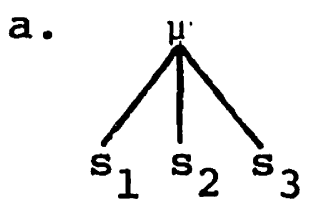

b.

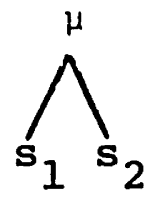

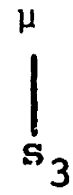

Notice, too, that the $\mu$-notation eliminates the need for the quite ad hoc convention for interpreting " + " in Chomsky and Halle (1968). Although "+" is a symbol in the segmental string, nevertheless it is transparent to phonological rules unless those rules explicitly mention it. This convention stipulates something that is an inalienable property of the $\mu$-notation. Explicit reference to $\mu$ in a phonological rule will limit the application of that rule to a particular morpheme. If $\mu$ is not mentioned, then the rule wiIl apply without morphological conditioning. No transparent boundary symbol appears in the segmental string. ${ }^{1}$

Furthermore, sequences of identical boundaries are ruled out here as well. Nothing directly prevents sequences "++" or "++" in the boundary notation. Again, this is logically impossible under the proposal offered here. Similarly, erasure and movement of boundaries are rendered impossible.

Direct empirical argluments for this proposal involve cases where the $\mu$-notation is richer than the boundary 
notation. They are essentially ex imples of Harris's long components and they come, not surprisingly, from semitic. The cases I present here all involve morphological conditionInc of phonological rules, rules that are restricted to applying in a given morpheme. In the second half of this chapter a much more extensive analysis of the morphological relationships involved is offered.

The first case is an assimilation rule that is peculiar to the eighth derivational class (binyan) of the Arabic verb. The characteristic morphology of this form is $a \underline{t}$ infix between the first and second consonants of the root: ${ }^{2}$ ftaraga 'to part', 9tarada 'to place something before one', ktasaba 'to earn one's living'. But ir verbs whose first root consonant is $\underline{w}$ or $\underline{y}$, we find geminate $\underline{t}$ in the eighth binyan: $\sqrt{\text { w9d }} \rightarrow$ tta9ada 'to receive a promise', $\sqrt{\text { ysr }}+$ ttasar 'to play a dreydl'. This assimilation is absolutely unique to this set of morphological circumstances. A roo-initial $\underline{w}$ or $\mathcal{Y}$ does not assimilate to a following $\underline{t}$ which is also part of the root (rather than the infix): $\sqrt{w t r}+$ yatiru 'to string a bow', $\sqrt{w t d}+$ ?awtaad 'tert pegs', $\sqrt{y t m} \rightarrow$ yaytimu 'to be an orphan'. There is a similar failure of assimilation in roots whose third consonant is $\underline{w}$ or $Y$ when followed by the second person masculine singular perfective agreement suffix ta: $\sqrt{\mathrm{s} \perp \mathrm{w}}+$ saruuta 'you were noble', $\sqrt{r \text { dy }}+$ radiita 'you were pleased with', $\sqrt{g z w}+$ ǵazawta 'you made a raid', $\sqrt{\mathrm{rmy}}+$ ramayta 'you threw'. 
The upshot of this is that, to apply the assimilation rule correctly, the grammar must be able to uniquely identify the $t$ infix of the eighth binyan of the verb. Under the boundary or hierarchical theories, though, there is no way to locate an infix as distinct from the unit that contains it. Infixes are not celimited by +-boundary -- this is an incoherent (and entirely ad hos) suggestion that leads to such absurdities as a morpheme composed solely of the first root consonant in the eighth binyan: $\underline{w}+\underline{t}+\underline{a 9 a d a}$. Under the $\mu$-notation, this rule is formulable as follows, where the $\underline{t}$ infix is characterized as reflexive:

(6) th-assimilation

$$
\left[\begin{array}{l}
\text {-cons } \\
- \text { syll } \\
\text { thigh }
\end{array}\right] \rightarrow t /\left.\right|_{[\text {refl] }} ^{t}
$$

There is, then, no logical or empirical problem with this case of morpheme discontinuity, even though this rule is entirely unformulable in the boundary-based theory.

An even more interesting example for this rotation ccmes up in the Akkadian reflex of this verbal class (as well as in the Hebrew). Akkadian also has a $t$ infix in the sn-called Gt and Gtn (passive and iterative) verbal classes: $\sqrt{\text { mḥs }}+$ mithas 'to be struck (Gt)', mitahhas 'to strike repeatedly (Gtn)'. But in forms where the first root consonant 
is a coronal spirant, we find that it and the t-infix exchange positions by some sort of metathesis rule: $\sqrt{\mathbf{s b t}} \rightarrow$ sitbutum $\rightarrow$ tisbutum 'to seize one another', $\sqrt{\mathrm{zqr}}+\underline{\text { zitqurum }}+$ tizqurum 'to be elevated'. This metathesis proceeds oniy across an intervening vowel; thus isstabbat 'he will seize' remains.

Again, we can show that this rule is restricted to a particular conjunction of morphological circumstances that require us to be able to identify the $\underline{t}$ infix. In the notation proposed here, this rule is formulated as:

(7) t-metathesis

$\left.\left[\begin{array}{c}\text { Cor } \\ -\operatorname{son} \\ +\operatorname{con} t\end{array}\right]^{\mathrm{V}}\right|_{\text {[păssive, iterative] }} ^{\mathrm{t}}$

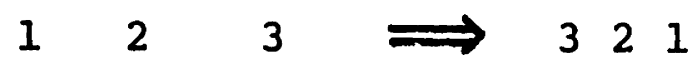

Although this rule is morphologically-conditioned, it is without a doubt a phonological rather than a morphological transformation. Note that it conforms to the typical type of phonological spirant-stop metatheses (U1tan 1971), discussed further in section 5.1 .

Akkadian has another very interesting phonological rule with similar properties. The nominal prefix ma (but not mu) is dissimilated to na when any root consonant is a labial: naphar 'totality', neereb 'entrance', narkabt 'chariot'. 
Only root consonants suffice to trigger this dissimilation; a stem vowel, even if labial, does not: mazuukt 'mortar'. A nonroot consonant (the $\underline{m}$ of mimation, following the case desinence) fails as well: maskattum 'deposit', meriitum 'pasture'. Consequently this rule must refer directly to the discontinuous string of root consonants with its clear morphological identity in Akkadian:

m-dissimilation

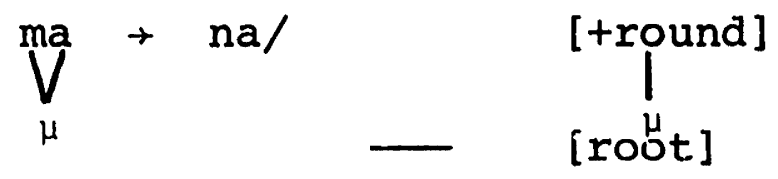

Here reference to the root, even though it is a discontinuous string of consonants, is necessary to the proper formulation of a morphologically-governed rule of some generality.

A final consideration lies in the realm of morpheme structure constraints. The Semitic root is subject to a number of rules for the cooccurrence of consonants within it, a fact originally noted by the Arab grammarians. For instance, Greenberg (1978) observes that, with a single exception, no root of a verb contains both $\underline{g}$ and $\underline{h}$, the voiced and voiceless pharyngeal glides respectively. Similar distributions hold for other points of articulation, though no such constraints apply to consonants outside the root. The conclusion must be that morpheme structure in 
Arabic refers to the root specifically despite the fact that it is a discontinuous morpheme. Similarly, the vocalism -- what I call. the vowel melody -- is not freely distributed among the vowels. For example, it is a fact that no Arabic word (with the possible exceptiun of recent loans) has the vocalism $\underline{i}-\underline{u}$, nor does any verb have a melody that begins with $\underline{i}$. Generalizations of this sort cannot be expressed without access to a notation like $\mu$ in the morpheme structure constraints.

In subsequent sections we will see reference to discontinuous morphemes as the basis of the analysis of Arabic word formation. The fact that it allows us to deal with these morphemes and their complex interrelations is the strongest confirmation we can offer for the $\mu$-notation.

\subsection{Autosegmental Theory}

Because of the dependence of the following account on certain principles of autosegmental phonology, it is appropriate here to outline the major characteristics of the theory as I assume them. The essence of the theory is abstraction away from the notion segment to a more general idea of autosegments, bundles of distinctive features which, whon joined together by rules of association or mapping, fully specify the surface phonological representation. So far as I know, most of the properties claimed here have been independently justified for tonal or vowel harmony 
systems in work by Goldsmith (1976) and Clements (1977). Where I deviate from their work, particularly in the somewhat richer characterization of autosegmental tier suggested here, explicit justification is given.

First, the operation of mapping or association in autosegmental phonology is perhaps its best-studied aspect. Goldsmith (1976) proposes two overriding constraints on the distribution of lines of association between two autosegmental levels or tiers:

(9) Well-formedness Condition

a. Every unit on one level must be associated with at least one unit on every other level.

b. Association lines may not cross.

Notice that there is a kind of metatheoretical difference between these two conditions: whereas the former is a natural consequence of a notation that uses lines on a plane to indicate association of two elements, the latter is stipulated independently of the notation. In fact, in more recent work (Goldsmith 1979) this first condition has been weakened somewhat. Rather what we might suppose is that languages allow elements under some conditions to remain or to become unassociated in the course of a derivation. Consequently these unassociated elements receive no phonetic 
roalization; in effect, they are erased as a result of being unassociated. We will see, particularly in the treatment of Arabic consonantism, that unassociated or extrametrical units do appear in derivations and that they appropriately enough do not make themselves felt. on the surface.

This brings us to another issue, the existence of representations where a unit on one level is associated with several units on another level. This is a great virtue of the autosegmental system, since it, in general, allows level-tone analyses of surface drnamic-tone phonologies. In general, then, there is a many-to-many association between autosegmental levels.

This presents some problems, however, in the treatment of nonprosodic autosegmental systems. The ordinary case is that each position in the string corresponding to a conventional segment is specified for one and only one value of each feature. I designate this level -- the level on which gross distribution of voweis and consonants is stated -- the prosodic template. The unmarked case is that association of nonprosodic features with the positions of the prosodic template is one-to-many but not many-to-one. Therefore the usual circumstance is that $a$ vowel does not have multiple specifications for the feature [back] nox a consonant for the feature [coronal], and so on. Schematically, for the hypothetical prosodic template CVIVC, the associations 
with the C-slots in (10a) and (10b) are permitted but that in (10c) is excluded by this principle:

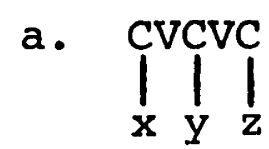

b.

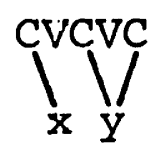

c. $\prod_{x}^{\text {CVCVC }}$

This is not to say that all such associations are excluded, but rather that they ordinarily are. Notable exceptions do exist, like the autosegmental treatment of preaspirates (Thráinsson 1978) or affricates as consonants with multiple specifications for laryngeal features or continuance. In Arabic there is a set of relevant data for one of the ancient dialects that I will present now, although it anticipates some of the following discussicon. By the operation of several phonological rules developed in Brame (1970), roots whose medial radical is a high glide undergo a complex set of morphophonemic changes. In the more or less standard dialect of Classical Arabic, the perfect passives of this root type show the following derivation:

(11)

$$
\begin{aligned}
& \text { a. quwila } \rightarrow \text { qiila } \\
& \text { b. suyira } \rightarrow \text { siira }
\end{aligned}
$$

Although the usual melody of the perfective passive is $\underline{u}-\underline{i}$, the $\underline{u}$ in these cases assimilates to the following $\underline{i}$ 
regularly. But one dialect, apparently still represented in some traditions of reading the Qur?aan, does not perform this assimilation, and instead allows the diphthong ui to appear on the surface. This vowel is described by the native orthoepists as the ?ismaam 'scent or taste' of $\underline{u}$, and is supposed to be pronounced as 배 or ui (Bravmann 1934, Schaade 1911).

But if the stem syllable of these verbs is closed by a following consonant-initial desinence (and invariably in the case of so-called geminate verbs like halla 'untie'), the stem vowel is shortened. In the standard dialect it continues to be $\underline{i}$, but in the diphthong-retaining dialect this short vowel is still described as ?iśmaam. In other words, this dialect allows a many-to-one assuciation of the passive melody $\underline{u}-\underline{i}$ with a single vowel slot in the prosodic template. Formally we can represent this situation as :

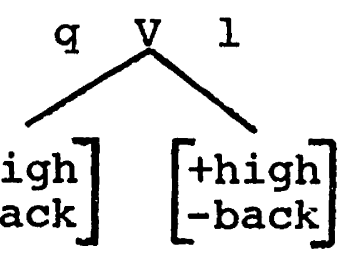

I am inclined to think that this pronunciation was limited to the high style, is in reading the Qur?aan. It shows, therefore, that the prohibition against many-to-one associations, while quite general for some nonprosodic autosegments, is nevertheless susceptible of sporadic suppression. 
apart from these dialectal fact,s, though, Arabic displays the general prohibition against many-to-one associations. On the other hand, one-to-many associations are freely generated, and we will see many of these in the course of the discussion. The usual mechanism for generating these is spreading, which results from a limited application of clause (9a) of the Well-formedness Condition. Since one-to-many associations are permitted, autosegments will in general extend association lines to all available slots of the prosodic template. This spreading is subject to several conditions developed in the cited literature.

First, in general unasscciated elements will spread in preference to elements with previous associations (Goldsmith 1976: 149). So a representation of the sort in (13a) will yield the result in (13b) and not the one in (13c):

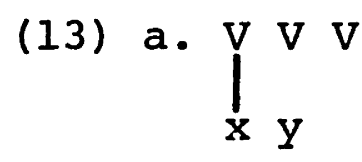

Second, spreading will not violate $(9 b)$. So the representation in (14a) will yield (14b) and not (14c): b.

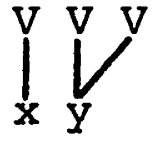

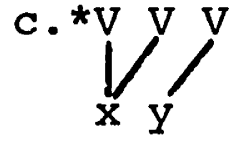

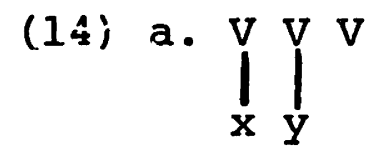

(14)

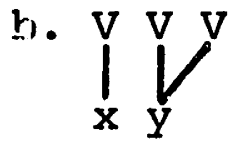

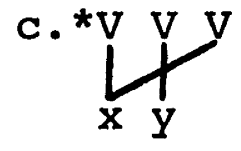


In a few respects I will go beyond the theoretical proposals already in the literature. I will claim that a rule of association is suppressed if it would create a representation that violates the prohibition against many-toone associations in those systems -- chiefly nonprosodic -that have this prohibition. That is, this principle serves as an overriding constraint on the function of melody mapping or association rules. So a rule that says "insert $z$ and associate it with the first V" will apply in (15a) to yield (15b) by reassociation in conformity with the prohibition, but it will be suppressed in (15c) : ${ }^{3}$
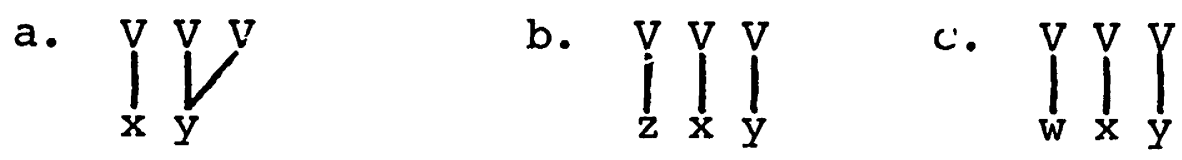

I also invoke a somewhat richer notion of autosegmental tier than has been accepted in previous work. Formerly a tier was defined solely by reference to phonological information. Particular languages might select certain sets of distinctive features and isolate those features on a separate autosegmental tier or level. Then all and only those features will be represented on that tier. Aiong the general lines of the $\mu$-notation developed in the preceding section, I will claim that languages have the option of restricting particular tiers to autosegments that belong to particular morphemes or morpheme classes. In this way 
consonantal roots and vowel melodies in Semitic, although they involve some of the same distinctive features, can nevertheless be represented on separate autosegmental tiers. Note that the original definition of tier is not supplanted, but only enriched. Only one set of phonological features can appear on a single tier, and different tiers cannot contain the same sets of phonological features unless those tiers represent different morphemes.

Finally, I suggest that the theory contain a revised version of Leben's (1973) Obligatory Contour Principle. Leben's principle says that no tonal melody can contain adjacent identical elements. Thus, a tone HHL is automatically simplified to $\mathrm{HL}$, while $\mathrm{HLH}$ remains. Goldsmith (1976) has argued against this principle on the basis of data from Tiv verbal conjugation, a system formally similar to Semitic in which tonal, rather than vocalic, melodies express many inflectional characteristics of the verb. Goldsmith's strongest example is the form of the Habitual 1 category, in which the abstract melody is HHL in inherent high tone stems and LHL in inherent low tone stems. The melody HHL clearly violates Leben's principle. But suppose that the lexical tone $\mathrm{H}$ or $\mathrm{I}$ in the beginning of the melody is represented on a separate morphologically-defined tier (in the sense of the preceding paragraph) from the inflectional HL melody. Then it will be possible to maintain the obligatory Contour principle as a generalization about melodies within 
particular tiers, rather than about melodies in general. Since we have occasion to refer to this later, let us state it outright:

(16) Obligatory Contour Principle (revised)

In a given autosegmental tier, adjacent identical autosegments are prohibited. For the Tiv case and others, this means in effect that violations of Leben's original principle are possible only when the offending elements are in different morphemes. This follows from the fact that the lexical tone of the verb stem appears on a separate morphologically-defined tier from the HL tone morpheme of the Habitual 1. The significance of this principle will emerge later in the analysis of Arabic roots. 
3. The Classical Arabic Verbal System

The system of the triconsonantal verb is based on fifteen derivational categories, which I will refer to by the traditional Hebrew term binyānî́m (sg. binyấn), although the Arabists' nomenclature has them as conjugations. They are in no way similar to the more familiarconjugational types of Latin or Greek. In fact, each binyan is inflected in almost the same way as aIl the other binyanim. What they differ in is the arrangement of root consonantism with respect to characteristic affixes and vowel positions.

The first binyan is a possible category for nearly all roots that can appear as verbs. It is relatively unmarked phonologically, at least in the finite forms, and it has no special semantic properties. This is roughly true as well for the first quadriliteral binyan, QI. But the others, the so-called derived binyanim, generally involve some special modification of the meaning of a related noun or verb or of the basic meaning of the root. So, for instance, the third triliteral binyan is usually reciprocal, while the sixth is usually the reflexive or effective of the reciprocal. It is, in general, an idiosyncratic property of any root whether it can appear in a particular binyan. Nevertheless, neologisms abound, loanwords are easily incorporated into the system, and speakers of Modern Standard Arabic report a reasonable facility in extending a root to other binyanim and interpreting the result. 
Subject to these lexical idiosyncracies, the binyanim cross-classify the roots morphologically and semantically, where the root supplies the basic meaning and the binyan (except for the first binyan) supplies some modification of this meaning or of the verbal diathesis. The meaning of any verb is not a composition of the meaning of root and binyan, but there is a reasonable amount of predictability. For instance, as we saw in the introduction, the root ktb expresses a notion like 'write', appearing in nouns like kitaab 'book', maktabat 'library', maktab 'office', kaatib 'emanuensis', mukaatabat 'correspondence', and so on. This root occurs in eight binyanim, reflected by the following uninflected forms of the perfective active:

\begin{tabular}{|c|c|c|}
\hline \multicolumn{3}{|c|}{ Binyan } \\
\hline I & katab & 'write' \\
\hline II & kattab & 'cause to write' \\
\hline III & kaatab & 'correspond' \\
\hline IV & ?aktab & 'cause to write' \\
\hline VI & takaatab & 'write to each other' \\
\hline VII & nkatab & 'subscribe' \\
\hline VIII & ktatab & 'write, be registered' \\
\hline 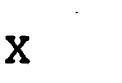 & staktab & 'write, make write' \\
\hline
\end{tabular}

The characteristic morphology of these forms -- permutations of vowels and consonants and so on -- will emerge shortly. 
While the second binyan is causative here, it can also be

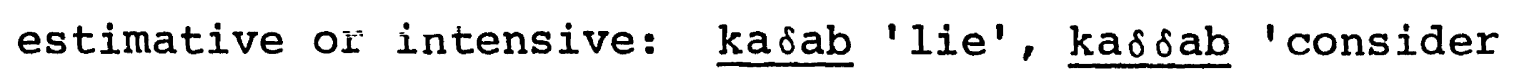
someone a liar'; darab 'beat', darrab 'beat up'. It can also be denominative, expressing the property of being occupied with the corresponding noun: mariid 'sick', marrad 'to nurse'. Similar variation exists in the other binyanim.

The ninth and eleventh binyanim are reserved for verbs of color or bodily defect, and describe the corresponding state of being. The twelfth to fifteenth binyanim are extremely rare, and they are generally intransitive or stative. Quadriliteral roots are limited to four binyanim which differ in interesting ways from the triliteral binyanim that they resemble. I will return later to this phenomenon. Besides the binyanim, Arabic verbs are marked for several other properties. There is a basic division into two aspects, perfective and imperfective. Voice is active or passive, with slightly different morphology for voice in the two aspects. Subject agreement is by number and person and, in nonfirst person forms, by gender as well. A noteworthy aspect of this agreement, taken up later, is that it is chiefly prefixing and partly suffixing in the imperfective and exclusively suffixing in the perfective. There are also six verbal moods, indicative, subjunctive, jussive, imperative, and two energics, all but indicative limited to imperfective aspect, but I will have little to say about this sort of inflection here. Similarly I will not discuss the 
form of direct and indirect object pronoun clitics, which essentially involve relatively unilluminating suffixing morphology. In all other respects, though, this analysis strives for a complete account of the formal characteristics of Arabic verbal morphology.

The following table, which will serve as the basis for much of the analysis, displays the citation triliteral root $\underline{k t b}$ in all fifteen triliteral binyanim and the root dhrj 'roll' in the four quadriliteral binyanim. Here and later each triliteral binyan is referred to by the appropriate Roman numeral of the traditional ordering, while the quadriliterals have a prefixed $Q$. The major aspect and voice inflections of the finite and nonfinite verb forms head the columns. Gaps in the passive inflections indicate binyanim that are regularly intransitive and stative, and therefore not susceptible of passivization for nonmorphological reasons.

Since the forms in this table involve a considerable degree of abstraction, a little caution is in order. First, since the purpose here is to map out the formal characteristics of the system, the roots $\underline{k t b}$ and dhrj may happen not to occur in particular binyanim, although formally equivalent roots do. Thus $\mathrm{V}$ takattab is not a real verb, although $\mathrm{V}$ takassab 'to earn' is one. In the first binyan, different Ablaut classes, treated later, yield different vocalism from that of $\underline{k t b}$ in the perfective and imperfective active. The 
forms in the table are all stems, so they do not contain mood, agreement, or case, gender, or number marking, which are also dealt with later.

Finally, some of the forms abstract away from certain generally accepted phonological processes dealt with in Brame (1970) and informally in most reference grammars. Forms with initial clusters, if not preceded by a vowel in the phrase, receive epenthetic 2V. Also the intervocalic glottal stop and the following vowel are deleted in some of the binyan IV forms. Some other rules apply with particular roots, but they make no difference here. Except in a few cases I will have nothing to say about these rules, and I assume that they appear essentially as in Brame (1970), perhaps with some occasional notational translations for the autosegmental morphological analysis developed here. 
Perfective Perfective Imperfective

Active

Passive
Active
Imperfective

Passive $\begin{array}{ll}\text { Active } & \text { Passive } \\ \text { Participle } & \text { Participle }\end{array}$

Triliterals

\begin{tabular}{|c|c|c|c|c|c|c|}
\hline$I$ & katab & kutib & akt.ub & uktab & kaatib & maktuub \\
\hline II & kattab & - kuttib & ukattib & ukattab & mukattib & mukattab \\
\hline III & kaatab & kuutib & ukaatib & ukaatab & mukaatib & mukaatab \\
\hline IV & ?aktab & ?uktib & u?aktib & u?aktab & mu?aktib & mu?aktab \\
\hline V & takattab & tukuttib & atakattab & utakattab & mutakattib & mutakattab \\
\hline VI & takaatab & tukuutib & atakaatab & utakaatab & mutakaatib & mutakaatab \\
\hline VII & nkatab & nkutib & ankatib & unkatab & munkatib & munkatab \\
\hline VIII & ktatab & ktutib & aktatib & uktatab & muktatib & muktatab \\
\hline IX & ktabab & & aktabib & & muktabib & \\
\hline $\mathrm{x}$ & staktab & stuktib & astaktib & ustaktab & mustaktib & mustaktab \\
\hline $\mathrm{XI}$ & ktaabab & & aktaabib & & muktaabib & \\
\hline XII & ktawtab & & aktawtib & & muktawtib & \\
\hline XIII & ktawwab & & aktawwib & & muktawwib & \\
\hline XIV & ktanbab & & aktanbib & & muktanbib & \\
\hline$x V$ & ktanbay & & aktanbiy & & muktanbiy & \\
\hline \multicolumn{7}{|c|}{ Quadriliterals } \\
\hline QI & dahraj & duḩrij & udaḩrij & udahrraj & mudahrij & mudahraj \\
\hline QII & tadahrraj & tudubrrij & atadahrraj & utadaḩraj & mutadahrij & mutadaḥraj \\
\hline QIII & dhanraj & dḩunrij & adhanrij & udhanraj & mudhanrij & mudhanraj \\
\hline QIV & aharjaj & dhurjij & adharjij & udharjaj & mudharjij & mudharjaj \\
\hline
\end{tabular}


3.1 Consonantism

Let's consider the differences between the various binyanim in just the perfective active, where the vowel characteristics are most muted. As a kind of minimal, barely adequate account of these differences, we would have to take note of the following characteristics:

(1) How are the consonants arranged with respect to the vowels -- what is the canonical syllable pattern of the form?

(2) How are prefixes and infixes like $\underline{t}$ or $\underline{\mathrm{n}}$ arranged among the root consonants?

(3) How are the root consonants arranged with respect to each other? Although the order of consonants in any root is invariant, we still must determine which if any consonants are geminated.

A first-order answer to (1) is very easy to get. The inventory of canonical syllable patterns in the perfective of the triliteral binyanim is: ${ }^{4}$ 
(4) a. CVCVC
b. CVCCVC
f. CCVCVC
c. CVVCVC
g. CCVCCVC
d. CVCVCCVC
h. CCVVCVC
e. CVCVVCVC

Certain obvious regularities appear in (4) which the grammar ought to take account of. First, the stems of all binyanim end in closed syllables (CVC) -- this is invariably true. Second, there is no binyan with a sequence of two light syllables like CVCVCVC. Third, no binyan contains a light syllable after a heavy syllable like cVCCVCVC. Fourth, no binyan which begins with a consonant cluster is three or more syllables long overall.

To minimally express these regularities, the grammar should contain some sort of templates regulating the canonical distribution of consonants and vowels in the binyanim in general. Two templates, either one of which must be fulfilled, are needed:

\section{(5) a. CV( (CV) [+seg]) CVC \\ b. $\operatorname{CCV}([+\operatorname{seg}]) \quad C V C$}

The first template allows all and only the patterns in the first column of (4) and the second template allows all and only the patterns in the second column of (4). [+seg] indicates an element that may be either a consonant or a vowel, 
Following the terminology of the introduction, I will refer to the schemata in (5) as prosodic templates. Each binyan characteristically chooses one of these schemata, and also chooses optional elements and consonantal or: vocalic values of [tseg] within the schema. Therefore we can say that one aspect of the specification of any given binyan in the grammar is an indication of the prosodic template of that binyan chosen from the set abbreviated by (5). The stem patterns of Arabic verbs must be selected from this restricted group of possibilities and no others. The complementary problem is describe the arrangement of root and affixal consonantism with respect to the c-slots of the prosodic templates. Let us assume, in anticipation of the following analysis, that the Arabic triliteral root is represented formally as an autosegmental tier containing three autosegments composed of the features that are contrastive for consonants. Rather than list all these features, I will informally abbreviate them as $\underline{\mathrm{ktb}}$ and so on, although it is strictly the case that the features [syll] and [cons] are represented on the prosodic template and not on the autosegmental tier. Similarly, affixes like $\underline{n}$ or $\underline{t}$ will appear on separate autosegmental tiers. These affixal tiers involve the same distinctive features as the root tier, but they are distinct because the tiers are morphologicallydefined, in the sense described in the introduction. The significance of this distinction will appear shortly. 
The problem now is account for the mode of association between the consonantal slots of the prosodic template and the autosegments of the various consonantal tiers. We will begin by considering some cases in detail.

The prosodic template (5a) abbreviates the five prosodic templates in (6):
(6) a. CVCVC
b. CVCCVC
c. CVVCVC
d. CVCVCCVC
e. CVCVVCVC

For the templates (6a) and (6c), the problem of association is trivial. A triconsonantal root will, by virtue of the Well-formedness Condition (WFC) and the prohibition against many-to-one associations, end up in a simple one-to-one association with the three C-slots of the template. This situation appears in (7):

(7)

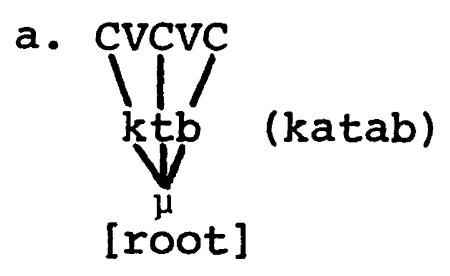

b.

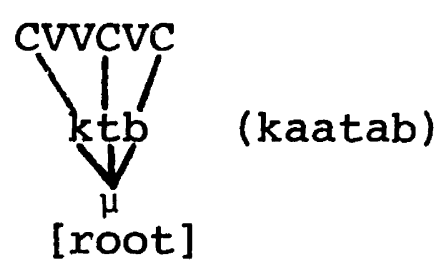

Consequently these two cases do not reveal the mechanism of root to prosodic template association. 
Now let's examine the forms that have an affix - a consonant which is demonstrably not part of the root -mapped onto one of the slots in (6). Each of the binyanim IV, V, and VI display additional morphological material, either $\underline{?}$ or $\underline{t}$. For these binyanim it suffices to associate this affixal material with the initial consonant in the template, yielding the outputs in (8):

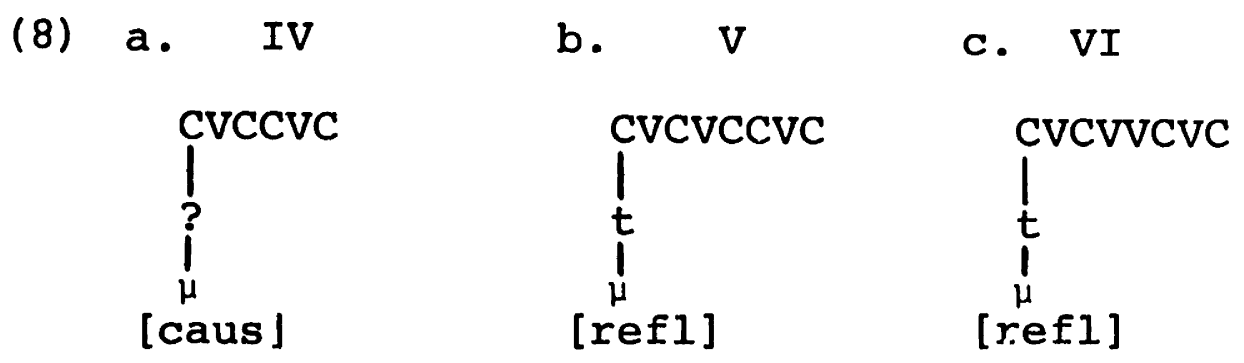

At this stage, the remaining c-slots in (8a) and (8b) can be unambiguousiy associated with the root consonants on a one-to-one basis.

But a problem remains in treating forms like the second and fifth binyanim. Even after affixation as in (8b), the templates of these two categories have four slots to accomodate just three root consonants: II CVCCVC, $v \underset{1}{\text { cVCVCCVC. }}$ What actually occurs is gemination of the middle root consonant, in effect expanding the triliteral root to fit four consonantal slots. I interpret this gemination formally as a one-to-many mapping of the single middle radical onto two slots in the prosodic template: 
(9)

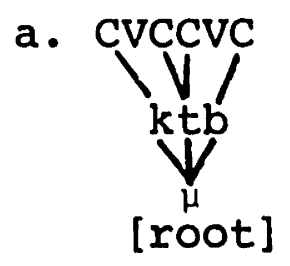

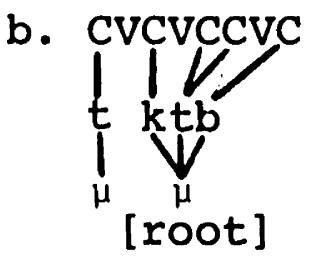

The structures in (9) represent the output of the processes forming the second and fifth binyanim. The question we have to answer is how the grammar produces these particular associations of root consonants with slots, and not ones where, say, the final root consonant is in a many-to-one relationship. We have to consider the other binyanim before we can answer this.

The other prosodic template, (5b), generates the following set of prosodic templates:
(10) a. CCVCVC
b. CCVCCVC
c. CCVVCVC

Template (10a) appears in the seventh binyan with an n-prefix, in the eighth with a t-infix after the first radical, and in the ninth with gemination of the final root consonant. (10b) appears in the tenth binyan with prefixed st, while (10c) appears in the eleventh binyan also with a geminated final radical.

First the affixal material must be dealt with. It suffices to say that $\underline{n}$, like the $\underline{\text { ?-affix, }}$ is associated with the first consonant of the template. This property -- 
association of the affix with the first consonantal slot of the prosodic template -- is observed consistently by the fifth and sixth binyanim for the affix $\underline{t}$, by the fourth

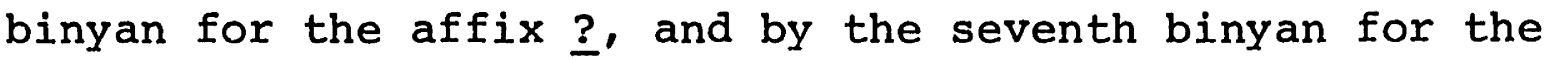

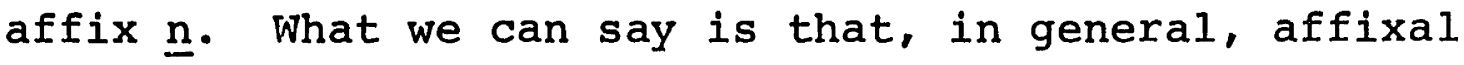
material is associated with slots of the prosodic template from the left, associating with the first consonantal slot of the template first of all. This operates as well for the complex affix st of the tenth binyan, since it lodges on the first two consonantal slots of the prosodic template. Since this principle is observed with some regularity, I will state it formally as a rule:

\section{(11) Consonant Association}

Autosegments are associated from leftto-right with appropriate slots of the template. Formally,

Template Melody

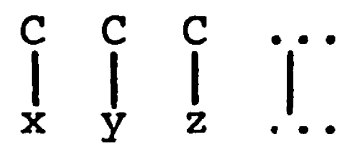

It emerges later that this rule also applies to nonconsonants. I note that, in an entirely separate realm, a similar principle of association has been extensively motivated for the tonal system of Japanese (Haraguchi 1975).

Now there is one systematic deviation from this wellordered behavior. The affix $\underline{t}$ of the eighth binyan is associated with the second consonant slot of the prosodic 
template and not the first. Here we can say that Consonant Association applies in its usual fashion, but that a subsequent rule, restricted to this affix and a particular prosodic template, flops the association of the affix over to the adjacent consonantal slot. Rules of this type are fairly common in tonal systems (Goldsmith 1976). Formally, the Arabic rule reads:

Eighth Binyan Flop

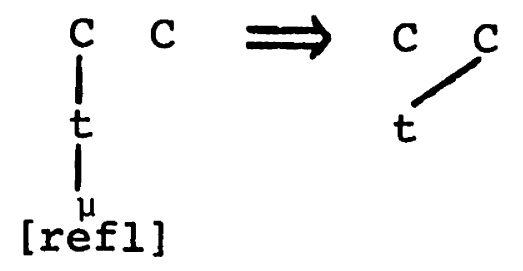

This flop rule, by moving the association of $t$ to the left, correctly makes it an infix in the eighth binyan. The morphological feature [reflexive] identifies this particular morpheme with the phonological shape $\underline{t}$, distinguishing it from the $t$ of, say, the agreement system. The requirement that the two consonants of the prosodic template be adjacent ensures that reflexive $\underline{t}$ will not flop in the fifth and sixth binyanim, where the consonants are separated by an intervening vowel.

The general principle of Consonant Association -left-to-right mapping -- can be extended to the treatment of root consonantism as well. In the binyanim where only 
three consonantal slots are present, or where only three are left after affixation, left-to-right association is adequate, though obviously any other mapping would work as well:

a

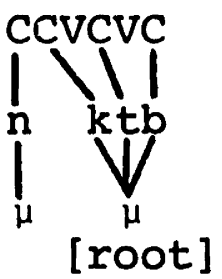

(nkatab) b. $\mathrm{x}$

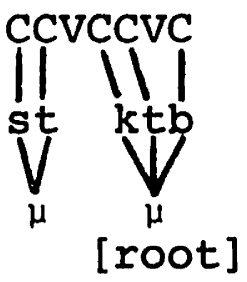

(staktab) c. IV

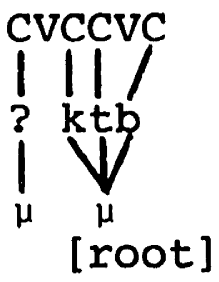

(?aktab) d. VI

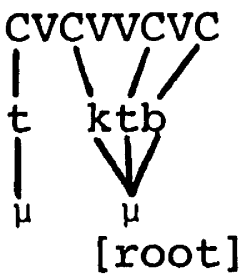

(takaatab)

Here the citation root $\underline{k t b}$ is displayed as mapped onto several of the binyanim with only three remaining slots. Since Consonant Association operates from left-to-right, the mapping of autosegments on the root tier must follow the mapping of those on the affixal tier within the verbal stem.

One other case remains where affixation leaves only three consonantal slots empty. This is the eighth binyan, ktatab, where the starred $t$ is the affix (cf. ktasab 'to earn'). Here we see the effect of the notion of morphologically-defined autosegmental tiers developed in the introduction. The affix $t$ is on a separate tier from the root ktb since they are different morphemes. The affix is first associated with the initial $\mathrm{C}$ of the eighth binyan template CCVCVC, and then the Eighth Binyan Flop Rule shifts its 
association to the second slot. At that point mapping of autosegments from the root tier is effected, in accordance with the consonant association rule. The slot with which affixal $\underline{t}$ is associated is already filled, and the prohibition against many-to-one associations will not allow it to be doubly filled. Therefore the root must associate with the other available slots, yielding the representation in $(14)$ :

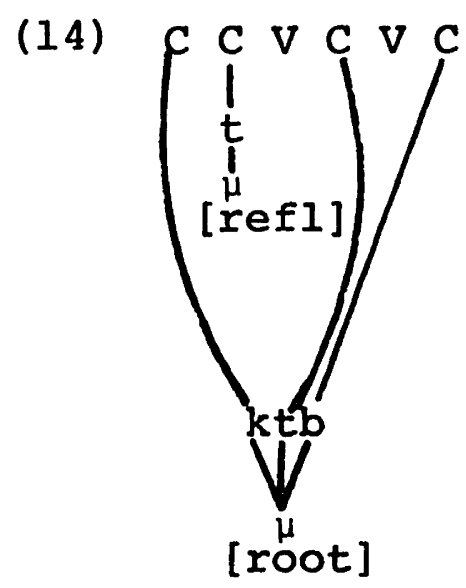

(ktatab)

The morpheme ktb does not contain the affix $\underline{t}$ in the strict sense; rather, they are distinct representations on separate tiers which have contact with each other by way of association with the same prosodic template.

This model eliminates the need for a transformational rule of infixation applying in the eighth binyan. Rather, the only language particular rule it substitutes for it is the Flop rule (12). It also provides a coherent environment for the $\underline{t-}$ assimilation rule developed in section 2 of this chapter. 
There is great significance to specifically left-toright association of roots with prosodic templates in the ninth and eleventh binyanim. These are formed on the templates (10a) and (10c). Simple association yields (15):

(15) a

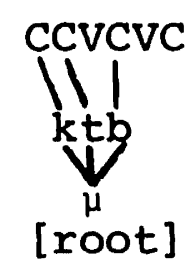

b. $\mathrm{XI}$

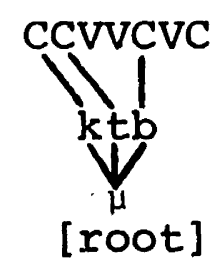

Now by the Well-formedness Condition, the unfilled template c-slot receives an association with some element such that no lines cross. This yields (16):

(16) a. IX

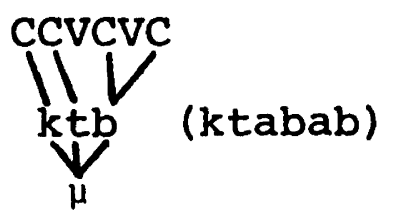

[root] b. XI

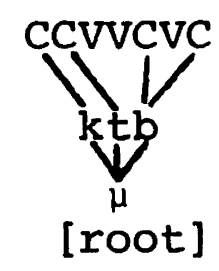

(ktaabab)

Consequently this sort of automatic spreading is sufficient to generate the gemination displayed by these two binyanim without any additional stipulations.

In a similar way we can derive the gemination of the medial radical in the second and fifth binyanim, kattab and takattab. Association of the affix $\underline{t}$ and left-to-right association of the root consonantism yields structures like those in (17): 
(17)

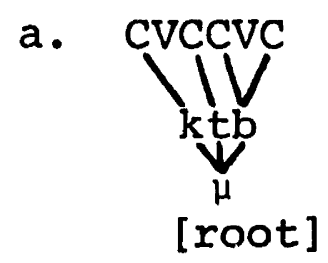

b.

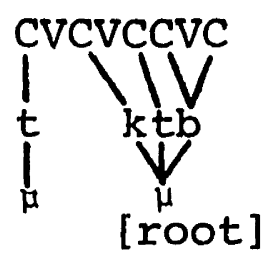

Then a new rule erases the association of the final rootconsonant with the medial $C$. This now empty $C$ is subject to the Well-formedness Condition, so it picks up an association with the autosegment associated with the nearest consonant; in this case, the medial radical $t$. This is the same mechanism of automatic spreading responsible for the ninth and eleventh binyanim, though in this case it presupposes prior application of rule (18):

(18) Second, Fifth Binyan Erasure

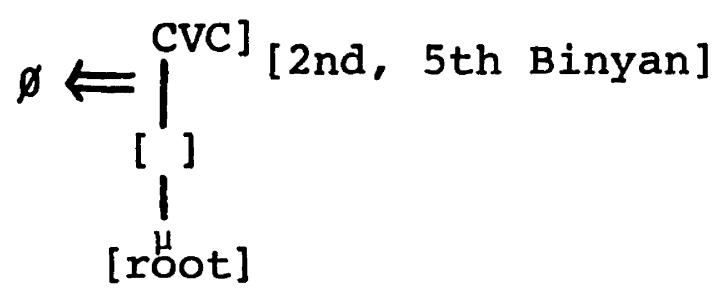

So a partial derivation of the perfective forms of these binyanim will proceed as:

(19) a. II.

CVCCVC

Affix tier

Root tier

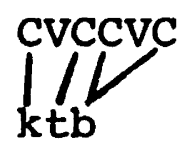

Rule (18) b. $\quad$ v
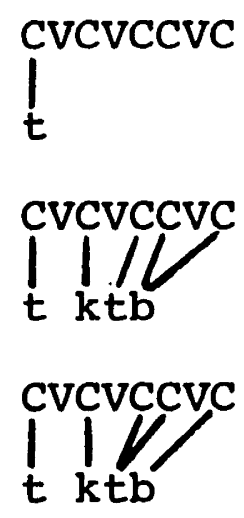
In sum, the basic formal apparatus that is specific to Arabic grammar (rather than part of the universal theory of autosegmental phonology) that generates the binyanim is :

(20) a. The prosodic templates (5a) and (5b).

b. The affixes $\underline{?}, \underline{t}, \underline{n}$, and $\underline{s t}$.

c. Left to right Consonant Association (11).

d. The Flop and Erasure Rules (12) and (18).

In addition, the grammar must contain a specification for each binyan of its choice from the vocabulary of prosodic templates and of affixes. For example, the sixth binyan will select the template CVCVVCVC generated by (5a) and the affix $\underline{t}$. The only other formal device needed is, obviously, a list of triconsonantal roots.

Considering the complexity of the phenomena, it is remarkable that such a small amount of stipulated mechanism is needed to capture a great number of generalizations. Interestingly, this grammar has quite a number of specific empirical consequences other than those already discussed. First, consider the triliteral binyanim XII-XV. These are indisputably rare, but nevertheless they do occur, they were recognized as binyanim in the classical grammatical tradition, and they usually are fairly transparently related 
to a verb of the first binyan or perhaps a noun. They are almost always intransitive.

They form a natural class in the prosodic template notation, since all of them are formed on the prosodic template CCVCCVC generated by $(5 b)$. They are also peculiar in having affixal material -- infixes $\underline{w}, \underline{n}$, suffix $\underline{y}$-- that is in no way associated from left-to-right. These affixes are lodged quite far from the left end of the stem. There seems to be no reason to suppose that a flop rule is operating here, so the additional complication of these very rare conjugations is that the affixes must indicate where they are to be associated on the prosodic template:

(21)
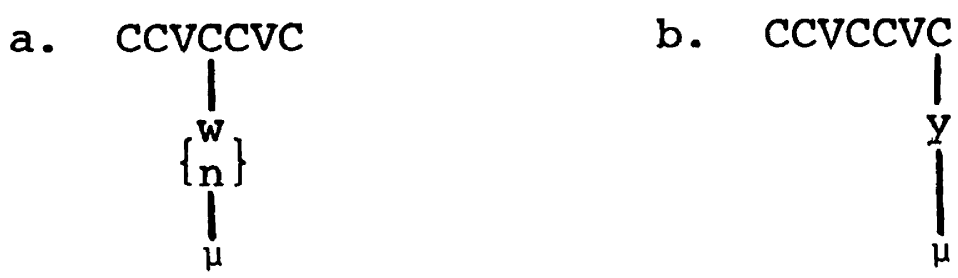

Except for these two special associations, the usual left-to-right apparatus works on the root consonants, yielding the following outputs for the XII-XV binyanim:

a. XII

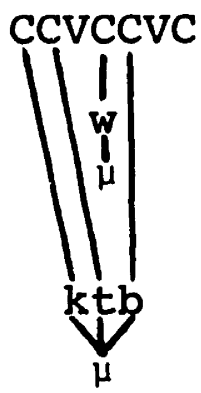

[root] b. XIII

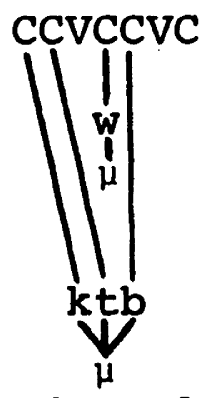

[root] c. XIV

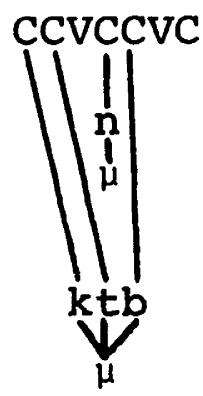

[root] d. XV

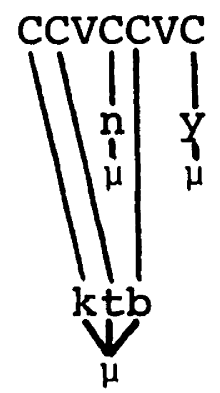

[root] 
The form ktanbay in (22d) is the correct result and so requires no further comment. (22c) needs only automatic spreading of the final root consonant to the final c-slot to yield the expected gemination. (22a) and (22b), on the other hand, are subject to the same erasure rule (18) as the second and fifth binyanim, with identical results:

(23) a.

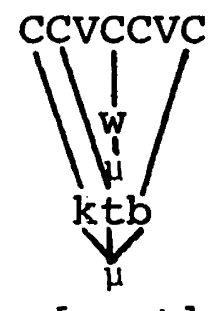

[root]

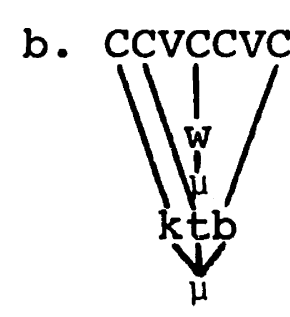

[root]

After erasure, we expect reassociation from the nearest consonant slot on the left -- in this case, w. But since the root and the infix are representations on separate autosegmental tiers, it is possible to reassociate from either the infixed $\underline{w}$ or from the second root consonant $\underline{t}$ and still conform at the Well-formedness Condition. In fact, the twelfth and thirteenth binyanim differ on exactly that point -- on whether the infix or the second root consonant is geminated: XII ktawtab, XIII ktawwab. The final result is the representations in (24):

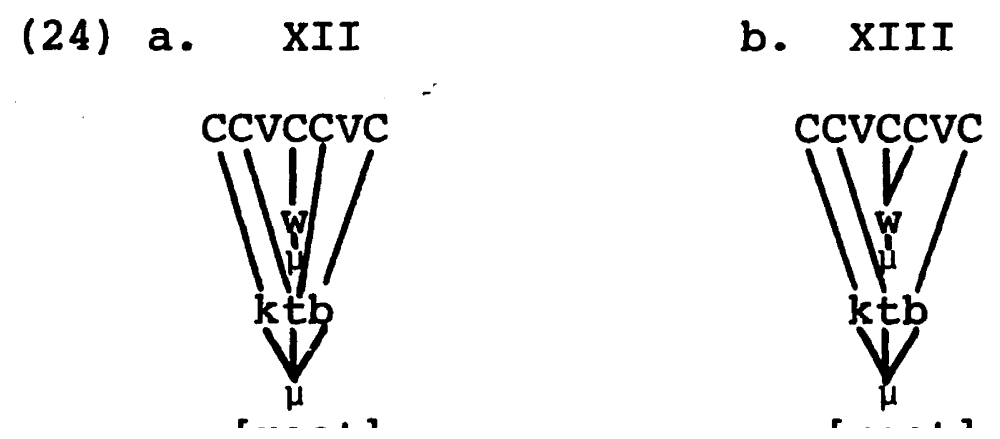


My general conclusion is that these rare binyaniin require no more theoretical or grammatical apparatus than the more common binyanim other than the peculiar affixes in (21). They can be subsumed under basically the same rubrics. The same is true even more dramatically for the quadriliteral verb forms.

Arabic recognizes four quadriliteral binyanim, the first two fairly common and the last two rather rare. In genera.l, quadriliteral roots are a good deal rarer than triliteral ones, though some of them are reasonably frequent. There are certain evident similarities between the quadriliteral and triliteral binyanim, some of which were recognized in the classical grammatical tradition. In several respects we can identify all the quadriliteral binyanim with corresponding triliteral ones. First consider the formal characteristics:

$\begin{array}{lcc}\text { a. } & \text { II } & \text { QI } \\ \text { kattab } & \text { dahraj } \\ \text { b. } & \text { V } & \text { QII } \\ \text { takattab } & \text { tadaḥraj } \\ \text { c. } \quad \text { XIV } & \text { QIII } \\ \text { ktanbab } & \text { dhanraj } \\ \text { d. XI } & \text { QIV } \\ \text { ktaabab } & \text { dharjaj }\end{array}$


The formal similarities between corresponding triliteral and quadriliteral binyanim are quite clear in terms of the analysis proposed here. In every case the corresponding forms in both columns are built on the same prosodic template and have the same affixes $\underline{t}$ and $\underline{n}$. Moreover, this affix $\underline{t}$ can be identified by a readjustment rule deleting it after a homophonous agreement prefix. This rule applies equally in binyanim $\mathrm{V}$ and QII. A partial exception to the overall similarity in (25) is (25d), where both forms result from the same prosodic template but with different realizations of the template slot that is designated only as [+seg]. Further similarities hold at other levels. Although QI is not generally causative like the second triliteral binyan, the other quadriliterals share some semantic correspondences with triliterals. The second quadriliteral is, like the fifth triliteral, generally reflexive (tasaltan 'make oneself sultan') or resultative (tašaytan 'act like a devil'). QIII and QIV are, like their triliteral correspondents, generally intransitive and stative. We shall also see later that there are significant similarities between quadriliterals and triliterals in the Ablaut classes of the verb and in the formation of infinitives from these verbs. Therefoie we need not stipulate four other binyanim that are restricted to guadriliteral roots. Rather, it is enough to notate fcur of the triliteral binyanim as also allowing the application of quadriliteral roots to their 
templates: binyanim II, V, XIV, and XI (where [tseg] is C). The direct result of mapping of affixes and left-to-right association of the four-consonant root dhrj is:

(26)

a. QI

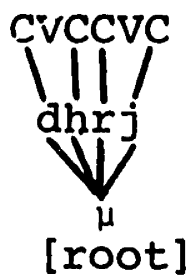

b. QII

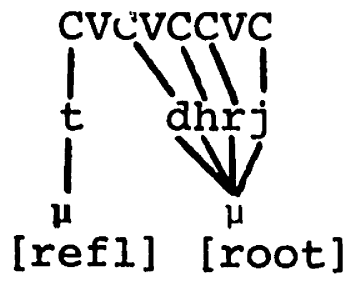

C. QIII

d. QIV

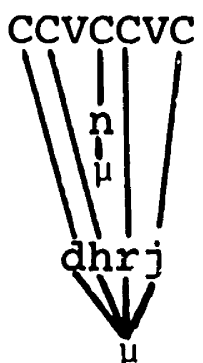

[root]

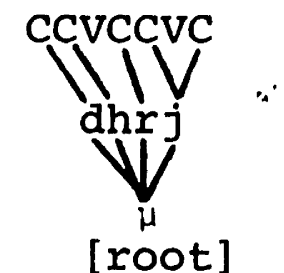

[root]

The gemination in (26d) is a familiar result of rightward spreading. One question raised by these forms is why, if QI and QII are actually just instances of the second and fifth triliteral binyan, the Second, Fifth Binyan Erasure rule (18) doesn't apply in (26a) and (26b). Since these forms are in the second and fifth binyanim, we would expect erasure of the association between the root consonant $\underline{r}$ and its slot on the template. Actually the erasure rule is prevented from applying by general principles, since any new association of $\underline{r}$ to the right would yield a prohibited many-to-one mapping.

In sum, the whole quadriliteral scheme requires no elaboration of the apparatus and bears clear and demonstrably correct formal relationships to corresponding triliteral binyanim. 
Another empirical consequence of this theory lies in the treatment of so-called geminate roots in Arabic. There is quite a number of roots (perhaps 200) whose second and third radicals are identical: smm, bll, mdd, etc. Greenberg's (1978) statistical study also found about 20 verb roots with identical first and third radicals: qlg, ndn. There is also a large number of roots restricted to nouns with identical first and third radicals: $\underline{\theta l a a \theta}$ 'three'. But certainly in Arabic, ard reasonably confidently in the other major Semitic languages, there are no roots of verbs or nouns with identical first and second radicals, except for the unique Arabic noun dadan, a nursery word for 'plaything', and a few verbs in Modern Hebrew. The grammars also note a unique Arabic root yyy, which means, as a first binyan verb, 'to write the letter $y$ '.

This asymmetry in distributional restrictions between first and second position versus other positions has not yet received a satisfactory explanation. Consider two representative roots with identical radicals in the permitted positions, like $\mathrm{glg}$ and smm. The first, $\underline{\mathrm{glg}}$, is unremarkable in the autosegmental treatment, and is formally indistinguishable from entirely regular roots like ktb. But the second, smm, as well as all other geminate roots, must be represented formally as a biliteral root sm according to the revised obligatory Contour Principle presented in section 2.5 This principle says that adjacent identical autosegments are 
prohibited. This holds for each morpheme separately or, strictly speaking, for each morphologically-defined autosegmental tier. Consequently it does not apply to heteromorphemic sequences of adjacent identical units. Now notice that if there were a traditional root of the nonoccurring type designated as ssm, this root would be formally identical to smm because of the operation of the Obligatory Contour Principle. Given this apparatus, the Consonant Association rule can explain the absence of verbs or nouns like sasam versus the existence of samam.

Now consider the mapping of the biliteral root onto the prosodic template of the first binyan perfective:

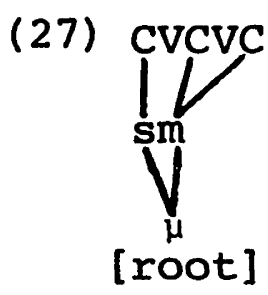

(samam)

Because mapping is left to right, the second radical is geminated by automatic spreading. This gemination has nothing to do with the morphology of any binyan -- it depends only on filling up the available slots. Given left to right mapping, though, there is no way, short of additional unmotivated rules, to induce gemination of the first radical, so we will never end up with first binyan verbs like *sasam. This is, in fact, exactly the right result, and it clearly accounts for this tremendous skewing of the Arabic (and Semitic) lexicon. 
In brief, Arabj.c allows roots of two, three, and four consonants, all of them subject to the obligatory Contour Principle. Biconsonantal roots are realized on the surface with gemination of the second consonant as a direct consequence of the Consonant Association Rule and the Well-formedness Condition. Note also that the obligatory Contour Principle excludes quadriliteral roots with adjacent identical autosegments, like hypothetical *darj or *drrj. In fact, this is the right result; thare are no QI verbs of the type *dadraj.

Notice that, because of the autosegmental treatment, there is a particular formal characteristic shared by biliteral roots and those triliteral and quadriliteral roots that appear in binyanim with characteristic gemination. In every case gemination is represented formally as a oneto-many association from the root tier to the prosodic template. This representation does not hold, however, of adjacent identical consonants that come from different morphemes, like root and affix. This makes a difference in the conditioning of a phonological rule of some generality.

The alternations in inflected forms of a biliteral root in (27a) are paralleled by alternations of a triliteral root in the ninth and eleventh binyanim in (27b) and of a quadriliteral root in the QIV binyan in (27c): 

a. samamtu 'I poisoned'
yasmumna 'they (f.) will poison' yasummu 'he will poison' samma 'he poisoned'
b. sfarartu 'I was yellow' sfarra 'he was yellow' c. Smaglaltu 'I hastened' šma9alla 'he hastened'

Roughly, the generalization emerges from (27) that if the second of two identical consonants is followed by a vowel, then the identical consonants are brought together into a cluster. What is significant is that this process does not apply to identical consonants that do not belong to the same root. Thus the eighth binyan ktatab does not become *kattab, since the first $\underline{t}$ is affixal and the second is radical. The same situation holds for $V$ yatatabba9u 'he will pursue' and VI yatataaba9u 'he will succeed' where the secord $t$ is the first consonant of the roc tb9. The process also fails with magatataa 'they (f. du.) detested'. where the first $\underline{t}$ is part of the root mgt and the second is an inflectional affix of the feminine.

Although these facts seem to demand some baroque morphological conditions, there is in fact quite a simple solution under the analysis presented here. All cases where the cluster-forming process does apply are those in which the identical consonants are represented by the association of a single consonantal autosegment with two slots of the 
prosodic template. The process fails to apply when the identical consonants are in different morphemes, and consequently appear on different autosegmental tiers. In this case there is no many-to-one association. Therefore it suffices to say that the process applies only to template positions that are associated with the same element on the autosegmental tier. If we suppose, following Brame (1970), that the cluster-forming process is a metathesis rule, then it can be formulated as in (28):

(28) Metathesis

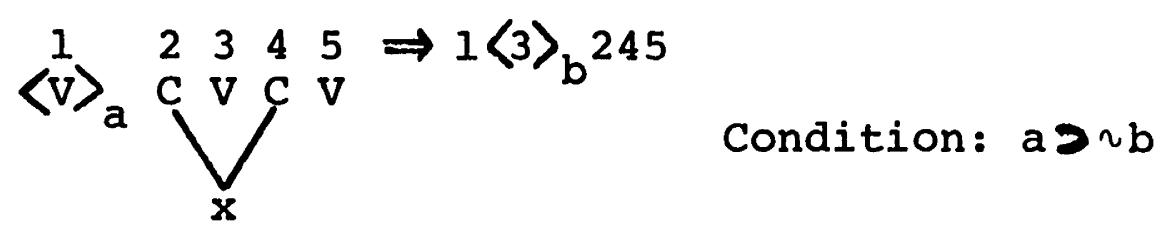

The angled brackets and the condition distinguish the two cases on the left and on the right in (27a). These aspects of the rule are not under consideration here, and could be reformulated. What is relevant, though, is the fact that both affected consonants must be associated with the same autosegmental element $x$; it does not suffice that they be identical. Metathesis will therefore apply to the geminated root consonants in (27), but it will be unable to apply to the forms cited above where the identical consonants are represented on separate autosegmental tiers since they are in different morphemes. 6 
There is still another consequence of this analysis for biliteral roots, but it does not appear directly in Arabic for historical reasons. It does, however, hold clearly in Tiberian Hebrew. Prince (1975) claims, convincingly I think, that verbs whose Arabic reflexes have a high glide as middle radical have been reanalyzed in Hebrew as essentially CVVC verbs with historical loss of the medial glide. In the traditional jargon, these are known as hollow verbs because of their lack of a middle radical. Under the treatment here, these Hebrew verbs have biliteral roots but also a special CVVC prosodic template that distinguishes them from biliteral verbs of the smm type.

In Arabic, where this reanalysis has not taken place, the second and fifth binyanim of hollow roots are just the same as those of other roots. They have gemination of the medial radical: gawwam, tagawwam. Hebrew has reflexes of the second and fifth binyanim, known as the pigel and hitpa9el. With ordinary triliteral roots these have the expected gemination of the medial radical kittēb, hitkattêb. But hollow verbs do not directly follow this type (except for rare forms in the later books like Esther, Ezra, and Ruth, which may reflect Aramaic borrowing). Instead, the grammatical tradition recognizes two special binyanim for hollow verbs, the polel and hitpolel: 'gömēm 'to set: up' Is 44,26; hitgōmem ' to get up' Ps 17,7, corresponding to the first binyan verb gâm 'to get up'. These special hollow verb 
binyanim have the same semantic force, causative and reflexive respectively, as the corresponding pi9el and hitpagel. Formally, the prosodic templates of the Hebrew pigel and hitpa9el are very similar to those of the corresponding Arabic binyanim, as are the association rules (including the Erasure rule):

(29)
a. Pi9el
b. Hitpa9el

CVCCVC

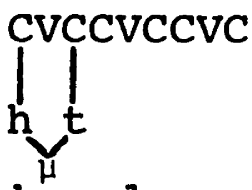

In (29b) I have already indicated the placement of the affixes that are peculiar to the Hebrew hitpa9el. For the hollow verbs, these prosodic templates are modified in only one respect: just as in the first binyan of hollow verbs, vowel length is substituted for one of the consonantal positions :

(30) a. CVVCVC

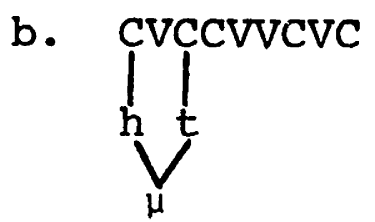

Mapping of the biliteral hollow root gm onto this pair of templates in (30) yields, by the usual left to right association, automatic gemination of the final radical in order to fill out the prosodic template: 
(31)

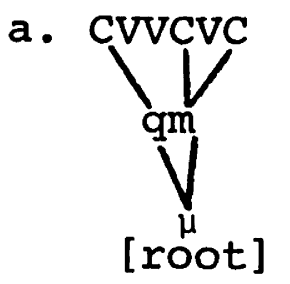

b.

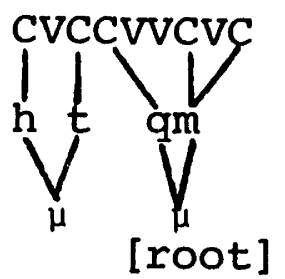

(hitqōōēm)

Therefore these Hebrew biliteral roots, which have a different historical source than the Arabic biliteral roots, show further how a kind of shortage of root consonants is dealt with automatically by spreading of the rightmost consonant.

Further evidence comes from consideration of the behavior of geminate roots in Hebrew. Geminate roots, like hollow roots, are formally represented as biliteral. The only difference between them lies in the fact that hollow roots have the special substitution of vowel length for a syllable-closing consonant, the property that distinguishes the prosodic templates in (29) from those in (30). Not surprisingly, there was some confusion between the two types of biliteral roots, with geminate verbs often appearing with the polel and hitpolel morphology of hollow verbs: 901ēl 'to ill-treat', hit9ס1ēl 'id. (reflexive)', corresponding to the hitpa9el verb hit9allēl 'to vex'. When his occurs, it apparently reflects dual lexical entries, since some geminate roots are attested in both types with somewhat different meanings: hinnēn 'to make pleasing', hionēn 'to have pity'; sibbēb 'to turn', sōbēb 'to go round'. Further confusions of the two ciasses abound in the Hebrew first binyan. 
This mixing of historically distinct root classes can be readily understood with the analysis presented here. After roots like gwm had been reanalyzed as gm, there was nothing to distinguish them as roots from the inherited biliteral roots like sm. They were thus available for the profusion of new morphological developments just described.

This theory also predicts the occurrence of doubly reduplicated root consonants. The only limitation on such reduplication is the difference between the number of root consonants and the number of empty consonantal slots in the template. Arabic routinely shows double reduplication in the second and fifth binyanim with roots like sm: sammam, tasammam. These are represented formally as:

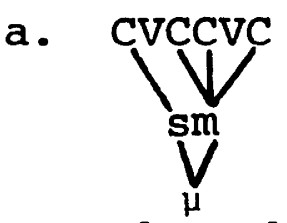

[root] b.

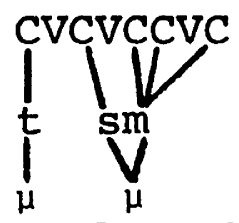

[root]

In these cases the erasure rule of the second and fifth binyanim will obviously apply vacuously. Akkadian even displays a rare deadjectival binyan that has double reduplication as one of its characteristic properties: Šuharrur 'be dumbfounded', sugammum 'be quiet as death'. Here again the left-to-right mapping has resulted in quite extensive spreading of a single root consonant. Also see footnote 6 for the significance of (32) in the formulation of Metathesis. 
Another kind of reduplication is quite interesting because it shows how far the notions of association and morphologically-defined tier can take us in dealing with problematic morphological types. In Arabic a number of quadriliteral verbs are of the pattern $C_{i} \mathrm{VC}_{j} \mathrm{C}_{i} \mathrm{VC}_{j}$ : ğarğar 'to gargle', waswas 'to whisper', zalzal 'to shake'. As is apparent from the glosses, these forms have some sort of elusive phonoesthetic effect. These words are not generally related to any triliteral verbs, so there is little evidence here for even a partly productive morphological category. Therefore I will concentrate my attention on Hebrew, where this evidence does exist. My remarks about the formal character of this sort of reduplication hold equally well for Arabic, so nothing really depends on switching languages here.

In Hebrew, traditional grammar recognizes a binyan known as the pilpel, and a related reflexive hitpalpel. In attested cases these can be formed from both biliteral historical root types: 
(33)

a. root:

first binyan:

pilpel:

hitpalpel:

b. root:

first binyan:

pilpel:

hitpalpel: gl

gālal 'to roll (intrans.)'

gilgēl 'to roll (trans.)'

hitgalgêl 'to roll o.s. along'

รैง

ร̌â9a 'to be smeared'

šigăśa9 'to stroke'

hišta9ắa9 'to indulge oneself'

Semantically, the pilpel generally has the usual transitivizing or causative force of the pigel (=Arabic second binyan), while the hitpalpel is a reflexive like the hitpa.9el (=Arabic fifth binyan). In formal terms, the pilpel and the hitpalpel are just instances of the Hebrew reflexes of the Arabic second and fifth binyanim, with which they share similar semantics and identical prosodic templates.

The autosegmental interpretation of these facts is that a biconsonatal root is expanded to fit a tempiate -- the CVCCVC iemplate of the causarive and CVCCVCCVC of the reflexive -- with four available slots. But in this case the expansion is not by reduplication of a single root consonant but rather by reduplicating the entire root. Now since we have a notion of morphological tier, it is possible to speak of a mapping between morpheme positions rather than directly between a morpheme and the corresponding template. That is, the root is reduplicated by a one-to-many morpheme to morpheme 
association, and then these morphemes are mapped onto the prosodic template. I will represent this formally in the following way:

(34)

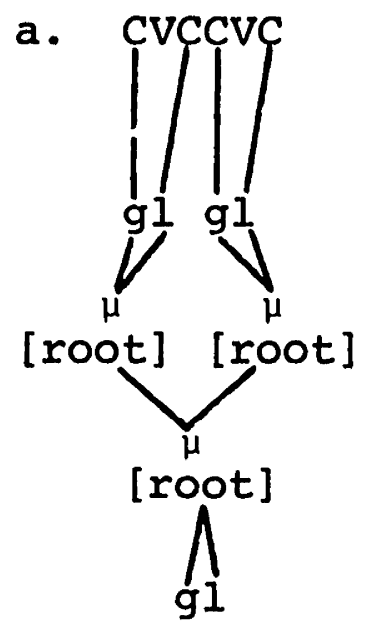

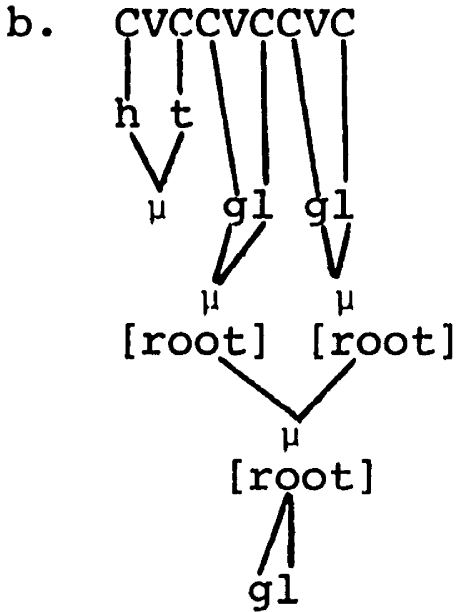

That is, reduplication is accomplished here by mapping one root morpheme onto two root morpheme positions in a separate tier. The units contained in these derivative morphemes are then mapped onto the prosodic template. All of this mapping follows directly from the Well-formedness condition. The sole thing that is stipulated is that verbs of this type in Hebrew (or in Arabic) have associated with them two positions labeled [root]' so the root can be reduplicated. This extra stipulation is justified because the usual result of mapping a biconsonantal root onto a four-slot template is double reduplication, like sibbēb 'he surrounded'. Reduplication of the entire root is limited to a lexicallygoverned class of verbs.

Clearly this mechanism will work in Arabic, and moreover Arabic has some additional evidence that verbs like zalzala constitute a definable class. One bit of evidence 
is the semantic consistency of this class alluded to earlier, where these forms seem to refer to repeated, iterative operations. A much stronger argument lies in the formation of gerunds or infinitives from verbs of this class. Verbs like zalzala often form gerunds of the pattern zalzaal, ğalğaal, and so on. However, no other triliteral or quadriliteral verb can form a gerund of this pattern. Therefore the rule responsible for just this type of gerund must be able to refer directly to verbs with reduplicated biconsonantal roots. The theory offered here allows exactly this, since verbs of this type all have a double [root] slot associated with them.

A small extension of this theory also handles the forms in a very rare binyan of Hebrew that is relatively common in Ethiopic. This is the so-called pagal9al, which seems to be connected with intensification of some sort. For instance, corresponding to the first binyan form sāhar 'to go about' is the pagal9al form saharhar 'to palpitate'. Clearly here it is not the whole root that is reduplicated, but rather the final syllable of the stem. Now the prosodic template of the pa9al9al is somewhat anomalous in Hebrew, since it involves an otherwise nonoccurring CVCVCCVC prosodic template. I suggest that it is derived from the CVCVC template of the first binyan by suffixation of CVC, and that then the syllables of the first binyan are mapped -- as always, from left-to-right -- onto the syllables of this 
new template. The notation for syllable structure used here is developed in Chapter 2:

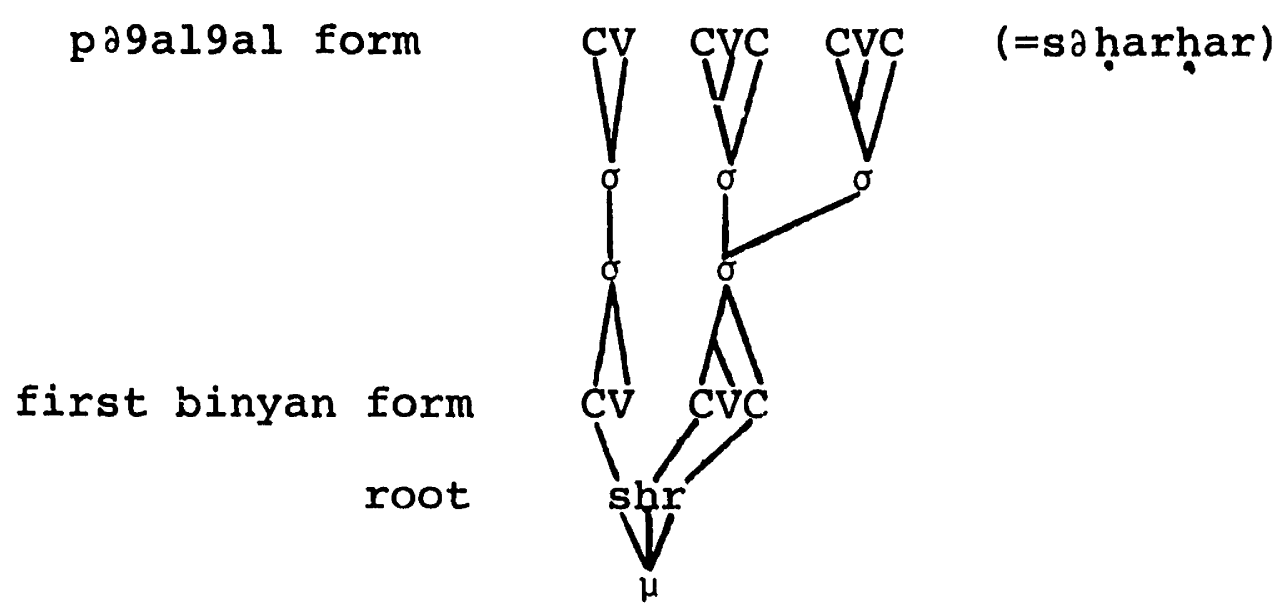

This treatment of reduplication is obviously of great intrinsic interest. One of the major results of it is that reduplication is limited to units that can be referred to as constituents on some level, since the mapping inherently deals in constituents. Another is that, as we saw in the case of Arabic gerunds, a formal trace of reduplication is maintained by the multiple association lines, suggesting a new solution to apparent postphonological reduplication. These and other issues are dealt with in the concluding section of this chapter. For now let me just point out one or two specifically semitic consequeices of this treatment. Because mapping is from left-to-right unless otherwise stipulated, it is impossible to reduplicate the initial syllable rather than the final syllable, as in (35). This follows from the same considerations that came up in the treatment of the nonexistence of verbs like *sasam. In fact, I know of ro systematic forms of this sort anywhere in Semitic, 
though there are very sporadic nouns. The idea of root reduplication in forms like gilgêl also supports the formal treatment of them as biconsonantal roots, as required by the modified obligatory Contour Principle. It is quite difficult to see how any analysis would create gilgēl out of a triconsonantal root like gll.

There is still another result of these proposals that can be stated very briefly. Arabic has some quinqueliteral roots that appear in nouns. These are invariably loan words or, in a few cases, acronyms. There are some examples of denominal verbs derived from these nouns quite transparently. When this happens, the final consonant of the root just disappears, and the result is a typical quadriliteral verb: magnatiiš 'magnet', magnaț 'to magnetize'; galansuw (at) 'cap', taqalnas 'to wear a cap'. These verb forms are from the first and second quadriliteral binyanim respectively. Supposing that we have left-to-right association, a root like mgnts will associated with the CVCCVC prosodic template as in (36):

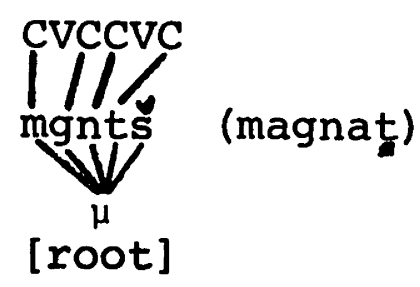

What happens is that the normal association leaves $\underline{s}$ stranded at the right without a consonantal slot. It cannot attach to any of the already filled slots because of 
the general prohibition against many-to-one associations. Consequently final š remains unattached and receives no phonetic realization. The left-to-right mapping correctly predicts that the unassociated consonant will be at the right side of the root. We will see this behavior much more extensively later in the treatment of noun morphology. What is perhaps the strongest argument in support of this theory has to do with the question of what particular verbs are derived from. This also necessarily introduces us to the problem of the form of the lexical entries and of the rules of the morphological component, though resolution of this question will have to wait until the final section. The basic issue here is the derivational source of the various binyanim -- what other forms in the language they appear to be most closely related to and derived from. This question is very difficult to answer for the first Arabic binyan. It is probably never derived from a verb of some other binyan, but it is usually impossible to say whether some nouns are derived from this binyan or this binyan from the nouns. Consequently I will not discuss the source of the first binyan further in this section.

But there is often clear evidence of a particular derivational source for a given verb of some other binyan. This sort of evidence includes the absence of any other binyanim (including the first) formed on the root, and specific 
semantic relationships to particular related nouns or verbs. It is this sort of evidence that is reflected in the following generalizations.

The forms in most binyanim, except the first, are derived from other binyanim of the same root or from nouns of the same root. I refer to these two types as deverbal and denominal respectively. For instance, some representative derivational relationships are:

(37) a. II

Deverbal: 9allam 'teach' + I 9alim 'know' $k a \delta \delta a b$ 'consider a liar' + I ka $\delta a b$ 'lie'

Denominal: marraḍ 'nurse' + mariiḍ 'sick'

$$
\begin{gathered}
\text { kabbar 'say battle + ?alaahu ?akbar } \\
\text { cry' }
\end{gathered}
$$

b. III

Deverbal: kaatab 'correspona' + I katab 'write' raasal 'correspond' + IV ?arsa]. 'dispatch'

Denominal: saafar 'travel' + safar 'a journey'

c. IV

Deverbal: ?ajlas 'to seat' + I jalas 'sit' ?a?kal 'feed' + I ?akal 'eat'

Denominal: ?aš?am 'go to Syria' + Śa?m 'Syria'

d. $x$

Deverbal: stawjab 'consider 4 I wajab 'be necessary' necessary for onself' staslam 'surrender onself' + IV ?aslam

'surrender'

Denominal: stawzar 'appoint as + waziir 'vizier' 
Several interesting properties of the binyanim emerge from (37). First, it is clear that these five binyanim allow both nominal and verbal derivational sources for the forms of different roots. In the examples given, the first and fourth binyanim both occur as derivational sources, as well as a number of different noun patterns. The second property is that there is no relationship between the form of the source and the form of the output except for the root consonants. Therefore a fourth binyan verb could come from a first binyan verb CaCaC or from a noun of the pattern, say, Cacc. Every property of the source except its root is ignored in the form of the derived binyan. This striking fact is perhaps the most interesting characteristic of the distinctive Semitic root and pattern morphology •

Formally, this means that whatever sort of rule relates a derived verb to its source, that rule will have to ignore the formal characteristics of the source except for the root. It will have to be able to isolate the root from the vowel quality and from canonical distribution of consonants and vowels represented here by the prosodic template. Under the theory proposed here the solution to this problem is almost trivial: the root is isolable by any rule as the morpheme marked $\underset{[r o o t]}{\mu}$. On the other hand, it is almost impossible to see how an essentially segmental transformational approach would deal with the relationships in (37). For 
instance, to fit wajab, ?aslam, and wazlir all into the tenth binyan would require a transformational apparatus of tremendous complexity. Any mechanism able to accomplish this transformationally would necessarily be capable of any operation on a string of finite length made up of elements from a finite vocabulary. Obviously this is far too powerful, since we have seen a number of cases where there are very specific constraints on the degree of freedom in Arabic verbal morpholngy. I conclude then that the notions of prosodic templates and roots as autosegmental melodies provide the most interesting and restrictive account available of Arabic verbal morphology. These issues -- both of the form of morphological rules and of the derivational relationships involved -- are dealt with in much greater depth in section 5 of this chapter.

\subsection{Vocalism}

As I have already observed, certain verbal categories like aspect and voice are marked on the various binyanim not by the typical disarrangement of consonantism but rather by altering the quality of the vowels of the stem in a systematic way. This is interestingly untrue of the first triliteral binyan, so my subsequent remarks in this section are restricted to the other binyanim, and I will return to the problem of the first binyan lacer. 
Let us examine the nature of this systematic variation in vowel quality. In the first column of table 1 above, the stem contains from two to four vocalic morae, all of which are $\underline{\text { a. }}$ In the second column, the last vowel is $\underline{i}$ but the other one to three vowels are $\underline{u}$. Skip the third column for the moment, proceeding in the same way with the remaining columns. The net result is the following set of vowel patterns associated with verbal categories:

$$
\begin{aligned}
& \text { Perfective Active } \\
& \text { Perfective Passive } \\
& \text { Imperfective Passive } \\
& \text { Active Participle } \\
& \text { Passive Participle }
\end{aligned}
$$

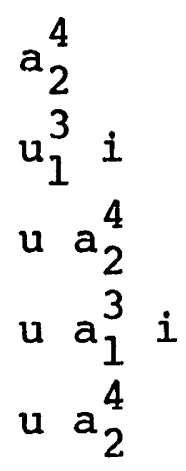

Each of these verbal vowel patterns serves for all binyanim but I. Each pattern has one vowel that spreads to fill up all the spaces in the stem except those that are occupied by other vowels fixed at either end of the stem. Therefore we have two generalizations to acceunt for: i. The categories in (38) do not alter the canonical shape of the stem.

ii. The categories in (38) do alter vowel quality. The one exception to the first of these generalizations is that the imperfective apparently has prefixed $V$ and the participles have prefixed $\underline{\mathrm{mV}}$ on the stems of the binyanim 
generated by the apparatus in section 3.1. Actually, both imperfective and participle prefix $\mathrm{CV}$, and the affix associated with $\mathrm{C}$ is dependent on agreement in the imperfective and is invariably $\underline{m}$ in the participle. More will be said about this in subsequent sections. For now, we can simply state the generalization:

(39) Prefixation

$$
\left.\emptyset \rightarrow c V /\left[\begin{array}{l}
\text { imperfective } \\
\text { participle }
\end{array}\right]\right]^{[}
$$

That is, the stem of the imperfective and of the participle receives a $\mathrm{CV}$ prefix.

Apart from this, it is apparent that the difference in the categories of (37) is solely a difference in the quality of the vowels. Consequently we can isolate melodies from each of the vowel patterns in (37). These melodies are the morphemes induced by the indicated categories:

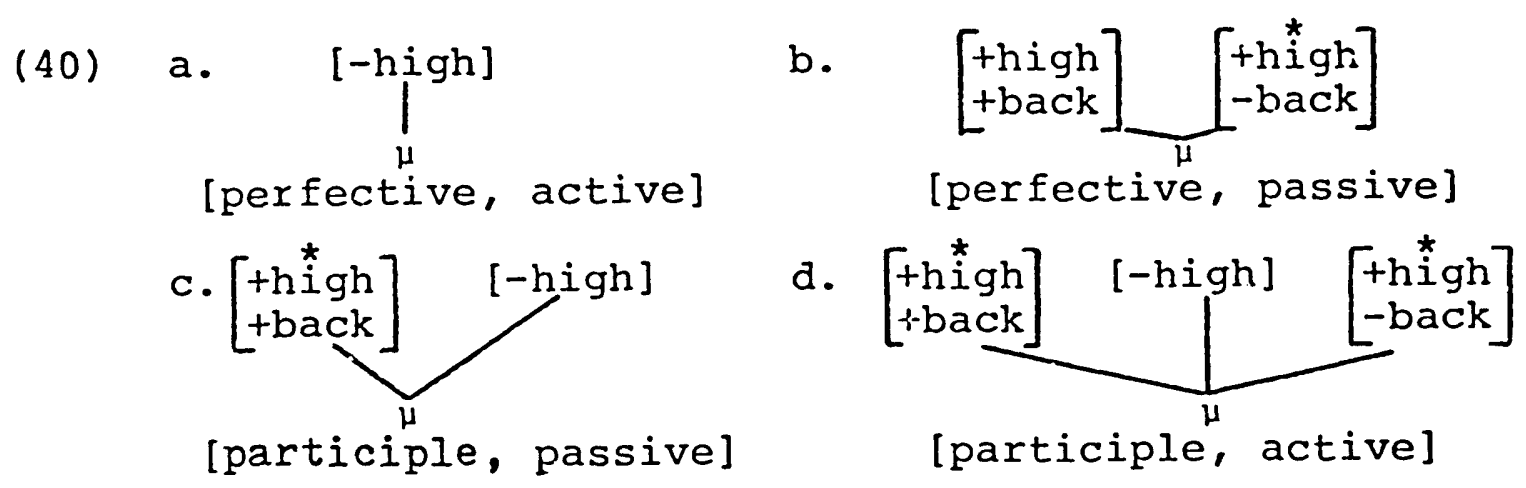


Because the mapping of these and other vocalj.c melodies does not follow the left-to-right rule of Consonant Assoriation developed in the preceding section, I have simply marked the nonspreading elements of the melodies with an asterisk. This is a preliminary, ad hoc device, and our next task is to eliminate these asterisks.

It is clear frcm the melodies of the perfect passive and active participle that an i-melody never spreads. Furthermore, this melody is fixed on the rightmost vowel of the stem. Other categories show that an $\underline{u}$-melody fails to spread if it precedes an a-melody. This melody is fixed on the leftmost stem vowel. Therefore we can posit two rules that associate melodies with vowels:

(41) Vowel Association

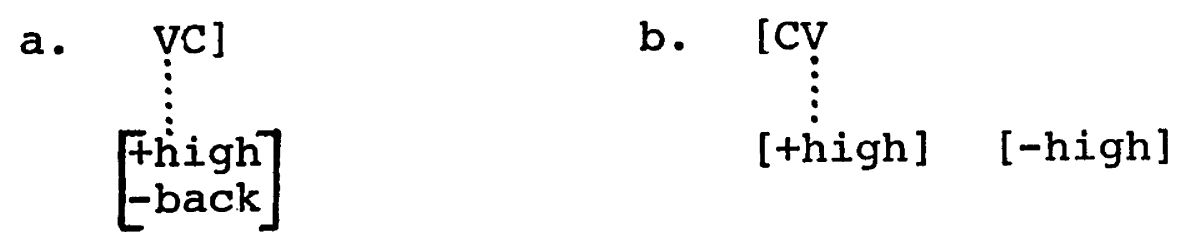

Rule (41) accounts directly for the fact that certain melodic elements are associated with the leftmost or rightmost vowel of the stem. But it also characterizes the autosegments that do not spread. Recall the principle presented in the introduction, due originally to Goldsmith (1976): in spreading, an unassociated element takes precedence over any that are already associated. Therefore any melodic elements that 
are unassociated after (41) has applied will automatically sprerd. No further stipulations are needed.

A few sample derivations of the vocal.ism run as follows:

(42) a. CVCVCVVCVC b. CCVCVC c. CVCVVCVC

by $(\leqslant 1)$

by WellFormedness Condition
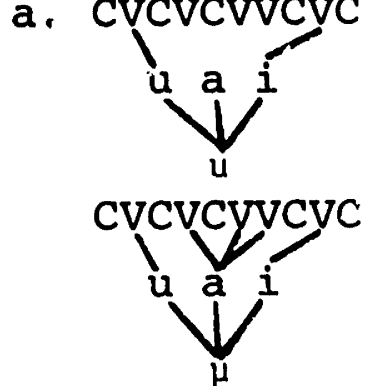

(mutakaatib)

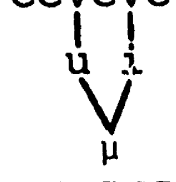

CCVCVC

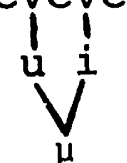

(ktutib)

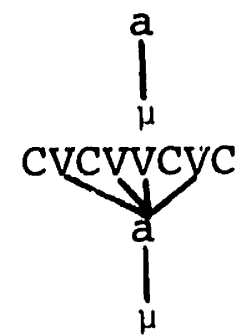

(takaatab)

There are certain interesting alternations among the various melodies under particular morphological conditions. Notably, the third column of table one displays several different vowel patterns associated with the imperfective active of the various binyanim. Three different melodies occur (again, the asterisk marks a nonspreading element):
(43) Binyanim
Melodies
a. II, III, IV, QI
$\left[\begin{array}{l}\text { +high } \\ \text { +back }\end{array}\right]$
$\left[-\right.$ high $\left._{1}^{2}\right] \quad\left[\begin{array}{l}\text { +hì } \\ \text {-back }\end{array}\right]$
b. $\quad \mathrm{VII}, \mathrm{VIII}, \mathrm{IX}, \mathrm{X}, \mathrm{XI}, \mathrm{XII}$,
$\mathrm{XIII}, \mathrm{XIV}, \mathrm{XV}, \mathrm{QIII}, \mathrm{QIV}$
[-high $\quad\left[\begin{array}{l}\text {-bäck } \\ \text { thigh }\end{array}\right]$
c. V, VI, QII
[-high $]$

Certain generalizations about the tabulation in (43) are evident and wight to be captured by any treatment. Melcdy (13a) u- $\underline{\text { u}}-\underline{i}$ occuro if and only j.f the first syllable 
of the imperfective stem is open and the second syllable is closed or contains a long vowel. Melody (43c) a occurs if and only if the imperfectlve stem contains a $t$ prefix, though a $\underline{t}$ infix won't do. When neither of these conditions is fulfilled, the melody is invariably the one in (43b).

Let us suppose that (43a) is the basic melody for all imperfective verbs other than the first binyan and that particular modifications of it yield (43b) and (43c). One clear fact in support of this assumption is the fact that the active participle displays the (43a) melody without any variation in different binyanim. Since the passive participle has the same melody as the imperfective passive, we could then generally treat both participles as forms with m prefixed onto the basic imperfective sten. This is dealt with below in the analysis of nouns.

First, it is clear that (43a) is compatible with the vowel mapping rules already developed. Therefore we can eliminate the asterisks from the melody and just take it as given that all imperfectives initially have u associated with the first syllable, 1 with the final syllable, and $\underline{a}$ with any intervening ones.

Given this underlying representation, the second problem is to write a rule to delete the u portion of the melody under certain segmental conditions: when the vowel associated with $\underline{u}$ is either in a closed syllable or is in an open syllable followed by an open syllable, This context of $\underline{u}$ 
deletion is an inherently interesting one since it mimics a major property of many accentual rules. It establishes a formal equivalence between two light syllables and a heavy syllable. If we think of the context in terms of moras, then given two successive moras, $\underline{u}$ associated with the first of them is deleted. In the theory of accentuation developed in Chapter 3, generalizations of this sort are expressed on a projection of rhymes.

The rhyme projection for the contexts vhere $\underline{u}$ is deleted are in (44a); the context for ux retention is in $(44 b):$

(44)

a.

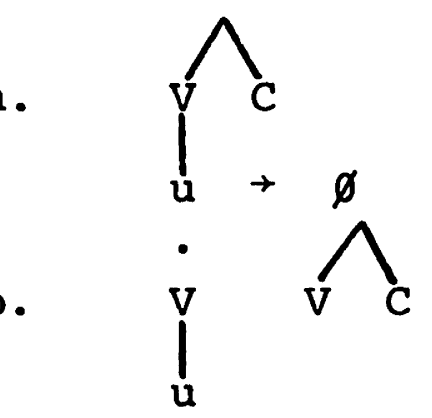

b.

Under the prosodic accentual theory, $\underline{u}$ is deleted if it is associated with the first of the nodes in the structure $\left[\begin{array}{ll}n_{1} & n_{2}\end{array}\right]$, where neither $n_{1}$ nor $n_{2}$ is a branching node. This deletion rule is formalized as (45):

(45) On rhyme projection,

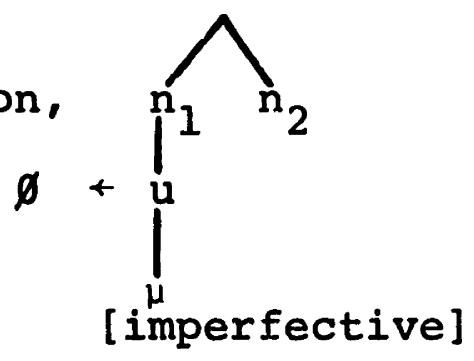

where neither $\mathrm{n}_{1}$ nor $\mathrm{n}_{2}$ branches. 
This new rule is of theoretical interest for two reasons. First, it shows that the mechanisms of rhyme projection and something akin to foot formation are not entirely restricted to accentual processes. It therefore supports the results of Chapter 3. Second, after the application of rule (45), the rubric of automatic spreading under the Well-formedness Condition allows the following a melodic element to fill the lacina created. It is therefore noi an accident that it is a which appears in the first syllable of those binyanim which lack initial u in the imperfective.

The second problem is the lack of $\underline{i}$ in the final syllable of the imperfective of those binyanim which have as a prefix, but not as an infix, the reflexive morpheme $\underline{t}$. Therefore the rule at issue will necessarily distinguish the two different positions of the one morpheme $t$. This property is incorporated into the following rule:

(46)

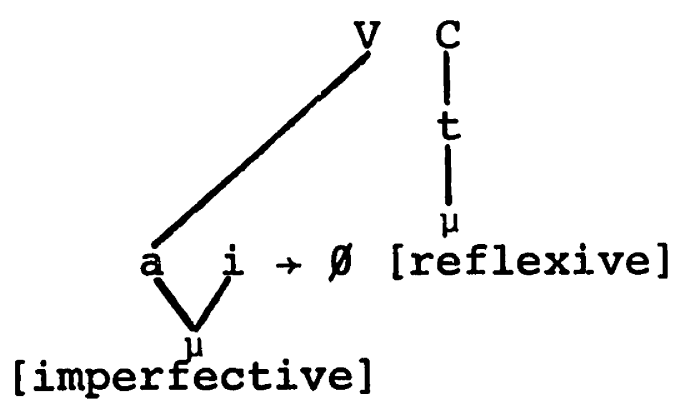

What this rule says is that the $\underline{i}$ portion of the imperfective melody is deleted if the a portion is associated with a vowel that immediately precedes the $t$ reflexive morpheme. 
Both the morphological environments of this rule are essential for its proper application.

Although (46) is complex, it has several advantages over other possible treatments of this pehnomenon. First, it exploits sequential ordering of rules, since it cannot apply until after the u portion of the imperfective melody has been deleted by rule (45). Second, rule (46), like rule (45), need not do any more than delete a portion of the melody, since the fact that the vowel of the final syllable becomes a follows directly from the property of automatic spreading. Third, the most significant feature of (46) is the absence of any essential variables. The phencmenon accounted for by $(46)$ is a clear discontinuous dependency, since the position of prefixal $\underline{t}$ affects the vowel of the final syllable. A purely segmental theory would either express this by an intervening variable (or by the artifice of listing the five or six intervening segments). Even theories that allow essential variables in the phonology have not generally permitted their use in morphological or readjustment rules like (46).

Full sample derivations of the vocalism of a few imperfective forms will run as follows: 
(47)

a. II

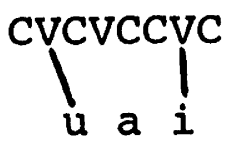

by Vowel

Assoc. (41)

by WFC

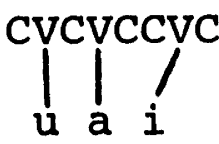

by $(45)$

by $(46)$ b. QIII
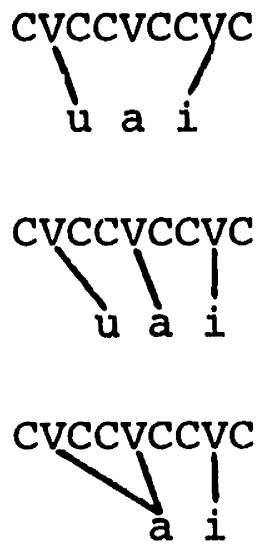

II
C. VI
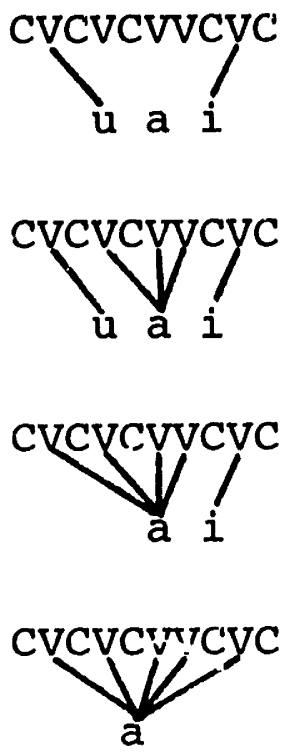

By this set of rules, then, we are able to derive all the variants of the imperfective melody from a single source, u-a- $\underline{\text { i. }}$. We will see later how this source melody can be systematically related to the invariant $\underline{u}-\underline{a}-\underline{i}$ melody of the active participle.

\subsection{The First Binyan}

Let's now consider the issues presented by the rather problematic finite forms of the first binyan. The first binyan is unique in that the canonical pattern of the perfective (CVCVC) differs other than in prefixation of CV by rule (2) from the canonical pattern of the imperfective (CVCCVC). Now the perfective pattern is already consistent with the prosodic template $(5 a)$, repeated below as (48). The imperfective, minus the prefixal $\mathrm{CV}$, can be brought into line with prosodic template (5b) if we allow a further very natural option in its expansion: 


$$
\begin{array}{lll}
\text { a. } & C V((C V)[+s e g]) & C V C \\
\text { b. } & C(C V([+s e g])) & C V C
\end{array}
$$

Therefore, although the selection of a particular expansion of a particular prosodic template is usually incumbent solely on the binyan, in the first triliteral binyan this selection must refer to aspect as well.

A further difference, and a much more complicated one, depends upon the vocalism of the verb. We have seen that it is possible to isolate a single perfective and a single imperfective melcdy for all other binyanim, but this property does not hold for the first triliteral binyan. First of all, in the first binyan the vowel of the initial syllable is invariably a in both aspects. We will record this observation with a special rule inserting this vowel, associated with the first vowel of the stem:

(49)

$$
\begin{aligned}
& \text { [First binyan] [C } \\
& \vdots \\
& \vdots \\
& {\left[\begin{array}{c}
- \text { high } \\
+ \text { back }
\end{array}\right]}
\end{aligned}
$$

Separate generalizations hold for the second syllable. It is subject to alternations in a complex set of Ablaut classes, which are: 
(50)

\begin{tabular}{|c|c|c|c|}
\hline & Perfective & Imperfective & Examples \\
\hline a. & $\mathrm{a}$ & $i$ & $\begin{array}{l}\text { qarab, yaḍrib } \\
\text { 'beat' }\end{array}$ \\
\hline b. & $a$ & $\mathfrak{u}$ & $\begin{array}{l}\text { katab, yaktub } \\
\text { 'write' }\end{array}$ \\
\hline c. & $i$ & $\mathrm{a}$ & $\begin{array}{l}\text { 9alim, ya9lam } \\
\text { 'know' }\end{array}$ \\
\hline $\mathrm{d}$ & $\mathrm{u}$ & $\mathrm{u}$ & $\begin{array}{l}\text { hasun, yahsun } \\
\text { 'be beautiful' }\end{array}$ \\
\hline
\end{tabular}

Some of these Ablaut patterns are associated with verbs of a particular semantic class, though not strictly. (50c) occurs only with verbs that are intransitive and some epistemic and perceptual transitives. (50d) is restricted to verbs that are strictly stative, while (50a) and (50b) never occur with such verbs. It is alleged that statives in $(50 \mathrm{c})$ are trarsitory, while those in (50d) are permanent, but the difference is often quite elusive.

ordinarily the first binyan form of a particular root is restricted to just cne of these Ablaut classes, but some slippage appears. A few verbs are in free variation between (50a) and (50b) like gaţas, yagtcus, ya9tis 'sneeze'. A few verbs also allow variants in the imperfective that belong to no Ablaut class at all: hasib, yahsib, yahsab 'think'. There are other rare cases of anomalous Ablaut, exhausting almost all the possibilities.

It is obvious that we cannot assign any given root uniquely to any Ablaut class. It is further clear that 
there is no unambiguous Ablaut function from perfective to imperfective or vice versa. That is, given any vowel in one aspect we cannot uniquely determine its quality in the other aspect. Nevertheless, it is possible to write a single Ablaut rule from imperfective to perfective if we exclude class (50d), which also has the well-defined semantic property of stativity. This rule, which reflects essentially the same observation as its counterpart in Chomsky and Halle (1968), invokes a polarity shift between aspects on the first binyan melody (before rule (49)):

(51) Ablaut

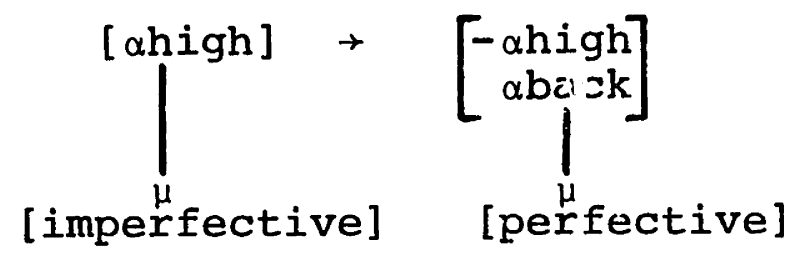

Unlike the formulation given by Chomsky and Halle, rule (51) is a generalization over the perfective and imperfective melodies, rather than the actual vowels of the stem. This has a few extræmely interesting consequences for some facts we have already discussed.

Fiist, consider the melodies of the perfective and imperfective active in the derived binyanim. They are repeated below for convenience: 


$$
\begin{array}{llll}
\text { a. Perfective active } & {[\text {-high }]} \\
\text { b. Imperfective active } & {\left[\begin{array}{l}
\text { +high } \\
+ \text { back }
\end{array}\right]} & {[- \text { high }]} & {\left[\begin{array}{l}
\text { thigh } \\
\text {-back }
\end{array}\right]}
\end{array}
$$

Now if the polarity rule in (5I) is applied to the imperfective melody, it will shift the final $\underline{i}$ of the melody to a. Then, by the revised obligatory Contour Principle discussed earlier in connection with the treatment of biliteral roots, this a collapses with the preceding identical melodic element into the single unit [-high]. Therefore it only remains to delete the initial u portion of the imperfective melody to yield the perfective of the derived binyanim. I will formulate this process as (53):
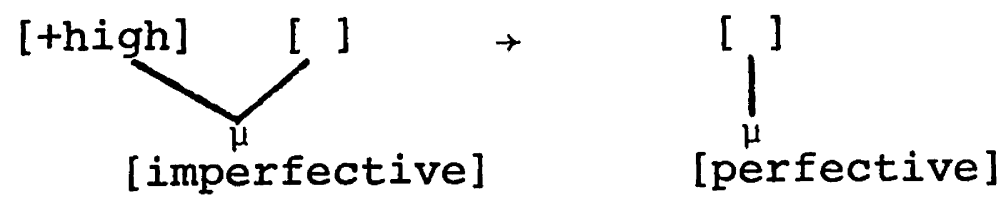

An even stronger argument can be made from the imperfective and perfective passive melodies, repeated in (54):

$$
\begin{array}{lll}
\text { a. Perfective Passive } & {\left[\begin{array}{l}
\text { thigh } \\
\text { +back }
\end{array}\right]} & {\left[\begin{array}{l}
\text { +high } \\
\text {-hack }
\end{array}\right]} \\
\text { b. Imperfective Passive } & {\left[\begin{array}{l}
\text { thigh } \\
\text { +back }
\end{array}\right]} & {[- \text { high }]}
\end{array}
$$


Now notice that the polarity rule in (51) also expresses the relation between these two melodies, but with a further consequence when the melodies are mapped onto segments. The second element of the melody spreads in the imperfective passive, so it is impossible to state the polarity generalization just on vowels, sirce up to four morae might be associated with that melodic element. If (5I) were just a segmental rule (as its counterpart is in Chomsky and Halle (1968)), then applying it directly to the imperfective utakaatab would yield *tukaatib. It is only at the level of the melody that the polarity rule can be extended to the aspect relationships of the passive.

\subsection{Subject Agreement}

Arabic verbs are ordinarily mar:: ad for subject agreement, though full agreement in all features occurs if and only if the subject is a pronouis which is not present on the surface. This is probably the typical case in most languages, and will excite no further comment here.

Perfective verbs are marked for agreement exclusively with suffixes. Agreement in imperfective verbs is chiefly prefixing, though some suffixes occur as well. Right now let"s consider just the suffixes of the perfective and the prefixes of the imperfective, and turn shortly to the suffixes of the imperfective: 
(55) a. Perfective suffixes

\begin{tabular}{|c|c|c|c|c|}
\hline \multicolumn{3}{|c|}{ Singular } & \multirow{2}{*}{$\begin{array}{l}\text { Dual. } \\
\text { aa }\end{array}$} & \multirow{2}{*}{$\begin{array}{l}\text { Plural } \\
\text { uu }\end{array}$} \\
\hline $3 r d$ & masc. & $a$ & & \\
\hline & fem. & at & ataa & na \\
\hline $2 \mathrm{nd}$ & masc. & ta & & tumuu $?$ \\
\hline & fem. & $t i$ & салыса & tunna \\
\hline lst & com. & tu & lacking & naa \\
\hline \multicolumn{5}{|c|}{ Imperfective prefixes } \\
\hline $3 r d$ & masc. & y & y & y \\
\hline & fem. & $t$ & $t$ & $t$ \\
\hline $2 n d$ & masc. & $t$ & $t$ & $t$ \\
\hline & fem. & $t$ & & $t$ \\
\hline lst & com. & $?$ & lacking & $\mathrm{n}$ \\
\hline
\end{tabular}

Certain rather surprising generalizations emerge from this agreement scheme. Notice that several categories have similar affixes in both aspects, with the affixes differing only as to whether they precede or follow the stem. All second person forms, perfective or imperfective, have $\underline{t}$ as at least part of their agreement marking. First person plural forms in both aspects are partly marked with $\underline{\mathrm{n}}$. These rather surprising generalizations can be expressed quite elegantly under the prosodic template theory. Suppose that verb stems are already fully specified with vowel and root patterns mapped onto their prosodic templates. All imperfectives receive a prefixed C-slot, and all nonthird person perfectives receive a suffixed c-slot. 
We can then immediately extract two consonantal melodies: $\underline{t}$ marks second person and $\underline{n}$ marks third person plural. By the Well-formedness Condition, these melodies will be mapped onto any unfilled consonantal slot; in this case, the consonantal slot that was just added. These melodies are therefore independent of the verbal aspect, while their position is dependent on it.

Before we can illuminate the properties of the other affixes, the suffixes of the imperfective must be considered:

Dual

Plural

3 rd masc. $\varnothing$

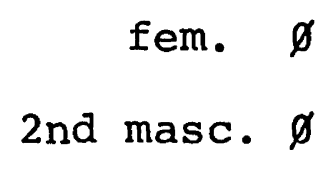

fem. ii

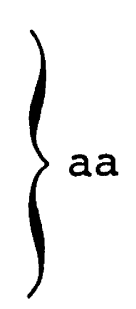

uu

na

aa

lst com. $\varnothing$

lacking $\varnothing$

First of all, it is clear that all dual forms of both aspects have aa and all masculine plural forms have uu suffixes. In more abstract terms, all duals and all nonfeminine plurals have an unspecified VV suffix, which bears the a melody in the dual and the $\underline{u}$ melody in the plural. A similar, though less significant, generalization holds for the second person feminine singular. It has the $\underline{i}$ melody always, mapped onto a V suffix in the perfective and a VV suffix in the imperfective. 
jecond, there is clearly a na suffix that appears in the feminine plural of both aspects. It is certainly consistent with this theory to treat this suffix as a combination of the template $\mathrm{CV}$ and the melody na, and in fact this is supported by consideration of the perfective dual and plural forms. The $\underline{t}$ of these forms has already been accounted for above. Apart from this, they have a common ul suffix, where $C$ is associated with $\underline{m}$ in the dual and masculine plural, but with $\underline{\mathrm{n}}$ in the feminine plural. You might suppose that feminine plural tunna is derived from underlying /tumna/ by a rather plausible regressive assimilation. Unfortunately, a putative $\underline{m n} \rightarrow \underline{n n}$ assimilation is entirely unattested in the semitic languages, and in fact in Arabic it is universally violated in surface forms like yamna9u 'he will stop' or šakamna 'they (feminine) bridled'. So this assimilation would be entirely ad hoc here:

On the other hand, we might say that all second person nonsingular perfectives have a VC suffix and a concomitant $\underline{u}$ melody. In the dual and the masculine plural, an $\underline{m}$ is associated with the empty $C$ slot of this suffix. But in the feminine plural, this slot picks up the $\underline{\mathrm{n}}$ melody that is also associated with the following na suffix. Consequently there is no assimilation, but rather an automatic gemination of the $\underline{\mathrm{n}}$ in response to an unfilled slot. The singular forms of the perfective all (except for the third person feminine) have a final short vowel. This 
vowel is associated with the a melody in the second and third person masculine, with the $\underline{i}$ melody (described above) in the second person feminine, and with the $\underline{u}$ melody in the first person. It is only the difference in vowel quality that distinguishes these different singular forms.

The third person feminine singular and dual has the same a melody as the third masculine singular, but this a is associated with a VC suffix. The $C$ of this suffix is associated with the same $t$ melody that appears in the third person feminine of the imperfective. In other words, the suffix at has the same melodic associations as other forms, but it idiosyncratically is built on a VC template.

These generalizations are little more than observations about a number of shared properties of the inflections, couched in terms of the prosodic template theory. What follows is a set of rules to generate just this set of affixes.

The general properties of prefixation and suffixation for subject agreement can be characterized by the prosodic templates in (57):

(57)

$$
\begin{array}{llllll}
\text { a. } & \text { Prefix } & \text { C } & & & \\
\text { b. Suffix } & \text { C V } & \text { C } & \text { [+seg] } \\
& 1 & 2 & 3 & 4 & 5
\end{array}
$$

A set of rules then stipulates which terms of (57) are present in finite verbs under certain conditions of person, 
gender, number, and aspect. I will assume that these conditions are specified by a set of features on the morphological categories. Gender is [ \pm feminine], and aspect is [tperfective]. Number is handled by features [plural] and [dual], where duals and plurals are [+plural], while singulars are [-plural, -dual]. Person falls into the feature classes [first] and [third], where first person is [+first, -third], second person is [-first, -third], and third person is [-first, third]. No particular claim of veracity is made for these features, though they generally seem to yield the right natural classes for this subject agreement system.

So the subparts of the prosodic templates in (57) are governed by the following distributional constraints.

The prefixal consonant slot is added by rule (39) of section 3.2 to all imperfectives. Consequently we need only deal with the suffixes here. The following rules govern the distribution of suffixal template material, according to the numbered terms of $(57 \mathrm{~b})$ : 
(58) Contexts for (57b)

$$
\begin{aligned}
& 1--\left[\begin{array}{l}
- \text { third } \\
\text { tperfective }
\end{array}\right] \\
& 2--\left[\begin{array}{l}
- \text { third } \\
+ \text { perfective }
\end{array}\right] \\
& 3--\left[\begin{array}{l}
\text {-first } \\
\text {-third } \\
\text { tplural } \\
\text { +perfective }
\end{array}\right] \\
& 4 \text { (i) if }[+ \text { seg }]=C \quad\left[\begin{array}{l}
\text { tplural } \\
+ \text { feminine } \\
- \text { dual }
\end{array}\right] \\
& \text { (ii) if }[+\mathrm{seg}]=\mathrm{V} \text { [+plural] } \\
& 5--\left[\begin{array}{l}
\text {-first } \\
\text { tplural }
\end{array}\right] \\
& 4(=\mathrm{V}) \text { and } 5--\left[\begin{array}{l}
\text {-third } \\
\text { +feminine } \\
\text {-plural } \\
\text {-perfective }
\end{array}\right] \\
& 2 \text { and } 3--\left[\begin{array}{c}
+ \text { third } \\
+ \text { feminine } \\
\text { tdual } \\
- \text { plural } \\
+ \text { perfective }
\end{array}\right]
\end{aligned}
$$

This set of rules incorporates all the observations made above as well as a few more in quite a natural way. The only fairly awkward complexities are the last two schemata; the first treats the notoriously inexplicable suffix ii of the second feminine singular imperfective, while the latter is responsible for the at suffix of the third feimine singular and dual of the perfective. 
The other half of the task of analyzing this agreement system is to correctly characterize the set of melodies that are mapped onto the template positions generated by (57) and (58). The full set of melodies and their privileges of occurrence is as follows:

(59) Consonantal Melodies

$$
\begin{array}{r}
\text { y - }\left[\begin{array}{l}
\text { +third } \\
\text {-feminine } \\
\text {-perfectivel }
\end{array}\right] \\
\text { ?-- }\left[\begin{array}{l}
\text { +first } \\
\text {-plural } \\
\text {-perfective }
\end{array}\right]
\end{array}
$$$$
\mathrm{n}-\left[\begin{array}{l}
\text { tfirst } \\
+ \text { plural }
\end{array}\right],\left[\begin{array}{l}
\text { +feminine } \\
\text { +plural } \\
\text {-dual }
\end{array}\right]
$$$$
\begin{aligned}
& t-\left[\begin{array}{l}
\text {-first } \\
\text {-third }
\end{array}\right],\left[\begin{array}{l}
\text { tfirst } \\
\text {-plural } \\
\text { +perfective }
\end{array}\right] ;\left[\begin{array}{l}
\text { third } \\
\text { +feminine } \\
\langle\text { tplural } \\
\text {-dual /a } \\
<- \text { perfective }>_{b}
\end{array}\right] \mathrm{a} \supset \mathrm{b} \\
& \mathrm{m}-\left[\begin{array}{l}
\text {-first } \\
\text {-third }
\end{array}\right]
\end{aligned}
$$

-feminine

tplural

+perfective]

Vocalic Melodies

$$
\begin{aligned}
& \text { a -- [+dua1], } \\
& {\left[\begin{array}{l}
\text {-first } \\
<- \text { third }>a \\
<- \text { feminine } \\
\text {-plural } \\
+ \text { perfective }
\end{array}\right] \text { a b, }} \\
& i--\left[\begin{array}{l}
\text {-first } \\
\text {-third } \\
\text { teminine } \\
\text {-plural }
\end{array}\right] \\
& {\left[\begin{array}{l}
\text { teminine } \\
\text { tplural }
\end{array}\right]} \\
& {\left[\begin{array}{l}
\text { tfirst } \\
\text { +plural } \\
\text { +perfective }
\end{array}\right]}
\end{aligned}
$$


(59) continued

$$
\text { u- }\left[\begin{array}{l}
\text { tfirst } \\
\text {-plural } \\
+ \text { perfect }
\end{array}\right],\left[\begin{array}{l}
\text { first } \\
\text {-third } \\
\text { tplural } \\
\text { tperfect }
\end{array}\right], \quad\left[\begin{array}{l}
\text {-first } \\
\text { tplural } \\
\text {-dual } \\
\text {-feminine }
\end{array}\right]
$$

In general these melodies are mapped onto any available slot that matches them in the $V / C$ contrast. In a few cases we have the possibility of ambiguity because two melodies must be mapped onto two $\mathrm{C}$ slots or two $\mathrm{V}$ slots. For instance, in the second feminine plural perfective and imperfective katabtunna and taktubna, we must indicate that the melody $t$ is assigned to a $c-s$ lot to the left of the

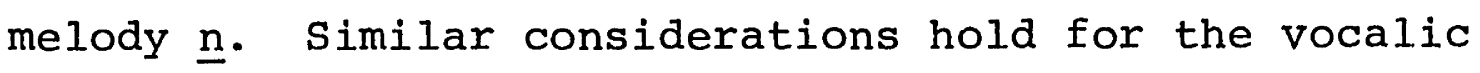
melodies $\underline{u}$ and $\underline{a}$ in the desinence tunna. There are really not enough examples of these to determine the exact mechanism operating here, but I will suggest that there is an ordering of the rules responsible for mapping the affixes, so that the c-slot on the left receives an affix before the one on the right. 
4. The Classical Arabic Nominal System

The morphology of the Arabic noun system is as heavily structured as the verb system though this structure is not quite as systematic. Nouns can be based on roots, of two, three, four, and even more consonants. Most triliteral and many quadriliteral nouns belong to identifiable root and vowel pattern classes with recognizable semantic characteristics, similar to the binyanim of the verbal system. An exhaustive treatment of these phenomena would require volumes. Consequently I have selected for analysis just a few of the most general ones that also promise to reveal the most about the basic properties of the system.

Sections 4.1 and 4.2 deal with nominal derivatives of verbs, as well as formally similar denominatives. The patterns in 4.1 share a prefix $\underline{m}$, while those in 4.2 are all examples of infinitives or nominalizations, known traditionally as masdars. Section 4.3 deals with what might be the most complicated root and pattern alternations in the noun system, the rules for forming diminutives and broken plurals. Both these categories are extremely general and quite productive. The final section, 4.4, treats externai pluralization and case marking. External or suffixing plurals make up a restricted residue of forms without broken plurals.

In almost every case discussed here there are lists of isolated exceptions and deviant subgeneralizations to be 
found in any reference grammar. Since irregularity can always be accommodated in the lexicon, I have not felt it necessary to list these exceptions when they are far outweighed by the regularity that this morphological theory explains.

4.1 Nouns with $\underline{\mathrm{m}}$-preformative

Quite a large number of nouns with a variety of semantic properties and derivational sources show up with an m-prefix. We have already seen notable examples of this in the participles of the triliteral II-XV binyanim and of the quadriliteral binyanim. Another class, called the nomen vasis by the orientalists, describes the time or place where an activity is performed. A similar type, the nomen instrumenti, describes the instrument with which an action is performed. Finally, we will consider the nominalizations (infinitives) with prefixed $\underline{m}$, the so-called mimi masdars. This leads to a further treatment of infinitives in the following section.

We have already noted certain regularities in the formation of participles of binyanim II-XV and QI-QIV. The passive participle evidently has, apart from prefixal $\underline{m}$, the same canonical syllable pattern and the same vocalism as the imperfective passive stem. Obviously the active participle similarly shares the canonical syllable pattern of the imperfective active. Moreover, the discussion above 
in section 3.2 argued for a level of representation in which all imperfective active verbs are associated with the vocalic melody $\underline{u}-\underline{a}-\underline{i}$, the same melody that appears in the active participle. Consequently, at this level we have a firm generalization -- a participle of a given voice (minus its prefixal melody $\underline{m}$ ) is identical to the corresponding imperfective stem of the same voice (minus the imperfective agreement melodies).

In sum, the participles of both voices share with the imperfective all characteristics except the identity of the prefixal consonant. In the imperfective, this consonant is $\underline{y}, \underline{t}, \underline{n}$, or $\underline{?}$, depending on the morphological conditions described earlier in section 3.4. But this consonant is invariably $\underline{m}$ in the participles under consideration. We can say, then, that the entire set of participial and imperfective stems shares prefixation of canonical $\mathrm{CV}$ to the stem that appears in the perfective. This generalization is captured by rule (38) of section 3. Furthermore, both participles and imperfectives share the active melody $\underline{\text { u}}-\underline{a}-\underline{i}$ and the related passive melody $\underline{u}-\underline{a}$. They differ only in that imperfectives associate a particular consonantal melody with the prefixal $C$ under conditions of subject agreement, while participles have the melody $\underline{m}$ associated with this slot.

Now to the formalization of these observations, The difficulty is that three distinct chunks of morphology -- 
prefixation of $\mathrm{CV}$, mapping of active $\underline{u}-\underline{a}-\underline{i}$, and mapping of passive $\underline{\text { u}}-\underline{a}$-- all refer to a disjunction of the imperfective and the participles. Since the participles are nonaspectual there is no nonadhoc feature that will crossclassify just this set of forms. So there is little hope of avoiding reference to this disjunction in several morphological rules. What we need is a mechanism that allows us to say that the participle is derived from the imperfective at a point just before the agreement and $\underline{\mathrm{m}}$ melodies are mapped on.

In fact, just such a mechanism exists in traditional grammar and has received some attention in recent work. Matthews (1974) calls this device a parasitic or Priscianic derivation, after an early proponent, the Latin grammarian Priscian. The difference between parasitic morphological rules and conventional ones is that the former are slightly more complex, predicting, correctly I think, that they are less highly valued by the grammar and consequently rarer. While conventional morphology involves a single operation, a change in some phonological material in a morphological context, the parasitic rules alter morphological features as well, substituting some new feature for one of the contextual ones. I will formalize these rules as:
(1)

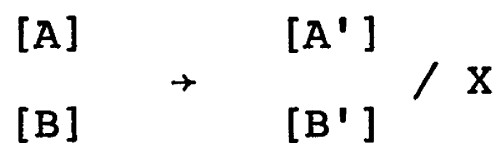


Where $A$ and $A^{\prime}$ are (possibly null) phonological specifications and $B$ and $B^{\prime}$ are morphological ones. It is understood from the formalization that [B] is deleted and [B'] is added to any form to which (1) applies. Like all morphological rules, rule (1) is optional in the strict sense (i.e., it is obligatory only as a result of principles on the well-formedness of words, etc.).

Therefore the rules for this subsystem of Arabic verbal morphology are formulated as follows:

(2)

a. $\varnothing \rightarrow \mathrm{CV} /$ [imperfective]

b. Map melodies of first binyan as in section 3.3. Other binyanim:
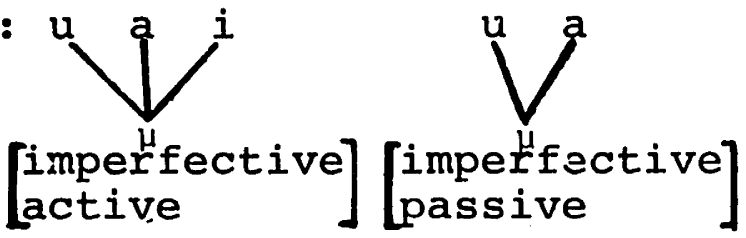

c. $\left[\begin{array}{l}\text { imperfective } \\ - \text { Binyan I }\end{array}\right] \rightarrow \underset{\mu}{\mathrm{m}}$

[participle]

d. Alter imperfective vocalism as in section 3.2.

e. Subject agreement as in section 3.4.

Rule (2a) is a simplification of rule (39) of section 3.2. That earlier version referred to either imperfective or participle; the parasitic rule (2c) permits this simplification by deriving the participle from the form of the imperfective. The mode of application of this parasitic rule is simple enough. It maps $m$ onto the only available slot, which is the consonantal slot inserted by rule (2a). The 
feature [imperfective] is erased from the form and the feature [participle] introduced by the structural change replaces it. In this case, the phonological specification of the structural description is null.

The result of incorporating (2c) into the grammar is evident. The prefixation rule (2a) and the melodies (2b) can be applied just to templates that are formally. [imperfective]. At the point when (2c) applies, imperfectives and participles diverge. Those which retain the feature [imperfective] will lack the prefix $\underline{m}$ but will be subject to the rules in (2d) and (2e), which are restricted to [imperfective]. Participles will go their separate way and eventually be subject to various sorts of noun morphology like case marking.

At this point I should call attention to one fact that is apparent from table 1. The participles of the first triliteral binyan do not conform to this sort of morphology. The first binyan active participle of ktb is kaatib and the passive participle is maktuub. There is some reason to suppose that the passive participle does participate in the parasitic morphology of (2): it has the appropriate $\underline{m}$ melody, and it has the expected canonical syllable pattern except for length of the final vowel. No such derivation can be supported for the active participle, however. In the absence of further evidence I will assume that these templates and melodies are simply listed in the grammar, 
reserving the possibility of incorporating the passive participle into (2). Some further discussion of the idiosyncratic characteristics of the first binyan participle can be found below in section 5.2 .

Not surprisingly, similar parasitic rules appear elsewhere in the morphology. We find $\underline{m}$ as trie melody of the initial C-slot in a number of other derived nouns, sometimes in an intimate relationship with the form of the related imperfective verb. The nomen vasis, or noun of place or time, depends formally on the imperfective verb in the first triliteral binyan. Recall that the imperfective active template in this binyan is CVCCVC (e.g., yaktub) where the quality of the second vowel is conditioned by the Ablaut class of the verb. In all other respects -such as agreement and passivization -- this form behaves like the other binyanim.

Now the nomen vasis of a first binyan verb informally takes the imperfective active stem and maps $\underline{m}$ onto the first consonantal slot. The vowel of the second syllable changes to $\underline{a}$ if it is $\underline{u}$; otherwise it remains unaltered:

(3) Imperfective stem
a. Canhal 'drink'
b. Cajlis 'sit'
c. Caktub 'write'

Nomen vasis

manhal 'place, time to water' majlis 'place, time of sitting' maktub 'place where writing is taught' 
(Idiosyncratically, many nouns of this type can have the feminine suffix at.)

There is something of this parasitic character to the formation of the nomen vasis from the other binyanim. It is formally identical to the passive participle, or, put another way, it is the same as the active participle but with a in the final syllable rather than $\underline{i}$ : The binyan is indicated on the left:

(4) Active participle Passive participle/nomen vasis
a. II mușalliy mușallay 'place of prayer'
b. IV mu?aşbiḥ mu?aşbah 'time of sunrise'
c. VII munşarif munşaraf 'place, time of
d. VIII mujtami9 returning'
e. X mustahlil mujtama9 'place of collection'
f. QI mudahrij mustahlal 'time of appearance' g. QIII muhranjim mudahraj 'place of rolling' muhranjam 'place of a crowd'

Therefore these binyanim, like the first binyan, form the nomen vasis from the stem of the imperfective system. But while the first triliteral binyan preserves an $\underline{i}$ in the final syllable (e.g., majlis), these binyanim shift it to a in the nomen vasis. I express these relationships with the following Ablaut rule: 
(5)

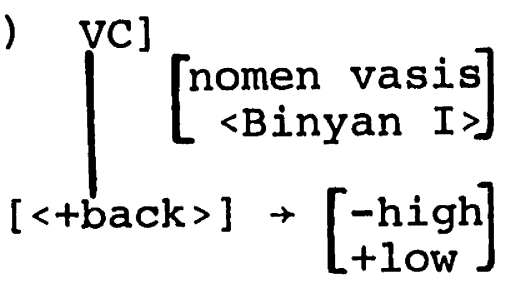

This says that the rightmost member of the melody in the nomen vasis is lowered; only $\underline{u}$ is subject to this rule in the first triliteral binyan. We will see shortly how this ties into the notion of a parasitic derivation.

Formally similar morphology appears on nouns, where it describes a place where the referent of that noun is present in abundance (nomen abundantiae). I assume that for essentially pragmatic reasons the "time of" reading that is available with deverbals is not possible for denominal nomina vasis These denominals are consistently of the pattern maCCaC, and they consistently have the feminine suffix at, which is present sporadically in the deverbals:

$$
\begin{aligned}
& \text { (6) a. ?asad 'lion' ma?sadat } \\
& \text { b. סi?b 'wolf' maŕ?abat } \\
& \text { c. bițțiix 'melon' mabțaxat 'melon patch' } \\
& \text { d. rummaan 'pomegranate' marmanat 'pomegranate bed' }
\end{aligned}
$$

These forms show a characteristic of denominals that we met with before in section 3.1 in the treatment of the verb system: the derived form depends only on the root of the source noun and nothing else. It specifically ignores the 
vocalism and the canonical pattern (including consonant gemination) of the source noun.

The apparent difficulty with a parasitic derivation of the nomen vasis from the imperfective verb stem is that there exist denominal nomina vasis like those in (6). These forms either have no related verb at all or they are only distantly related to some verb, yet they share several formal characteristics with the deverbal nomina vasis.

A basic insight that solves this clilemma is to say that nouns like those in (6) are put into the form of first binyan imperfective verbs for the purpose of applying the parasitic nomina vasis morphology to them. Therefore they have the same canonical pattern as the deverbal nomina vasis in (3).

This insight is confirmed by the behavior of quadriliteral roots under this sort of morphology. Apparently there is idiosyncratic or free variation of quadriliteral nouns in forming the nomen vasis between the maCCaC pattern of the triliteral nouns and the muCaCC $\underline{i c}$ pattern of the active participle of the first quadriliteral binyan:

(7) Noun

\begin{tabular}{|c|c|c|c|}
\hline & & $\mathrm{maCCaC}$ & muCaccic \\
\hline a. $\theta a 91 \mathrm{ab}$ & 'fox' & $\operatorname{ma} \theta 9 a 1 a t$ & muta9libat \\
\hline b. 9 aqrab & $\begin{array}{l}\text { 'scor- } \\
\text { pion' }\end{array}$ & ma9qarat & mu9aqribat \\
\hline
\end{tabular}


Note that in the second column of (7) we see a further instance of a type of behavior that follows from the left-toright mapping of consonants to the template. Recall from section 3.1 what happened when quinqueliteral roots were mapped onto quadriliteral verb templates: the rightmost consonant of the root failed to associate and so received no phonetic realization. By parity of reasoning, a quadriliteral root mapped onto a triliteral template should act the same way, and it does here in forms like maggarat, which displays loss of the final root consonant $\underline{b}$.

The behavior of quadriliteral nouns in (7) confirms the observation that the formation of denomina] nomina vasis is mediated by the morphology of the verbal system. The quadriliterals can either be mapped onto a triliteral imperfective template CCVC or a quadriliteral template CVCCVC. Either template then receives prefixal CV by rule (2a). The vocalism of denominal nomina vasis can be brought under the same rubric. The quadriliterals receive the melody $\underline{u}-\underline{a}-\underline{i}$ by rule (2b) just as if they were actually occurring verbs though the denominals are exceptions to (5). The triliterals will have the vowel a assigned to the first vowel slot of CVCCVC by rule (49) of section 3.3 since they are effectively first binyan verbs. But since they are not listed as members of a particular first binyan Ablaut class, no vowel is lexically associated with the second vowel slot. Consequently a will spread from the first to the second $V$, yielding the obseryed surface vowel pattern a-a. 
What is paradoxical in this model of the formation of these denominal nouns is that they form imperfective verbs solely in order to feed the parasitic rules that generate the nomina vasis. These verbs do not actually occur as verbs, but arise only in the course of deriving a nomen vasis from a noun.

I suggest that this rather strange behavior of nouns in forming nomina vasis is a general property of parasitic derivations. It is clear from the deverbal forms that the nomen vasis is parasitic off the form of the imperfective, so the feature [imperfective] will appear on the left side of any rule that forms the nomen vasis. Suppose, then, that imperfective forms are freely generated for any root in order to feed this parasitic rule. In ordinary verbs, the imperfective form will be the appropriate one for the particular binyan; but in nouns, this purely formal imperfective will be the imperfective of the first triliteral binyan for triliteral roots, and of the first triliteral or, usually, the first quadriliteral binyan for quadriliteral roots.

This allows us to formulate a single parasitic rule for the formation of participles and of nomina vasis:

(8) [imperfective] $\begin{aligned} \rightarrow & \left.\right|_{\mu} ^{m} \\ & {\left[\left\{\begin{array}{l}\text { participle } \\ \text { nomen vasis }\end{array}\right]\right.}\end{aligned}$ 
That is, we simply extend rule (2c) to form nomina vasis as well as participles.

This very simple rule of noun formation raises several questions to which there is basically one answer. Let me reiterate the characteristics of the model proposed here. Two kinds of imperfective verbs exist: most are actually occurring, true verbs, but there is another class that is freely generated by the template apparatus from the roots of nouns. Both are then potentially subject to all rules that can refer to imperfectives; in particular, rule (8). The difficulty is that this model grossly overgenerates deviant forms. Why is it that the freely-generated imperfectives from roots of nouns like those in (6) and (7) do not also show up as imperfective verbs, but only reach the surface by the mediation of rule (8)? Why is it, for example, impossible to form denominal participles, though it is possible to form denominal nomina vasis? What prevents the formation of nomina vasis from imperfectives with passive vocalism? The answer is that all these nonoccurring forms lack a semantic interpretation, either in the lexicon or as a result of applying a semantic rule. For example, there is no regular semantic relationship between first binyan verbs and nouns. Therefore the freely generated first binyan denominal verbs, which ultimately feed the nomen vasis morphology, will be without semantic interpretations and therefore blocked in the lexicon. 
Clearly this solution is largely conjectural, since I have no suggestions as to the form of a rule in lexical semantics. Nevertheless we can say with some confidence that many forms are morphologically correct but lack meaning, and this theory begins to explain this observation.

The nomen vasis shares several prosodic properties with the nomen instrumenti. The nomina instrumenti vary idiosyncractically among three different patterns, represented in the following examples:

(9) a. fatą̧ 'to open'

b. sarạ 'to comb'

c. Șarat. 'to incise' miftạ

miftaab 'key'

misrạ̧

misrahat 'comb'

miśraţ

mišraaṭ 'lancet'

Perhaps the most common pattern is micCac, but there is as well idiosyncratic or free variation to the pattern miccaac. Like the nomen vasis, the nomen instrumenti also allows sporadic forms with the feminine ending at.

The nomen instrumenti has all the characteristics -prosodic template, $\underline{m}$ prefix -- of the nomen vasis, except two. It allows a variant form with a long vowel in the second syllable of the template, and it has just the melody i-a, with no dependence on the Ablaut class of the verb. 
A formally similar category is the denominal form also called nomen vasis, which usually describes a vessel containing something:
a. ?ibrtat 'needle'
mi?bar 'needle-case'
b. laban 'milk'
milban 'milk-pail; brick- mold' libntat 'brick'
c. bawl 'urine'
mibwal 'chamberpot'

Again, these show the characteristic behavior of the denominal nouns: the arrangement of consonants in the derived form follows that of the imperfective of the first binyan, entirely independently of the arrangement in the source noun.

So obviously we have to add the category nomen instrumenti to the m-prefixation rule (8):

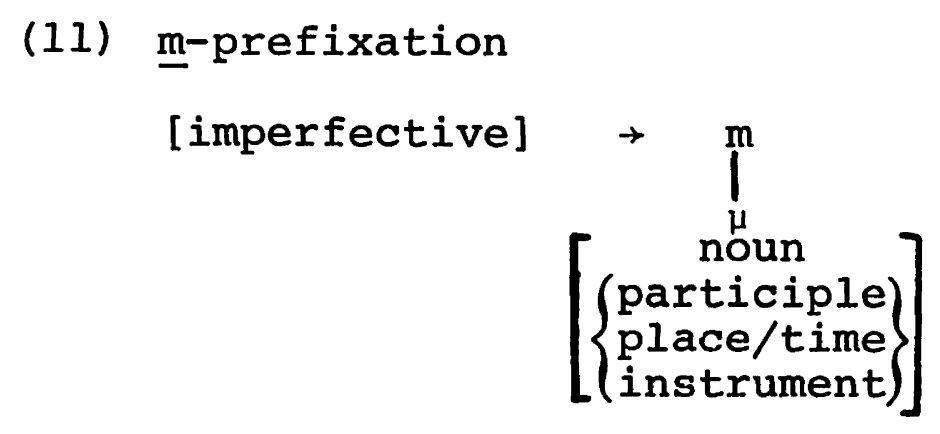

The noun of instrument in particular demands the vocalism i-a , which supplants any vocalism it has received either from the lexicon or from the application of other rules. 
I will formulate this rule simply with the predicate "map", and I will assume that this automatically erases any residual vocalic melodies:

(12) Map

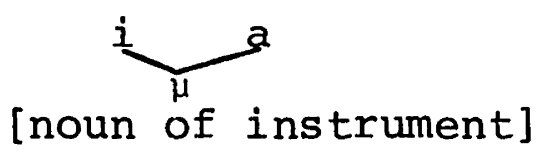

So what this mechanism permits is formation of any possibility -- participle or noun of place/time or instrument -- from any noun or verb, subject to the availability of a sernantic interpretation. As expected, we find nouns and verbs which have both nouns of instrument and nouns of place/time, with distinct meanings for both:
(13) a. Verb
$\mathrm{Place} /$ time
Instrument
ǵasal 'wash' mağsalat 'wash- miğsal 'washbasin'
ğazal 'spin' mağzil 'spin- miğzal 'spindle' ning mill'
9araj 'ascend' ma9raj 'route mi9ra(a)j 'ladder' of ascent'
b. Noun

laban 'milk' malbanat 'dairy' milban 'milk-pail'
bawl 'urine' mabwalat 'urinal' mibwalat
'chamber-pot'

A final case of prefixation of $\underline{m}$ is the mimi masdar, a type of infinitive or gerund. In the first binyan there is a great deal of lexical idiosyncracy in the selection of a masdar by any given verb, discussed below. The mimi 
masdar there is just one of the possibilities. Moreover, the mimi masdar of the first binyan displays a great deal of variation in the vocalism of the second syllable, though no variation in the canonical pattern or in the vocalism of the first syllable:
(14)
a. madxal 'entrance'
b. makbir 'magnitude'
c. mahluk (rare) 'destruction'

Another source of variation is the presence of the feminine suffix at, as in mahmadat 'commendable act' or ma9rifat 'knowledge' .

Let us isolate the predictable characteristics of the mimi masdars. They have the canonical pattern of the first binyan imperfective and they also have a in the first syllable, which is a consistent feature of active first binyan imperfectives. We can capture these generalizations simply by bringing the mimi masdars under the rubric of the parasitic rule (11). This will determine the canonical pattern, the $\underline{m}$ prefix, and the vocalism of the first syllable. The vocalism of the second syllable, idiosyncratic as it is, is determined by a set of minor morphological rules.

What recommends this treat even more are the facts of the mimi masdars of the other binyanim. There the masdar is invariably identical to the passive participle, which is 
also, as you will recall, identical to the nomen vasis. I will assume that this masdar is derived by extending ruie (5) to the masdar cateogry. So these forms require no new apparatus.

\subsection{Masdars}

Since the first triliteral binyan has over forty different, relatively idiosyncratic masdar patterns for different verbs, I will delay the discussion of it. Instead I will concentrate first on the far more general masdar formations of the other binyanim.

One masdar pattern appears in almost all these binyanim, though with varying degress of frequency:

\section{(15)}

$$
\begin{aligned}
& \text { II [kittaab] } \\
& \text { III [kiitaab] } \\
& \text { IV ?iktaab } \\
& \text { V [tikittaab] } \\
& \text { VI }
\end{aligned}
$$

VII nkitaab

VIII ktitaab

IX ktibaab

X stiktaab
XI ktiibaab

XII ktiwtaab

XIII ktiwwaab

XIV ktinbaab

XV ktinbaay

QI dihraaj

QII ---

QIII dḥinraaj

QIV dḥirjaaj 
Although there are some gaps in (15), and although the bracketed patterns are quite rare, it is nevertheless clear that there is a significant generalization about the masdars that cuts across the various binyanim. Basically, the masdars have the same template as the perfective verb but with the added feature of a long vowel in the final syllable. The vocalic melody is $\underline{i-a}$, where the a is associated with both vocalic morae in the final syllable.

Since the perfective of the ver's never has a long vowel in the final syllable of its template, we will need a rule to lengthen that vowel in the masdar. This rule is parasitically applied to the ordinary perfective verb template:

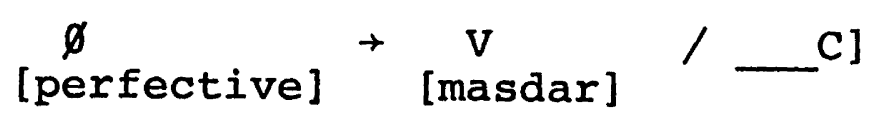

Now since this rule is parasitic, the rule mapping the vowel pattern cannot be parasitic off the perfective as well. Rather, it must refer to information that is introduced by (16). As I formulate it, it depends crucially on a masdar with a long vowel in the final syllable:

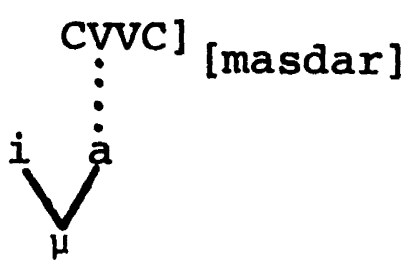


This rule maps the melody $\underline{i-a}$ onto the masdar stem, associating the a portion of the melody with the final long vowel. This complex formulation of the mapping rule accounts for the unexpected spreading of $\underline{i}$, rather than $\underline{a}$, in the rare masdar pattern of the fifth binyan. A simpler formulation of (17) is possible if we ignore this rare pattern.

Now this particular ordering of (16) before (17) makes certain predictions: in particular, there can exist exceptions to (17) that are not exceptions to (16), but the opposite is not possible (since (16) feeds (17)). This prediction is supported by the other masdar patterns, the common ones that take the place of the rarer forms in (15). In the second triliteral binyan, there are three reasonably common patterns:

$$
\begin{aligned}
& \text { (18) a. taktiib } \\
& \text { b. taktibat } \\
& \text { c. taktaab }
\end{aligned}
$$

(18b) is just a variant of (18a) -- it has the feminine ending at idiosyncratically, and this ending shortens the vowel of the preceding syllable by a minor rule developed below.

The basic observation here is that this binyan has a t prefix and loss of the medial gemination in the masdar form. It is exceptional in that the masdar is only rarely 
the expected kittaab. But we can certainly extract the generalization that the forms in (18) have the final long vowel of the patterns in (15), so they must be subject to the parasitic lengthening rule (16).

In other words, the derivation begins with the perfective second binyan form kattab. This is then subject to the parasitic rule (16), yielding the masdar stem kattaab. This form has exactly the prosodic template of the actual masdars in (18), but with prefixed $\underline{t}$ and a different mapping of the root consonants. We can capture this generalization with the following rule, ordered after rule (16):

(19)

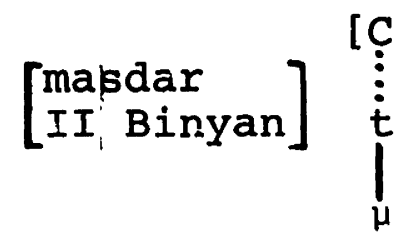

This $\underline{t}$ is mapped on the stem-initial consonant of the second binyan masdar. Because of the general exclusion in Arabic of many-to-one mappings, this rule induces automatic reassociation of all the root consonants on the template, as in the following derivation:

(20)

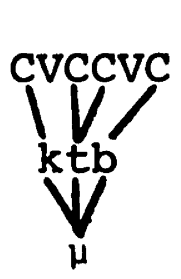

by $\underset{\rightarrow}{(19)}$

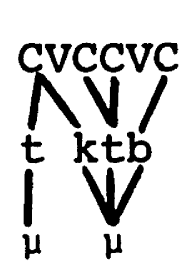

by convention

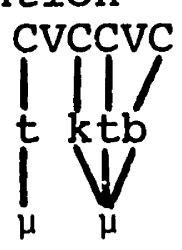


No further rules are needed to derive the masdars of the pattern (18c) taktaab, since they retain the perfective vocalism unaltered. Another rule, restricted to this binyan, adds the a-i melody of taktiib in lexically specified cases. Rarer vocalizations of this same template are taktubat and tiktaab. This second rare pattern is derived by rule (17), to which this binyan is ordinarily an exception.

Another assortment of masdar forms occurs in the third binyan. Here the most common form is the mimi masdar mukaatabat, which was described in the preceding section. Fairly common as well is the pattern kitaab, which is identical to the expected masdar in (15) except for shortening of the vowel in the initial syllable by a rule restricted to the masdar of this binyan.

The fifth and sixth binyanim have the most unusual masdar forms. Quite generally the patterns are takattub for the fifth and takaatub for the sixth. These are, then, identical to their corresponding perfectives except for the quality of the vowel in the final syllable. They are apparently not subject to the lengthening rule (16). Similar properties hold for the second quadriliteral binyan, with its masdar tadahruj. It is clear, then, that the suppression of rule (16) is to be related to prefixed $\underline{t}$. Notice, incicientally, that $\underline{t}$ of the second binyan masdar is not added until after (16) has applied, so that form is no counterexample. 
Therefore a different parasitic rule is responsible for deriving the masdars of binyanim V, VI, and QII. It says that an u-melody is inserted at the right of the amelody of the perfective stem only when the form has prefixed $\underline{t}:$

(21)

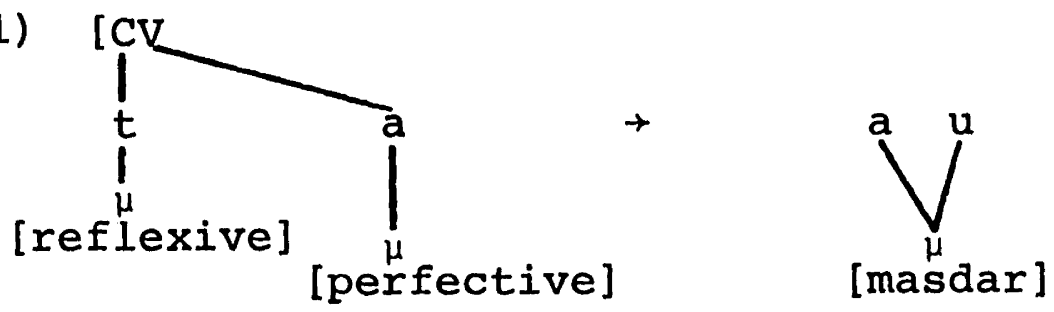

Note again here that a discontinuous dependency over the length of the stem can be stated in this notation without reference to essential variables. Rule (21) precedes rule (16), and it bleeds it as well, since the feature [masdar] of the structural change erases the feature [perfective] of the structual description.

Now if we turn to the masdars of the first binyan, we can detect some regularities in the midst of otherwise chaotic complexity. The reference grammars list about 47 different masdar patterns here; one or more are idiosyncratically selected by particular verbs. There is some slight predictability, but it is primarily of a semantic rather than formal character. Nevertheless there are some significant formal consistencies in this set. 
First, many fewer than 47 actual stems occur -- most stem patterns appear several times but with different suffixes like at, aan, iyyat, and so on. A few other odd stem patterns are represented by just one or two verbs, like ğulubbat 'subjugation' or jibillat 'disposition'. Once these forms have been eliminated, the total repertoire of stems is fairly manageable:

$\begin{array}{rrr}\text { (22) a. katb } & \text { b. katab } & \text { c. kataab } \\ \text { kitb } & \text { kitab } & \text { kitaab } \\ \text { kutb } & \text { kutab } & \text { kutaab } \\ & \text { katib } & \text { katiib } \\ & & \text { katuub } \\ & & \text { kutuub }\end{array}$

This distills down to just three canonical patterns -- CVCC. CVCVC, and CVCVVC, or the output of the prosodic template in $(23)$ :

(23) $\quad[\mathrm{CVC}(\mathrm{V}(\mathrm{V})) \mathrm{C}]$ $\left[\begin{array}{ll}\text { masdar } \\ \text { I } & \text { Binyan }\end{array}\right]$

There are one or two interesting observations about the melodies of these forms, and then we'll leave them. In (22) six different patterns of vocalism occur -- $\underline{a}, \underline{a}-\underline{i}$ : $\underline{i}-\underline{a}$, 
$\underline{u}-\underline{a}, \underline{a}-\underline{u}$, and $\underline{u}$. This is all the possible one and two member permutations of the three vowels in Arabic except for the melodies $\underline{i}, \underline{i}-\underline{u}$, and $\underline{u}-\underline{i}$. I will exclude these melodies by a general constraint on the vocalism of masdars, and most probably all except a few nouns as well:

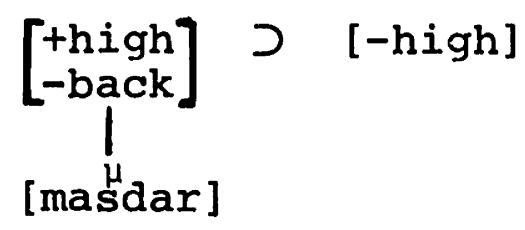

That is, if a melodic morpheme contains an $\underline{i}$, then it must contain a as well.

It should not be a source of distress that masdars of the first binyan are so much more intractable than those of the other binyanim. They really are quite different -they have this vast irregularity, a great lack of semantic predictability, and several formal differences with other masdars. What these masdars take from the verb to which they are related is the triliteral root and little else. The relationship is expressed almost without reference to any morphological rules.

Two important morphological categories are derived from masdars by suffixation of the feminine ending at. If the masdar means $x$, then the nomen vicis means 'the act of performing $x$ once' and the nomen speciei means 'the way $x$ is performed'. The form of these two categories differs 
slightly in the various binyanim. In all but the first triliteral binyan, the nomen vicis and nomen speciei are formed by suffixing at directly to the usual masdar, so the two categories are homophonous. Some representative examples are:

$\begin{array}{ll}\text { Masdar } & \text { Nomen vicis/speciei } \\ \text { II taqliib 'scrutiny' } & \text { taqliibat } \\ \text { IV ?ikraam 'honor' } & \text { ?ikraamat } \\ \text { QI diḥraaj 'a rolling' } & \text { diḥraajat }\end{array}$

But the nomen vicis and nomen speciei are nonhomophonous in the first triliteral binyan. Suffixation of at appears here as well, but not directly to the usual masdar of some particular verb, which as we saw varies widely. Instead, regardless of the regular form of the masdax, the nomen vicis has the pattern CacCat and the nomen speciei has the pattern Ciccat.

$\begin{array}{cll}\text { (26) Masdar } & \text { Nomen vicis } & \text { Nomen speciei } \\ \text { ģarb 'beating' } & \text { darbat } & \text { dirbat } \\ \text { šurb 'drinking' } & \text { šarbat } & \text { širbat } \\ \text { rukuub 'riding' } & \text { rakbat } & \text { rikbat }\end{array}$

The two stem patterns Ca-CC and CiiCC actually occur fairly frequently as masdars of the first form. The peculiarity 
of the nomen vicj.s and nomen speciei is that they ignore the host of lexical masdar patterns and select just these two forms to receive the suffix at.

Therefore the first binyan is subject to the following template and melodies in the formation of nomina vicis and nomina speciei:

(27) a. Template [CVCC]

$\left[\begin{array}{l}\text { nomen vicis/speciei } \\ \text { I Binyan }\end{array}\right]$

b. Melodies

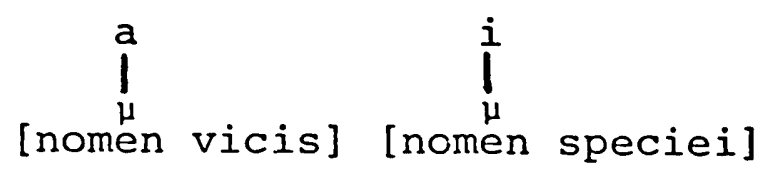

It is of no great moment, but we might add (27) as a codicile to the formal regularities of first binyan masdars, capturing the generalization that CacC and CíCC do actually occur independently as masdars, though not for all verbs. This would also exclude the suffixation of at to form nomina vicis and speciei from other masdar patterns in this binyan.

\subsection{Diminutives and Broken Plurals}

Perhaps the most revealing area of Arabic nominal morphology is the system of forming plurals. The external or sound plural involves simple suffixation only; it is discussed in the following section. The vast bulk of the Arabic lexicon -- except for certain well-defined sets of nouns -is subject only to formation of broken plurals, which involve 
stem-internal Ablaut and elision and insertion phenomena. Diminutives, which can be productively formed from any noun as well as some particles, share many formal properties with the broken plurals.

As in the first binyan masdar, the first impression is one of chaotic, unsystematic formation of broken plurals. Some nouns form only a single broken plural, some form several different but synonymous ones, and some have several with different nuances of meaning. But under the analysis presented here it turns out that there are really only three basic classes of broken plurals. First, the bulk of plurals are formed by a very small number of rules that refer to the prosodic form of the stem in the singular. Second, several widely scattered patterns refer only to the root of the singular but none of its other properties. Some illustrative examples of these, though not a thorough list, are presented later. Third, some patterns are so rare that nothing can be said about them, and it is unlikely that they have a significant place in morphology.

I have referred to two useful studies for much of the frequency data and some of the taxonomy in this section. Levy (1971) collected all broken plurals from a Modern Standard Arabic dictionary, and Murtonen (1964) did the same for an arbitrary third of a Classical Arabic dictionary. Any of my comments about frequency are based on Murtonen's results, which differ in small respects frcm Levy's. 
4.3.1 Quadriliteral Nouns

The noun patterns that contain four consonants turn out to be a reliable place to start, since they exhibit very little of the lexical exceptionality that we will find in the shcrter nouns. Here I do nol use quadriliteral in the technical sense of the preceding sections; it refers not only to nouns based on quadriliteral roots but also nouns with an affixal consonant like the $m$ p-efix. Examples of the latter are in (28a). The former are in (28b), and notice the many loan words to which this morphology has been productively extended:

$\begin{aligned} \text { (28) a. miftaah 'key' } & \text { mafaatiị } \\ \text { maktab 'office' } & \text { makaatib } \\ \text { b. jundab 'locust' } & \text { janaadib } \\ \text { šu?buub 'shower' } & \text { sa?aabiib } \\ \text { šayțaan 'devil' } & \text { šayaațiin } \\ \text { sulțaan 'sultan' } & \text { salaațiin }\end{aligned}$

There are two spearate generalizations about the plural morphology in (28). At the level of the prosodic template, we find singulars of the pattern CVCCV(V)C corresponding to plurals CVCVVCV(V)C, where the quantity of the final syllable is held constant. At the level of vowel quality, we find $\underline{i}$ mapped onto the final syllable and a mapped onto the other two syllables. 
The second of these generalizations is the easiest to capture. We just need to map the melody a- i and the mapping rules for vowels in section 3.2 will ensure its proper distribution:

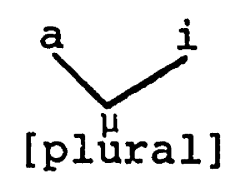

Now at first glance it appears that the prosodic template of the singular is subject to a transformation that inserts $\mathrm{VV}$ after the second consonant in the stem of the plural. This is a little suspect since no other phenomena in Arabic have demonstrably required full transformational formalism in the morphology. In fact, such a transformation is unlikely on empirical grounds as well. Arabic has some nouns that are very long, with five or even six consonant in the stem. They form plurals in a way that is obviously similar to what goes on in (28), but they retain only the first four consonants:
(30) 9ankabuut 'spider'
9 anaakib
9 andaliib 'nightingale'
9 anaadil
jạmariš 'lazy old
jahaamir 
Occasionally other reductions are found -- elimination of nonroot consonants or arbitrary consonants -- but all with the goal of fitting onto a four consonant template. Moreover, it appears that loss of the final consonants, as in (30), is the preferred mode and is permissible with any noun.

This necessity of reducing longer nouns to the pattern CVCVVCV(V)C in the plural is pretty clearly a reflex of a prosodic template for plural nouns, while the loss of supernumerary consonants at the right is typical of a left-toright mapping rule. Therefore I propose that a redundancy rule systematically relates the prosodic templates of the singular and plural in quadriliteral nouns:

(31) Quadriliteral Noun Redundancy $[\mathrm{CVCCV}<\mathrm{V}>\mathrm{C}]_{[\text {singular] }} \sim[\mathrm{CVCVVCV}<\mathrm{V}>\mathrm{C}]_{\text {[plura].] }}$

The material in angled brackets expresses a related generalization: the vowel of the final syllable in the plural is long if and only if it is also long in the singular. This fact is apparent from inspection of the forms in (28). Sporadic forms violate this portion of the redundancy, like muftir 'fast-breaker', mafaatiir, ?igsaar 'dust-storm', ?a9aasir. 
The vowel melody is mapped onto the pluial template of (31) by rule (29). The plural template receives consonantism in exactly the same way as the singular, but the restriction of this template to just four C-slots induces loss of extrametrical consonants, as in (30).

The diminutive of the quadriliteral noun is almost identical to the broken plural in its prosodic template, though it has a much different vowel melody:

$\begin{array}{cl}\text { a. 9aqrab 'scorpion' } & \text { 9uqayrib } \\ \text { dirham 'dirham' } & \text { durayhim } \\ \text { masjid 'mosque' } & \text { musayjid } \\ \text { b. 9usfuur 'sparrow' } & \text { 9usayfiir } \\ \text { miftaah 'key' } & \text { mufaytiin }\end{array}$

The difference between (32a) and (32b) lies in whether the vowel of the final syllable is long or not. Notice that diminutives of quinqueliteral nouns also lose extrametrical consonants; compare 9unaykib and 9unaydil to the forms in (30).

In fact, the diminutive has exactly the prosodic template of the broken plural except that in the diminutive the fifth slot (from the left) is $C$ while it is $V$ in the broken plural. Moreover, this C-slot in the diminutive is invariably associated with the consonantal melody $y$. We 
can capture both these generalizations by supposing that the Quadriliteral Noun Redundancy (31) is extended to diminutives as well as broken plurals, and that a rule adds the $y$ melody while changing the appropriate vowel slot to $C$ :

(33)

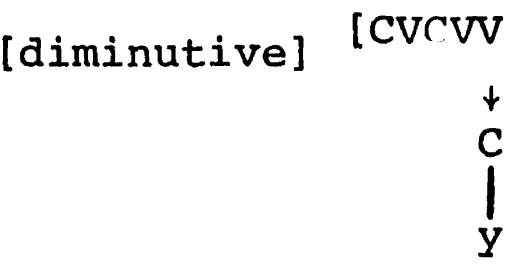

The vocalic melody of these diminutives is $\underline{u}-\underline{a}-\underline{i}$, which is mapped on correctly by vocalic association rules already developed in section 3.2 .

The only major idiosyncrary in quadriliteral plurals and diminutives is the sporadic appearance of the feminine suffix at with the plurals of some nouns, chiefly loans. This at regularly induces shortening of the final vowel of the stem by a minor rule:

(34) qayaaşirat

mațaariin

maţaarinat

In sum, I have claimed that broken plurals and diminutives of quadriliteral nouns are not derived structurally from their singulars, but rather that they have separate prosodic templates subject to the same consonant mapping 
rules and special vowel melodies that are mapped in the usual way. We will see many similarities to this behavior as we consider other nominal patterns.

\subsubsection{Nouns CVVCV(V)C}

A small but not insignificant number of triliteral nouns have singulars with the canonical pattern CVVCVVC. A very large number have the canonical pattern CVVCVC. In the latter group are the active participles of the first binyan with the vocalism Caacic. Since this class forms plurals in a way different from that of other CVVCVC nouns, I will delay consideration of them for a time. Representative examples of the two patterns are:

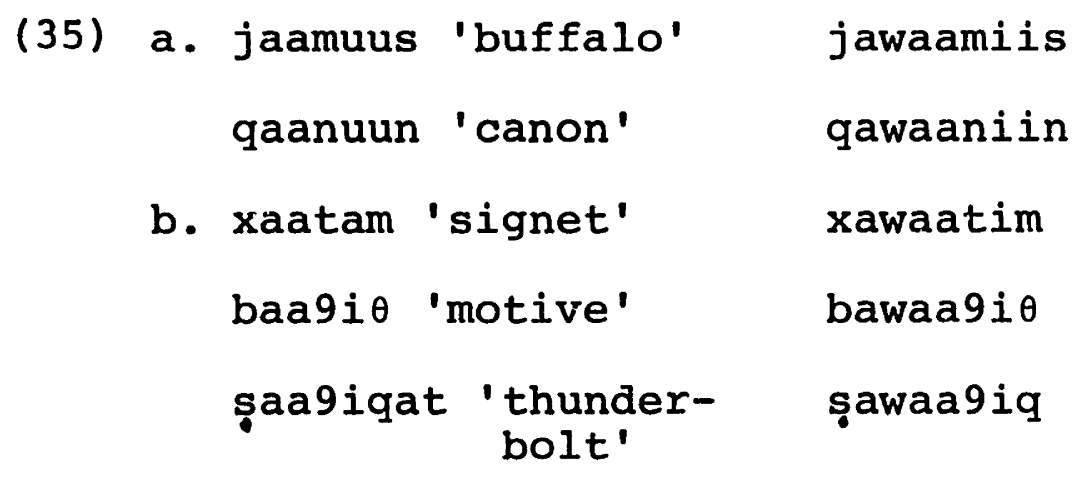

A similar distribution of forms holds for the diminutives of CVVCV(V)C nouns:
a. miizaan 'pair of scales'
muwayzi in
b. xaatam 'signet'
xuwaytim
c. šaair 'poet'
Suway9ir 
It is apparent that these broken plurals and diminutives have all the characteristics of the broken plurals and diminutives of quadriliteral nouns. They have the same prosodic template, the same melodies, and the same rules of association. I will capture the first of these generalizations by a slight reformulation of the broken plural/ diminutive redundancy rule

(37) Broken Plural/Diminutive Redundancy $[\mathrm{CV}[+\mathrm{seg}] \mathrm{CV}<\mathrm{V}>\mathrm{C}]$ [singular $] \sim[\mathrm{CVCVVCV}<\mathrm{V}>\mathrm{C}]$

This allows a singular with a long vowel in the first syllable, rather than just a closed first syllable, to be subject to the redundancy.

These two types of nouns -- triliteral and quadriliteral -- differ in only one respect: since only three consonants are associated with the singular triliteral stem, there is an extra C-slot in the prosodic template of the plural and diminutive. A new rule associates w with this slot:

(38) Triliteral Rule [CVC
$\vdots$
$\dot{w}$ 
There is no need to restrict this rule to broken plurals and diminutives, nor even to restrict it to triliteral broken plurals and diminutives. Because, as I indicated in the introduction, rules are blocked if they create many-to-one mappings onto the consonantal slots, the Triliteral Rule (38) will not apply unless the extra slot is available. When it does apply, it induces reassociation of consonants toward the right. To see how this works, consider the following derivations of a quadriliteral and a triliteral broken plural:

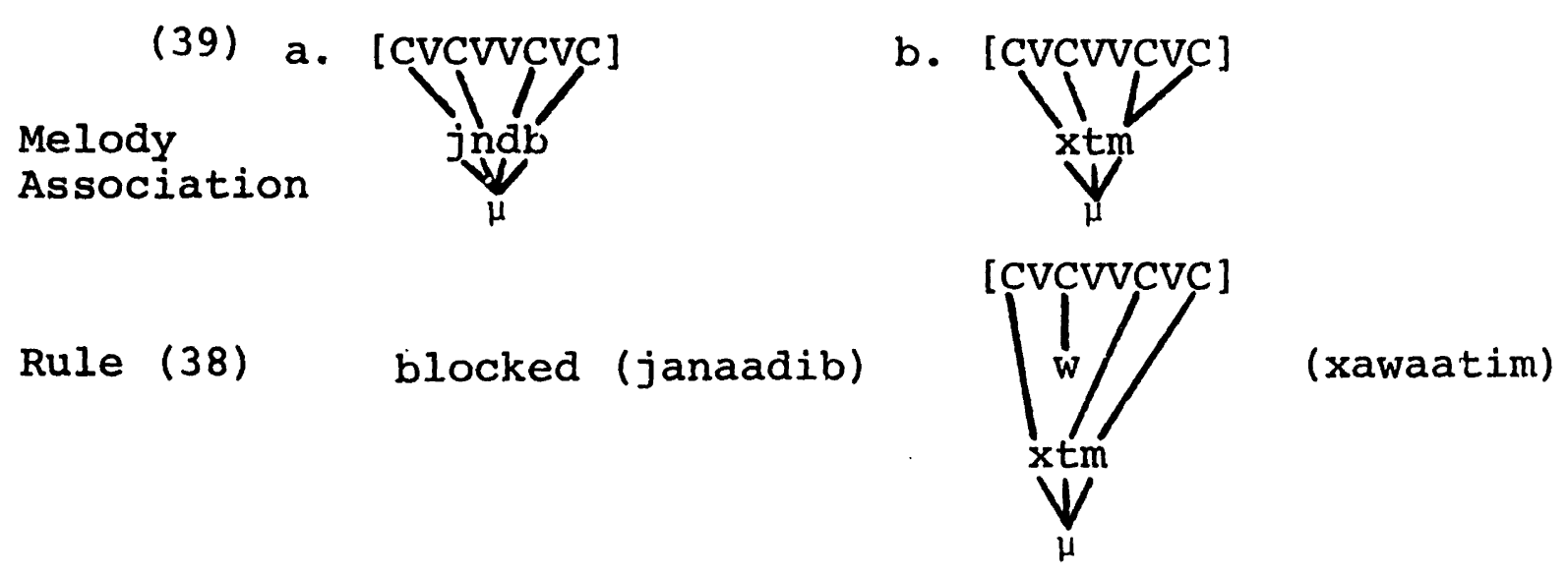

If rule (38) were to apply in (39a) -- or for that matter in a singular noun -- it would generate a many-to-one association with the second c-slot that could not be resolved by reassociation. This is not the case in $(39 b)$, so the rule applies successfully.

Some confirmation for this treatment of insertion of w comes from a small class (about ten) of triliceral nouns 
that are not subject to this rule. What they display instead is gemination of the medial radical to fill up the extra slot:
(40) Singular
Plural
Diminutive
diinaar 'dinar'
danaaniir
dunayniir
diibaax 'brocade'
dabaabiix
dubaybiix

I assume that this is the result of a minor rule that adds an association line between the middle radical and the appropriate C-slot. For reasons that I do not understand, this sort of behavior is confined to triliteral nouns with the canonical pattern CVVCVVC.

\subsubsection{Nouns CVCVVC}

This class has a good ideal more exceptionality than the previous two classes, so for the moment I will discuss only one fairly well defined subclass. Most feminine nouns CVCVVC, whether they are formally feminine (with suffixal at) or grammatically feminine, have a plural that is similar to that of the nouns above. A few masculine nouns of this type also display this plural: 
(41) a. Formal Feminine

$$
\begin{array}{ll}
\text { jaziirat 'island' jazaa?ir } \\
\text { sahaabat 'cloud' } & \text { sahaa?ibat }
\end{array}
$$

b. Grammatical Feminine

šimaal 'left hand' šamaa?il

9ajuuz 'old woman' 9ajaa?iz

c. Masculine

$$
\begin{array}{ll}
\text { damiir 'pronoun' } & \text { damaa?ir } \\
\text { wașiid 'court' } & \text { wașaa?id }
\end{array}
$$

The diminutive forms of this noun class are quite regular and independent of the gender of the base noun. They are similar to the broken plurals in (41):

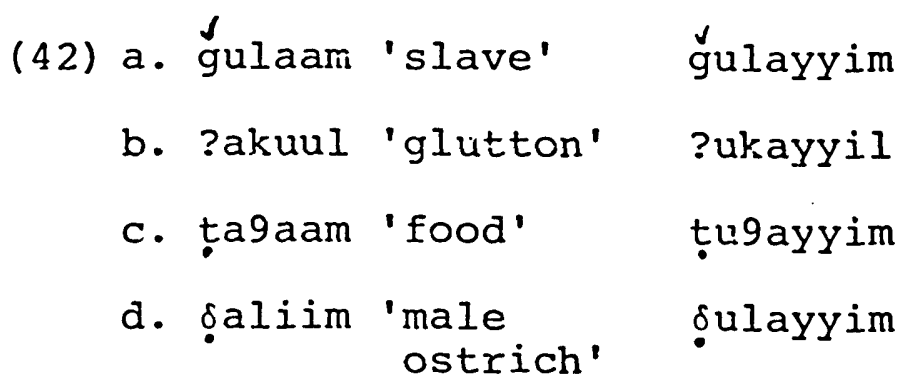

Clearly these forms have the same inserted $\underline{y}$ as the diminutives of other nouns, with $\underline{y}$ inserted in the same position in the prosodic template. They also have the same vocalic melody. But there are some significant differences.

First, the generalization about the length of the vowel in the final syllable being the same in the singular as it is in the broken plural and diminutive clearly does not hold. 
These forms have long vowels in the final syllable of the singular but they lack them ir the derived forms. Second, they do not appear to have the inserted $\underline{w}$ of the triliteral broken plurals and diminutives treated in the preceding section. What they have instead is? in the broken plural and $\underline{y}$ in the diminutive forms with both of these attached to the second last consonantal slot of the stem.

Consideration of a little phonology partly illuminates the second of these problems. There is a fairly regular process that changes $\underline{w}$ or $\underline{y}$ to $\underline{?}$ if they are preceded by a long vowel and followed by a short vowel: /qaawim/ $\rightarrow$ qaa?im, /saayir/ $\rightarrow$ saa?ir. We can suppose, then, that broken plurals like jazaa?ir are represented as jazaawir or jazaayir at an earlier stage of the derivation. In the diminutive, this $\underline{w}$ or $\underline{y}$ immediately follows the $\underline{y}$ that is introduced by diminutive morphology -- specificaily, rule (33). Although $\underline{w}$ would assimilate to $\underline{y}$ under these conditions (i.e., $\underline{y w} \rightarrow \underline{y y})$, the existence of unassimilated forms where $\underline{w}$ is underlying like jadwal 'brook', diminutive judaywil suggests that the best solution is to treat the segment as $\underline{y}$.

Therefore I propose the following separate redundancy rule for this class of diminutives and broken plurals:

(43) CVCVVC Noun Redundancy

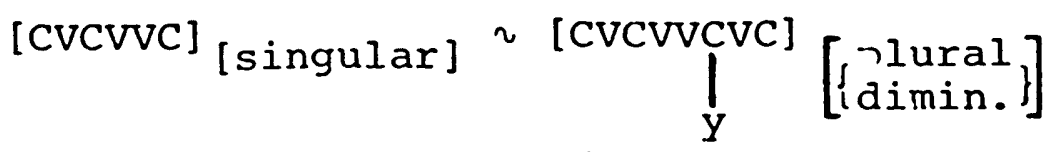


This says that this class will have a CVCVVCVC template, where $\mathrm{Y}$ is invariably associated with the second last C-slot in the stem. In the broken plural, this $y$ is subject to the rule turning it into ?; it remains $y$ in the diminutive.

\subsubsection{Nouns $\operatorname{CVC}(\mathrm{V}) \mathrm{C}$}

Here again there is a basic division in plural formation between masculine and feminine nouns. The latter generally take sound plurals, discussed later, though with some poorly understood vowel insertion phenomena. I will treat only the masculine here, which share many properties with plurals of other types:

$\begin{array}{ll}\text { (44) a. Cacc } & \\ \text { nafs 'soul' } & \text { nufuus } \\ \text { kahl 'middle-aged } & \text { kuhuul } \\ \text { bahr 'man' } & \text { bihaar } \\ \text { farx 'Yuung of a } & \text { ?afraax } \\ & \text { bird' }\end{array}$

b. CuCC

$\begin{array}{ll}\text { hukm 'judgment' } & \text { ?ahkaam } \\ \text { qufl 'lock' } & \text { ?aqfaal } \\ \text { rumh 'spear' } & \text { rimaah } \\ \text { burd 'robe' } & \text { buruud } \\ \text { c. Cicc } & \end{array}$

himl 'load'

?ahmaal 


$$
\begin{array}{ll}
\text { ?ibt 'armpit' } & \text { ?a?baat } \\
\text { qiḍ 'arrow' } & \text { gidaah } \\
\text { dirs 'molar' } & \text { duruus }
\end{array}
$$

d. CVCVC

$$
\begin{array}{ll}
\text { qadam 'footstep' } & \text { ?audaam } \\
\text { 9irab 'grapes' } & \text { ?a9naab }
\end{array}
$$

Probably the bulk of nouns CVCVC have a vocalism in both syllablas, but enough occur with other vocalism to show that no differences in plural formation exist. There is relatively little variation in the canonical patterns of the broken plurals in (44). Most have the pattern CVCVVC, though there is a significant subgroup with the pattern CVCCVVC, like ?afraax or ?ahkaam. The generalization about this subtype is that it invariably has a in the first syllable as well as a prefixed $\underline{?}$. The other plural patterns do not have $\underline{a}$ in the first syllable. Consequently we can derive these forms from underlying CaCaac $b_{j}$ a minor phonological rule of metathesis, bringing tris $\therefore y p e$ into conformity with the othe: $s$ in $(44)$. Given the similarities we have already seen between the broken plural and the diminutive, we might expect to find more here. In fact; the diminutives of this type have the pattern CVCVCC, where $y$ is associated witil the second last consonantai slot: 

(45)
a. kalb 'dog' kulayb
b. hind 'P. N.' hunayd+at
c. jabal 'hill' jubayl
d. rajul 'man' rujayl

These forms are clearly subject to the diminutive $y$-insertion (33) already developed. We will return shortly to the problem of their $\underline{u}-\underline{a}$ vocalism.

Modulo these considerations, a unified prosodic template for broken plurals and diminutives as well

of this type is CVCVVC. The form of the plural or diminutive is not sensitive to whether the singular is disyllabic or not: CVCC nouns and CVCVC nouns behave alike. We can incorporate these observations into a new version of the redundancy rule (43):

(46) $\operatorname{CVC}(\mathrm{V}(\mathrm{V}))$ C Noun Redundancy $[\mathrm{CVC}(\mathrm{V}<\mathrm{V}>) \mathrm{C}][$ singular $] \sim[\mathrm{CVCV}<\mathrm{VC}>\mathrm{VC}]\left[\begin{array}{l}\text { plural } \\ \text { dimin. }\end{array}\right]$

The parentheses allow both CVCC and CVCVC nouns to have identical patterns in the plural and diminutiva. The angled brackets ensure that only those nouns with a long vowel in the second syllable will have trisyllabic broken plurals or diminutives with $Y$ associated with the second 
last consonantal slot. As expected, in the diminutive this template is subject to the $\mathrm{y}$-association rule (33). Now we can turn to the problem of the vowel melodies. It is apparent that only three patterns of vowels occur in the broken plurals of (44): uㅡ, a, and $\underline{i}-\underline{a}$. Moreover, all these plural vowel patterns correspond to all possible singular vocalisms. Nevertheless, the plurals listed first in each group seem to predominate, so there may be some subgeneralization to express here. In general, though, each noun selects one of these three melodies purely under lexical government. The a- $\underline{i}$ melody of the trisyllabic plural forms is not available for the disyllabic plurals. The melody of the diminutive is somewhat more interesting. Disyllabic diminutives like kulayb and so on have the vowel melody $\underline{u}-\underline{a}$, in contrast to the $\underline{u}-\underline{a}-\underline{i}$ melody of tha trisyllabic liminutive forms like mufaytiih. This is instructive besause it is the first case we have seen where a vowel melody (rather than a consonant melody) is automaticaliy reduced to fit the available number of slots. That is, we can isolate just one diminutive melody $\underline{u}-\underline{a}-\underline{i}$, but if $\underline{i}$ fails to associate with a vocalic slot, it also fails to have a phonetic realization by the principle stated in the introduction.

Recall the rules for vowel association given originally as (41) in section 3.2 , which $I$ repeat here: 
(47) Vowel Association
a. $\mathrm{v} C]$
$\left[\begin{array}{l}+ \text { high } \\ - \text { back }\end{array}\right]$
b. $\begin{array}{ll}{[C V} \\ \vdots \\ {[+ \text { high ] [-high] }}\end{array}$

These two rules, applying in this order, will yield the following derivations for the vocalism of representative trisyllabic and disyllabic diminutives:

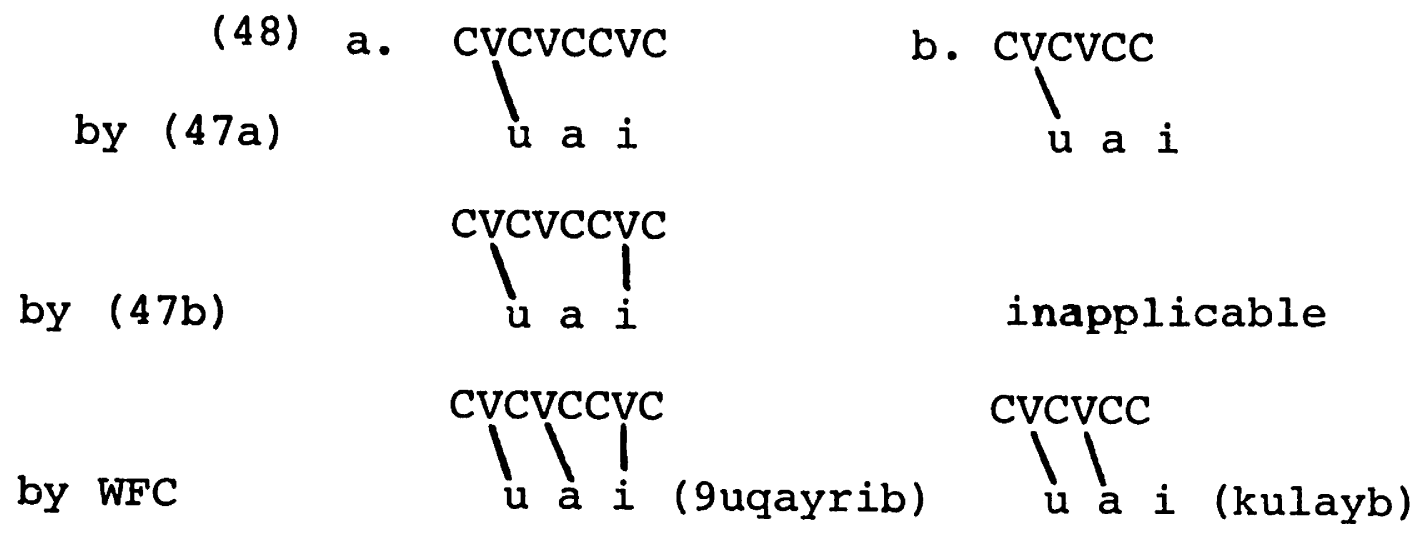

The point here is that rule $(47 \mathrm{~b})$, which associates $\underline{i}$ with the last stem vowel in (48a), cannot apply in (48b) because two consonants end the stem. What happens then is that either $\underline{\text { a }}$ or $\underline{i}$ could associate automatically with the one remaining slot. I assume that in cases like this the general left-to-right mapping rule determines that a takes precedence. It follows, then, that variation in the diminutive melody depending on the number of syllables is a direct consequence of independently motivated rules of the 
grammar, by virtue of which $\underline{i}$ remains unassociated anú so receives no phonetic realization.

\subsubsection{Other Plural Patterns}

Certain other modes of forming the plural (although not the diminutive) have fairly strict morphological constraints on their distribution. I will not attempt to exhaust these possibilities, but most of the major ones are treated here. In some cases it is possible to express similarities between these and the broken plurals treated earlier in terms of the theory proposed here.

One class of nouns CVVCVC consistently deviates from the CVCVVCVC plural pattern predicted by the redundancy rule (37) -- these are the active participles of the first binyan, generally used as agentive nouns of various sorts:

(49)

$$
\begin{array}{ll}
\text { a. saajid 'prostrating oneself' sujjad } \\
\text { saanir 'conversing at night' } & \text { summar } \\
\text { b. haakim 'judge' } & \text { hukkaam } \\
\text { jaahil 'ignorant' } & \text { juhhaal }
\end{array}
$$

The $\underline{\text { u}}-\mathrm{a}$ melody of these plurals is clearly unrelated to any melody of the broken plurals already discussed, though we will see shortly that there seems to be a generalization about the use of $\underline{u}-\underline{a}$ in the plurals of nouns referring to rational beings (like these participles, typically). 
As for the other characteristics of their form, we can see that the plurals in (49a) have almost the canonical pattern of the corresponding singular, but they substitute gemination of the medial consonant for length of the first vowel. We can treat this formally as a rule that adds an autosegmental association between the middle consonant of the root and the final segment of the first syllable of the stem:

(50) Participle Plural

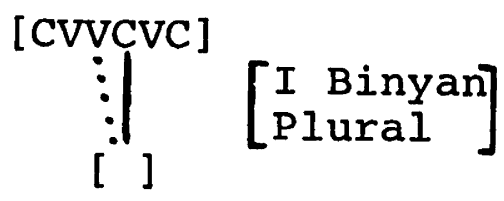

That is, whatever melody is associated with the second Cslot of the template also gets associated with the preceding V-slot in the plural. I will assume that this anomalous mapping of a consonantal melody onto a vocalic template position automatically changes that position to $C$, though obviously this effect could be encoded into rule (50) as well.

The lengthening of the vowel in the second syllable in (49b) is lexically idiosyncratic; some words have one plural or the other and some vary between the two. We can express this with a minor vowel insertion rule that I will not: formulate here. 
Somewhat more interesting properties hold for the broken plural patterns of most masculine nouns with the singular pattern CVCVVC. There is a basic split here into nonrational and rational nouns, with a different major plural pattern for each:

(51) a. Nonrational

$\begin{array}{ll}\text { janaab 'wing' } & \text { ?ajnibat } \\ \text { himaar 'ass' } & \text { ?ahmirat } \\ \text { 9amuud 'pillar' } & \text { ?a9midat } \\ \text { qaḍilb 'branch' } & \text { ?aqḍibat } \\ \text { Rational } & \\ \text { ?amiir 'rommander' } & \text { ?umaraa? } \\ \text { baxiil 'stingy' } & \text { buxalaa? } \\ \text { hakiim 'wise' } & \text { hakamaa? }\end{array}$

In both nonrational and rational types the pluxal noun has a feminine suffix, at for nonrationals and aa? for rationals. This is the primary peculiarity of these forms, thcugh we saw earlier that some quadriliteral nouns idiosyncratically took the feminine ending at as well. Recall also from the discussion of those nouns that this feminine ending induced shortening of the vowel in the final syllable of the stem. Clearly we could exploit this phenomenon here as well, and derive the broken plurals in (51) from the corresponding singulars by the following rule: 
(52) $\mathrm{V}+\varnothing / \mathrm{V}{ }^{\mathrm{C}]}$ [plural] ${\underset{\text { [feminine] }}{\mathrm{V}}}_{\mathrm{V}}^{\mathrm{V}}$

This says that the suffixes at and aa?, which bear the feature [feminine], shorten the vowel of the preceding syllable in the plural. It may require additional specifications to restrict it to broken plurals (and not to the feminine sound plural described later), but this would not require burdensome apparatus.

It is clear, then, that the forms in (5lb) can all be related to the prosodic template CVCVVC, which is subject to (52) in the plural. Moreover, the melody of the plural forms in (51) can clearly be identified with the plural of the active participle forms in (49). Since the active participles of the first binyan will in general refer to rational beings, we can describe the melody u-a as the plural vocalic melody of rational nouns generally that are not subject to the usual broken plural rules.

Now the nonrational plurals in (5la) interestingly do display the typical $\underline{a-1}$ melody of the other broken plural types, rather than the special u- $\underline{\mathrm{u}}$ melody of the rational plurals. Their initial syllable ?VC is a consequence of the same minor rule applying in the plurals of (44). Therefore they involve no new generalizations.

In sum, these types of morphologically or lexically restricted plurals differ basically from the other broken 
plural patterns discussed in that the template of the singular serves as the basis for forming the plural. In the participles, the basic operation is the association rule (50). In the masculine CVCVVC nouns, it is suffixation of the feminine desinences at or aa?. Rational nouns of both types share an u-a plural melody, while the nonrational CVCVVC nouns have the $\underline{a}-\underline{i}$ melody that is typical of most other broken plurals.

\subsection{Case and External Pluralization}

The ordinary case marking of singular nouns, whether masculine or feminine, is triptotic. That is, a three-way case distinction is made, as in the paradigm of the word $\underline{\text { kalb }}$ 'dog':

a. Masculine

Nominative kalbu

Genitive

Accusative kalbi

kalba b. Feminine

kalbatu

kalbati

kalbata

In the spirit of the analysis presented here, we can isolate a basic template for case marking as a sincle $V$ suffix on the stem, subject to three different melodies: 
(53) Case Marking (triptotic)

a. Suffix V

b. Melodies

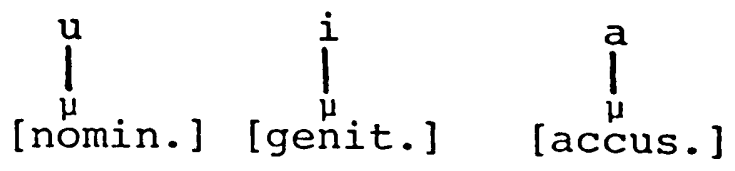

Some initial support for this analysis comes from the behavior of two nouns -- mru?u 'man' and bnumu 'son' -- where the quality of both the stem and desinential vowels depends on the case: mru?u, mri?i, mra?a. Here the stem vowel is unspecified for quality, and only receives its quality by virtue of the melodies in (53).

In general this mode of case marking holds for most singular nouns as well as most broken plurals, though some of them as well as certain classes of singulars have diptotic declension, marking both genitive and accusative with a. There is, however, a slightly different mode of inflection in the dual and sound plural. All nouns potentially take a dual except for nouns that are already in the sound plural category. Even broken plurals can form duals, although the meaning is somewhat specialized: jamal 'camel', jimaal 'camels', jimaalaa 'two herds of camels'. Sound plurals are, however, limited fairly strictly to certain well-defined classes of nouns. Some discussion of this limitation can be found below in section 5.2 .

Both the dual and the sound or external plural involve suffixation with no stem Ablaut: 

(54)
a. Masculine
b. Feminine

Dual

$\begin{array}{lll}\text { Nominative } & \text { kalbaa } & \text { kalbataa } \\ \text { Gen/ACC } & \text { kalbay } & \text { kalbatay } \\ \text { Plural } & & \\ \text { Nominative } & \text { kalbuu } & \text { kalbaatu } \\ \text { Gen/ACC } & \text { kalbii } & \text { kalbaati }\end{array}$

I will have nothing to say about the dual; it apparently resists incorporation into the full desinential scheme. But the plural has some interesting similarities with the singular. First, both genders of the plural recognize a two-way case distinction, with trie genitive/accusative marked by the $\underline{i}$ of the genitive singular. That is, the plural neutralizes the genitive/accusative aistinction in favor of the genitive. We can obviously capture this with the melodies in (53b) if we say that accusative a goes to $\underline{i}$ in the plural.

Now if we turn to the prosodic templates of these forms, another generalization is apparent. The feminine plural has a single desinential vowel that bears the melody for case-marking. The masculine plural has a geminate vowel desinence that carries the melody. But the feminine plural also has lengthening of the vowel in the feminine ending at. Therefore we might suppose that external pluraiization simply adds a single $\mathrm{V}$ immediately after the stem 
(before the feminine ending if there is one). This inserted vowel picks up the a melody of the feminine but in the masculine it receives the melody of the appropriate case. 


\section{Theoretical Consequences}

Two distinct sets of results follow from the proposals made in this chapter. The first of these concerns the issue of the form of morphological rules. I argue that it is possible to place a very strong constraint on such rules and still capture a wide variety of significant generalizations. The phenomena of reduplication and infixation, as well as the notion of a prosodic template, figure prominently.

The second set of results concerns the form of lexical entries and the overall structure of the morphology. I offer a formal characterization of a lexical entry as a tree structure, in which domination expresses the relationship "is derived from". It is shown that this allows a plausible description of otherwise intractable phenomena in Arabic both in morphological relationships and in lexical irregularities.

5.1 Formal Properties of Morphological Rules

We have seen that, just at the level of surface phenomena, Arabic offers a wide variety of discontinuous dependencies, Ablaut processes, apparent movements of segments, reduplication and infixation, and so on. The most surprising result of the analysis offered here is that all of this manipulation can be accomplished without recourse to full transformational formalism. Rather, it is sufficient to capture all the relevant generalizations to have rules 
of the form $A \rightarrow B / X$ and the universal and partly languageparticular apparatus of autosegmental phonology. By any account the alternative adopted here is weaker than a transformational one, and consequently more explanatory. No need was demonstrated for transformational rules of reduplication, infixation, movement, and so on, in spite of the tremendous complexity of the observed phenomena and the significant depth of the analysis.

Notice, however, that we cannot dispense with nonsyntactic transformational rules entirely. Consider, for example, the phonological rules of metathesis. There exists a number of well-motivated analyses that incorporate phonological metathesis rules; examples that come to mind are Latvian (Halle and Zeps 1966) and Maltese (Brame 1972), as well as the rules of Arabic and Akkadian discussed here in sections 3.1 and 2.1, respectively. Although some of these rules have morphological as well as phonological conditions, they are clearly not morphological rules nor are they allomorphy rules in the sense of Aronoff (1976).

Since it is impossible to express a metathesis rule by anything except transformational formalism, we must conclude that phonological rules do have this richer formalism available to them. Therefore the observation made about Arabic must be confined to morphological rules. Now that we have mapped out the general domain of this observation, I will suggest the following universal constraint: 
(1) Morphological Transformation Prohibition (MTP)

All morphological rules are of the form

$A \rightarrow B / X$, where $A, B$, and $X$ are (possibly

nul1) strings of elements.

That is, morphological rules must be context-sensitive rewrite rules, and no richer rule type is permitted in the morphology. Incidentally, I should point out that I have no evidence to determine whether the MTP should or should not extend to readjustment or allomorphy rules (Aronoff 1976) as well, since I know of no rule in the analyses presented here that demonstrably belongs to either of these types.

It is obvious that a theory that incorporates the MTP strongly generates a much smaller class of grammars than a theory without this constraint. Morphological transformations potentially allow any arbitrary operation on a segmental string. For example, transformational morphological rules of this sort can freely move particular segments an unbounded distance within the word, copy all and only the vowels in a word, or reverse strings of finite length. They can as well reduplicate only, say, a final lateral, and at no greater cost than reduplicating any final consonant. If the segmental representation is further enriched by permitting integral indexing of segments, as in Chomsky's (1951) analysis of Modern Hebrew intercalation described in 
the introduction to this chapter, then morphological transformations can perform their arbitrary operations on only the prime or factor-of-twelve numbered segments in the word with no further enrichment of the formalism.

These examples, although bizarre, are not facetious. It is a fact that a morphological theory without the MTP allows all of these types and in some cases values them more highly than morphological rules that actually occur in some language. The theory with the MTP is therefore vastly more explanatory than the one without it.

of course, one could object that although the MTP delimits a theory with lessened strong generative capacity, it has no corresponding effect on weak generative capcity. It is fine to eliminate morphological transformations, so the argument goes, but isn't it possible to encode the same effects into the phonological rules, which do allow transformational formalism?

The defect in this argument is that it takes no cognizance of the theory of phonological rule naturalness which, although only imperfectly understood at this point, nevertheless must be a part of linguistic theory as a whole. To see how this works, let us return once again to the rather problematic phonological metathesis rules. It has been observed both traditionally and in more recent surveys (Ultan 1971) that only a very limited set of metathesis rule types exist, depending on the phonetic character of 
the affected segments. One type is the vowel-liquid metathesis, of which old English hros/hors or the Maltese rule are examples. This apparently reflects a more general type of metathesis between adjacent sonorant noncontinuants, as the Latvian vowel-glide metathesis shows. The other sort is stop-spirant metathesis, like the Akkadian rule. This type is particularly evident in speech errors and spoonerisms like English ask/aks. A third metathesis type, involving identical consonants separated by a vowel, is represented by Classical Arabic.

It is fairly clear from these brief observations, as well as others by Ultan (1971), that there exists a quite limited set of possible metathesis rules, which we could characterize as a preliminary theory of natura]. metathesis. Although linguistic theory allows full transformational formalism in phonological rules, it is nevertheless subject to this sort of substantive constraint. Therefore only a small subset of the formally possible metathesis rules will actually occur, so the claim that the MTP does not affect weak generative capacity is incorrect. Notice, however, that it is impossible to make any such constraints on the phonetic naturalness of morphological rules. It follows directly from l'arbitraire du signe that phoneticallydetermined considerations of naturalness have no place in morphological rules. Therefore any constraint on the morphology must be an essentially formal one, like the MTP. 
I conclude, then, that a linguistic theory that incorporates the MTP is more constrained than and consequently superior to a theory that does not, all other things being equal. Of course, it could still be the case that the MTP is incorrect on empirical grounds, so that we must nevertheless prefer the descriptively richer theory. It is perhaps needless to say that the MTP cannot be falsified simply on the basis of surface phenomena in some language, but it should hold for any analysis comparable in depth to the treatment of Arabic presented here.

Pretty clearly ordinary concatenative morphology is entirely consistent with the MTP. The same is true of relatively simple Ablaut processes, like those found in most Indo-European languages. On the other hand, there are several types of phenomena that are usually described by morphological transformations, either explicitly in generative analyses or implicitly in more traditional frameworks. These include morphological metatheses and infixation and reduplication. The cases in the literature number far too many for reanalysis here. I will, however, show for some trenchant examples that a prosodic analysis along the lines followed in Arabic not only is consistent with the MTP, but also, in the case of reduplication, accounts for a variety of phenomena that have not been adequately dealt with in transformational morphological analyses. 
Consider, for example, the prima facie case of a morphological metathesis rule in English: the accentual alternation between noun and verb pairs like torment/torment. Regardless of which category is underlying, the morphological rule must apparently exchange the positions of [1stress] and [3stress], an operation that cannot be accomplished without transformational formalism. In fact, such a transformation would be slightly more powerful than the sort ordinarily appearing in syntactic descriptions, since syntactic rules have not usually exploited the possibility of exchange rather than simple movement.

But under a metrical analysis of English stress like that provided by Liberman and Prince (1977) and in Chapter 3, there is no need for a metathesis rule here. Let us assume arbitrarily that the verb pattern is basic, with final stress. In the metrical formalism, this is represented by the tree $\widehat{w}$, while the related noun is associated with the tree $\widehat{s}$. The morphological rule altering verb to noun simply says "change the right branch to w". Since sister nodes can, in the nature of the formalism, only have complementary values, the right branch automatically becomes s. The operation is not metathesis but changing of a single label under appropriate morphological conditions. The fact that the result looks like metathesis is not stipulated in English grammar but follows from universal constraints on the notation. 
Even more dramatic evidence of the same sort of phenomenon comes from two accent shift rules of Hebrew described in Chapter 3. These rules, Imperfect Consecutive Stress Retraction and Perfect Consecutive Stress Shift, move the accent leftward and rightward respectively to mark special aspectual forms used in narration. Not only are these rules formulated as simple rewrite operations on a single label of a metrical subtree, but they demonstrably refer to a particular formal characteristic of that subtree, its status as a foot. A treatment of these same facts by stress metathesis would not only require transformational notation but it would also miss the generalization afforded by the metrical theory that an identical prosodic unit, the foot, is functioning in both these rules. In this case, then, proper consideration of metrical structure consistent with the MTP actually provides a descriptively superior account.

Much more frequent than apparent morphological metathesis are the phenomena of reduplication and infixation. A fair amount of the discussion in recent works on morphology has been devoted to studying them. Arabic, and Semitic in general, though they have not usually appeared in these discussions, are the extreme cases of languages with almost total reliance on infixation and reduplication in the morphology. Virtually no word of Arabic can be divided into morphemes on a purely segmental linear basis. 
Yet it should be clear by now that a transformational treatment of these phenomena would yield a grammar of almost ludicrous complexity, belying the underlying symmetry of the whole system. It would invoke wholescale movements of consonants and vowels, arbitrary replacements of potentially infinite strings of vowels by others, and so on. The analysis presented here captures these generalizations without transformations and in a far more explanatory way. Many of these explanatory characteristics should be already apparent: the essential nature of the root in the formation of words, the existence of vowel melodies whose function is to mark aspectual or voice differences, and so on. But some are more subtle. In particular, certain very general properties of reduplication and infixation are predicted by the theory adopted here.

Let's consider the basic characteristics of reduplication and infixation in the prosodic model. I will, however, confine most of my attention to the better-studied phenomenon of reduplication. The basis of Arabic morphology is a set of prosodic templates that vowel and consonant melodies are mapped onto by certain rules of great generality. Infixation is represented by the association of affixal material, like the $\underline{t}$ morpheme of the eighth binyan, with an internal position of the template. Reduplication can be characterized formally as a one-to-many association of a single melodic element with more than one slot of the 
prosodic template. That is, reduplication is just an instance of the more general autosegmental phenomenon of spreading. This is the case, for example, with reduplication of the $\underline{u}$ portion of the perfect passive melody in sixth binyan tukuutib or of the final root consonant in ninth binyan ktabab. In every instance the surface reduplication is not a consequence of a transformational rule but rather of the spreading of a particular melodic element to fill up the available slots of the template.

Although the bulk of Arabic reduplication results from spreading of melodies onto a template made up of $\mathrm{V}$ and $\mathrm{C}$ positions, this is not always true. In the Arabic verbs of the type zalzal, as well as the Hebrew pilpel binyan discussed extensively in section 3.1, a biconsonantal root is mapped onto a template composed of two [root] positions. That is, reduplication can be a one-to-many association of a morpheme with a template consisting of morphemes. The result of this spreading is then mapped onto one of the basic $C / V$ prosodic templates. Similarly, the Hebrew pa9al9al binyan maps a syllable onto a template composed of two o-positions, again in conformity with the usual left-to-right mode of association. Although the bulk of the verb system is based formally on the $\mathrm{C} / \mathrm{V}$ prosodic templates, these two special binyanim of biconsonantal roots stipulate additional templates composed of morpheme or syllable positions. 
In general, then, the formal basis of surface redupli.cation is the specification of a template composed of positions like $V, C, \mu$, or $\sigma$, and the regular autosegmental mapping onto that template. No transformational apparatus has any function in this system. No special rules of reduplication are needed -- the phenomenon simply arises whenever the regular rules of mapping yield a one-to-many association between the melody and the template. Ve:bal categories with characteristic reduplication, like the Arabic verbs of the zalzal type and the related Hebrew pilpel, simply stipulate a template in which this sort of association necessarily arises.

Not surprisingly, there are several interesting empirical consequences of this very reduced apparatus for describing reduplication phenomena.

First, the directionality of reduplication is, in general, invariant. Since the direction of reduplication -the position of the reduplicated element with respect to the rest of the form -- is a direct consequence of the direction of association, a left-to-right rule of association yields reduplication at the right end of the stem. Clearly other rules of association, right-to-left in particular, could yield other directions of reduplication. But the prediction, generally borne out by the semitic verb data as well as casual observations of other languages, is that the apparent direction of different reduplication 
phenomena should be invariant. Languages can deviate from this only at greater cost. Thus, it requires the stipulation of an additional rule, the Second, Fifth Binyan Erasure Rule of section 3.1, to yield medial reduplication in the forms kattab and takattab. Notice that this prediction is not made by the transformational theory; each reduplication transformation in a given language stipulates its direction independently of the other rules.

Second, there is only very limited possibility in the prosodic theory of restricting reduplication to particular phonologically-defined classes of forms. To see the significance of this, consider two putative reduplication rules in the transformational model. One rule reduplicates any final syllable CVC, while the other only reduplicates the syllable if the final consonant is a lateral. These two rules are equally valued in the transformational theory; the first applies to $\mathrm{CV}[+\mathrm{cons}]$, the second to $\mathrm{CV}[+1 \mathrm{lat}]$. This is, however, almost certainly the wrong prediction, and clearly the first rule should be much more highly valued if the second is possible at all. In fact, one result of Moravcsik's (1978) survey of a number of reduplication phenomena is that no phonetic specification of the reduplicated string is ever necessary except its composition in terms of $\mathrm{V}$ and $\mathrm{C}$. This observation is obviously supported by the more detailed analyses of Arabic and Hebrew 
presented here. In the transformational theory, any arbitrary phonetic characteristic of the reduplicated string is permitted and can be as highly valued as the actually occurring $\mathrm{V}$ and $\mathrm{C}$ specifications.

This problem is inherently absent from the prosodic model of reduplication. A morphological category which ordinarily reduplicates stipulates an output template in terms of the properties indicated earlier. The template can be composed of $V / C$ positions, morphemes, or syllables, but it cannot refer to the whole rich set of phonological features. It is therefore impossible to restrict reduplication to forms sharing some other phonological characteristic, short of additional arbitrary restrictions on the mapping rules. It follows, then, that the prosodic theory is superior to the transformational theory in granting much higher value to the actually-occurring restrictions on the reduplicated string.

A kind of corollary to this property of the theory is that reduplication is limited to strings that form constituents at some level of representation. The notions of mapping and spreading are meaningful only insofar as they involve the association of constituents at one level -like individual elements of the autosegmental melody -with units at another level -- like $\mathrm{V}$ or $\mathrm{C}$ positions in the prosodic template. Not all reduplication phenomena result from mapping onto V/C positions. For example, we saw 
that Arabic verbs like zalzal or the Hebrew pilpel involve mapping an entire morpheme, the root. The Hebrew pa9al9al maps a syllable onto a template composed of syllable positions. Other units that may function in this way are subconstituents of the syllable, like the rhyme or onset in the sense developed in Chapters 2 and 3 . Even the metrical foot is available for this sort of many-to-one association. For example, it is a fact that English reduplicated compounds of the higgledy-piggledy type (a thorough list can be found in Jespersen (1956)) invariably consist of two feet exactly and no other material. Although this sort of reduplication is hardly productive in English, it nevertheless suggests the possibility" of mapping a single foot onto two foot positions in the output template. I would tentatively suggest as well that reduplication of disyllabic units in Tagalog (Carrier 1979) is also an instance of foot reduplication. This is consistent with the fact that Tagalog has, though with many exceptions, predominant penult stress, which can be characterized by a disyllabic metrical foot. Although I know of no clear cases, I presume that the word (in the sense of Rotenberg (1978) and Selkirk (forthcoming)) is also a constituent subject to reduplication.

Here again the transformational treatment makes no prediction at all. An arbitrary string of segments can be reduplicated by a transformational rule, so there is no 
requirement that the string form a constituent at a morphological, prosodic, or phonological level. Note that, as with any property of the theory developed here, the claim that reduplication phenomena are limited to constituents will not necessarily be obviously true of the surface facts of any language. This generalization does hold, however, for the fairly deep analyses offered here, from which I conclude that the prosodic theory is superior.

I will now discuss two phenomena from the literature which are not evidenced in Hebrew or Arabic, but nevertheless offer strong support for the prosodic treatment of reduplication. Since I am familiar with these cases only through the cited works, my analyses are tentative and preliminary. But since these facts have not, to my knowledge, received adequate explanations until now, and since they do involve clear predictions of the prosodic theory, I present them here.

One aspect of the prosodic theory that should be evident is that a given morphological category will stipulate an output template composed of some set of units at a particular level of representation. The transformational theory specifies an operation rather than actually indicating a final output. Essentially this distinction turns out to be relevant in Cupeño according to Hill's (1970) very thorough analysis. I will not repeat the entire argument, but will only cite her conclusion. The morphology of the 
habilitative construction involves no change in verb stems that end in a vowel. Thus, input representations cí, céli, and yélici remain unaffected. Likewise, if two syllables follow the stress, then the form is also unchanged: pine?wex. But if only one syllable follows the stress, we get insertion of glottal stop plus a copy of the vowel in that syllable: pácik $\rightarrow$ pácieik. And if no syllables follow the stress, then the result is two copies of the stressed vowel and two inserted glottal stops: téw $\rightarrow$ té?e?ew. The appropriate generalization is evident from these forms: in consonant-final stems, the result of habilitative morphology must be a form with two syllables following the stress, regardless of the number of syllables in the input. Hill correctly concludes that a phenomen of this sort cannot be adequately characterized by the available, essentially transformational, apparatus. She suggests that the habilitative rule has a kind of glocal power, which she calls peeking, that allows it to set an output target and then perform a reduplication operation until it reaches that target. The target is, obviously, to have two syllables follow the stress in consonant-final verb stems.

I have insufficient knowledge of the phonology of Cupeño -- particularly the metrical structure of stress and syllabification -- to offer a thorough reanalysis of these facts. But nevertheless it should be apparent what 
the general outline of the prosodic treatment is. The template of the habilitative, at least as it applies to consonant-final stems, specifies that two syllables follow the stressed syllable. I will represent this with a V/C template, as in (1):

\section{(1) $\quad \ldots \quad \dot{v} c \vee c \vee c]$}

The material preceding the stress is apparently irrelevant; thus the "...". I will stipulate first that the stressed vowel of the stem is mapped onto $\dot{v}$ in this template, and that the final consonant of the stem is mapped onto the c]. Notice that this encodes the fact that this template is available only to consonant-final stems. The familiar left-to-right mode of association then yields, with spreading according to the Well-formedness Condition, the desired reduplication. The results of these two rules of association are represented in $(2):^{8}$

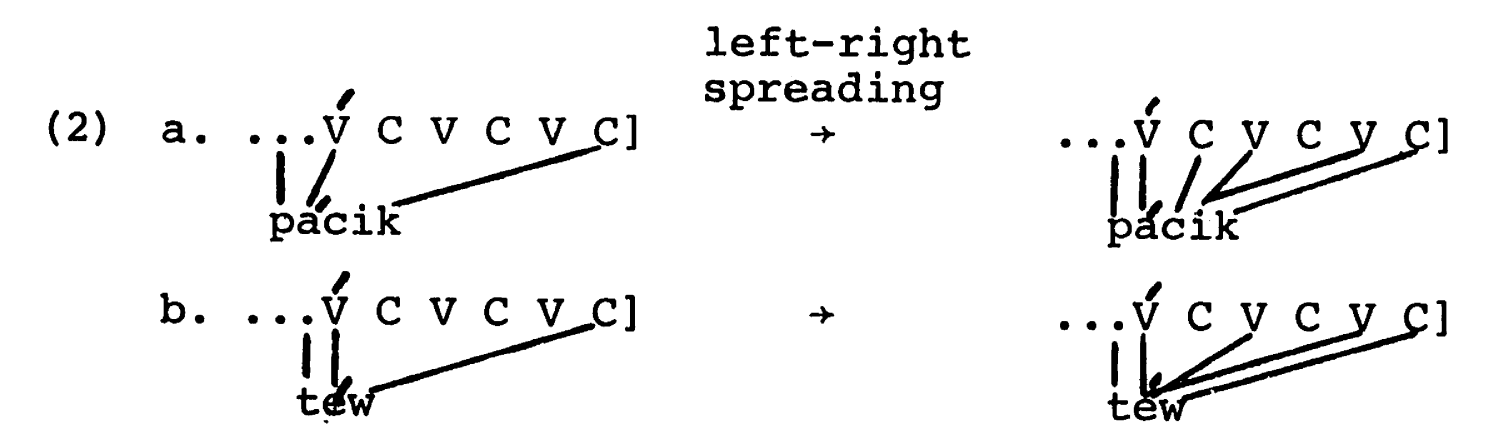

I assume that the unspecified C-slots are filled by glottal stops to avoid hiatus, yielding the observed surface forms. 
Although this characterization of Cupeno reduplication is necessarily informal, it does seem to capture Hill's basic generalization. Forms with one syllable following the stress will reduplicate once and those with no syllables will reduplicate twice, all as a consequence of left-toright mapping and the theory of autosegmental phonology, given a template like that in (1). Forms which already have two syllables following the stress will fill all the available slots, so no surface reduplication will result. These properties, which are quite natural consequences of the prosodic theory, cannot be expressed in a transformational account without recourse to a global output constraint like Hill's or perhaps a baroque assortment of angled brackets. The existence of this Cupeno example is therefore strong support for the proposals made here.

The last, rather lengthy point to be made about reduplication concerns the so-called ordering paradoxes, the cases where a morphological reduplication transformation must apparently follow the application of one or more phonological rules. The basic phenomena behind these paradoxes are of two kinds. One sort, underapplication, involves a phonological rule whose environment is met as a result of reduplication but which nevertheless fails to apply. In this type the prior application of the phonological rule is a kind of counterfeeding order, so the rule has been passed before reduplication. The other sort, apparently more 
common, is overapplication. Here the rule applies not only in one half of the reduplication where its environment is met but also in the corresponding segment in the other half. Therefore the phonological rule precedes reduplication, and the appropriately mutated segment is copied. The original observation of this sort appears in a discussion of Tagalog by Bloomfield (1933). Essentially the same approach has been followed in more recent work like Anderson (1975), Aronoff (1976), and Carrier (1979), though with individual differences concerning the character of the ordering relationships and of the rules involved. A different treatment, involving a global device for linking the corresponding segments in the two halves of the reduplication, is adopted by Wilbur (1973). However, in view of Aronoff's (1976) convincing arguments that this approach requires far less restrictive a theoretical apparatus than is justified by the actual phenomena, I will confine most of my attention to the ordering theory of Bloomfield and the others.

Here I will suggest another interpretation of the reduplication paradoxes that is superior to the ordering theory on empirical grounds, that is no less restrictive, and that involves no apparatus, like late ordering, that is arbitrarily restricted to reduplication. The basic insight here is that, in one respect, the autosegmental formalism is slightly richer than the transformational 
formalism. In a limited way the prosodic treatment allows the reduplicated form to retain a trace of reduplication by virtue of having a one-to-many association. On one autosegmental tier such a form has a single constituent that corresponds to two or more constituents on another level. I have already exploited this property in two ways discussed in section 3.1. First, recall that there is a masdar (infinitive) pattern in Arabic that is restricted to verbs of the type $C_{i} V_{j} C_{i} V_{j}$ : ğalğaal 'agitation', zalzaal 'convulsion'. Even more dramatic is the rule of Metathesis, which applies if and only if the two affected consonant slots are associated with the same element of the melody. Given that we have this formal characteristic of reduplication available, and further given that there is independent evidence in Arabic in favor of it, then we could conceivably exploit it in other phonological rules besides Metathesis. A basis for this is an extensirr. of the notion of percolation in a prosodic tree, developed by Vergnaud (1976) and discussed in section 4 of Chapter 3.

Consider the tree whose root is the melody and whose terminal nodes are the elements of the prosodic template in reduplication, as in (3):

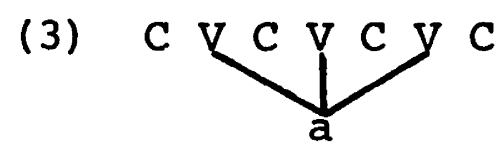


Suppose further that a phonological rule applies, changing a to $\underline{i}$ in a final closed syllable. There are two possible results of such a rule. Either the rule applies only where the environment is met, yielding CaCacicic, or the derived features [thigh, -back] percolate up to the root node, changing all of its daughters to $\underline{i}$. In this case we will get the effect of apparent postphonological reduplication, Cícicic. While the ordering solution would say that reduplication here follows the $\underline{a}$ to $\underline{i}$ rule, the prosodic treatment claims that reduplication, like usual morphology, is prephonological, but the a to $\underline{i}$ rule induces feature percolation within a characteristic structure of reduplication like that in (3).

There are certain interesting limitations on this prosodic theory that do not hold for the ordering or global solutions to reduplication paradoxes. First, the most important point is that percolation is coherent only as an operation on feature values. That is, we can percolate some value for a distinctive feature, but we cannot percolate the insertion or deletion of a segment. Furthermore, accentual characteristics that are represented by prosodic trees of their own, like those of Chapter 3, will clearly not be susceptible to percolation. Neither the ordering nor the global theory place any such constraint on the limits of the reduplication mimicry phenomena. 
Second, there is no provision in this theory for the underapplication type of paradox, though both of the other theories recognize this possibility. Although the percolation mechanism deals easily with overapplication, as in the hypothetical case just described, it cannot account for the failure of a phonological rule to apply in reduplicated forms. However, Aronoff (1976) correctly points out that the instances of underapplication that have been proposed can be considered as juncture-strength phenomena. That is, in some cases the juncture between the two halves of the reduplicated form is not close enough to permit application of the relevant phonological rule. Junctural effects of word-formation have been extensively studied in English by Siegel (1974) and Allen (1978), who propose boundary solutions to these facts, and by Selkirk (forthcoming), who deals with them in terms of categories. I conclude, then, that the inability of the prosodic theory to deal with underapplication is a virtue, since underapplication can be handled by an independently necessary theory of juncture types.

Th1s treatment of reduplication paradoxes is, of course, logically distinct from the rest of the prosodic theory, and so we could reject the percolation device yet still keep the other results. Moreover, there may be some unknown constraints on the percolation mechanism. For example, it seems likely that percolation would be suppressed when it 
leads to extreme opacity in the sense of Kiparsky (1973). This is perhaps the case when both the trigger and the target of the phonological rule are linked prosodically. For example, the application of Grassmann's law to reduplicated forms in Greek does not result in percolation:

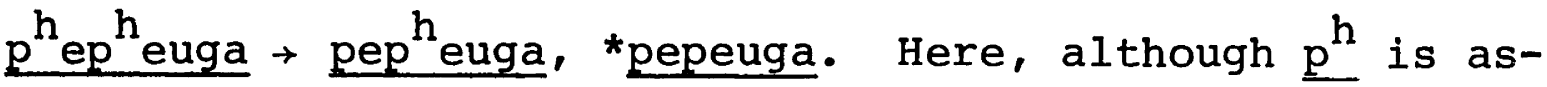
sociated with two C-slots, no percolation of [-asp] results, conceivably because it is the second $\mathrm{p}^{\mathrm{h}}$ that is triggering the deaspiration. Furthermore, the observations of Carrier (1979), though cast in a much different theory, suggest that there may be some resistance to percolation by the outputs of automatic, exceptionless phonological rules. Finally, there may be irreducible cases where particular rules or particular reduplicated constructions invariably resist percolation. This seems to be the case for the postvocalic Spirantization rule in Hebrew described in Chapter 2. This is the only phonological rule I know of in Hebrew or Arabic that clearly tests for a reduplication paradox. The fact is that no percolation occurs, as forms like yakalkēl (*yakalkēl) and lisbób (*lisbób) show. It is an empirical question whether languages can choose to arbitrarily suppress the percolation effect, like the choice of prephonological reduplication in the ordering theory.

An interestingly complicated case of the interaction of reduplication and phonological rules in Luiser̃o (Munro and Benson 1973) illustrates the major points of the 
percolation proposal ir a way that is superior to the ordering theory. Percolation predicts exictly which phonological rules will and will not be mimiced by the reduplicated form, and, moreover, it sulves a problem in vowel syncope that has been noted in previous literature in the ordering theory.

Stress ordinarily falls on the initial syllable, though second-syllable long vowels attract the stress. of relevance here is the fact that one class of suffixes

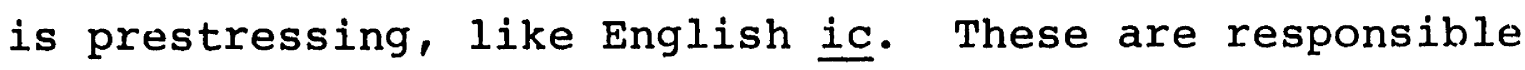
for the following alternations:

(4) a. hédi- 'to open' hidíki 'to uncover'
b. qára- 'to spill out' qarápa 'to fall (pl. subj.)'

This sort of exceptionality can be handled by a mechanism like that adopted for the feminine agreement suffixes in Cairene Arabic (see Chapter 3). That is, these suffixes exceptionally form a foot, labeled s-w, over themselves and the preceding syllable.

A vowel deletes in a doubly-open syllable if the preceding syllable is stressed:

(5) a. p̧č̀iku + pášku- 'to leach corn flour' b. čáq ${ }^{w} i l a+c^{c a ́ q}{ }^{w} 1 a-$ 'to wrestle' 
In rough metrical notation, we can formulate this rule as follows :

(6)

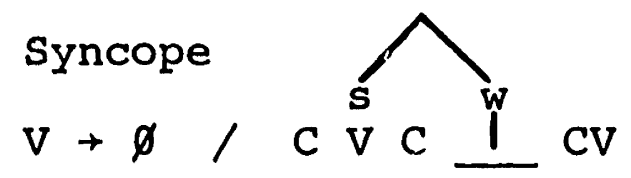

This rule obviously must follow the application of stress. Arother rule demonstrably follows syncope. The segments $\underline{\underline{c}}$ and $\underline{\underline{s}}$ are in complementary distribution on the surface. $\underline{c}$ precedes any [tcont] segment, while $\underline{\underline{s}}$ precedes word-boundary and noncontinuants (where, following Munro and Benson, $\underline{l}$ and $\underline{r}$ are treated as noncontinuant). This distribution is evident from the following alternations:

(7) a. té:nališ 'medicine' té:naličum 'medicines'

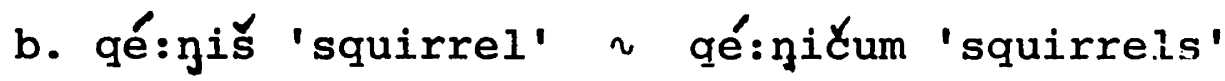
c. wanís 'river (acc.)' waní:ča 'river'

Munro and Benson formulate the rule accounting for this as a change from $\underline{\underline{c}}$ to $\underline{\underline{s}}$ before noncontinuants and word-boundary. Since the segments are in complementary distribution, nothiny prevents us from treating $\underline{\underline{s}}$ as underlying, which actually yields a formally simpler rule:

(8) 's-‘ Allophony $\xi+\varepsilon / \ldots[+$ cont $]$ 
This rule must follow Syncope, as the following derivations witness :

(9) a. né:šu- $\stackrel{\text { Allophony }}{\rightarrow}$ né:ču 'to become an old woman' b. né:Sumal $\stackrel{\text { Syncope }}{\rightarrow}$ né:šmal $\stackrel{\text { Allophony }}{\rightarrow} \underset{\text { DNA } \stackrel{\text { others }}{\rightarrow}}{ }$ nésmal 'old woman'

Therefore the Syncope rule must bleed Allophony by preceding it for the correct forms to result.

So the ordering of the three rules discussed must be as follows:

\section{(10) Stress \\ Syncope \\ Allophony}

Although the ordering of Stress before Allophony is not independently demonstrable since the two rules do not interact directly, I will assume this ordering on the basis of transitivity.

Now Luiseno has a fairly productive reduplication prom cess that forms deintensive nominals from roots. These forms regularly appear on the surface with the suffix $\underline{\underline{s}}$ in the absolutive: 

(11)
a. ?áva- 'to be red' ? ?avá?vał 'pink' b. máha- 'to stop' mahámhašs 'slow'

These forms have several different peculiarities. First, stress falls on the second syllable of the first occurrence of the root, deviating from the usual initial stress. With Munro and Benson, we can suppose that the second occurrence of the root bears the diacritic feature for prestressing which it shares with the class of suffixes in (4). Therefore reduplication follows Stress Assignment. Second, the vowel of the first syllable in the second occurrence of the root is deleted. Since this vowel meets the structural description of Syncope -- short in a doubly-open syllable preceded by the stress -- we could ideally treat this deletion as a reflex of syncope by ordering the Reduplication process before Syncope.

What apparently mititates against this solution is the observation that Reduplication must also follow Allophony, as the following forms demonstrate:
a. čóka- 'to limp'
ح čukáčkaš 'limping' *čukáškaš
b. Čára- 'to tear'
čaráčrał 'torn' *čarásraš

We could say that in (12a) underlying / ̌oka/ besomes čoka and is then reduplicated with syncope of the fir:st vowel in the second root. If Reduplication preceded Allophony, 
then we would expect the starred forms in (12), since the position before $\underline{k}$ and $\underline{r}$ is not a precontinuant environment.

The way out of this dilemma suggested by Munro and Benson and adopted by Aronoff (1976) is to claim that the phonological rules are ordered as in (10) and Reduplication follows all of them, but that Reduplication operates as in (13):

(13) $\mathrm{CVCV}$

$1234 \rightarrow 12341 \varnothing 34$

That is, the effect of syncope is encoded into a postphonological reduplication transformation. This obviously gives up the generalization that the loss of the vowel in reduplicated forms is independently predictable. Aronoff points out that we cannot prove that Syncope applies here, but nevertheless the loss of a generalization is evident. Since Reduplication also follows Stress Assignment, it is also impossible under this account to offer a unified treatment of reduplicated roots and prestressing suffixes. So two generalizations are lost.

Other possible solutions present themselves. For instance, we could, with Munro and Benson, suppose that a special diacritic feature is assigned to this class of reduplicated forms to induce the correct rule application. They concede that this is as ad hoc as the special stipulation on Reduplication in (13). A prosodic treatment of 
these facts, however, allows the usual prephonological application of the morphological reduplication while maintaining all of the phonological generalizations.

I will assume that this reduplication phenomenon in Luiseno is a reflex of the type of many-to-one mapping found in the Hebrew pilpel. That is, one [röot] position is mapped onto two [root] positions:

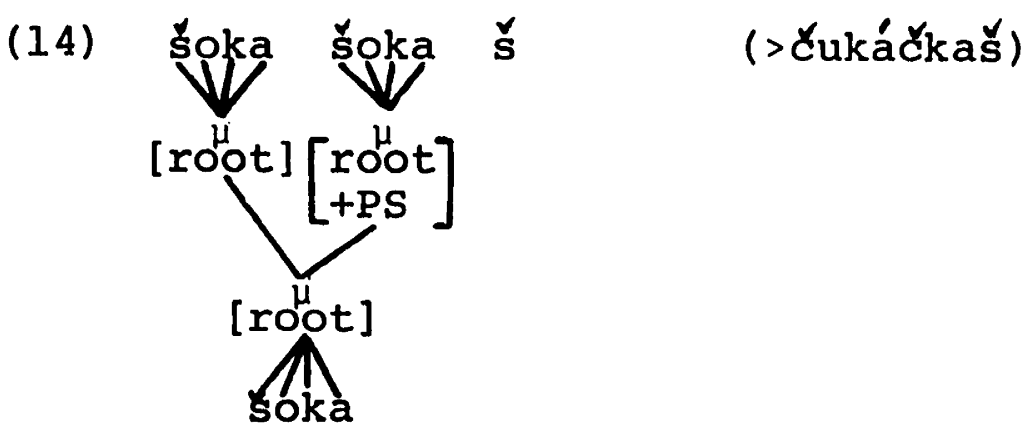

Probably the root morphemes have more structure than this, since Munro and Benson point out that nearly all major lexical category roots conform to the template CVCV. But the simple structure in (14) suffices for now.

This structure is created in the morphology before the application of any phonological rules. The diacritic [+PS] assigned to the second occurrence of the root morpheme marks it as prestressing, a mechanism needed in any of the theories discussed here. We can now proceed to the phonological derivation.

Consider the derivation of surface čukáčkaś from the root /soka/. The reduplication structure appears in (14). This is then subject to the following phonological rules: 
(15)
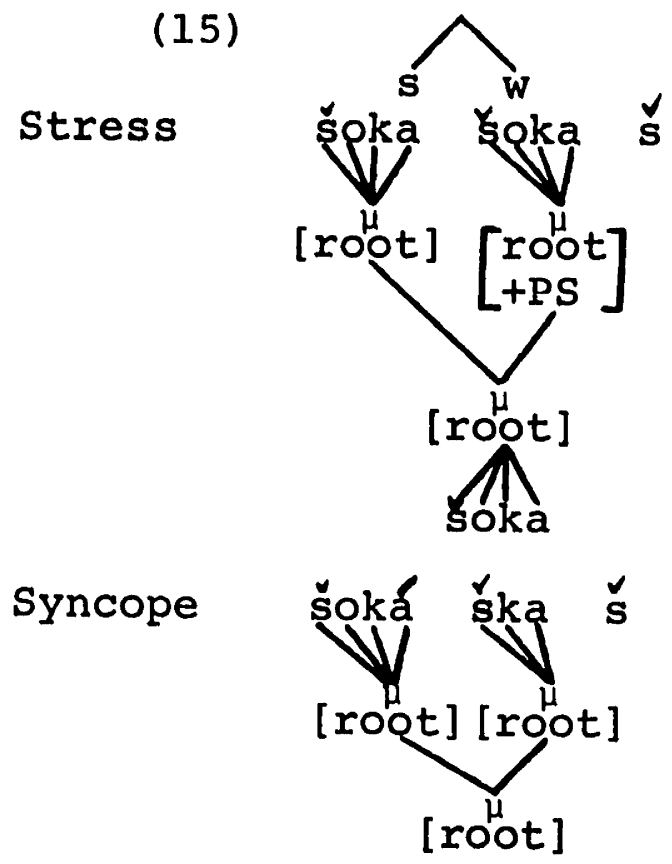

Allophony

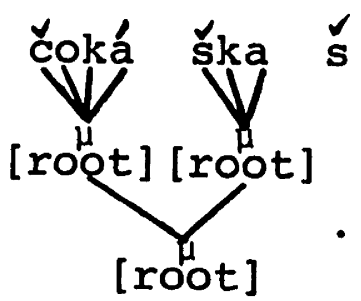

Percolation

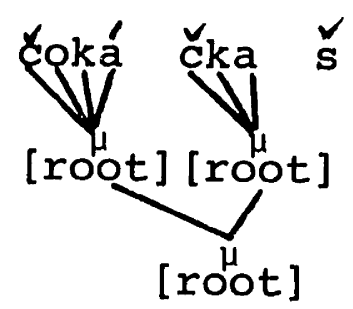

I have somewhat abbreviated the full reduplication structure in (15) for expository reasons. Let's now consider this derivation in detail.

Stress Assignment applies first, creating a binary s-w branch over the second and third syllables. This particular application of stressing is induced by the feature [+PS] on the second occurrence of [rŏot], marking it as a prestressing morpheme. Since the theory of stress assignment developed in Chapter 3 allows for no feature [stress], but only for a metrical structure of stress, there is no possibility of percolating stress onto the second occurrence of the reduplicated form. Only true phonological features may be percolated. 
Similar considerations hold for the application of Syncope. Syncope deletes the vowel in the syllable immediately following the stress, which is the first syllable of the second occurrence of the root. The deletion of a segment involves the erasure of features, and not substitution of feature values. It is incoherent to speak of the percolation of the absence of a set of features, so syncope is not copied in the first occurrence of the root even when it has applied in the second occurrence.

This is, however, not the case with Allophony. Allophony substitutes a set of feature values -- [+delrel, -cont] -- for the values of underlying $\underline{s}$ in the prevocalic environment of the first half of the reduplicated form. These feature values of this segment percolate up through the [root] nodes and then lodge on the corresponding segment in the other $\begin{gathered}\mu \\ {[r o o t]}\end{gathered}$. Therefore the application of Allophony to the initial segment $\underline{s}$ is mimiced by the following $\underline{s}$ of its sister root, even though that second $\underline{\mathbf{s}}$ is not in the proper environment for Allophony since it precedes a noncontinuant.

I conclude, then, that the percolation theory predicts correctly which rules will display the mimicry effect in reduplicated forms, and moreover it allows the grammar to express a single generalization about syncope rather than encoding its effect into a complex reduplication transformation. This completes the discussion of the prosodic treatment of reduplication. 
A final note on the formal properties of this morphological system. The notion of a prosodic template is not confined to Semitic nor to complex morphological phenomena like reduplication. Wherever we find that morphemes seem to be composed of units of a particular type, we might suppose that word formation processes are exploiting devices of this sort. Thus, for instance, Germanic root monosyllabism can be characterized by a template ${ }^{[\sigma]}$ root' while Luiseno apparently requires [CVCV] root ' Similarly, morphological processes that refer to the overall length of the base in syllables may also demand prosodic templates. Thus, the well-known limitation of English comparatives in -er to monosyllabic bases would require that the input to this rule conform to a $[\sigma]$ template. This mechanism is, then, by no means confined to the rather unfamiliar morphological structure of Semitic.

\subsection{Morphology and the Lexicon}

We have seen a wide variety of well-motivated morphological rules in Arabic. The previous section resolved some questions about the form of morphological rules, particularly insofar as they affect the phonological representation. The other side of this issue is the effect of morphology on the lexicon: how does it express fundamental notions like "is related to" or "is derived from"? 
Let me first reiterate a point made in the introduction. I assume, essentially following Halle (1973), that the lexicon is fully specified with all forms, including inflections. Halle presents a number of arguments for this position, and I see no reason to reject it. The morphological rules, whatever their form, serve to evaluate the lexicon, though they are referred to directly to interpret and generate neologisms. I make this assumption chiefly for coherence, since nothing here really depends on full instantiation of all inflections in the lexicon.

First let's consider the outlines of a theory of morphology. The form of morphological rules will, in general, be restricted to context-sensitive rewrite rules and redundancy rules, like the prosodic templates. These rules can make reference to morphological categories, morphemes proper, and to any available phonological properties like consonantism, syllable structure, other prosodic structure, and so on. This much should be evident from the preceding discussion.

I define a lexical entry of a form $w$-- referred to as $L(w)$-- as a directed graph whose root is w. That is, a lexical entry is a rooted, n-ary branching tree. For any b which is dominated by a in $L(w)$, we say that $b$ is derived from $a$. If $a$ and $b$ are both dominated by some $w$ in $L(w)$, then we say that a is morphologically related to b. I assume that nodes dominate themselves, so that $w$ is morphologically related in this sense to all nodes in $L(w)$. 
A graphic representation of a lexical entry schema appears in (16):

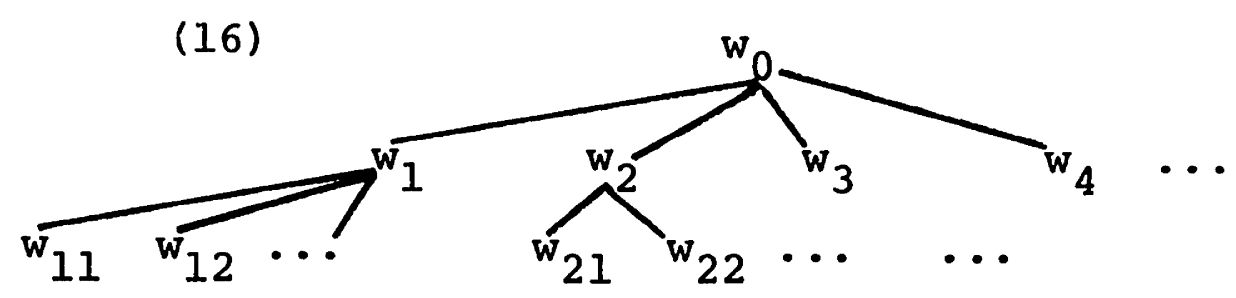

Although nodes are indexed in the schematic representation in (16), this indexing does not appear in actual lexical entries. Rather, reference to domination and immediate domination suffice to express lexical relationships. In (16) the root node $w_{0}$ is the form whose lexical entry is represented; that is, (16) is a $L\left(w_{0}\right)$. All other nodes of the tree are forms derived from $w_{0}$, and further forms derived from them are their daughters. Thus, $w_{1}$ is derived from $w_{0}$, and $w_{11}$ is itself derived from both, though most immediately from $\mathrm{w}_{1}$.

The other aspect of this morphological system is an evaluation metric. Any relationship of immediate domination in a lexical entry that can be predicted by any morphological rule is without cost. Unpredictable relationships of immediate domination are relatively costly. Therefore the ideal morphological system -- the one that is most highly valued -- will have only the value of the sum of the values of all root nodes of lexical entries plus the sum of the 
values of all morphological rules. I have, however, no solution to the question of how minor rules count against lexical listing for limited subgeneralizations, but this question is by no means unanswerable.

I further stipulate that the specification of idiosyncratic information, including especially unpredictable meaning and phonological and morphological diacritic features, is limited to the root of a lexical entry. This is not to say that the forms in nonroot nodes may not bear idiosyncratic information, but rather they may bear it only at the cost of having separate lexical entries as well. Suppose, for instance, that $w_{1}$ in (16) has a diacritic to form its plural irregularly, or suppose its meaning is not piedictable from the meaning of $w_{0}$ plus the rule relating $w_{1}$ and $w_{0}$. Then $w_{1}$ will still appear in the lexical entry $\mathrm{L}\left(\mathrm{w}_{0}\right)$, but it will also appear, with all its daughters, in another lexical entry $L\left(w_{1}\right)$. In $L\left(w_{1}\right)$, the form $w_{1}$, by virtue of being the root node, can then bear the appropriate idiosyncratic information.

There is one other point of a substantive nature to make about this model of lexical structure. I do not insist that the nodes of lexical entry structures be words in the (lexicalist) syntactic sense of this term. Insiead I make the claim that every node must have an isolable meaning.

It is uncontroversially the case that, in languages with extensive inflection, fully-inflected forms are derived 
from stems, the same forms without inflections. This is expressed formally here by having the node of the stem dominate the nodes of the inflected forms. Since only fully-inflected forms are words in the syntactic sense, we might suppose that all and only the terminal nodes of the lexical entry tree are subject to lexical insertion. We therefore have a forn il means to determine the output of the lexicon and the input to the systax.

There is no principled reason to suppose that stems or roots cannot serve as the inputs to derivational rules as well as inflectional ones.

First, I have found no basis, formal or substantive, to support the inflection/derivation distinction in morphological rules. Notice in particular that what may be the strongest of the traditional arguments for this distinction -that inflection appears outside derivation -- is extensively violated in the Arabic nominal and verbal systems. The categories of nominal number and verbal aspect and voice, which must by añy syntactic or semantic criteria be counted as inflectional, exploit exactly the same formal apparatus of melody mapping as the traditionally derivational binyanim.

Second, it is absolutely necessary to recognize derivation from roots to express fundamental generalizations in Arabic or, for that matter, in any essentially root-based morphological system. To cite just one of many examples, recall the complex of verbs based on the root $\underline{k t b}$ given 
above as (1) in the introduction to this chapter. In some cases particular forms are transparently derived from others, like (ld) takaatab, the reflexive of (lc) kaatab. But (If) kitaab 'book' cannot be derived by any regular process from any of the other forms in (1), although Cicaac is a regular noun pattern, nor can any forms in (1) be derived from kitaab. There are, however, obvious generalizations to be captured, since kitaab shares both the root $\underline{k t b}$ and some element of meaning with the other forms. I conclude, then, that the root $k$ tb serves as the root node of a lexical entry, with essentially the following shape (minus inflected forms):

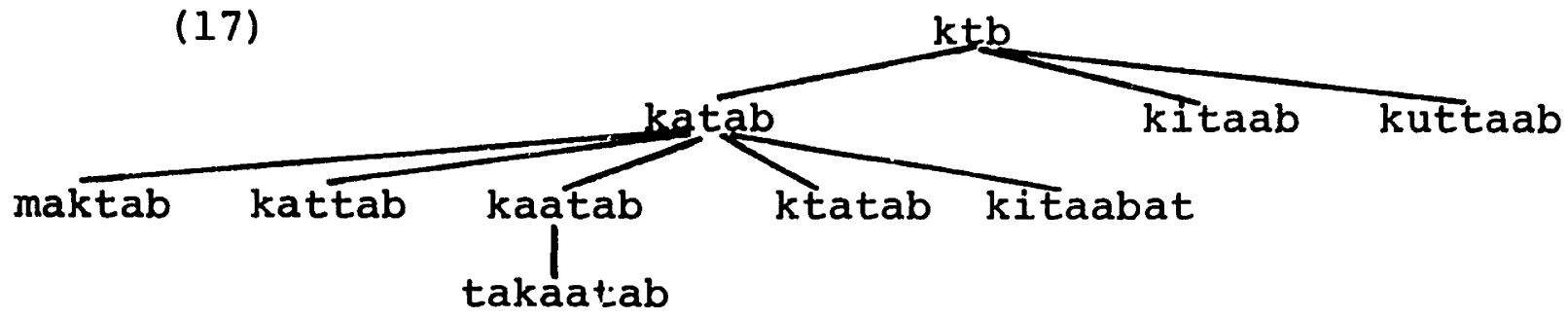

In sum, then, any consonantal root will serve as the root node of some lexical entry tree, though obviously not of all lexical entry trees. I note that this differs fundamentally from Aronoff's (1976) Word-based Hypothesis, which excludes the formation of words from nonwords like the Arabic root.

Although this is a very simple model of lexical structure, it embodies a large number of separate claims about morphological phenomena in natural language. The claims 
that are of greatest intrinsic interest, and the ones that I will treat in greatest detail, are the following:

i. That relations between forms like "is derived from" can only be expressed by reference to a structured lexical entry that is evaluated by the morphological rules.

ii. That there is a relationship between the form of a lexical entry and the distribution of semantic, morphological, and phonological anomaly.

The sections that follow consider both of these issues in succession, with special reference to the analysis of Arabic developed here. Although both of these claims can be extensively justified, I should point out that they are essentially logically independent, and that the stipulations behind each claim, if incorrect, can be severed from the rest of the theory.

\subsubsection{The Structured Lexical Entry}

The basic claim -- though often a tacit one -- in previous studies of morphology is that the relationship "is derived from" can be determined solely by examination of the prephonological or enriched surface representation of a form, perhaps with reference to the morphological. rules as well. This means that for every derived word $x$ there exists a parsing of $x$ into a concatenative combination of affixal morphemes and a base $y$, where $x$ is derived from $y$. The nature of $y$ is determined in the representation of $x$, since 
$\mathrm{y}$ will be a string in $\mathrm{x}$ that is bounded by proper bracketing. In other words, the relationship "derived from" can be determined solely by examination of any proper bracketing internal to a form.

A few studies of basically concatenative morphological systems have partly questioned the correctness of this view, although not directly. Pesetsky (1979) discusses cases in Russian where a single base bears both prefixes and suffixes. The bracketing motivated by phonological rules -- cyclic application or bounding being the criteria -- is shown by him to conflict with the bracketing motivated by considerations of semantic regularity. 9 Wile base plus suffix is the phonological constituent, prefix plus base is a semantic unit. Pesetsky therefore suggests a mechanism for semantic interpretation of morphologically-complex forms that deviates from the proper bracketing.

But, as we shall see, semantic criteria form just one of several means of determining the relationship derivedfrom. I take it that these cases reflect a larger defect in the theory that says bracketing or constituent structure directly reflects morphological relationships.

Rather, I will say that proper bracketing in the enriched representation of a form has no direct role in the determination of morphological complexity, lexical structure, or the relationship derived-from. This is not to say that bracketing can vary freely in a way unrelated to 
morphological structure. Instead, there exists a function $\beta$ determined partly on a language particular basis that maps lexical structure onto the proper bracketing of forms. In English, where the cyclic structure needed for proper application of the stress rules generally follows the lexical derived-from relationship, $\beta$ will be a simple isomorphism. In the Russian case discussed by Pesetsky, $\beta$ will state that stem plus suffixes are arranged in a leftbranching structure to which prefixes are then adjoined in the creation of bracketing.

The function $\beta$ is not always so simple, and it sometimes has a quite idiosyncratic character. For instance, Brame (1974) argues for a cyclic treatment of stress in Maltese on the basis of vowel syncope behavior. Ordinarily the relevant bracketing for cyclic application follows morphological lines: stem plus subject agreement is a constituent to which object enclitics are appended. One subject agreement marker, which happens to be homophonous with an enclitic, deviates from this scheme and instead appears outside the brackets of the stem. Here the function $\beta$ must refer to a particular morpheme in constructing the bracketing for phonological rule application.

In fact, we needn't look so far afield for idiosyncracy of this sort. It has long been nuticed that in English some morphologically-complex words allow dual pronunciations, like instrum[e]ntality $~$ instrum[n]tality. A direct 
isomorphic mapping of lexical/morphological structure onto the proper cyclic bracketing of this work yields the first pronunciation, by cyclic reference to instrumental. It has been said (Chomsky and Halle 1968) that the pronunciation with reduction reflects noncyclic derivation of the stress, though no one has ever come to terms with this idea in any strict way. Does it mean that the set of English stress rules is so arbitrarily cyclic that it can fail to apply cyclically in arbitrary forms? or does it mean that speakers sometimes or invariably fail to recognize these words as morphologically complex? The latter view is surely incorrect empirically, since no one has ever disputed the morphological complexity of this form. And the former suggests a model of rule application that is at best ad hoc and may be theoretically incoherent. Rather, what I would say is that the function $\beta$ in English, while generally simple, has fuzzy edges that allow it to assign no internal bracketing to some or all morphologically complex forms. In particular, forms in ality are subject to this variation, which allows them to recelve a totally flat structure. of course there are alternative, albeit unconvincing, treatments of each of these facts. But what is absolutely fatal to the view that moxphological structure is encoded entirely into proper bracketing is the morphological behavior of languages that mostly lack concatenative morphology. Since nonconcatenative morphology is resistant to analysis 
by proper bracketing, there is no way under this theory to express phenomena of morphological relatedness and the derived-from relationship by means of brackets. Even apparent surface similarity, whether in bracketing or not, fails to express absolutely essential generalizations in this case. Let's turn now to the facts of Arabic for extensive justification.

Consider the following array, which includes a subset of the words that are formed with the triliteral root drs 'study'. I have identified verb forms by the Roman numeral of their binyan, and nouns by the standard terms:

$$
\begin{gathered}
\text { a. I daras 'to study, } \\
\text { learn' }
\end{gathered}
$$

masdars: dars 'act of studying' diraasat 'study' adjective: diraasiy 'scholastic'

occupation: darraas 'student' place: madrasat 'school' adjective: madrasiy ' 'scholastic' participle: daaris 'study-

b. II darras 'to teach' masdar: tadriis 'teaching' participle: mudarris 'teacher'

c. III daaras 'to study masdar: diraas 'act of...' with someone' participle: mudaaris 'one who...' 
(18) continued

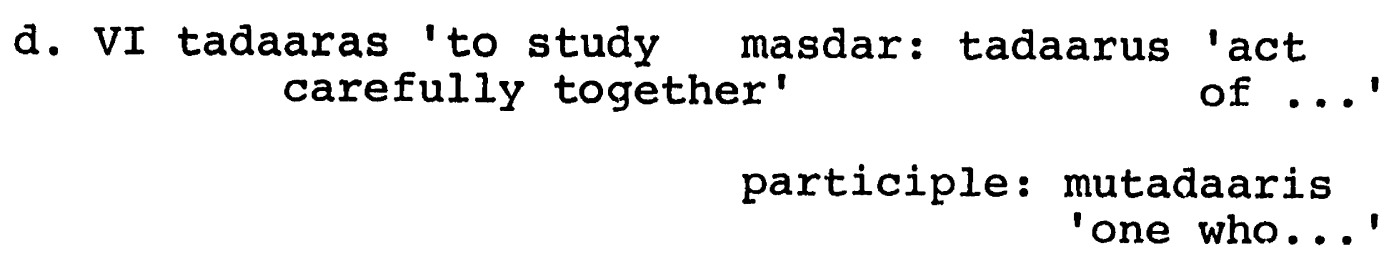

Even this list does not exhaust the possibilities, since for instance passive participles can be formed from each of the binyanim in (18) as well. For completeness broken plurals ought to be included too.

We can motivate the relationship derived-from for an array like (18) on a variety of grounds that have nothing to do with the phonological shape or apparent bracketing of the forms. First, there is extensive semantic evidence for this relationship. For instance, the noun of occupation darraas is clearly derived from the first binyan verb daras, since the former means 'student' and the latter means 'to study'. If darraas were derived from the second binyan, say, then it would presumably mean one who teaches rather than studies habitually or occupationally. Or the noun of place madrasat means 'place where studying is done'. This is not the same as a place where teaching is done, since study can be done without instruction. 
Second, the relationship derived-from can be motivated on grounds of morphological distribution. If a putative derived form occurs only if some other form aiso occurs -that is, if the presence of the derived from is contingent on the presence of its source -- then this further argues for the relationship. (Here I ignore rare gaps of the canriy type.) So the noun of occupation or noun of place that is claimed to be derived from the first binyan verb is contingent on the root occurring in an actual first binyan verb. So for instance the root hlg, which means 'to shave' in the first binyan, has the derivative occupation noun hallaag 'barber' and noun of instrument mihlag 'razor', but does not occur in this sense in other binyanim at all.

Finally, certain types of phonological or allomorphic irregularity argue for the derived-from relationship. If we find that a particular irregularity is confined to one cluster of forms based on a single root, then this argues that these forms are more intimately related than other forms from that root. For example, certain forms are exceptions to the complex of rules that affect high glides (Brame 1970). This is the case with the tenth binyan verb staşwab 'to approve', which would regularly go to *staşaab. The same root in the first binyan is regular, though, yielding saab $(</$ sawab/) 'to be right'. What is interesting is that the exceptionality of the tenth binyan verb extends 
to its masdar, which I claim is derived from it. Thus the masdar is stiswaab 'approval' instead of 'stişaabat which is expected by regular application of the rules. Similar properties hold for the related participles. In this root exceptionality is confined to all and only those forms that are derived from the terth binyan verb.

Although none of these are new forms of argument for morphological relatedness, it was nevertheless necessary to make them entirely explicit to show that they extend clearly and unambiguously to cases of nonconcatenative morphology like Arabic. Considerations of this sort show in particular that the nouns listed on the right in (1.8) are derived from the corresponaing verb forms listed on the left. Similar considerations show that the verb forms are interrelated in complex ways. For instance, the verbs in (18b) and (18c) are derived from the first binyan verb (18a) while the verb in (18d) is derived from the verb in (18c).

Yet nearly all of these relationships hold, and consequently must be expressed by any adequate grammar, without reference to proper bracketing. There is no sense in which the active participle daaris could be said to properly contain the first binyan verb from which it is derived, nor could the masdar tadriis ccntain the second binyan verb darras. Even surface similarity, weaker by far than bracketing, is deceptive. The pair daaris and darraas are 
surely more similar phonologically to the second and third binyan verbs respectively than to the first binyan verb from which they are derived.10

This point is made aven more clearly by the behavior of some of the derived binyanim. For instance the tenth binyan can, in different verbs, be demonstrably directly derived from either the first binyan or the fourth binyan. So the tenth binyan verb stahyaa 'to keep alive for one's own benefit' is derived from the fourth binyan verb ?ahyaa 'to keep alive', which is itself derived from the first binyan verb hayaa 'to live'. On the other hand, the tentr. binyan verb stawjab 'to consider necessary for oneself' is derived from the first binyan verb wajab 'to be necessary' and not from the fourth binyan verb ?awjab 'to make necessary'. There is no meaningful sense in which we can say that one tenth binyan verb properly contains by bracketing the fourth binyan verb and one doesn't. Clearly the derivedfrom relationship -- and the corresponding variation in what the tenth binyan is derived from -- must be expressed in the lexical structure of each form. Morphological rules will, on the other hand, include the generalization that the only verbal sources for tenth binyan verbs are the first and fourth binyanim.

It is possible to multiply evidence of this sort almost endlessly. A brief look at the possibility of denominal versus deverbal derivation of the binyanim in (37) of 
section 3.1 should convince anyone of the possibilities. For example, the fourth binyan denominals like ?aš?am 'go to Syria', ?ayman 'go to Yemen', and ?atham 'go to Tihama' are transparently derived from the place names ša?m, (1) yaman, and tihaamat, yet there is absolutely no way for these verbs to contain the corresponding rouns by proper. bracketing.

To sum up the discussion to this point, I have argued that there is a relationship derived-from that has both semantic and formal correlates in morphological phenomena. I demonstrated first by consideration of facts from English and elsewhere that the morphological structure of complex forms like instrumentality is not necessarily reflected directly in the proper bracketing needed for cyclic rule application. Evidence from Arabic showed the complementary position: forms can be morphologically complex -- that is, they can be derived from other forms, and so on -- without containing any proper bracketing at all. The conclusion mus'c be that the relationship derived-from is represented directly in the lexicon. This is the empirical basis for the formal characterization of a lexical entry given in (16) and the adjacent text. Since the lexical entry is structured as a directed graph, we can say that $\mathrm{x}$ is derived from $y$ if and only if $y$ dominates $x$ in some lexical entry. This is not to say that forms may be morphologically related to one another arbitrarily purely by lexical 
stipulation of this relationship, Each lexical entry structure is subject to evaluation by the morphological rules, and deviations from these rules are costly. For instance, saglab 'to throw down' is probably morphologically related to first binyan galab 'to turn over' (it is the historical

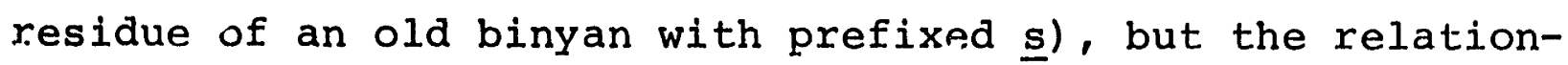
ship can only be expressed at cost in the lexicon since it does not depend on any regular morphological rule -- that is, there is no regular binyan with prefixed $\underline{s}$ and the CVCCVC prosodic template. Two forms that did not even share the same triconsonantal root would be even more costly to relate, and in fact few such cases occur. The closest we come is sporadic possibilities of varying one root consonant, as in gataf 'to carve', gatag 'to cut', gataf 'to harvest', gatam 'to cut off'. Occasionally forms differ in relative position of the root consonantism: malaj, lamaj 'to suck.'. These relationships, though probably expressed in the lexicon, are thoroughly unsystematic and ungoverned by morphological rules (perhaps even historically). Therefore this small rumber of relationships can onl $\ddot{y}$ be ex?ressed at cost, though the point: əre is that they are expressible under the lexical structure theory.

Al.though, the lexical structure theory of (1.6) allows the grammar to capture a somewhat richer set of generalizations than a bracket-based morphological tineory, it also has certain interesting constraints inherent in it. These 
constraints mostly concern the sorts of relationships that morphological rules can express.

First, there is no possibility under this theory of deriving one form from two distinct forms that are also morphologically related. Suppose $\mathrm{c}$ is putatively derived from both $a$ and $b$, where $a$ and $b$ are related morphologically although neither $a$ nor $b$ figures in the derivation of the other. Formally this means that $a$ and $b$ are both nodes of the same lexical structure tree, where neither dominates the other. For $c$ to be derived from both, the tree would have to have roughiy the following structure:

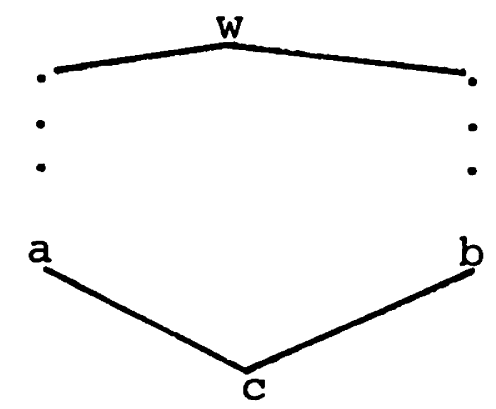

A representation of this sort is simply prohibited by the notation. A structure of the sort found in (19) is no longer a directed graph (a tree) but rather some sort of littice. Consequently this sort of derivation is impermissible.

This claim is not without some empirical content. We can easily see how a grammar could be constructed that derives, say, the active participle by referring to the form of both the verb and some ncndeverbal noun. Or another 
possibility, potentially realizable under the bracketing theory, is the compounding of morphologically related forms, like*run-runner or*dream-dreamer. These can hardly be ruled out on semantic or quasi-syntactic grounds, since English does permit paronomastic constructions like dream a dream. I conclude, then, that the impossibility of these formations is a consequence of the formal lexical structure.

Second, let's consider the results of incorporating a formal principle like subjacency into the morphology, as argued by Siegel (1978) and Allen (1978). In the most general case, this principle explains why morphological rules of the form "do $x$ to a deverbal noun" do not exist. Given that the bracketing structure of forms of this sort is $\left[x\left[_{N} \ldots\left[V_{V} \ldots\right]\right]\right]$, the rule assigning $x$ has access to information only on the immediately subjacent $c_{y} c l e$, that is, the noun cycle. It cannot determine that the noun is derived from a verb since that information is present only on a more deeply embedded cycle, access to which i.s prohibited by subjacency.

Although it is possible to maintain the view in a bracketing theory that morphological subjacency is sensitive to a structural difference in the internal bracketing of forms, this predicts that subjacency plays no role in the operation of morphological rules in systems without bracketing. In fact we have seen no case of a morphological rule in Arabic that is sensitive to any properties like lexical 
category of the form other than the one from which it is immediately derived. That is, Arabic lacks rules like "do $\mathrm{X}$ to a deverbal noun" even when both the operation $\mathrm{X}$ and the deverbal operation are nonconcatenative and therefore not subject to any sort of bracketing interpretation.

Consequently the principle of morphological subjacency on bracketed forms is too weak, although it does express many interesting generalizations in basically concatenative morphologies. These same generalizations hold in derivations that could involve no proper bracketing at all. What we might say instead is that subjacency is a princsple of morphological rule function over lexical structure trees. That is, subjacency, as it governs the material to which morphological rules may refer, depends on the lexical structure of the sort in (16). Apart from this, the principle is identical to the more familiar notion of subjacency.

Finally, let me turn to the process of compounding. Under the lexical structure theory, compounding is represented formally by including the compound in the lexical entry of each part of the compound. That is, given a compound of the form $a b$, where $a$ is in the lexical entry $L\left(w_{1}\right)$ and $b$ is in the lexical entry $L\left(w_{2}\right)$, the compound $a b$ will appear in $L\left(w_{1}\right)$ dominated by $a$ and in $L\left(w_{2}\right)$ dominated by $b$. For regular, rule-governed processes of compounding this double-listing does not involve extra cost, since each lexical entry is evaluated with respect to the morphologica? rules. 
Nothing has been said in this study about compounding up until now because the ancient semitic languages display almost no true compounding, although modern Arabic and Hebrew have introduced some. Nevertheless there are two categories in C.lassical Arabic that have true compounds: some proper names and the numbers from 11-19: Although limited, these types suffice to show that the model of lexical structure offered here should incorporate compound formation.

Proper names formed by compounding are quite common: ma9dii-karib, ba9la-bakk, hadra-mawt. And the numbers from 11 to 19 are formed by compounding one to nine with ten: ?arba9a-9ašrata 'fourteen (f.)', xamsa-9aSrata 'fifteen (f.)'. I have given the feminine forms because of certain complications with gender agreement that pervade the number system. These are irrelevant to the point made here.

The extremely productive process of diminutive formation, which applies to prepositions and complementizers as well as to nouns, applies also to these compound forms. The result of this is the usual diminutive morphology appearing on the first member of the compound:

(20) a. mu9aydii-karib

bu9ayla-bakk 'P.N. (dim.)'

hุuḑayra-mawt

h. xumaysa-9ašrata 'fifteen (f. dim.)' 
This selection of the first member of the compound to receive further derivation is fairly general; it holds as well for the denominal adjective nisbe form that I have not discussed here.

The result that we can gather from the forms in (20) is that compounds are subject to the same sorts of discontinuous prosodic morphology that simplex forms get. Since the mapping of a root onto the prosodic template of the diminutive allows for only one root, it is not surprising that only one member of the compound has the cie cayc form of the diminutive. Clearly the relationship of the diminutives in $(20)$ to their nondiminutive sources cannot be expressed by bracketing. Therefore the lexical structure theory must, as it does, treat compounds in the same way as other morphological categories.

\subsubsection{Irexical Idiosyncracy}

The lexical structure theory developed here claims that only the root node of a lexical entry tree may bear idiosyncratic information, whether a semantic anomaly or a morphological or phonological diacritic feature. This means that forms which are not rout nodes must have a meaning that is a composition of the meaning of the form that immediately dominates them plus the meaning induced by the morphological rule responsible for the derivation. Any morphological information must also be obtained solely frum the source 
plus the relevant morphological rule. The most highly valued lexicon will incorporate only such predictiable derivations.

of course, it is not usually the case that a finite system like the lexicon and morphology behaves in such a well-ordered way. Suppose we have a form b derived from $a$, where the meaning of $b$ is not compositional. Under this theory, $b$ is included in the lexical tree $L(w)$ and a dom!nates $b$. But $b$ must also have a separate lexical entry where it is the root, therefore $L(b)$. If the derivation of $b$ from a is morphologically regular, then the lexical entry I(w) will be highly valued in this respect since the domination of $b$ by $a$ is sanctioned by some morphological rule. But the listing of a separate entry $L(b)$ will generate extra cost in the lexicon as a whole, so this grammar is less highly valued than a grammar in which b has compositional meaning •

This is certainly the correct claim to make about the relative value of lexical anomalies. Woreover, unlike most other treatments of facts of this sort involving either special ad hoc semantic rules or other lexical entries, it makes the additional empirical claim that there should be a correlation between semantic anomaly and other sorts of anomaly. Since the grammar is compelled to generate a separate lexical listing under any sort of anomaly, it will be more highly valued if it causes anomalies of different types 
to cluster together. If a form is deviant both semantically and morphologically, then only one extra lexical tree is needed with this form as the root.

Exactly this sort of clustering comes through with overwhelming clarity in the distribution of broken versus external pluralization in the noun systam. By sheer counting of noun types in the dictionary, it appears that the formation of broken plurals of various types prevails over suffixing plurals. This is not so clear if we consider the several broken plural processes separately. Furthermore, there is significant evidence that suffixing plurals are formally regular, although in the minority, and that broken plurals are formally irregular and therefore available only by a morphological diacritic.

Several classes of nouns with no morphological source accept only suffixing pluralization:

\section{Plural}

(21) a. Proper Nouns

$9 u$ maan

hind 9u $\operatorname{maanuu}$ (pl. masc.)

hindaat (pl. fem.)

b. Letters of the Alphabet

$\begin{array}{lll}\text { ?alif 'aleph' } & \text { ?alifaat } & \text { (pl. fem.) } \\ \text { miim ' } m \text { ' } & \text { milmat } & \text { (pl. fem.) }\end{array}$

c. Unassimilated Loans

biimaaristaan 'hospital' biimaaristaanaat (pl fem.) baašaa 'Pasha' baašwaat (pl. fem.) 
Al1 three of these categories are notoriously deviant in other properties of the lexicon. The first two contain only names rather than ordinary referring expressions. The last category has a notable cross-linguistic property of avoiding full integration into the morphology -- for instance, such nouns are often indeclinable. Most importantly, all three categories include many nouns that are not susceptible to analysis by the usual root and pattern mechanism. So, for instance, they will not form denominal verbs at all. This correlation is supported by the regular application of external pluralization to those few native nouns that are similarly deviant: bn, banuu 'son (m. pl.)'; ?iwazz, ?iwazzuu 'goose (m. pl.)'.

The simplest formal treatment of these facts is to suppose that there exists a diacritic feature [+BP], which, when assigned to nouns, induces broken plural morphology. Names cannot bear this diacritic since they are not listed in the regular lexicon, and foreign words have not been in the lexicon long enough to have it extended to them.

The:-efore a form must bear the feature value [+BP] to be subject to broken plural morphology. Other diacritics may be necessary to distinguish different types of broken plural formation (like the different vowel patterns of the plurals in section 3.2), but this one feature suffices for the argument here. This is, in the strict sense, a miror morphological rule diacritic, so broken plural formation 
is formally irregular. Only forms which are the roots of lexical structure trees may, by hypothesis, bear the feature $[+B P]$.

Now we can consider the several classes of derived nouns that are subject to external pluralization only:

a. Participles (othe: than Binyan I)

II mudarris 'teacher' mudarrisuu (pl. masc.)

III mukaatib 'corresponderit' mukaatibuu (pl. masc.)

b. Masdars (other than Binyan I)

II ta9riif 'definition' ta9riifaat (pl. fem.)

IV ?iqțaag 'fief' ?iqtaa9aat (pl. fem.)

c. Nomina vicis et unitatis

darbat 'single act of darataat (pl. fem.)

bagarat 'cow' baqaraat (pl. fem.)

d. Diminutives

Gubayd 'P. N.' 9ubayduun (pl. masc.)

kutayyib 'little book' kutayyibaat (pl. fem.)

Although I have not treated the nomen unitatis type explicitly, it clearly has no great differences from other denominal categories. A few other types, like elative (comparative and superlative) adjectives, are similarly restricted to external pluralization.

What all of these categories share to the exclusion of any other systematic fragment of Arabic nominal morphology is their nearly absolute semantic compositionality. Consider, 
for instance, the morphological relationship between the first binyan verb daras 'to study', its noun of place madrasat 'school', and the latter's diminutive mudayrisat 'little school'. The noun of place takes broken plural morphology but its diminutive, like all diminutives, has a suffixed plural. Although the meaning of madrasat is reasonably predictable from the fact that it is the noun of place of the verb 'to study', this meaning is by no means compositional. If one studies in the marketplace, the marketplace still cannot be referred to by madrasat. But mudayrisat refers unqua? ifiedly to the diminutive of 'school', where diminutive has its usual metaphorical (hypochoristic and pejorative) as well as literal meaning.

The observation here, then, is that there is a correlation between the distribution of broken plurals and semantic noncompositionality in derived nouns. It is supported by the facts immediately above, as well as by the obvious point that nonderived nouns have inherently idiosyncratic meanings and correspondingly almost invariably take broken plurals. But the real confirmation of this view, and not, say, a restriction of sound plurals to productively derived forms, comes from the derived nouns of the first binyan. First, let's consider the formation of masdars. It is somerhat surprising that masdars of the first binyan generally accept broken plurals while masdars of the derived binyanim are limited to sound plurals." Several different 
facts correlate with this distinction. Although it is apparent from the discussion in section 3.2 that the derived binyanim allow some variation in the mode of formation of masdars, they have nothing to compare to the 46 patterns of the first binyan. The best analysis that could be developed for this enormous variation was a few limitations on their form. Moreover, the first binyan masdars complement this formal idiosyncracy with semantic as well; they almost invariably have relatively unpredictible meanings. For instance, the first binyan verb hakam glosses as 'to pass judgment; to govern; to bridle (a horse)' but its masdar hukm has only the sense of 'judgment' and a substantive meaning 'statute'. A different masdar, hakm, refers to 'the act of bridling a horse'. Facts like these pervade the verbal system.

Confirmation for this relationship between semantic unpredictability and broken plural distribution comes from the occasional masdars of other binyanim that take broken plurals. Wright (1971) describes these as masdars of the second and fourth binyanim "used in a concrete sense". This means that they are no longer strict nomina actionis, but have come to refer to the result of the action as well. This additional semantic import is not predictable from the ordinary meaning of the masdar, as the following forms show: 
a. Binyan II

Şannaf 'to compose, write'

taşniif, taşniifaat 'composition, writing (pl. fem. )' taşaaniif 'literary work (broken pl.)'

b. Binyan IV

?asnad 'to support, base'

?isnaad, ?asaaniid 'the chain of authorities

for a tradition (broken pl.)'

It is only when the masdar has the extra, concrete sense that it takes a broken rather than a suffixing plural. Exactly this sort of situation is easily compatible with the theory proposed here. In the lexical structure tree the node for sannaf of (23a) will dominate its masdar taşnif. This masdar within the lexical entry will bear the compositional meaning 'act of doing $x$ ' but will not bear the feature [+BP]. There will, however, be a separate lexical entry with taşniif as root node. This tasniif, which can be identified as the masdar by examining the lexical entry of sannaf, bears the unpredictable meaning 'literary work' as well as the feature [+BP]. Therefore exactly the right distribution of semantic and morphological irregularity can be derived.

Similar facts hold for the participles of the first binyan. In other binyanim the participles generally take sound plurals in conformity with their predictible meaning. 
Generally the passive participle of the first binyan also has predictable meaning and suffixing plural morphology. But the active participle of the first binyan has systematic variation between suffixing and broken plurals along roughly the same lines as the masdars in (23). For an interesting survey of data from Modern Standard Arabic, see Levy (1971:23-26).

What these facts show is that there is an intimate relationship between nuncompositional meaning in derived nouns that the susceptibility of those nouns to broken plural morphology. The theory presented here predicts exactly this sort of correlation. Since any irregularity of this sort compels the creation of a new lexical entry with the irregular form as its root, a grammar is more highly valued if it clusters its irregularities together rather than spreading them over different lexical entries. This prediction is supported by the data offered above. 
Chapter 4: Footnotes

${ }^{1}$ In one important respect the $\mu$-notation is significantly richer than the +-boundary notation of Chomsky and Halle (1968). It is possible, by judicious use of $\mu$, to require that two segments belong to the same morpheme in the structural description of the rule, while this is impossible under the earlier proposal. This enrichment is supported by the rules developed later in section 2.1, as well as elsewhere in the chapter, particularly the metathesis rule of section 3.1 .

${ }^{2}$ Here and subsequently I abstract away from the phonological effects associated with hamzat al-wasl. More discussion of this can be found in the introduction to section 3 .

${ }^{3}$ Since this was written an article by Clements and Ford (1979) appeared in which nearly all the principles. invoked here are posited as part of universal grammar and supported by an extensive analysis of tone in Kikuyu. In particular, they include in linguistic theory virtually all the apparatus of spreading and association, including the rule of left-toright association developed in section 3.1. Furthermore, they note that their apparatus does not allow for the automatic creation of many-to-one associations in spreading, thus including much of the effect of the prohibition proposed here. I suggest that this close similarity between extremely abstract principles in the analysis of such widely different data as Kikuyu tone and Arabic morphology provides very strong support for the general model followed in both cases.

${ }^{4}$ Here and elsewhere the notation C refers to [-syll] segments, and thus includes the high and low glides as well as true consonants.

${ }^{5}$ I should point out that this synchronic analysis is neutral with respect to the traditional question of whether protoSemitic contained biliteral roots. That question does not hold at the same level of abstraction as the synchronic analysis, since it refers to actual biliteral surface verb forms. Notice also that there is often alleged to be some consistent semantic character to geminate roots, referring to iterative activities, so they may result from some now lexicalized derivational process.

${ }^{6}$ Actually metathesis will need to be complicated slightly to prevent its application in forms of the II and $\mathrm{V}$ binyanim like sammama and tasammama, where the first prevocalic consonant is already a member of a geminate cluster. The representation of forms. of this type is shown later in 
section 3.1 at (32). In view of these representations, there is a very simple account of this additional stipulation: the melody $\mathrm{x}$ in (28) cannot be associated with a segment in the 1 position of the structural description. Therefore the final formulation of Metathesis will be as follows:

Metathesis

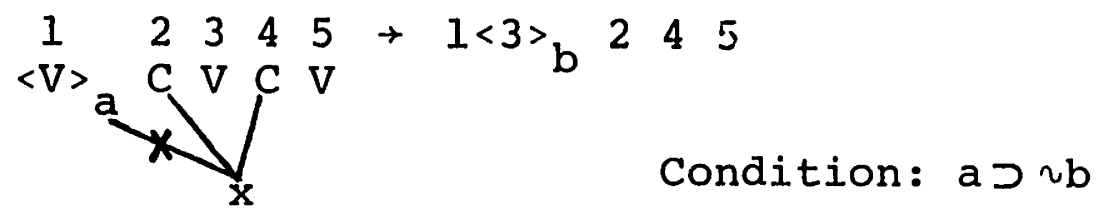

Following Kahn (1976), a crossed-out association line indicates that $x$ explicitly lacks any associations to the left of $C$ in position 2 .

${ }^{7}$ This is actually the sandhi form, which I take as underlying. The citation surface form is tum.

${ }^{8}$ Actually a rather different template may be needed to incorporate the cluster in péne?wex, though this requires a somewhat better understanding of cupeno syllable structure than I have. I am indebted to Paul Kiparsky for pointing this example out to me.

${ }^{9} \mathrm{~A}$ recent unpublished paper by David Nash at MIT makes a similar point for Warlpiri.

10 The parasitic relationships of section 4 may be the extreme cases where phonological similarity to the parasitic source has relatively little to do with aspects of the derived-from relation.

${ }^{11}$ The feminine masdars, like many other feminine forms, take sound or suffixing plural morphology even in the first binyan. 
Bibliography

Abul-Fadl, F. (1961) Volkstumliche Texte in arabischen Bauerndialekten der Mgyptischen Provinz Sarqiyya, Westalische Wilhelms-Universitut, Munster (Westf.).

Al-Ani, S. ed. (1978) Readings in Arabic Linguistics, Indiana University Linguistics Club, Bloomington, Indiana.

Allen, M. (1978) Morphological Investigations, Doctoral dissertation, University of Connecticut, Storrs, Connecticut.

Allen, W. (1973) Accent and Rhythm, Cambridge University Press, Cambridge.

Anderson, S. (1975) "On the Interaction of Phonological Rules of Various Types," Journal of Linguistics 11, $39-62$.

Aronoff, M. (1976) Word Formation in Generative Grammar, Linguistic Inquiry Monograph 1, MIT Press, Cambridge, Massachusetts.

(1978) "Lexical Representations," in D. Farkas, W. Jacobsen, and K. Todrys, eds., Papers from the Parasession on the Lexicon, Chicago Linguistic Society, Chicago, IIlinois.

Baer, S. (1867, 1868) "Die Methegh-Setzung nach ihren tberlieferten Gesetzen dargestellt," Archiv fthr die wissenschaftliche Erforschung des Alten Testaments $1,56-67 ; 2,194-207$.

(1880) "De Primarum Vocabularum Literarum Dagessatione," in S. Baer, ed. "Liber Proverbiorum, Bernhard Tauchnitz, Leipzig.

Barkai, M. (1974) "On Duration and Spirantization in Biblical Hebrew," Linguistic Inquiry 5, 456-459.

Bauer, H. and P. Leander (1962) Historische Grammatik der Hebrälischen Sprache des Alten Testamentes, Georg 0lm, Hildesheim.

Bell, A. and J. Hooper (1978) "Issues and Evidence in Syllabic Phonology," in A. Bell and J. Hooper, eds., syllables and Segments, North-Holland, Amsterdam. 
Bergstrăsser, G. (1962) Hebräische Grammatik, Georg Olm, Hildesheim.

Birkeland, H. (1954) Stress Patterns in Arabic, Avhandlinger utgitt av det Norske Videnskaps-Akademi i Oslo II, Hist.-Filos. Klasse, 3, Jacob Dybwad, Oslo.

Blanc, H. (1978) "The 'Sonorous' vs. 'Muffled' Distinction in Old Arabic Phonology," in Al-Ani, ed., (1978).

Bloomfield, L. (1933) Language, Holt: Rinehart, and Winston, New York.

Brame, M. (1970) Arabic Phonology: Implications for Phonological Theory and Historical Semitic, Doctoral dissertation, MIT, Cambridge, Massachusetts.

Brame, M. (1971) "Stress in Arabic and Generative Phonology," Foundations of Language 7, 556-591.

(1972) "On the Abstractness of Phonology: Maltese 9," in M. Brame, ed., Contributions to Generative Phonōlogy, University of Texas Press, Austin, Texas.

(1973) "On Stress Assignment in Two Arabic Dialects," in S. Anderson and P. Kiparsky, eds., A Festschrift for Morris Halle, Holt, Rinehart, and Winston, New York.

(1974) "The Cycle in Phonology: Stress:.+ Palestinian, Maltese, and Spanish," Linguistic Inquiry 5, 39-60.

Bravmann, M. (1934) Materialien und Untersuchungen zu den phonetischen Lehren der Araber, Dieterische UniversitatsBucharuckerei, Gottingen.

Brockelmann, C. (1961) Grundriss der vergleichenden Grammatik der semitischen Sprachen $I$, Georg Olm, Hildesheim.

Brфnno, E. (1943) Studien tuber hebralische Morphologie und und Vokalismus auf Grundlage der mercatischen Fragmente der zweiten Kolumne der Hexapla des Origenes, Abhandlungen fur die Kunde des Morgenlandes 28 , Leipzig.

Broselow, E. (1976) The Phonology of Egyptian Arabic, Doctoral dissertation, University of Massachusetts, Amherst, Massachusetts.

Carrier, J. (1979) "The Interaction of Morphological and Phonological Rules in Tagalog," revised version of paper presented at 1977 Winter LSA meeting. 
Chafe, W. (1970) A Semantically Based Sketch of Onondaga, International Journal of American Linguistics Memoir 25, Baltimore, Maryland.

Chomsky, N. (1951) Morphophonemics of Modern Hebrew, Master's thesis, University of Pennsylvania, Philadelphia, Pennsylvania.

(1970) "Remarks on Nominalization," in R. Jacobs and P. Rosenbaum, eds., Readings in English Transformational Grammar, Blaisdell, Waltham, Massachusetts.

and M. Halle (1968) The Sound Pattern of English, Harper and Row, New York.

Chomsky, w. (1933) David Kimhi's Hebrew Grammar (Mikhlol), The Dropsie College for Hebrew and Cognate Learning, Philadelphia, Pennsylvania.

*

Clements, G. N. (1977) "The Autosegmental Treatment of Vowel Harmony," in W. Dressler and O. Pfeiffer, eds., Phonologica 1976 (Innsbrucker Beiträge zur Sprachwissenschaft, vol. 19), Institut fur Sprachwissenschaft der Universität Innsbruck, Innsbruck.

and K. Ford (1979) "Kikuyu Tone Shift and its Synchronic Consequences," Linguistic Inquiry 10, 179-210.

Cowan, W. (1960) A Reconstruction of Proto-colloguial Arabic, Doctoral dissertation, Cornell University, Ithaca, New York.

Diem, W. (1970) "Die unregelmässigen Formen der 3. Person feminin Singular Perfekt in den Dialekten der Sesshaften des syrisch-libanesisch-palästinischen Sprachgebietes," Crbis 19, 346-359.

(1973) Skizzen jemenitischer Dialekte, in Kommission bei Franz Steiner Verlag, Wiesbaden.

Dothan, A. (1971) "Masorah," in Encyclopedia I. 1daica 16, Macmillan, New York.

Ferguson, C. (1956) Review of Birkeland (1954), Language $32,384-387$.

(1978) "The Arabic Koine," in Al-Ani, ed., (1978).

Fraenkel, E. (1928) Iktus und Akzent im lateinischen Sprechvers, Weidmannsche Buchhandlung, Berlin. 
Gesenius, W. (1910) Hebrew Grammar, edited and enlarged by E. Kautzsch, trans. A. E. Cowley, Oxford University Press, London.

Goldsmith, J. (1976) Autosegmental Phonology, Doctoral dissertation, MIT, Cambridge, Massachusetts.

(1979) "The Aims of Autosegmental Phonology," in D. Dinnsen, ed., Current Phonological Theories, Indiana University Press, Bloomington, Indiana.

Greenberg, J. (1978) "The Patterning of Root Morphemes in Semitic," in Al-Ani, ed., (1978).

Halle, M. (1973) "Prolegomena to a Theory of Word Formation," Linguistic Inquiry 4, 3-16.

and S. J. Keyter (1971) English Stress: Its Form, its Growth, and its Role in Verse, Harper and Row, $\overline{\text { New }}$ York.

and J-R. Vergnaud (1979) "Metrical Structure in Phonology," unpublished paper, MIT, Cambridge, Massachusetts.

and V. Zeps (1966) "A Survey of Latvian Morphophonemics," Quarterly Progress Report of the Research Laboratory of Electronics, MIT, 83, 105-113.

Haraguchi, Sh. (1975) The Tone Pattern of Japanese: An Autosegmental Theory of Tonology, Doctoral dissertation, MIT, Cambridge, Massachusetts.

Harrell, R. (1957) The Phonology of Colloquial Egyptian Arabic, American Council of Learned societies, New York.

Harris, Z. (1941) "Linguistic Structure of Hebrew," Journal of the American Oriental Society $62,143-167$.

(1951) Methods in Structural Linguistics, University of Chicago Press, Chicago, Illinois.

Hill, J. (1970) "A Peeking Rule in Cupeno," Linguistic Inguiry 1, 534-539.

Jackendoff, R. (1975) "Morphological and Semantic Regularities in the Lexicon," Language 51, 639-671.

Jakobson, R. (1971a) "Uber die Beschaffenheit der prosodischen Gegensätze," in Jakobson (1971c). 
(1971b) "On Ancient Greek Prosody," in Jakobson (1971c).

(1971c) Selected Writings I, Mouton, The Hague.

Janssens, G. (1972) Stress in Arabic and Word Structure in the Modern Arabic Dialects, Orientalia Gandensia V, Peeters, Louvain.

Jespersen, O. (1956) A Modern English Grammar on Historical Principles 6, George Allen \& Unwin, London.

Kahn, D. (1976) Syllable-based Generalizations in English Phonology, Doctoral dissertation, MIT, Cambridge, Massachusetts.

Khalafallah, A. (1969) A Descriptive Grammar of Sa9i:di Eqyptian Colloguial Arabic, Mouton, The Hague.

Kiparsky, P. (1973) "Phonological Representations," in O. Fujimura, ed., Three Dimensions of Linguistic Theory, TEC, Tokyo.

(to appear) "Metrical Structure Assignment is Cyclic," Linguistic Inquiry 11 .

$\dagger$

Langendoen, D. (1968) The London School of Linguistics, MIT Press, Cambridge, Massachusetts.

Leben, W. (1973) Suprasegmental Phonology, Doctoral dissertation, MIT, Cambridge, Massachusetts.

Lecerf, J. (1974) "L'accent de mot en Arabe d'orient," in A. Caquot and D. Cohen, eds., Actes du premier congrès international de linguistique semitique et chamitosémitique, Mouton, The Hague.

Lees, R. (1957) Review of N. Chomsky (1957) Syntactic Structures, Language $33,375-407$.

Levy, M. (1971) The Plural of the Noun in Modern Standard Arabic, Doctoral dissertation, University of Michigan, Ann Arbor, Michigan.

Liberman, M. (1974) The Intonational System of English, Doctoral dissertation, MIT, Cambridge, Massachusetts. and A. Prince (1977) "On Stress and Linguistic Rhythm," Linguistic Inguiry 8, 249-336. 
Margolis, M. (1909) "The Pronunciation of the Šbwa according to New Hexaplaric Material," American Journal of Semitic Languages $26,62-70$.

Matthews, P. (1974) Inflectional Morphology, Cambridge University Press, Cambridge.

McCarthy, J. (1976) "On Hierarchic Structure within Syllables," unpublished paper, MIT, Cambridge, Massachusetts.

(1977) "CT," in J. Kegl, D. Nash, and A. Zaenen, eds., Proceedings of the Seventh Annual Meeting of the North Eastern Linguistic Society, MIT, Cambridge, Massachusetts.

and J. Rotenberg (forthcoming) "Prosodic Structure and Sandhi in Tiberian Hebrew."

Moravcsik, E. (1978) "Reduplicative Constructions" in J. Greenberg, ed., Universals of Human Language, Stanford University Press, Stanford, California.

Mitchell, T. (1975) Principles of Firthian Linguistics, Longman's, London.

Munro, P. and P. Benson (1973) "Reduplication and Rule Ordering in Luiseno," International Journal of American Linguistics $39,15-21$.

Murtonen, A. (1964) Broken Plurals: Origin and Development of the System, E. J. Brill, Leiden.

Nanni, D. (1977) "Stressing Words in -Ative," Linguistic Inquiry 8, 752-763.

Nash, D. (1979) "Yidin Y Stress: A Metrical Account," in Proceedings of the Ninth Annual Meeting of the North Eastern Linguistic Society $=$ CuNY Forum $5 / 6$.

Orlinsky, H. (1966) "Prolegomenon," in C. D. Ginsburg Introduction to the Massoretico-critical Edition of the Hebrew Bible, Ktav, New York.

Palmer, F. (1956) "'Openness' in Tigre: A Problem in Prosodic Statement," Bulletin of the School of Oriental and African Studies $18, \overline{561}-577$.

(1962) The Morphology of the Tigre Noun, Oxford University Press, London. 
Pesetsky, D. (1979) "Russian Morphology and Lexical Theory," unpublished paper, MIT, Cambridge, Massachusetts.

Pike, K. and E. Pike (1947) "Immediate Constituents of Mazateco Syllables," International Journal of American Linguistics $13,78-91$.

Prătorius, F. (1897) Uber den rückweichenden Accent im! Hebralischen, Buchhandlung des Waisenhauses, Haile.

Prince, A. (1975) The Phonology and Morphology of Tiberian Hebrew, Doctoral dissertation, MIT, Cambridge, Massachusetts.

(1976) "Applying Stress," unpublished paper, University of Massachusetts, Amherst, Massachusetts.

Puech, G. (1978) "A Cross-dialectal Study of Vowel Harmony in Maltese," in D. Farkas, W. Jacobsen, and K. Todrys, eds., Papers from the Fourteenth Regional Meeting, Chicago linguistic Society, Chicago, Illinois.

Rabin, Ch. (1978) "The Beginnings of Classical Arabic," in Al-Ani, ed., (1978).

Ross, J. (1972) "A Reanalysis of English Word Stress," in M. Brame, ed., Contributions to Generative Phonology, University of Texas Press, Austin, Texas.

Rotenberg, J. (1978) The Syntax of Phonology, Doctoral dissertation, MIT, Cambridge, Massachusetts.

Sam.pson, G. (1973) "Duration in Hebrew Consonants," Linguistic Inquiry 4, 101-104.

Sapir, E. (1930) Southern Paiute, a Shoshonean Language, Proceedings of the American Academy of Arts and Sciences $65,1-3$.

Schaade, A. (1911) ST̄bawaihi's Lautlehre, E. J. Brill, Leiden.

Selkirk, E. (1979) "The Role of Prosodic Categories in English Word Stress," to appear in Linguistic Inquiry 11.

(forthcoming) Phonology and Syntax: The Relationship between Sound and Structure, MIT Press, Cambridge, Massachusetts.

Siegel, D. (1974) Topics in English Morphology, Doctoral dissertation, MIT, Cambridge, Massachusetts. 
(1978) "The Adjacency Constraint and the Theory of Morphology," in M. Stein, ed., Proceedings of the Eighth Annual Meeting of the North Eastern Linguistic Soclety, University of Massachusetts, Amherst, Massachusetts.

Sievers, E. (1901) "Metrische Studien I. Studien zur hebraischen Metrik. Erster Teil: Untersuchungen," Abhandlungen der philologisch-historischen Classe der Koniglich Sachsischen Gesellschaft der Wissenschaften 21, $1-400$.

Sturtevant, E. (1940) The Pronunciation of Greek and Latin, Linguistic Society of America, Phỉadelphia, Pennsylvania.

Thrainsson, H. (1978) "On the Phonology of Icelandic Freaspiration," Nordic Journal of Linguistics 1, 3-54.

Tomiche, N. (1964) Le parler arabe du Caire, Mouton, The Hague.

Trubetzkoy, N. (1969) Principles of Phonology, University of California Press, Berkeley, California.

Ultan, R. (1971) "A Typological View of Metathesis," Working Papers on Language Universals 7, Stanford University, Stanford, California.

Vergnaud, J-R. (1976) "Formal Properties of Phonological Rules". [In R. Butts and J. Hintikka, eds., (1977) Basic Problems in Methodology and Linguistics, Reidel, Amsterdam.]

Wilbur, R. (1973) The Phonology of Reduplication, Doctoral dissertation, Indiana University, Bloomington, Indiana.

Wright, $W$. (1971) A Grammar of the Arabic Language, Cambridge University Press, Cambridge.

*Chomsky, W. (1972) "The Pronunciation of the Shewa," Jewish Quarterly Review 62, 88-94.

tLambdin, T. (1971) "The Junctural Origin of the West Semitic Definite Article," in H. Goedicke, ed. , Near Eastern Studies in Honor of William Foxwell Albr Ight, Johns Hopkins University Press, BaItimore, Maryland. 


\section{Biographical Note}

John McCarthy was born in Medford, Massachusetts on April 29, 1953, the son of John and Joan McCarthy. He attended Xavier School in Concord, Massachusetts and graduated from Harvard College in 1975 with an $A B$ summa cum laude in linguistics and Near Eastern languages. While at MIT he held a National Science Foundation Graduate Fellowship and teaching and research assistantships in the Department of Linguistics and Philosophy. He has accepted a position as an assistant professor in the Department of Linguistics, University of Texas at Austin, beginning in September, 1979. His publications are: (1977) "CT", in J. Kegl, D. Nash, and A. Zaenen, eds., Proceedings of the Seventh Annual Meeting of the Northeastern Iinguistic Society, Cambridge, Massachusetts.

(1979) "On Stress and Syllabification", Linguistic Inquiry 10,3 . 